University of Rhode Island

DigitalCommons@URI

Open Access Dissertations

2017

\title{
Undergraduate Student Perspectives on Electronic Portfolio Assessment in College Composition Courses
}

Bridget Fullerton

University of Rhode Island, bridget72@mac.com

Follow this and additional works at: https://digitalcommons.uri.edu/oa_diss

\section{Recommended Citation}

Fullerton, Bridget, "Undergraduate Student Perspectives on Electronic Portfolio Assessment in College Composition Courses" (2017). Open Access Dissertations. Paper 620.

https://digitalcommons.uri.edu/oa_diss/620

This Dissertation is brought to you for free and open access by DigitalCommons@URI. It has been accepted for inclusion in Open Access Dissertations by an authorized administrator of DigitalCommons@URI. For more information, please contact digitalcommons-group@uri.edu. 


\section{UNDERGRADUATE STUDENT PERSPECTIVES \\ ON ELECTRONIC PORTFOLIO ASSESSMENT \\ IN COLLEGE COMPOSITION COURSES}

BY

BRIDGET KATHERINE JEAN FULLERTON

\section{A DISSERTATION SUBMITTED IN PARTIAL FULFILLMENT OF THE \\ REQUIREMENTS FOR THE DEGREE OF \\ DOCTOR OF PHILOSOPHY}

IN

ENGLISH

UNIVERSITY OF RHODE ISLAND

2017 


\section{DOCTOR OF PHILOSOPHY DISSERTATION \\ OF \\ BRIDGET KATHERINE JEAN FULLERTON}

\section{APPROVED:}

Dissertation Committee

Major Professor: Nedra Reynolds

Annemarie Vaccaro

Jody Lisberger

Nasser H. Zawia

DEAN OF THE GRADUATE SCHOOL

UNIVERSITY OF RHODE ISLAND

2017 


\section{ABSTRACT}

Though Linda Adler-Kassner and Peggy O’Neill claim that ethical writing assessment models "must be designed and built collaboratively, with careful attention to the values and passions of all involved, through a process that provides access to all," college students have not typically been included in scholarly conversations about writing and assessment (Reframing Writing Assessment to Improve Teaching and Learning 2010). In response, this dissertation privileges the perspectives of 18 college students at a mid-sized university from different majors and at varying levels of a vertical writing curriculum (100, 200, 300, and 400) to examine their experiences with a common writing assessment model - the electronic portfolio. This study uses a qualitative approach to listen well (Royster) for the messy truths (Broad) and emergent learning insights (Gallagher) students offer about their e-portfolio experiences, paying careful attention to the writerly selves (Yancey) they perform. Findings suggest that students desire connections between their past and present e-portfolio experiences, between the assignments and artifacts they are required to produce for an e-portfolio, between themselves, their peers, their instructors, and outside audiences, and between writing courses and across writing experiences within and outside of their majors. Students report valuing the e-portfolio because it offers them opportunities for revision, ample time to compose, and an alternative to final exams. This study also reveals a curious contradiction between this Millennial generation of "digital natives" who value technological expertise yet who also express anxiety about technology. Valuing writing primarily as alphabetic text, they exhibit uncertainty with design, 
and want more digital, modal, and design support. They also desire clear and consistent instructor expectations and a deeper "sense" of an e-portfolio assignment - more than descriptive lists, outcomes, and rubrics—so that it serves or works for them and not only writing instructors and institutions. The study calls for writing instructors and program and university administrators to attend closely to the evolutions and performances of students' writerly selves throughout any assessment experience. 


\section{ACKNOWLEDGEMENTS}

There were many beautiful minds that played a role in the production of this document and I wish to pay tribute to them here. Firstly, thank you to my dearest family and friends who donated $\$ 1,011$ to my Kickstarter fund so that I could purchase a Screencast-O-Matic subscription and SurveyMonkey account for my research, and provide small thank-you gifts to several student participants. Thank you, also, to Donna Hayden, who helped me in my recruitment efforts, particularly researching potential writing courses and contacting writing instructors. I am grateful to those writing instructors who allowed me to enter the sacred spaces of their classrooms to talk with and recruit their students for my study. Though I cannot name them by name, I want to express my deepest gratitude to the eighteen students who participated in my study_-from start to finish — and who offered their precious time, honest insights, and messy truths about their electronic portfolio experiences. I also wish to honor here those students who participated in one or more of the first-stage online surveys and whose voices I was unable to include in this dissertation.

I am truly thankful for having such thoughtful, gracious, and challenging female mentors on my dissertation committee: Annemarie Vaccaro encouraged and guided me in developing a case study methodology and gracefully modeled a feminist and social justice approach to qualitative research; Jody Lisberger not only gave me a shot at my first teaching position at the university level, but also kindly agreed (in the eleventh hour) to offer her keen literary and feminist perspective on my dissertation; Julie Coiro provided welcomed affirmation by way 
of her thoughtful insights into how this work and the tensions I uncovered line up with scholarship in educational psychology. I am also indebted to Libby Miles for her enthusiasm for my project (even when she could no longer be a part of it) and for grounding me so skillfully—as a teacher, scholar, and mentor —in the history of writing pedagogy and in the most current scholarship on assessment; Libby also introduced me to the subfield of Writing Program Administration, which undoubtedly will be a large part of my future academic career and where I will seek to continue and test the research and findings begun in this dissertation. Thanks, Libby!

With her always perfectly timed catchphrase, "Onward!", Nedra Reynolds has been a crucial, stable, and highly influential emotional and intellectual force throughout my time at URI. I am eternally grateful for her unfailing encouragement, for her perceptive reading and editing, for her ability to guide my writing to it most succinct (without losing its heart), for her portfolio prowess and teaching mentorship, and for her depth and breadth of knowledge of the field. I am also thankful for Nedra's recommendation to Peter Elbow (in 2012) that he accept me into his summer symposium which ultimately led to my "conversion experience" from a $\mathrm{PhD}$ student of English Literature to a $\mathrm{PhD}$ student of composition and rhetoric, a field that I so very much love and feel at home in. Thank you, Nedra.

I am also grateful to Dr. Shannon Madden for her friendly encouragement and intuitive ability to say just what I needed to hear, whether I hit a writing block or a mountain of doubt. Thanks also, Shannon, for listening and taking notes on all 
the ideas scrambling around in my head to help me make sense of them. Finally, I am thankful for the support and fellowship of my brilliant graduate student colleagues with whom I have written, thought, argued, presented, laughed, and cried. We did it! 


\section{DEDICATION}

I dedicate this dissertation to my family. Mom, you are the reason I am here and why I came this far and did this thing. Thank you for being such an amazing teacher and for your constant love and guidance, even from the other side. Dad, thank you for your curiosity, your intellect, and your eloquence - and for always letting me tag along. I am grateful for the role you have played in "the making" of the woman I am today. (I was moved and calmed by your presence at my dissertation defense. Thanks for that, too.)

For Rick, my gentle, stalwart partner and husband, I dedicate this work to you in honor of all the hours you listened, supported, and thought with me-and in honor of all the extra hours you cared for our son while I sat at my "com-pooter" working on the "silly disher-tayshen." You are my rock and, gosh, I love you. Thank you.

For my sweet, silly, and oh-so-loveable son, Ciaran Michael Richard, I dedicate this work to you in the hopes that you, too, follow your biggest dreams and always speak your truth. You are truth. I love you dearly and forever. 


\section{TABLE OF CONTENTS}

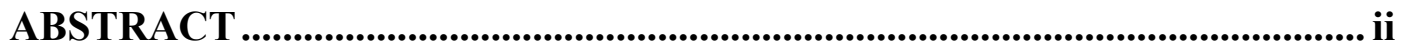

ACKNOWLEDGEMENTS........................................................................ iv

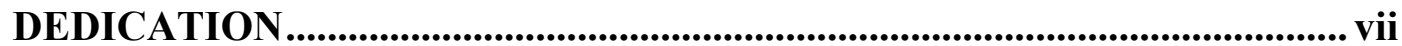

TABLE OF CONTENTS................................................................................. viii

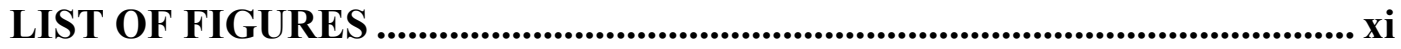

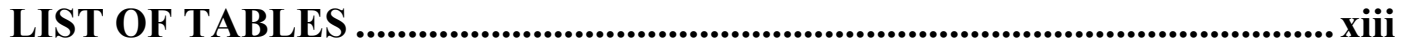

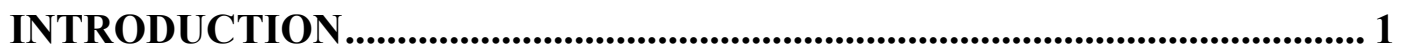

Or, Finding A Guitar, a Voice, and a (Portfolio) Calling .................................................................1

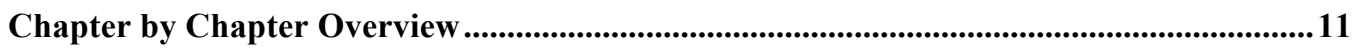

CHAPTER 1: JUSTIFICATION, SIGNIFICANCE, \& STUDY DESIGN.... 14

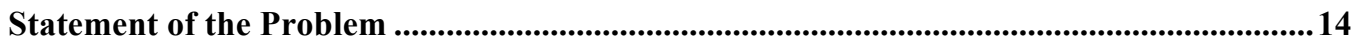

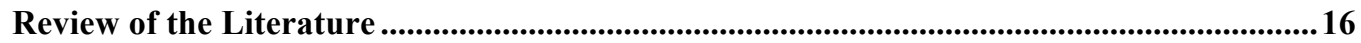

Two Model Studies .....................................................................................................................................31

My Research Questions..............................................................................................................35

My Qualitative Study

An Overview of the University and Writing Program ……................................................. 38

Stage 1: Recruitment \& Online Data Collection.................................................................... 38

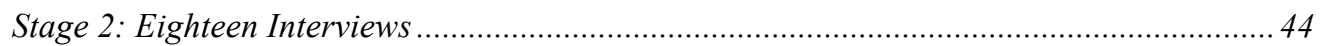

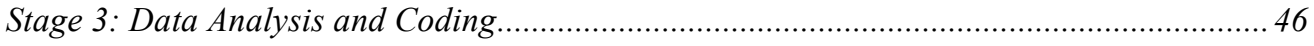

A General Description of the Eighteen Participants.............................................................4 47

A General Description of the Eighteen e-Portfolios ................................................................... 58

CHAPTER 2: STUDENTS REFLECT ON EXPERTISE, INSTRUCTION, \&

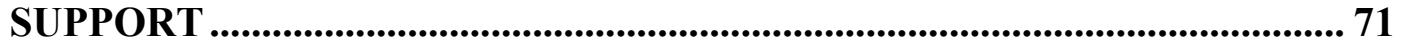




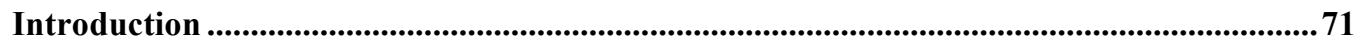

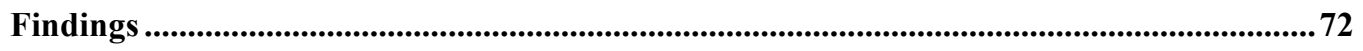

Considering Expertise: Technology (and) Experience...................................................... 72

Experiencing Context: The e-Portfolio Genre, and Its Subgenres......................................... 78

Understanding Expectations: Giving Us "Answers, "Giving Us "A Sense"........................... 83

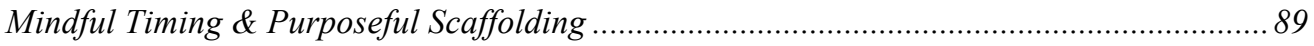

Considering Who's "On My Side" and Who's "In Control": Support, Connections, Feedback,

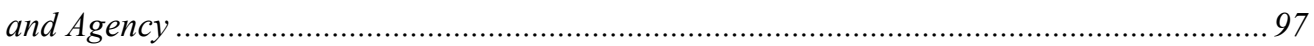

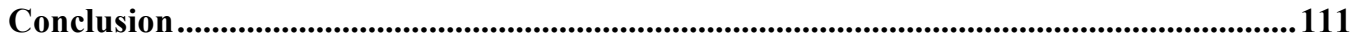

\section{CHAPTER 3: STUDENTS REFLECT ON MODES, MODAL}

AFFORDANCES, \& DESIGN ................................................................ 113

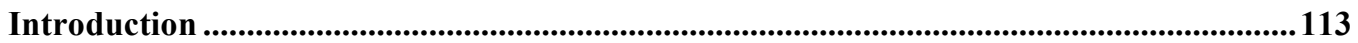

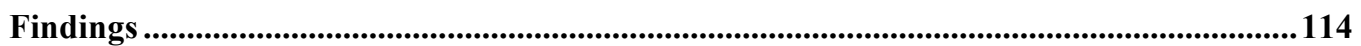

What "Count[s] as a Word"?: Writing As/Beyond Alphabetic Text (on Paper) ................... 114

Concerning Design: Happy Places, Sneak Attack[s], and Retro-90s Designs ..................... 128

Conclusion

CHAPTER 4: STUDENTS REFLECT ON CLASSROOM ASSESSMENT147

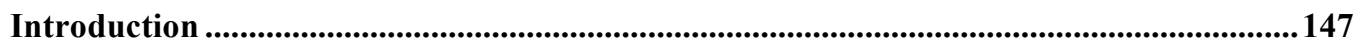

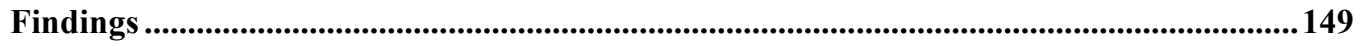

Concerning Weighted Percentages, Final Exams, \& Final Grades ................................... 149

Concerning Institutional Learning Outcomes and e-Portfolio Reflections........................... 161

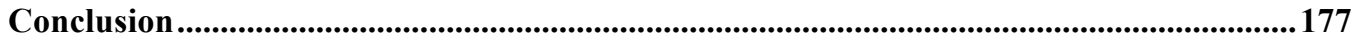

CHAPTER 5: SUMMARY, ANALYSIS, \& IMPLICATIONS........................ 179

Summary

An Overview of Student Insights .............................................................................................182

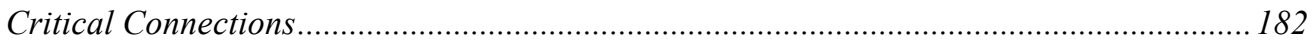

Curious Contradictions, Tech-(Un)Assertiveness, \& Digital Preoccupations ..................... 187 
Recommendations for Writing Instructors and Programs .............................................197

Making and Drawing Connections.................................................................. 198

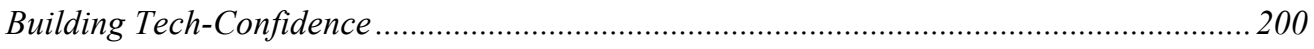

Re-Assessing the e-Portfolio as a Classroom Assessment Model ........................................ 206

Areas of Further Study ...........................................................................................................211

A Final Heuristic (Adapted and) Offered ..........................................................................214

Conclusion.................................................................................................................... 216

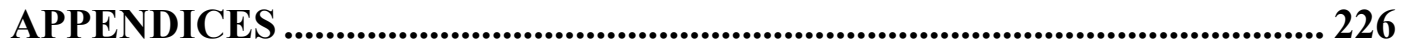

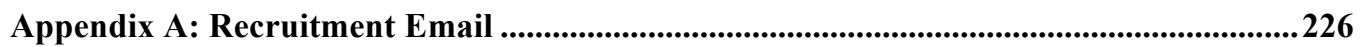

Appendix B: Recruitment Flyer..............................................................................................228

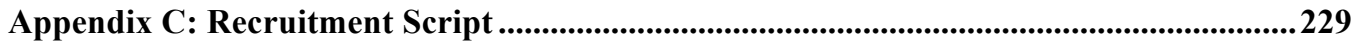

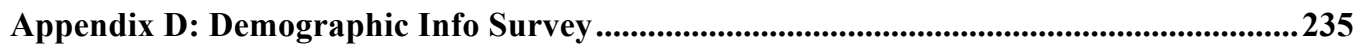

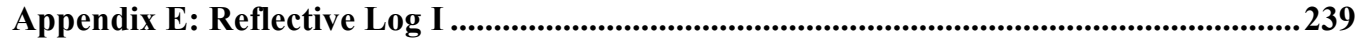

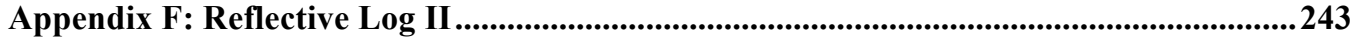

Appendix G: Student Interview Questions ...................................................................247

Appendix H: List of Course Learning Outcomes..............................................................256

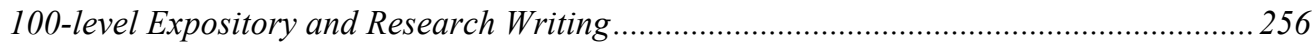

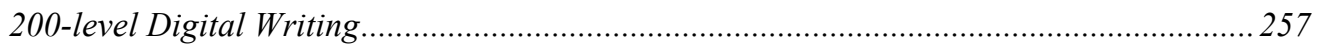

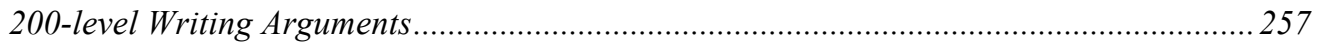

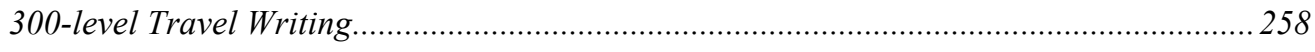

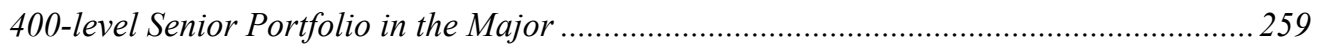

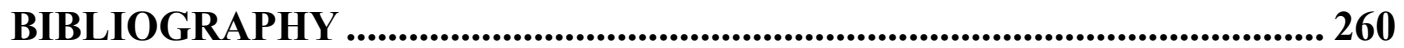




\section{LIST OF FIGURES}

Figure 1: Visual Overview of the Three Stages Used in Recruitment Presentations

Figure 2: "[This Shows] How Brainstorming, Making a Web, Really Helped Me

Organize My Ideas" (Original Extension Image, Valerie).....

Figure 3: "Something I Did On My Own About . . . Our Oppressive System and Poverty and Police Brutality" (Whole Original Video Artifact, though it includes borrowed extension images/videos like the clip of Dr. Martin Luther King, Jr. here, Holly).

Figure 4: "Something I Did For Our Production Lab . . . To Try And Showcase

The Programs We Have" (Whole Original Graphic Artifact, Holly)

Figure 5: "A Graph From NOAH To Prove, Hey, Since The 1960's, CO2 Levels

Have Increased A Lot!" (Borrowed Extension Image, Bethany).................. 63

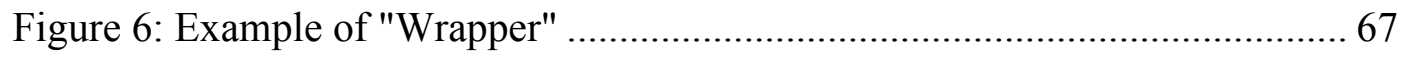

Figure 7: Example of Single Reflection with Passages from Project ................... 69

Figure 8: Borrowed Ornamental Images in a Reflection ................................ 70

Figure 9: Alphabetic Text-Only Word-to-PDF e-Portfolio ............................. 116

Figure 10: Alphabetic Text Only CMS e-Portfolio ...................................... 117

Figure 11: "An Old Picture of My Grandpa That Hangs On The Wall In My

Room" (Embedded Original Image, Eva) ........................................... 120

Figure 12: "I Created An Intro For [Our Show]. It's Kinda Crazy, Kinda Goes

Along With How We Were" (Whole Original Audio Text, Charlotte) ....... 125 
Figure 13: A Digital Artifact Charlotte Created As Part of Her Whole Original Text, i.e. Buzzfeed Article (Original Extension Image, Charlotte)

Figure 14: "I didn't want to hear that I was a 'man hater' or that I was only a feminist because I was a woman." (Quote from Whole Original Text, i.e. Buzzfeed Article; Borrowed Extension Image, Charlotte)

Figure 15: The Top of Amy's Tumblr e-Portfolio with 3,800 words of alphabetic text below "Intro."

Figure 16: "I just wanted it to look pretty. . . . Weebly just offers them. . . . I guess it reflects some of my happy places" (Borrowed Ornamental Image, Regina).

Figure 17: Bethany's Web e-Portfolio 134

Figure 18: Amber's Blog 1 (w/ original, ornamental image)

Figure 19: Amber's Blog 2 (w/ original, extension image) 136

Figure 20: Ned's e-Portfolio

Figure 21: Julia's e-Portfolio

Figure 22: Hope's e-Portfolio 140

Figure 23: Katja's Homepage (all original art, photos, and graphics; self-portrait on "Fine Art" graphic omitted, though I wish you could see it—beautiful!).... 141

Figure 24: Screenshots of Ariel's e-Portfolio, "The Worst Millennial Ever" ...... 188 Figure 25: "I Did An Equal Bar, Because Feminism Is About Being Equal. I Put Women [In The Top] and Men In The Bottom. It's Literally As Simple As That" (Graphic of a Whole Original Art Piece, Drawn by Ariel).... 188 


\section{LIST OF TABLES}

Table 1: Participant Recruitment Efforts .......................................................... 42

Table 2: Stage 1 Participation Records ............................................................. 43

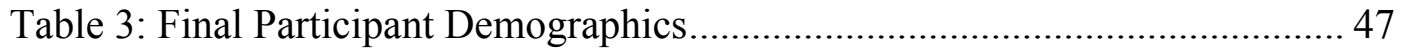

Table 4: Participants Levels of Experience, Preparedness, and Excitement for the

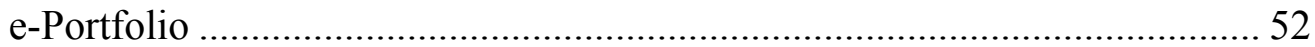

Table 5: Participants' College Writing Course Experience................................... 54

Table 6: Partitipants' Previous Portfolio Experience ........................................ 55

Table 7: Participants' Previous Experience with e-Portfolios .............................. 55

Table 8: Experienced Participants' Perceived Preparedness ............................... 56

Table 9: Less Experienced Participants' Perceived Preparedness ......................... 56

Table 10: Participants' Levels of Excitement..................................................... 58

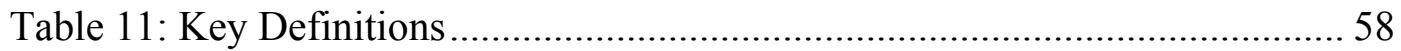

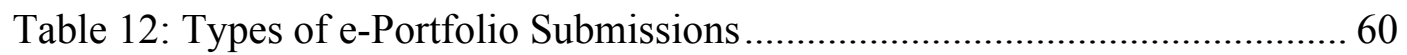

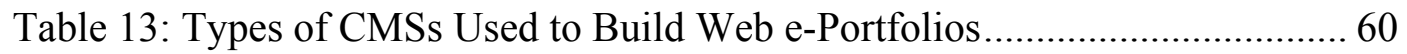

Table 14: Types of Whole, Original Writing Projects Included in e-Portfolios .... 65

Table 15: Modalities Employed in Students' e-Portfolios ............................... 115

Table 16: Weighted Percentages of e-Portfolio Final Grades............................ 149

Table 17: Participants' Levels of Nervousness About Final e-Portfolio Grade ... 154

Table 18: Final Grades Students Received on e-Portfolios ............................. 155

Table 19: Learning Outcomes for First Year Writing Courses........................... 161

Table 20: Learning Outcomes for the 200-level Argumentative Writing Courses 


\section{INTRODUCTION}

\section{Or, Finding A Guitar, a Voice, and a (Portfolio) Calling}

I was painfully shy until around the age of thirteen when I found an old classical guitar in my father's closet and taught myself how to play. Using the guitar to accompany myself, I began to write and sing angsty teenage songs about crushes, fights with my mom, and my absolutely irreplaceable best friends, many of whose names I've now forgotten. Throughout college and into my twenties, my guitar abilities improved and life got more complicated. I wrote and sang songs about the agony of love, my parents' divorce, friends' battles with addiction and, eventually, my mother's untimely death from cancer. As I moved into my thirties and after having played in some bands and gone on a national grassroots tour with my sister, my songs became odes to love of the less agonizing sort, testaments of survival and persistence in the face adversity and doubt, and ironic — and sometimes even informed - social critiques. Along the way, I have collected a variety of well-loved musical artifacts, including a small, red spiral notebook with pages of pencil scratched tablatures and lyrics, a pocket thesaurus for song-writers, set lists and homemade marketing flyers for the various stage names I'd gone by and bands I'd been in (Wavy Train, Venus in Furs, Buttafly Beats, Ten Dollar Jeans, CJ Sister, etc., etc.), and pages and pages of song ideas on yellow legal paper, sticky notes and napkins (one emblazoned with the message "Get outta this town and GO BIGTIME!" from a guy in a bar I often played in while working on my Masters degree and living Charlotte). Essentially, my guitar gave me a voice 
and I have curated the various iterations of that voice over time and space in a multimodal assortment of audio tapes and CDs, videos, photos albums, t-shirts, gig relics and songs, all mostly in the nooks and crannies of one brown leather bag and a few crumbling boxes. I suppose this represents my first inkling to compile a portfolio. ${ }^{1}$

I was not properly introduced to portfolios, however, until later in my thirties, when, after being laid off from my high school teaching job in California and being accepted into a $\mathrm{PhD}$ program in English, I took a professionalization course for graduate assistants teaching first year composition. It was not my first time teaching writing; I had been teaching English for several years by then, mostly in middle and high school, but had a few college experiences, too. In all that time, however, portfolio assessment had never been part of my pedagogical training. As a lover of narrative, an ardent collector of drafts and ideas, and a disciple of the writing process, I was nearly prepared to adopt them wholeheartedly into my college pedagogy. But there was still some ice around my teacherly heart regarding assessment that needed melting.

I began my teaching career as a middle school teacher in North Carolina just a few years before the No Child Left Behind Act went into effect and since that time, I had grown accustomed to (and often felt stifled by) the public education panopticon, particularly one of its most proliferous ideological

\footnotetext{
${ }^{1}$ Though whatever dreams I've had of becoming a full-time musician and/or memoirist seem to always get annoyingly waylaid by my actual full-time career in education, I intend one day to use this portfolio as a curation of my song-writerly self that will help me write and publish my first memoir. Perhaps a CD will accompany it. Likely that CD will be one of the hundreds still neatly packaged and wrapped in a box from the 2002 CJ Sister "tour." Let me know if you want on the mailing list.
} 
apparatuses: standardized assessments. These assessments required me as a teacher to prepare my students for state learning tests, undergo classroom observations, attend state-run workshops, use board-approved textbooks, and submit lesson plans that adhered to approved outcomes and curricula. By the time I hit the postsecondary scene, standardized curriculum, valid and reliable assessment, and learning outcomes had become the bane of my teaching existence. I loved learning about portfolios and the innovative ways they were being used in college composition classrooms and programs across the nation (since the early nineties no less; where had I been?) and (later) the world. I began to see portfolios as an opportunity for greater instructional creativity and freedom, as a chance for my students' writerly voices to be more fairly represented, and as a fluid site that offered their writing the time and space it properly deserved. As Peter Elbow and Pat Belanoff suggested about the first portfolio model they implemented at Stony Brook in the late eighties,

The portfolio process uses a very different model of evaluation [than the traditional evaluation model of ranking and differentiating students, or 'measuring' minds] — criterion-referenced or masterybased or competence-based — which assumes that the ideal end product is a population of students who have all finally passed because they have all been given enough time and help to do what we ask of them. (99)

This assessment model seemed to me the most democratic and anti-psychometric than any of those I had ever been subjected to. The fact that it was meant to allow 
for expertise-sharing between student and teacher, to be centered in pedagogical practice, and to promote collaboration among instructors (not administered with a top-down approach), made the portfolio extremely appealing to my assessmentweary self. Hence, beginning with that graduate student professionalization course on portfolio instruction and assessment, and soon after taking two other graduate seminars - one on composition pedagogy and another on assessment and curriculum design - the ice indeed began to thaw.

In tandem with my portfolio coming-of-age, I was discovering in my English Literature $(\mathrm{PhD})$ coursework - which included courses I was taking towards a certification program in Gender and Women's Studies - the ways in which, as a woman, I had been marginalized, objectified, victimized and silenced throughout my life; in other words, I was forming the foundation of what would soon become a feminist consciousness that eventually permeated all of my teaching, writing, and research. After having taught mostly in low-income areas and Title 1 schools with high percentages of students of color, I also began to read critical race and social justice education scholarship that helped me understand what I inherently felt but could never quite articulate about my own white, middleclass privilege, and I became keenly aware of hegemonic systems that kept particular voices on the margins while centering the most dominant discourses and rhetorics of power.

I also began to understand how I was complicit in some of these systems as I devoured all the readings I could on power and resistance and voice. After struggling through the theory of Immanuel Kant, Karl Marx, and Friedrich 
Nietzsche, I found greater kinship (and some ease) with Virginia Woolf, Michel

Foucault, Hélène Cixous, Gloria Anzaldúa, and Donna Haraway. I read the intersectional feminist work of bell hooks and Jacqueline Jones Royster and was intrigued by their notions of talking back and voicing difference. The pragmatic yet radical labor and writings of Mary Wollstonecraft, Jane Addams, and Paolo Freire offered models of how to combine my love for teaching, my appreciation for literature, and my respect for theory with more practical and activist pursuits (i.e with my desire to live my scholarship); while the personal accounts of ZitkalaSa, Gertrude Stein, Maya Angelou, Maxine Hong Kingston, Riverbend, and Alison Bechdel and the groundbreaking documentaries of the women of Studio D showed me just how powerful (and powerfully multimodal) female narrative storytelling can be. Finally, Lynn Bloom, Peter Elbow, Linda Brodkey, Mike Rose, Deborah Brandt, and Ralph Cintron were a few of the contemporary luminaries who taught me the field of composition and rhetoric was the place where I could combine all of these seemingly disparate threads of interest and inspiration. ${ }^{2}$ In many ways my partiality to portfolios and the study that emerged from my curiosity about the voices that were missing in our field's conversations about those portfolios in particular - and about assessment more broadly—have

\footnotetext{
${ }^{2}$ It was, in fact, after taking a course on American autobiography with Lynn Bloom at UCONN the second semester of my PhD program in English and then, the summer following, of having the privilege (and dumb luck) of attending a week-long intimate (we ate dinner at his house with him and his wife) and intensive graduate symposium with Peter Elbow at UMASS-Amherst that I had my "conversion experience" (as the many ex-lit-pats in our field commonly refer to it) and left the English Literature PhD program to "come to the other side" (i.e. to focus my doctoral studies in the field of composition and rhetoric; thank you, Nedra!). Before coming to URI, I had little knowledge of the field and its history (again, where have I been all these years?). I am incredibly grateful, though, to have made the transition; it is truly where my people are, though my experiences and colleagues in English Literature will always hold a special place in my heart (that is not iced-over in the least).
} 
been directly influenced by every one of the names I mention above. I am, indeed, indebted to them.

As the theoretical underpinnings of my (peculiar?) brand of writing pedagogy grew more and more solid, I sought new and innovative ways to "teach the arts of the contact zone," which Mary Louise Pratt (in 1991) described as exercises in storytelling, and in identifying with the ideas, interests, histories, and attitudes of others; experiments in transculturation and collaborative work and in the arts of critique, parody and comparison; the redemption of the oral; ways for people to engage with suppressed aspects of history, ways to move into and out of rhetorics of authenticity; ground rules for communication across lines of difference and hierarchy that go beyond politeness but maintain mutual respect; a systematic approach to the all important concept of cultural mediation. (40)

I began to teach e-portfolios as spaces where students could and should use the digital and multimodal writing technologies and affordances at their fingertips to research and tell stories about (via a blend of narrative and argumentative writing) the "local cultures" of which they were a part. ${ }^{3}$ I encouraged them to reflect on and research what they sensed were some of the inequalities, and/or social, political, or economic tensions they felt as part of those local cultures and to consider and write

\footnotetext{
${ }^{3}$ I borrowed the concept of writing about local cultures from a composition textbook no longer in print but that one of my composition professors contributed to and mentioned in a course I took with her. I found a copy of it on Amazon and refer to it regularly for teaching ideas: Four Worlds of Writing: Inquiry and Action in Context (4th edition, 1991, Harper Collins) by Janice Lauer, Andrea Lunsford and a whole host of other great writing teachers (Libby Miles included). The chapter on writing about local cultures is by Lisa Langstraat (Chapter 5).
} 
about either the ways in which they were complicit in those inequalities and tensions or subject to them (or something in between). Some of my attempts at teaching the arts of the contact zone were more successful than others.

One of my more successful teaching (and research) moments with eportfolios in the contact zones was when I presented at a local graduate conference with five students from a 200-level argumentative writing course I had taught the previous fall semester. They were a diverse group_-female, male, black, white, American, American-Asian, and Jamaican — and my goal was to briefly offer the burgeoning critical e-portfolio pedagogical philosophy I was still developing and had "piloted" in the course and then to center the students' and their e-portfolio narratives, or the writerly selves they chose to perform within the constraints of the assignments and technological platforms I required and/or suggested (I give options when I can). I talked about treating e-portfolios like auto-ethnographic exercises, or practices in critical narrative self-exploration. Students presented the multimodal website e-portfolios they created and then each student presented on the particular local cultures and contact zone issues they researched and argued about: feminazi-ism in the life of a college feminist, homophobia and the fear of interracial marriage in Jamaican society, the community and connection offered by the b-boy culture, the various (and problematic) definition(s) of the term "hawking" in the hetero college male population, and the unethical (and possibly illegal) management practices of a local (and beloved) ice cream stand. It was a delicate balance, but it all worked out okay. 
After our presentation, a peer audience member kindly praised my attempts and the work of the students. Then echoing the question that had led me to first propose the panel (though one I hadn't thought to mention), she asked, "Why don't we hear more from students like this?" Indeed I had nearly taken for granted the fact that, as a result of my pedagogical interests and research focuses, I was offering something novel in this academic setting: listening to students and presenting alongside them as if we were peers, or at least, as if we had something to learn from each other and to offer, equally, to others.

This question lingered as I prepared for my dissertation proposal armed with the most current scholarly research and debate information about rater bias, validity and reliability, power and authority in assessment, and building a culture of assessment which I explored in Professor Libby Miles' graduate seminar, Writing Assessment and Curriculum Design. In the course, Professor Miles encouraged us to follow our own instincts and scratch the assessment issues that itched us the most; and I had an itch: I knew I loved e-portfolios, but having now had several semesters as an avid practitioner and being somewhat well-versed in the theory and thinking behind them, I was beginning to wonder if and in what ways they were still just standardized assessment models that privileged a systemic power structure (i.e. an assessment and outcomes-focused academy) in which I was, once again, complicit. ${ }^{4}$

\footnotetext{
${ }^{4}$ Another course that had a pivotal influence on me around that time was a graduate level education seminar, Social Justice in Higher Education, offered one summer by Dr. Annemarie Vaccarro. Its focus on critical pedagogies and including the voices of women, minorities, and students in academic administrative issues gave me faith that I had comrades in other disciplines as well.
} 
Two texts were particularly influential for me in helping me enter the assessment debate and keep my interest turned towards students: Bob Broad's What We Really Value: Beyond Rubrics in Teaching and Assessing Writing (2003) and Linda Adler-Kassner and Peggy O'Neill's Reframing Writing Assessment to Improve Teaching and Learning (2010). I will quote them often in the first and last chapters of this dissertation, but particularly illuminating for me was Broad's suggestion that the field of composition and rhetoric is, at times, complicit in more positivistic and empirical ways of knowing than it would profess itself to be. Particularly, Broad troubled the way rubrics—one of the most pervasive tools of assessment used in writing instruction today (and one I was often mandated to use in my public school teaching years) — "prevent us from telling the truth about what we believe, what we teach, and what we value in composition courses and programs" by shielding outside stakeholders and our students from the "wilderness of rhetorical values" that we actually, well, value — such as "dissent, diversity, context-sensitivity, and ambiguity," or what he calls the "messy facts at hand" about our views of what writing is, does, and can be $(2,6,7)$. Basically, the tool of rubrics, for Broad, make our evaluations of writing seem neat and tidy where in fact they are often tousled and unkempt. He presents a constructivist model, Dynamic Criteria Mapping (DCM), as a way to uncover, publicize, discuss and think more critically about the implications (for students) of the convergent and divergent values of writing instructors when it comes to assessing student writing. The main goal of DCM is 
for instructors to be on the alert for criteria around which various dynamics, especially differences among instructors, put students at risk of being unfairly penalized ... [and] to keep the process going so that the DCM reflects the program's rhetorical values steadily and more faithfully and ... that [it] keeps up with inevitable—and desirable — changes in the program's frameworks of values. (134, 135)

It can be a long, messy process but the ethical, political, and pedagogical implications of Broad's method compelled me to build my own research project in its image.

Adler-Kassner and O'Neill's text, published seven years after Broad's, suggests the current debates about writing assessment are "the most important discussions happening on our campuses (and even beyond them) today" (their emphasis, 4). These co-authors believe that with so many cooks in the kitchen staking the (same) claim to "writing [as] their business"—particularly those cooks from outside the field of composition and rhetoric — that "we as college-level educators and scholars [must learn to] interact with them around these issues [and tensions] of writing assessment" (9). Their suggestion is not to balk at the frames through which each stakeholder views writing assessment, but instead to simply get involved and work strategically "with others in our programs, institutions, and communities" to create localized and context-sensitive assessments that serve the needs of all stakeholders and honor the perspectives of each. It's a very democratic approach to a difficult issue, and yet, in Adler-Kassner and O'Neill's 
comprehensive report there is still an inadequate number of examples of institutions and programs attempting such an approach that also includes the needs and perspectives of the college student stakeholder.

I am certain today that the guitar I found in my father's closet and learned to sing along to was the writing technology that shepherded me on my journey through a silencing, self-conscious, inhibited, and insecure girlhood and young adulthood into a comfortable, confident, and (mostly) well-adjusted womanhood; because others listened well to my voice and encouraged me to develop it, I gained, over time, a sense of my own musician-writerly self and have since been privileged to be able to share my voice (and story) with others. Sometimes, particularly in my classrooms and on stages, that voice has had an important impact on others. I do not take this for granted. In return, I will always seek to encourage students to find their own writerly voices and to challenge those in positions of authority—myself included—to listen more closely to them.

\section{Chapter by Chapter Overview}

Chapter 1 of this dissertation presents the call to action that this dissertation heeds at the intersection of writing and e-portfolio assessment and a brief history of the debates about writing assessment, particularly the e-portfolio and its role in writing assessment writ large. Following a review of the literature, I outline my research questions and offer a case study description and a description of the student participants and their e-portfolios. Chapter 2 outlines the common themes and trends that arose regarding students' perceptions of their e-portfolio expertise and the kinds of instruction and support they felt they needed and/or received 
throughout their e-portfolio assessment experiences. Chapter 3 uncovers a curious contradiction about a generation of avid tech-users who are also anxious about technology. This chapter also reports on students' understandings of (a) the affordances of the modal selections they used or were required to use in their eportfolios and (b) the effects those affordances then had on students, particularly in regard to how they shaped students' concepts of "writing" and prompted students to consider the design or form of their e-portfolios. Chapter 4 outlines the stressors and/or motivating factors that students felt contributed to their feelings of confidence and/or anxiety about their e-portfolios as both an formative and summative assessment experience. Students report specifically on how what I call "The Four Pillars of College Assessment"_-or, weighted percentages, final grades, final exams, and learning outcomes — shaped and influenced their experiences. Chapter 5 summarizes the messy truths of students' e-portfolio experiences as well as their emergent learning insights (or the consequences of the e-portfolio assessment on/for students) and offers a description of the particular writerly selves enacted by students in their e-portfolios. These truths, insights, and selves indicate areas for growth and further research, especially as related to the affective and academic connections students desire more of, the technological assertiveness and modal and design competencies students concern themselves with, and the particular points of anxiety and apathy, validation and verification that this model of writing assessment brought students to. The Conclusion offers a more personal take on what this all means to me as a writing teacher and composition scholar.

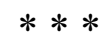


NOTE: I have used pseudonyms for all student participants mentioned in this dissertation and do not offer any descriptions of them that may reveal their identity. I will also keep anonymous the actual names and/or titles of the courses, instructors, and university involved in the study. 


\section{CHAPTER 1: JUSTIFICATION, SIGNIFICANCE, \& STUDY DESIGN}

\section{Statement of the Problem}

Writing assessment scholar and composition teacher, Edward M. White, argued in 2003 that compositionists needed to pay closer attention to the too-often misguided political purposes that writing assessment serves, or what it "does unto" its subjects. One of White's colleagues somewhat tongue-in-cheekily coined "White's first law of assessodynamics"_- Assess thyself or assessment will be done unto thee" — now a commonly referred to call-to-action for those in the field of composition and rhetoric who continue to be concerned with writing, assessment, and its consequences (33). This dissertation seeks to enter the very heart of this tense and ongoing debate in academia, or to engage in the contact zone of writing assessment.

Evoking Patricia Bizzell's call for English studies to organize its model of writing instruction not around literary, theoretical, or chronological events, "but rather in terms of historically defined contact zones, moments when different groups within the society contend for the power to interpret what is going on" (167), I contend that this is such a moment. This study represents my attempt to take agency and interpret "what is going on" in one subset of this contact zonethe subset of writing assessment — of which I have been on the forefront since I began teaching public middle school English over twenty years ago.

Within this subset of the contact zone, portfolios have become a commonly used assessment tool. They were essentially designed by compositionists and writing instructors as a political and intellectual response to what they saw as the 
decontextualized, psychometric testing models of writing assessment's first and second waves, from 1950-1970 and 1970-1986, respectively (Yancey 1999). ${ }^{5}$ Now a pervasive assessment model of the third wave (1986-present), portfolios also provide a practical tool for compositionists contending with White's first law. Though originally portfolios were intended for classroom and writing program assessment, or for internal uses, they now also help us offer a justification for what we do to stakeholders outside of the field of composition and rhetoric and outside of the academy, or to those who have less knowledge of writing assessment scholarship yet who still have a say in how and what we teach in our college writing courses and programs. In continuing to use and promote portfolios as one of the most effective and ethical means of assessing student writing, the field has done its due diligence to build this particular assessment tool in its image and not, necessarily, in the image (or shadow) of outside stakeholders. But there are messy truths about this model of writing assessment with which we still must contend. A look back at White's scholarship reminds us that

Each of these assessments represents a gate through which students must pass if they are to gain access to the privileges and enhanced

\footnotetext{
${ }^{5}$ Yancey describes the objective "multiple choice tests of usage, vocabulary, and grammar" as the most popular writing assessment model of the first wave (134). Often mandated, these tests were increasingly frowned upon by newly forming groups of composition scholars and writing teachers because they were indirect measures of student ability, or, as Yancey puts it, "a test of something assumed to be related to the behavior, but not the behavior itself" and because testing specialists, not practitioners, created the tests (134). Practitioners (i.e. writing instructors and composition scholars) were more involved in the development of the second wave, holistically scored essay exams, which were assumed to more directly measure student ability. However these timed, oneoff, high stakes summative models still did not reflect the values of revision and feedback that compositionists were advocating for as an integral part of the writing process for students. Further, student agency was not a consideration in either model. Portfolios, however, honor process and student agency by way of reflection and choice and are intended to benefit students and teachers as more formative assessment models.
} 
salaries of college graduates, and so they carry a particular social weight along with their academic importance. In other words, each of these tests carry significant consequences or high stakes. (23).

If this is so, and, indeed, I believe it is, why have there as yet been so few voices of these students invited to enter the political, social, and educational writing assessment fray? This dissertation is an attempt to purposefully privilege the voices of these stakeholders still at the gate and to hear about the consequences of our well-intentioned — and perhaps still problematic — portfolio assessments on them and from them.

\section{Review of the Literature}

In 1999, Kathleen Blake Yancey claimed the portfolio to be the defining new model of writing assessment's third wave (1986-2000). It has since become one of the most widely used models not only for assessing individual student writing in the college classroom, but also for departments and universities to assess their writing programs, and even for larger scale university-wide and intrauniversity assessments of student writing (see Peters and Robertson or AdlerKassner and O'Neill). In the thirty years since the introduction of the portfolio into the field of writing, studies on the efficacy, instructional value, validity, and reliability of this assessment tool have abounded (see, for example, Durst, Roemer, and Schultz, Hamp-Lyons and Condon, Huot and Williamson, Black et al., Elbow 1994, or White). Composition specialists have argued for and against using the portfolio in their writing classrooms; writing program administrators have debated their value for program evaluations; college administrators have supported and 
challenged portfolios as effective models for university-wide assessments of student writing ability (see, for example, Burnham, Broad 2000, or Cambridge 2008). To date, however, only a few discussions have included the perspectives of those stakeholders whose writing these popular assessment tools are most often used to assess: the college student.

The concept of inviting key stakeholders-including faculty, administrators, university leaders, and even the public - to participate in writing assessment initiatives is now well documented (see, for example, Adler-Kassner and O'Neill or Broad 2003). Linda Adler-Kassner and Peggy O'Neill's (2010) argument that workable and sustainable assessment projects must not only be "thoughtfully grounded in research," but also "designed and built collaboratively, with careful attention to the values and passions of all involved, through a process that provides access to all" is an ideal that assessment practitioners in the field of composition and rhetoric continue to work toward (183). However, though there is no shortage of allusions within this scholarship to the need to involve students in writing assessment practices, there are only a few examples of how instructors and administrators have attempted to actually include students in their assessment initiatives (see, for example, Cambridge 2008). Even as Adler-Kassner and O'Neill suggest that our assessments should be iterative and generative processes "integrally tied to the identities and passions of teachers, administrators, and even students" (my emphasis, 178), nearly all of the examples—or case studies—of assessment initiatives they refer to involve only the passions of writing instructors, program and writing center directors, and department heads. Indeed, among the 
many models they offer, only one includes a national survey conducted by The Consortium for the Study of Writing in College (CSWC) that asked students to describe the strategies they use for writing, the types of writing they are assigned, the kinds of information they are given by instructors, and the types of final projects they compose (174-176). This is an excellent start, but otherwise, student voices, particularly those concerning e-portfolio assessment, are still noticeably lacking in the assessment literature.

Similarly, in 2003, Bob Broad proposed one method of assessment that allowed faculty and departments of writing to articulate and map out for themselves, as well as for a larger public, what they valued as "good writing" in student portfolios. Broad introduced Dynamic Criteria Mapping, or DCM, as a unique method of assessment because of its hermeneutical power to uncover and publicize "the [messy] truth about writing assessment" - with its ever-changing, socially-constructed, rhetorical diversity (120). Broad argues that publicizing this truth is an integral part of the DCM process as it can give "a more complex and more true portrait of how writing is learned, practiced, and valued" by the faculty who teach and assess it (120). Though he does briefly mention involving students in assessment and recommends that our field conduct research on "students' perspectives on DCM" (121), his model only includes the values of writing administrators and instructors. Students, according to Broad, should be brought in at the tail end of the DCM process - after faculty have mapped their values - and shown what parts of the writing process are deemed valuable for them. Instead, this dissertation engages in the also messy business of considering the diverse 
values of students, particularly when they engage in an e-portfolio assessment, in order that those complex values - an important and missing piece of what Broad calls the "communal quilt" — might be sewn into the bias (see Brodkey 1994). In this way my dissertation seeks to uncover — and dynamically map — students' perceptions of their experiences in an attempt to include their voices in the quilt of e-portfolio assessment.

Kathleen Blake Yancey (1999) has claimed that writing “assessment must be specific, purposeful, contextual, and ethical...because it is social" and therefore, "we — students, faculty, administrators, legislators — all have rights and responsibilities" in the current and often contentious discourse about it (500). Indeed, this dissertation assumes that students have a right to voice their perspectives about their e-portfolio assessment experiences and our field has an ethical responsibility and political imperative to hear these perspectives. At the very least, this dissertation aims to include and represent as accurately as possible the unheard voices of students in the portfolio assessment literature, and-at most - to give writing instructors and writing administrators cause to formulate more supportive, meaningful, and motivating e-portfolio assessments in their classrooms and programs.

By extension, it may also offer writing program and university administrators one model for including student perspectives in the formulation of their composition course assessment goals and program outcomes. ${ }^{6}$ In so doing,

\footnotetext{
${ }^{6}$ Though I will not pretend that the perspectives of eighteen students at one university should dictate the assessment initiatives and learning outcomes of all writing programs and writing courses
} 
this dissertation attempts to uphold Darren Cambridge's ideal (2008) that the most ethical assessment models require college faculty and administrators not teach their students to be dependent upon the university to mandate what they learn, but that they instead foster the "interdependence" of the two entities — student and school-allowing "each [to shape] the other over time in a manner that balances their interests without glossing over their differences" (53), even when those differences may, at times, make us "pull out our hair" (see Broad 2000).

Cambridge argues that such responsive relationships give students a much-needed "voice in charting the course of the university" (53) and help them prepare for a citizenship beyond the walls of their classrooms.

Though the findings in this dissertation may fall short of charting the course of this or any university, they may perhaps at least suggest some ways for instructors and program administrators, myself included, to chart their/our writing courses and programs equipped with a deeper sense of what students need to feel more supported throughout, confident in, and connected to their e-portfolio assessment experiences in our classrooms. Further, perhaps in hearing the voices of students in this study, these stakeholders may feel informed and buoyed by (instead of anxious or apprehensive about) including their own students' voices and the messy truth(s) they offer in their e-portfolio assessment practices. Broadly, then, my work here seeks to meet and sustain Jacqueline Jones Royster's challenge that we (continue to) keep our writing classroom "boundaries fluid," our “discourse[s] invigorated with multiple perspectives" and our "policies and process of determining what those assessments and learning outcomes should or could look like. 
practices well-tuned toward a clearer respect for human potential and achievement from whatever their source and a clearer understanding that voicing at its best is not just well-spoken but also well-heard" (1126).

One specific way this dissertation invites students to negotiate and collaborate is to listen to their perspectives on three key aspects of e-portfolio assessment: choice, variety, and reflection, or "collection, selection, and reflection" (Reynolds and Davis, Yancey 2001). Even though most portfolio models have moved from paper to electronic formats, the basic processes behind them — and general structures of them — have remained relatively the same (see Cambridge or Kimball). Students are usually asked to collect and select a variety of writing samples that either represent their best work in a course or subject area or that show their writing process and/or progress over a particular span of time or for a particular course or educational experience. Portfolios also usually include a reflective piece in which the writer reflects on his or her writing process, on writing goals and objectives for the course or program, and/or on the particular choices the writer made in selecting and revising the writing samples (see Reynolds and Davis). Asking students to reflect on their writing, giving students a choice to select a variety of contents to include their portfolio, and offering students chances to revise their work before finally submitting a portfolio to an instructor or group of instructors who will then discuss, assess, and assign it a grade or score, honors the social, transactional qualities of the writing experience. Though the portfolio model indeed gives students much more choice and voice than the timed essay or multiple-choice tests of the past, I wondered how 
comfortable, prepared, and/or empowered students felt to engage in such collection, selection, and reflection practices, particularly in a high-stakes evaluative situation. What did students think about their final reflections after those reflections had been assessed as part of a final portfolio grade? This dissertation seeks to answer these questions by revisiting these three key aspects of the portfolio model of assessment from the student's perspective.

Furthermore, this dissertation will question the assumption of student engagement when it comes to e-portfolio assignment design versus e-portfolio assessment. Though many instructors have sought to engage students by designing e-portfolio assignments that ask them to create portfolios that relate to their personal lives, educational experiences, and/or career goals, no studies have focused on how students feel about such portfolio assignments when they become assessments. In 1999, just as they were emerging onto the writing assessment scene, Kathleen Blake Yancey (1999) lauded e-portfolios for their ability to allow students" "[multiple] sel[ves] to emerge" (499). A few years later in her Chair's Address at the Conference on College Composition and Communication (2004), Yancey reminded us again that with digital technologies, you have more contexts you can link to, more strata you can layer, more 'you' to invent, more invention to represent. In sum, the potential of arrangement is a function of delivery, and what and how you arrange-which becomes a function of the medium you choose-is who you invent. (317-8) 
This dissertation seeks to discover the level of complexity students engage in when asked to compose their e-portfolios. Were they aware of the "who" they were inventing, or the "writer self" they were composing? Did students feel that the eportfolio assessment model allowed them a space to represent these writerly selves and present their best writing?

As Yancey suggests, the act of writing has undergone a significant metamorphosis in the last twenty-five years - since the introduction of the computer to the classroom; and in the last ten years, the electronic portfolio-or the e-portfolio - has gained considerable traction as students and writing instructors have become more and more adept at composing multimedia and multimodal texts using the plethora of software programs available to them through the internet and/or their programs and schools. Indeed, as Yancey predicted in 1999, writing assessment is currently in the midst of a fourth wave that is "tak[ing] on the challenges posed by non-canonical texts (email, hypertext, multi-generic writings)" (501). The benefits and challenges of the fourth wave's multimodal possibilities have intensified writing's millennial metamorphosis as college students of this generation have exponentially more and more interaction with multimodal literacies (see Yancey 2004). In 2015, for example, the Pew Research Center reported that "92\% of teens report going online daily-including $24 \%$ who say they go online 'almost constantly," which means most students in our composition classrooms regularly interact with modalities other than textsuch as video, images, audio, and hyperlinks (Lenhart 2). Indeed, as Anne Herrington and Charles Moran have suggested, "outside of the classroom, the 
convergence of audio and video with reading and writing is normal literacy practice for many young people today" (7).

It has also been largely assumed that students find electronic, multimodal, and multimedia assignments more engaging, meaningful, relevant, appealing, and contextually purposeful than their non-electronic counterparts. Jody Shipka, for example, claims that students who are given the freedom to engage in multimodal compositions of their own choice "often [report] being highly engaged with that work and spen[d] considerably more time on their texts than those [who write mono-modal textual essays]" (345). But how [well] and to what extent do students bring their outside digital literacy practices into the writing classroom via the eportfolio? Further, if multimodal compositions are the most ideal, (how) are students being asked to engage in them in the first place? And do students (still) feel so enthusiastic when their e-portfolio scores are returned, their final grades are calculated, and their multimodal compositions have transformed into a multimodal assessment of their writing abilities?

The pressure to investigate and understand the implications of digital technologies on writing and learning has been felt by our flagship organizations and associations. In the last decade, the Council of Writing Program Administrators (WPA), the National Council of Teachers of English (NCTE), and the Conference on College Composition and Communication (CCCC) have all made public their stances on digital learning and writing technologies. CCCC's 2004 position statement suggests that we provide instruction that (1) "introduce[s] students to the epistemic...characteristics of information technology," that (2) 
"provide[s] students with opportunities to apply digital technologies to solve substantial [common and socially-situated] problems," and that [3] "include[s] much hands-on use of technologies," among other things. In 2008, the NCTE contended that in order for students to be prepared in $21^{\text {st }}$ century literacy practices, the digital learning environments in which they engage must promote "proficiency and fluency with the tools of technology," "create, critique, analyze, and evaluate multimedia texts" and to be aware of the ethical implications of these practices. More recently, the WPA listed in its 2014 Outcomes Statement for FirstYear Composition that students should engage often in digital practices at all stages of the writing process (including drafting, reviewing, editing, etc.), that they should become adept at using electronic and other online databases for source searches and even more "informal electronic networks," and that they need to understand the varied rhetorical uses for print versus digital composing processes. These are skills that the instruction and creation of electronic portfolios assuredly promote and an integral part of this educational paradigm shift has involved the call for writing programs and university administrators to work together to implement electronic portfolios as a standard digital learning and assessment practice. In 2014, for example, CCCC got more specific about best practices in composing in digital environments and released a position statement specifically about electronic portfolios which, they contended, have become "an important part of the learning-to-write process" and that faculty, writing program administrators, technology staff, and college administrators must work together to help students "develop digital literacies in composing, collaboration, and records-keeping, and 
consider the rhetorical implications of circulating e-portfolios to both public and private audiences." 7

Overall, these suggested best practices, goals, and outcomes taken together give us a sense of the broad definition and demands of e-portfolio instruction. They also make clear that e-portfolios require instructors to be trained in the affordances, implications, and ethical uses of digital composing technologies, and for students to engage skillfully and critically with the technologies with which they choose to compose. ${ }^{8}$ My study seeks to understand if, as Cynthia L. Selfe warned composition instructors and scholars in 1999, we still need to recognize the relevance of technology in the English studies disciplines [as] not simply a matter of helping students work effectively with communication software and hardware, but, rather, also [as] a matter of helping them to understand and be able to assess - to pay attention to - the social, economic, and pedagogical

\footnotetext{
${ }^{7}$ For these and other position statements, please visit http://www.ncte.org/cccc/resources/positions, http://wpacouncil.org/positions/index.html, and http://www.ncte.org/positions.

${ }^{8}$ The term affordances comes from field of ecological psychology, particularly from the work of $\mathrm{J}$. J. Gibson (1977), who defined the affordance of something as "a specific combination of the properties of its substance and its surfaces taken with reference to an animal" (67). More recently, those in the field of educational technology have adapted the term to refer to digital media, like Matt Bower who define affordances as "the action possibilities [e-learning technologies] offer the user" (6). The field of composition and rhetoric uses the term primarily to refer to the capabilities and limitations of a text, which can be technological, social, cultural, geographical, or otherwise. As one compositionist aptly summed up, "Affordances are the representational qualities of a semiotic mode that make it distinctive. They both enable and constrain and offer potentials and limitations, which make possible or exclude certain meaning-making possibilities (see Cope and Kalantzis; Kress and van Leeuwen)" (as cited in Alexander, note 1). In regards to multimodal compositions, like e-portfolios, the term affordances often refers to the capabilities and limitations of the modes composers choose to employ within a digital or media-based text and of the mediums they use to disseminate those texts (see, for example, Jewitt or Kress). This dissertation will be interested in the latter iteration of the term.
} 
implications of new communication technologies and technological initiatives that affect their lives

and if such "critical technological literacy" continues to be an integral part of our learning environments (1181). Again, when used thoughtfully, electronic portfolios can prepare and offer students practice in such literacies, but how are these skills and fluencies being exercised?

Further, now that portfolios have moved online and into new and exciting electronic and multimodal formats that include not only alphabetic text, but also images, sounds, hyperlinks, and video, it is important to ask if and how these eportfolios are still relevant to the students composing them. With the advent of digital technologies, multimodal theory has offered us another way of looking at meaning-making and how we-and our students—come to truth through writing and speech, as well as a panoply of other discursive modes. As Carey Jewitt and Gunther Kress state in their book Multimodal Literacy, a multimodal approach to learning "starts from a theoretical position that treats all modes as equally significant for meaning and communication" and allows one (or more) mode(s) to be preferable over another depending upon the situation, the context (2-3). Communicative interactions, according to multimodal theory, are not just vocal, or mono-modal; they are varied and multi-modal. They involve text and letters, signs and gestures, digital technologies, sounds and silences, tastes, visuals, and kinesthetic acts. Engaging in these varied modes helps us construct knowledge and to understand our place in the culture. Basically, multimodality challenges the 
assumption, like Jewitt and Kress point out, "that [only] language is a full means of representation" (3).

But when we choose to engage in these modes in our classrooms and with our students, we must do it intentionally and with a real understanding of what multimodality means to our writing students. If we do not, Yancey claims "students in our classes learn only to fill up...templates and fill in...electric boxes...[instead of] compos[ing] and creat[ing], making use of all the means of persuasion and all the possible resources thereto" (320). Instead of allowing technologies to invent or constrain our students' experience, we can develop together a critical understanding of multimodality and learn how to invent multimodal compositions that help us — and our students - come to know our/themselves and to know what we/they know. Yancey writes, that digital texts are "compositions that live inside digital gaps, that create their own unity through patterning, that are located in a kind of coherence like print and yet different from print...that weave together...fragments of a postmodern world...offer us new opportunities for invention, for the making of meaning" (100). This dissertation is interested in the coherent and/or fragmented selves that students perform in their eportfolios.

Jody Shipka answers Yancey's calls to redefine our goals in teaching writing in the new media age. Shipka attends to what Kress would call her students" "multimodal communicational events" in a way that does more than simply give students access to technologies with which they may create such events, but to also "present students with the opportunity to begin structuring the 
occasions for, as well as the reception and delivery of, the [multimodal] work they produce" (279). This work they do, Shipka claims, should train them in the critical and thoughtful uptake, employment, arrangement, delivery, and distribution of various semiotic resources beyond text and including "even [the] threedimensional layering of words and visuals — as well as textures, sounds, scents, and even taste" (278); their creations only have to be "purposefully engineered, out of anything" (300). Shipka allows for this kind of composing to avoid privileging one mode of discourse over another. There are others, like Madeline Sorapure (2006) and Meredith Zoetewey and Julie Staggers (2003) who have also attempted to consider inventive and valid ways of assessing our students' multimodal compositions. Such assessment considerations compel writing instructors to be aware of - and to instruct students to be aware of - the affordances of these modes. To add to the current discussion about multimodality and e-portfolio assessment, my dissertation explores the various types of e-portfolio technologies students chose (or were required) to use, the diversity of modalities they employed within their e-portfolios, and their level(s) of critical engagement with those technologies and modalities.

Finally, a few theorists have underscored the importance of allowing students to be a central part of the articulation of educational aims in writing course and writing program assessment measures (see Cambridge, Gallagher 2012, and Turley and Gallagher). In "On the 'Uses' of Rubrics: Reframing the Great Rubric Debate" (2008), Turley and Gallagher offer one way to involve students' passions and interests in the assessment process as it relates to rubric design. They 
suggest a heuristic for assuring the fair and equitable design of a rubric used for classroom assessment. The students in their study are involved in the collaborative creation of the rubric from the start, and they even add a "Wild Card" feature to the rubric in order to leave room for students to write in a characteristic or key concept that they believe appears favorably in their writing and upon which they wish to be judged by the instructor. Turley and Gallagher explain,

While most goals that individuals set for their writing overlap with those that the community of writers deems important, individual writers often have additional or different goals as well. The "wild card" offers students the opportunity to identify one or more of those goals and to evaluate their work accordingly. (90)

Turley and Gallagher's rubric and wild card feature suggests one way we might allow our students opportunities to reflect upon the unique characteristics of their writing experiences that they come to value — and that may differ from our own. Their statement takes for granted, however, that "most goals" that students have for their own writing are the same as ours. This may be true, but how can we know this for sure if we have not really been asking them-from start to finish and even after an assessment has ended?

More recently, Chris Gallagher (2012) claimed that student articulations are a pragmatic ideal that those who oversee writing assessment initiatives should work towards in order for our educational aims to be more truthful and inclusive. He writes, "the operative aims — the ones that matter most for student learning — emerge from the conditions, needs, and activities of students as they experience 
them" (56). Gallagher also points out that attending to such emergent aims may even surprise and delight because they allow writing instructors and administrators to attend more closely to the "unintended [and perhaps highly significant] results of our interactions with students" $(47,56)$. This dissertation will seek to uphold Cambridge's ideal by working to influence more responsive assessment practices in college composition classrooms and writing programs and will take up Gallagher's challenge by attending closely to the unintended results of students' experiences with e-portfolio assessment_or to be interested in the "wild card" categories that students report. Specifically, my dissertation focuses on what participants reported learning from their e-portfolio assessment experiences, particularly those articulations that differed from what they were supposed to have learned or were expected to learn as outlined in the course syllabi or learning outcomes. Since the best assessment practices inform and influence how writing is taught in the composition classroom, so should the findings of this dissertation inform how writing instructors, writing program administrators, and university leaders might more responsively formulate the educational goals and curricular outcomes for their composition courses and programs.

\section{Two Model Studies}

In looking for models, I located two studies that investigated students' perceptions of the portfolio model. In both studies, Nancy Westrich Baker (1993) and C. Beth Burch (1998) reported their findings on student attitudes towards the writing portfolio, then a newly burgeoning pedagogical method in writing studies. The Baker study contributed valuable insights to the field regarding how portfolio 
instruction affects students' final exam scores, course grades, and attitudes towards writing. Burch's study provided insight into how portfolio instruction affected students' attitudes towards writing and writing assessment, students' confidence about writing, students' perception of their writing progress and their instructors' attitudes about assessment, as well as students' attitudes about revision and final grades.

These studies offer excellent models for my own and I borrow some ideas from them, though they also differ from mine in terms of data collection methods, sample sizes, and research focus. Foremost, these two researchers are particularly interested in the portfolio as an instructional model and how students felt the pedagogical approaches taken by writing instructors had an affect on them. My study adds a layer to this: it, too, asks students how they felt the e-portfolio instruction they received affected their grades, their attitudes, and the three key eportfolio processes of collection, selection, and reflection but is also interested in other influences that had an effect on these aspects of their experience-like peers, technology, past experience, and institutional outcomes. My study also seeks to consider the portfolio as a final evaluation of student writing and the effects of the portfolio's summative assessment aspects on students, especially in comparison to its formative assessment features. ${ }^{9}$ In regard to the summative aspects of their e-

\footnotetext{
${ }^{9}$ The NCTE offers a helpful definition of these two terms in relation to the portfolio model: "Inside the classroom, writing assessment is often formative. When teachers respond to student work, their intent is to help students, which is the purpose of formative assessment: to help students while they and their texts are still in formation. As many students already know, however, we have many kinds of summative writing assessments as well-from the writing essay portion of the SAT to endof-course Advanced Placement essays - which are thought of as summative because they are final (i.e., they sum up) and, typically, are used to rank students. Writing portfolios-which are collections of writing selected from a larger archive and reflected upon by portfolio composers-
} 
portfolio experiences, I investigate student attitudes about what I call the "Four Pillars of College Assessment," or, weighted percentages, final grades, final exams, and learning outcomes, and the consequences these have on students' levels of engagement and motivation. I also seek to understand how the writerly selves that students enact in their e-portfolio reflections-ideally a formative aspect of their e-portfolio experience - compare to the writerly selves they report to me, and what kinds of peer and instructor feedback students find valuable in their eportfolio processes.

In many ways, my study also seeks less breadth and more depth than these two studies. Baker and Burch, for example, used a mixed-methods approach with a few interviews of instructors ( 1 and 10, respectively), no interviews of students, and primarily surveys and analyses of portfolios collected from a large sample of students (224 and 338, respectively). In order to provide more context and to focus more readily on students' voices and narratives, this study includes the in-depth perspectives of eighteen students as gathered through primarily open-ended reflection logs and lengthy one-on-one interviews, as well as some document analysis of student e-portfolios, which they share and explain in detail during the interview. Instructors' perspectives were not a focus of my study, though course syllabi, outcomes, and e-portfolio assignments were collected and used for context and triangulation.

can be either formative or summative. Because they tend to provide a much fuller and richer picture of a student's writing development, they often lead to better decisions about student development and achievement — and at the center of writing assessment is the ability to make such decisions" (528). 
The Baker and Burch studies were also focused on comparing the attitudes of students in classrooms that used portfolio instruction with the attitudes of students in classrooms that used non-portfolio instruction. Partly because of access and resource challenges, my case study approach compares students' experiences only in classrooms that use portfolios as the primary classroom assessment model; but this variable also allowed me to garner a baseline understanding of students' varied e-portfolio experiences within this particular context and to generate several hypotheses about those experiences that I-or others - can later test as part of a quasi-experimental case study that includes random placement and/or more controlled independent variables (i.e. interviews with students in writing classrooms not using e-portfolios as a final assessment model).

On the other hand, the scope of my study is broader than Baker's and Burch's in that it compares students' experiences with portfolios in a range of writing classrooms across a vertical curriculum (100, 200, 300, and 400 course levels) and from a variety of majors_-including writing majors — and represents students from all years (freshman to senior). This broader snapshot of "the eportfolio experience" becomes important in being able to discuss how students' past experiences with portfolios affects their current experiences and to describe some compelling similarities in student experiences across these seemingly diverse contexts - like the value of relevance and connection. Finally, the portfolios of the nineties were primarily print-based and the students in my study report on their experiences with electronic portfolio assessment in the current century and technological age, which becomes an important new focus in Chapter 3. 


\section{My Research Questions}

This dissertation investigates several questions regarding students' perspectives of their e-portfolio assessment experiences. Generally,

- What do students at varying course levels of a vertical college writing curriculum report as the most valuable components of their e-portfolio assessment experiences?

More specifically, in regard to instruction during the e-portfolio composition process:

- When and how do students feel supported in composing an e-portfolio?

- What influences students to feel supported, prepared, instructed, and/or otherwise led to compose a successful e-portfolio?

- What do students need in order to feel more confident about and/or supported in composing their e-portfolios?

More specifically, regarding what students know and value about the technological, modal and design affordances, or form/at/ting, of their e-portfolios:

- How do students understand "writing" as a technology and its modal and design possibilities in an e-portfolio?

- What influences students to make modal selections and design choices in an e-portfolio assessment?

- What do students need in order to better understand the affordances of the various technologies, modalities and design choices they have at their disposals (and/or are required to use) in an e-portfolio assessment? 
More specifically, regarding what students value about the e-portfolio as a method of assessment in the writing classroom:

- How do students feel about the e-portfolio as a method of writing assessment (especially as compared to other ways their writing can be or has been assessed)?

- What influences students to feel confident and/or anxious about an eportfolio assessment?

- What do students need to feel more confident and supported in an eportfolio assessment experience?

And finally, in regard to why all this matters:

- How might e-portfolio assessments be more meaningful to students? ${ }^{10}$

- How can instructors improve our e-portfolio pedagogies and/while also improving our students' e-portfolio (and) assessment experiences?

Particularly, how might we change or alter our e-portfolio pedgagogies, writing programs, and assessment models in ways that might help students enact more confident, less anxious, and less frustrated "writerly selves" in an assessment experience ${ }^{11}$

\footnotetext{
${ }^{10}$ A nod here to The Meaningful Writing Project (http://meaningfulwritingproject.net/) and the exciting new findings being published therein about what students find meaningful in their writing experiences. I have recently learned about this project (thank you, Professor Shannon Madden!) and intend to read the newly published companion book as soon as I can get my hands on a copy. ${ }^{11}$ Kathleen Blake Yancey wrote (1999) that one way to historicize writing assessment is to ask "Which self does any writing assessment permit?" or "Which self does an assessment construct?" On August 10, 2015, as I began preparing a dissertation proposal and IRB application for my study, I alluded to these questions on the first page of my research journal. They were written alongside F.A. Hanson's claim (which Yancey quotes) that "tests create that which they purport to measure" (484). Beside that I wrote (in all caps), "WHAT STUDENT SELF DO E-PORTFOLIOS CREATE?" In essence, this question has been on the forefront of my mind since then and this
} 


\section{My Qualitative Study}

My IRB-approved qualitative study was conducted from January to June of 2016 in the form of an embedded single-case study with a common case rationale. It focused on the perspectives of eighteen college students and their experiences with electronic portfolio - or e-portfolio — assessment in their writing classrooms at the 100-, 200-, 300-, and 400-, or Senior Capstone level. E-portfolio assessment was the single "case" or unit of analysis that I examined (Yin 51); the "embedded subunits of analysis" were the student participants who completed all three stages of the study and their perspectives on their e-portfolio experiences (54). The "contextual conditions" that represented the boundaries of my case study were the multilevel writing courses (e.g. 100, 200, 300, and 400) offered as part of the vertical composition curriculum at my home university (50). The study is a "common" single-case study as its objective has been "to capture the circumstances and conditions" of students' experiences of this mainstream assessment model "because of the lessons [these experiences] might provide [the field of writing] about the social processes related to [my] theoretical interest," particularly, the kinds of instructional support and practice that students value and need to enact more confident, more prepared, less anxious, and less frustrated "writerly selves" in an e-portfolio assessment in the writing classroom (52). 
An Overview of the University and Writing Program

As a graduate student with limited funding resources for travel and participant recruitment, studying students from the school I attend was practical and made the work more feasible for me. Importantly, however, my university is one of a little over 60 universities nationwide that offers an undergraduate major and minor in composition and rhetoric, and all of our majors are required to complete an electronic portfolio in a senior capstone (400-level) course. Students who take other courses in our vertical curriculum, like the two (100-level) first year writing courses, or the 200-level digital writing and writing arguments courses, for example, whether majors or not, are also often required to complete eportfolios. Having immediate access to such a wide range of college students engaged in various subgenres of e-portfolio assessment and taking courses offered by our Department of Writing and Rhetoric provided me with a highly relevant sample for my study. ${ }^{12}$

\section{Stage 1: Recruitment \& Online Data Collection}

By December of 2015, I had secured IRB approval to conduct my study in three stages. Stage 1 of my study (January to May, 2016) involved participant recruitment and online data collection (via surveys and logs) of students'

\footnotetext{
${ }^{12}$ Generally, the undergraduate body is comprised of just under 15,000 students. The Writing Department offers approximately twenty different writing courses each year, about three-quarters of which are cross-listed with other departments and/or are required for the writing major and minor. The university does not require undergraduates to take any one particular writing course, though several are offered to fulfill General Education requirements (students can self-select to take them) and some outside departments and programs require students to take a particular writing course. On average, 3,000 undergraduates take writing courses each year and approximately fifteen to twenty writing majors graduate from the program. At the time of my study, there were seven FT/TT faculty (from inside and outside the Writing Department) and approximately twenty PT/adjunct instructors and ten graduate students teaching writing courses at the university. The instructors of the students in my study represented a range of these instructor types.
} 
perspectives of the e-portfolio assignments they were working on during the semester. I began in early January researching how many writing courses were going to be taught in the spring semester of 2016 and finding out who would be teaching those courses. Then I reached out (via email and in-person) to those adjunct instructors, faculty, and graduate instructors to (1) find out if they planned to require a final electronic portfolio as part of their course assessment ${ }^{13}$ and (2) if so, to seek their permission to give a short (10-minute) in-person presentation to their class(es) in order to describe my study to their students and recruit volunteer participants (see Appendix C: Recruitment Script).

By the end of January, I had garnered permission from seventeen instructors to present to their students, ${ }^{14}$ and over the first three weeks of the spring semester I gave twenty-two in-person recruitment presentations in various writing classrooms across the university, two of which were broadcast live (via Skype) to satellite campus classrooms. Additionally, students in five online or hybrid courses were asked by their instructors to view a recruitment video I had created on YouTube. ${ }^{15}$ I also created informational flyers about the study and hung them in strategic locations around campus, including on doors, bulletin boards, and hallway walls where I knew students taking writing courses would be more likely see them (see Appendix B: Recruitment Flyer).

\footnotetext{
${ }^{13}$ In doing so, I was asked by several instructors how I defined a final electronic portfolio. My rough working definition was "a final project that students would submit in an electronic format at the end of the semester for a grade and that required them to collect their writing from the course, select pieces of that writing, and reflect on those pieces of writing in some way as defined by the instructor."

${ }^{14}$ To my knowledge, all of the instructors who were requiring e-portfolios that spring had pity on this graduate student researcher and kindly said "yes" to my request.

${ }^{15}$ If you are interested, this video is public. To view it, you can click on this link to the video or visit the following URL: https://youtu.be/IQuqjafmSys.
} 
During the twenty-two in-person and Skype presentations I explained the three stages of the study (using the visual in Figure 1 below), reviewed and distributed an IRB-approved consent form to all students in the classroom, and asked students wishing to be in the study to sign the form and put it in an anonymous envelope that I left in the classroom at the end of my presentation (and which I collected later after all forms had been returned).

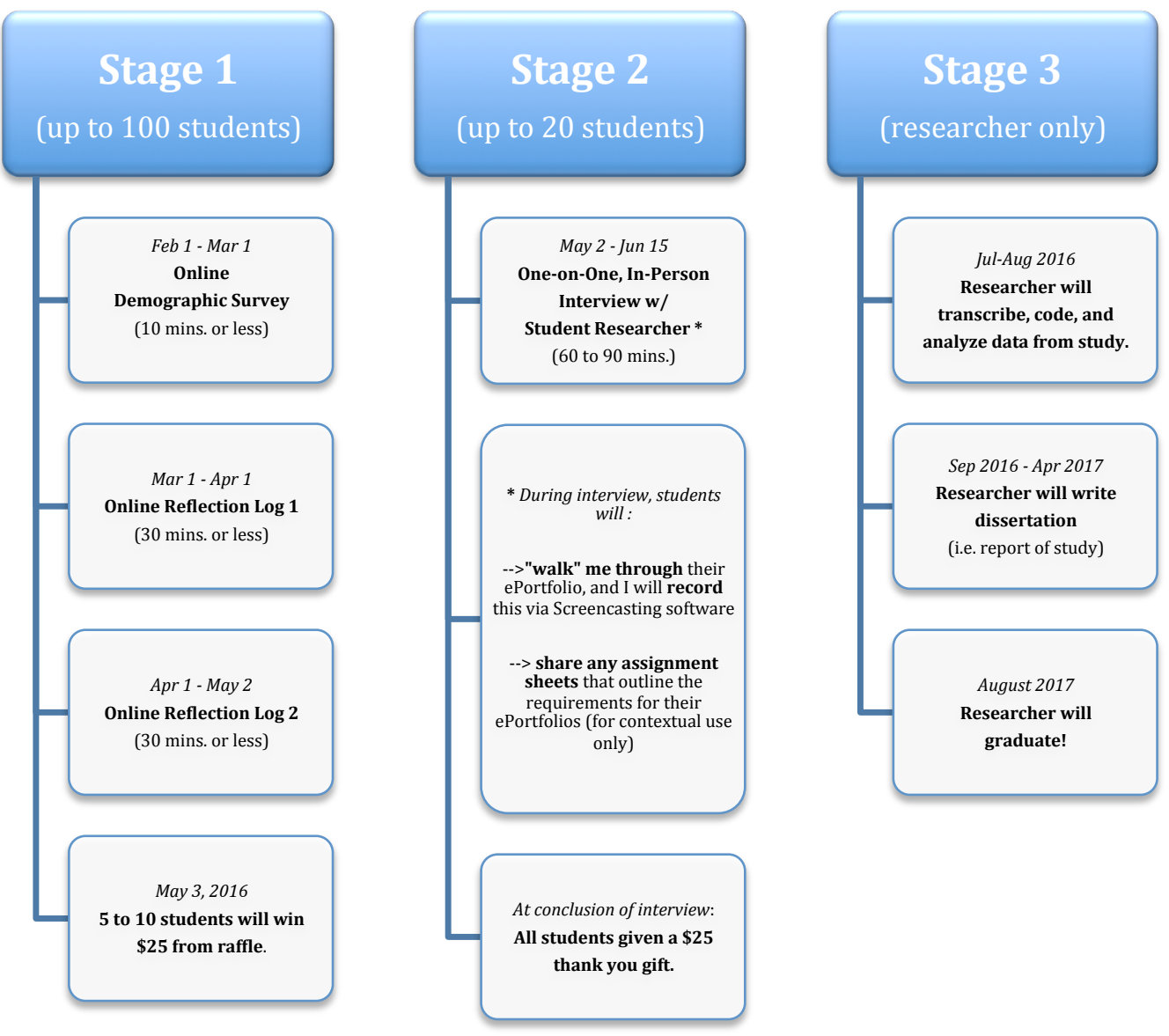

Figure 1: Visual Overview of the Three Stages Used in Recruitment Presentations In the video and on the flyers, I told students to contact me via email if they were interested in participating and that I would arrange to meet with them privately on campus to review the consent form. 
I took great pains not to assert any undue pressure on students to join my study while also trying to protect their anonymity and fairly compensate them for their time if they did choose to volunteer. For example, so it was not visually obvious to me, to others, or to the instructor who volunteered and who did not, I asked those students who did not wish to be in the study to simply return the form to the envelope unsigned. Also, I asked that instructors leave the room with me while students made their decisions and we did not return until all forms had been placed into the envelope. ${ }^{16}$ Instructors did not collect the consent forms, and I only opened them after I was in a private location. Instructors were never told whether or not their students volunteered for or participated in the study. Students were also told they could drop out of the study at any point with no consequences and that their grade would in no way be affected by their choice to participate. For incentives I promised that students who completed the survey and two reflection logs in Stage 1 of the study would be entered into a raffle to win a thank you gift of \$25. I also promised that I would give a \$25 thank-you gift to every student who completed an in-depth, in-person interview with me in Stage 2 of the study. ${ }^{17}$

\footnotetext{
${ }^{16}$ For the two Skype presentations (for the same instructor), I sent the forms to the instructor ahead of time. The instructor then distributed the forms to students, had one student seal the envelope after all the forms had been placed inside it, and returned the two sealed envelopes to me.

${ }^{17}$ I raised the money for these gifts $(\$ 1,100$ to be exact) from close family and friends using the online crowdfunding platform, Kickstarter. Originally, I predicted I would have enough funding to give $\$ 25$ to about 1 to 5 students in Stage 1 and 20 students in Stage 2, and told students so; but as my Kickstarter fund grew in January and February (it ended in March), I was able to eventually offer $\$ 25$ to twenty (20) students in both stages of the study. Thank you, funders! One raffle winner never responded to my multiple attempts to arrange to give him his $\$ 25$ gift and another student refused her interview thank-you gift saying that she just wanted to help me and did not want money from me (God bless her!). I put this extra $\$ 50$ towards my Screencast-O-Matic and SurveyMonkey subscriptions. Interestingly, when asked "off the record" about why they chose to participate in the study, an overwhelming majority of interviewees did not report it was because of the financial incentive; most simply wanted to help and/or be involved in a research project that valued their voices.
} 
By the third week of classes (mid-February), I had presented to approximately 525 students in a total of twenty-five writing courses and had signed consent forms from 124 students interested in taking part in the study. ${ }^{18}$ The following chart (Table 1) outlines the efforts and outcome of my recruitment presentations:

Table 1: Participant Recruitment Efforts

\begin{tabular}{|c|c|c|c|c|}
\hline $\begin{array}{l}\text { Course } \\
\text { Level }\end{array}$ & $\begin{array}{c}\text { No. of } \\
\text { Classes } \\
\text { Presented } \\
\text { To }\end{array}$ & $\begin{array}{c}\text { No. of } \\
\text { Participants } \\
\text { Garnered }\end{array}$ & $\begin{array}{l}\text { Percentage of } \\
\text { Those Recruited } \\
\text { (per total } \\
\text { presented to; } \\
\text { approx. } n=525 \text { ) }\end{array}$ & $\begin{array}{c}\text { Percentage of } \\
\text { Those Recruited } \\
\text { (per course } \\
\text { level, } n=124 \text { ) }\end{array}$ \\
\hline 100 & 13 & 70 & $13 \%$ & $27 \%$ \\
\hline 200 & 8 & 38 & $7 \%$ & $24 \%$ \\
\hline 300 & 3 & 8 & $2 \%$ & $13 \%$ \\
\hline 400 & 1 & 8 & $2 \%$ & $50 \%$ \\
\hline Total & 25 & 124 & $24 \%$ & $\mathbf{n} / \mathbf{a}$ \\
\hline
\end{tabular}

During recruitment, the only information I gathered from students was their names, signatures, phone numbers, and school email addresses so I could contact them to begin the study (if they still wished to be involved). I collected more

\footnotetext{
${ }^{18}$ It may be important to note here that all of my student participants came from the face-to-face presentations I gave in classrooms; no students contacted me to join my study after viewing the recruitment video or flyer. I'm not sure if this is a testament to the merits of person-to-person recruitment efforts (vs. online or flyer recruitment), or simply a result of my piteous in-person graduate appearance. Either way, future graduate student researchers take note!
} 
demographic and experiential information from students in the first online survey, which I emailed between February 1 and March 15 to all who signed the consent form (see Appendix D: Demographic Info Survey). ${ }^{19}$ Students responded to this survey between February 15 and March 15. I emailed the first Reflection Log to students just after midterm and student responses came back to me between March 15 and April 15 (see Appendix E: Reflective Log 1). This first log mostly asked students about their past portfolio experiences. I emailed the second, and final, Reflection Log in late April and students responded to those by May 2, the final day of classes (see Appendix F: Reflective Log 2). The second log asked students about their collection processes and their feelings about the upcoming portfolio submission and final grades. As I expected, about half of the 120 original student volunteers completed the demographic survey and the number of respondents declined a bit more for each of the subsequent reflection logs. The following table (Table 2) represents the numbers of students who participated in each subset of Stage 1 of the study:

Table 2: Stage 1 Participation Records

\begin{tabular}{|l|l|}
\hline \multicolumn{1}{|c|}{ Stage 1 Subset } & Number of Students \\
\hline a) Signed consent forms (i.e. Study Volunteers) & 124 \\
\hline b) Demographic Survey Participants & 60 \\
\hline c) Reflection Log 1 Participants & 46 \\
\hline d) Reflection Log 2 Participants & 37 \\
\hline
\end{tabular}

\footnotetext{
${ }^{19} \mathrm{I}$ bought and used a private, password protected SurveyMonkey account for this and the two other data collection tools (reflection logs) for Stage 1.
} 
During the final week of this stage (the first week of May), I thanked students via email who completed the online survey and/or any of the reflection logs. In the end, I was able to offer $\$ 25$ to twenty students who completed all subsets of Stage 1 and who were chosen randomly from a raffle. This ended Stage 1 of the study.

\section{Stage 2: Eighteen Interviews}

Stage 2 of my study began in early May as I reviewed the survey and reflection log data closely and selected the most information-rich and widely representative, or diverse cases to interview. Of the forty-eight different students who participated in Stage 1 of the study, I did not ask thirteen of them for interviews because they had not completed either the demographic survey and/or one or both of the reflection logs, which left me with an incomplete view of their past and/or present e-portfolio experiences. From the remaining pool of thirty-five (35) students, I looked for a mix of students from the Writing and Rhetoric major as well as non-majors from a range of years-freshman through senior. I also chose to interview some older, non-traditional students and attempted to interview as many male students as possible, which was difficult when only seven, or about $15 \%$ of the Stage 1 participants who responded to the survey and both logs were male. ${ }^{20} \mathrm{I}$ also looked for interviewees to have a range of previous experience with portfolios (electronic and/or print) and for some to be completely new to electronic (and even to print) portfolios. When there was an overabundance of candidates in

\footnotetext{
${ }^{20}$ In the end, I asked six of the seven male students for an interview and only two agreed to meet with me. Two others responded and asked not to be interviewed. I did not hear back from the other two. In future research, I would like to get more male participation as well as more diverse ethnic/racial representation (all of my participants were white, and most were female).
} 
one area (i.e. students at the 100-level, freshman, females, etc.), I chose to interview those students who offered compelling stories and/or perspectives that represented opposing or varying viewpoints in their reflection logs. For example, some students were very anxious about their e-portolios and final grades whereas some were quite confident; I attempted to interview students with both perspectives (as well as some in the middle). Finally, I chose some participants simply because they put a significant amount of effort into their online responses, which led me to believe they would similarly take the interview seriously.

In the end, I requested twenty-nine interviews from a pool of thirty-five students. Six students declined the interview for various reasons (e.g. working in the summer, too busy, simply did not wish to participate any longer) and five did not respond at all to my interview requests (I sent two). This left me with eighteen students with whom I was finally able to schedule and conduct interviews at each student's convenience and only after their e-portfolios had been submitted to their instructors and their final grades had been posted.

I conducted these eighteen interviews between May 20th and June 10. They lasted anywhere from forty-five to ninety minutes. During the interviews, I asked each student open-ended questions about his or her experience with the eportfolio assessment in his or her course and, when appropriate, asked each student to refer me to sections of his or her e-portfolio in Photovoice fashion as a projective technique (see Wang and Guest et al; also Appendix G: Student Interview Questions]. ${ }^{21}$ Each student also provided me with the syllabus from his

\footnotetext{
${ }^{21}$ I recorded these interviews using a headset with a microphone and GarageBand software.
} 
or her course, a list of course or program learning outcomes, and an e-portfolio instruction sheet, checklist, or grading rubric if they had one. As each student walked me through the key components of his or her e-portfolio on a computer screen, I used screencasting software to record the student's voice along with the navigational moves he or she made with the mouse ${ }^{22}$. Students also granted me unlimited access to their web and PDF e-portfolios, so I could refer back to them as needed after the interview had concluded and as I worked through the data analysis phase (i.e. Stage 3) of my study.

\section{Stage 3: Data Analysis and Coding}

Stage 3 (July to December 2016) marked the end of my interaction with student participants and the beginning of my data compiling, mining, and coding; it also signaled the start of my dissertating. I began data analysis by organizing the online survey and reflection log data, compiling all of my research journal and field notes, and viewing and (re-)listening to the recorded interviews and portfolio screencast walk-throughs. ${ }^{23}$ I was unable to transcribe every interview (which would have involved over 30 hours of audio recordings), though I listened closely to them all in full at least one more time and took copious notes on what students said. As I began to compile emergent, or "in vivo," codes or themes (see Guest et al., Galletta, and Auerbach et al.) that arose from the data, I would return to the audio and video recordings as needed to be certain I was quoting students in

\footnotetext{
${ }^{22}$ Screencast-O-Matic was the software program I bought and used.

${ }^{23}$ Throughout the data collection stages and into the data analysis stage of my research, I kept a research journal where I made notes on how I was selecting participants and/or noting and coding emergent themes and ideas.
} 
context and correctly. Similarly, I used coding and content-driven (exploratory) document analysis to analyze student e-portfolios and the supporting course documents and artifacts (Guest et al) with which they provided me. This process guided my further analysis and eventual reporting of the major themes and insights that emerged from my case study data and that offered answers to my research questions as outlined earlier in this chapter. And because such analysis, as Rosaline Barbour points out, "is a complex and inherently 'messy' process” that requires the researcher to engage in a "systematic and thorough iterative process, whereby coding categories are continuously subjected to review in the light of disconfirming examples or exceptions to concepts and patterns identified" (127), I attempt in this dissertation to include negative cases and/or unusual or distinctive experiences reported by student participants.

\section{A General Description of the Eighteen Participants ${ }^{24}$}

The following table (Table 3) represents the demographic breakdown of the eighteen students who participated fully (in Stage 1 and 2) and upon whose insights and perspectives this dissertation is based:

Table 3: Final Participant Demographics

\begin{tabular}{|c|c|c|}
\hline \multicolumn{1}{|c|}{ Type } & Number & Percentage \\
\hline All Participants & & \\
\hline Total & 18 & $100 \%$ \\
\hline Self-Identified Gender & & \\
\hline
\end{tabular}

\footnotetext{
${ }^{24}$ I have used pseudonyms for all student participants and do not offer any descriptions of them that may reveal their identity. I will also keep anonymous the actual names and/or titles of the courses, instructors, and university involved in the study.
} 


\begin{tabular}{|c|c|c|}
\hline Female & 16 & $89 \%$ \\
\hline Male & 2 & $11 \%$ \\
\hline \multicolumn{3}{|l|}{ Year } \\
\hline Freshman & 6 & $33 \%$ \\
\hline Sophomore & 4 & $22 \%$ \\
\hline Junior & 2 & $11 \%$ \\
\hline Senior & 6 & $33 \%$ \\
\hline \multicolumn{3}{|l|}{ Age } \\
\hline $18-22$ & 14 & $78 \%$ \\
\hline $23-33$ & 2 & $11 \%$ \\
\hline $34-44$ & 2 & $11 \%$ \\
\hline \multicolumn{3}{|l|}{ Course Level } \\
\hline 100-level & 7 & $39 \%$ \\
\hline 200-level & 5 & $28 \%$ \\
\hline 300-level & 2 & $11 \%$ \\
\hline 400-level & 4 & $22 \%$ \\
\hline \multicolumn{3}{|l|}{ Major/Minor } \\
\hline Writing Majors & $5^{25}$ & $28 \%$ \\
\hline Writing Minors & $2^{26}$ & $11 \%$ \\
\hline Non-Majors & $13^{27}$ & $72 \%$ \\
\hline
\end{tabular}

${ }^{25}$ Of these Writing majors, 3 were double-majors representing the fields of Film Media, Business, and English and 2 had minors, one in English and one in Philosophy and Public Relations.

${ }^{26}$ Of these Writing Minors, one was a Nursing major and the other had a dual major in English and History.

${ }^{27}$ The variety of majors represented in my final interview sample were as follows: Psychology and Communications, Nursing, Business, Environmental Science and Management, Kinesiology,

Biotechnology, Communications and Public Relations, Computer Science, Environmental and Natural Resource Economics, English, History, and Film/Media. Of these non-Writing majors, 3 had minors in GIS and Remote Sensing, Psychology, Classics, Writing and Rhetoric. 
Though I attempted to recruit and retain male participants, especially for the interviews, most of the students $(89 \%)$ in my study were female; two males participated in the full study. Though participants ranged in year from freshman to senior, about one-third (33\%) were freshman and another third $(33 \%)$ were seniors; four $(22 \%)$ were sophomores and two $(11 \%)$ were juniors. This made for a decent spread of experience. Most students were 18-22 years of age, but four participants were over 22. These students in particular often offered an alternative perspective to several of my inquiries. Students in 100-level courses represented the highest number of participants per course level, but my study did include students from all levels. This variety of perspectives plays an especially important role when I discuss themes that relate to students' levels of experience with eportfolios and college writing courses. For example, senior majors have a very different perspective from freshman non-majors about the value and relevance of e-portfolios; both became equally valid and important parts of my findings and recommendations.

Of the six seniors in my study, four were Writing and Rhetoric majors, one (an English/History major) was minoring in Writing and Rhetoric, and the other was an English/Film Media major. I had one other writing major participate in my study; he was a sophomore and had taken two writing courses prior to this one. I also had one freshman writing minor participate in my study; the course she was enrolled in at the time of my study was her first college writing course. The other thirteen participants represented the following majors (as noted in the footnote on page 45): Psychology and Communications, Nursing, Business, Environmental 
Science and Management, Kinesiology, Biotechnology, Communications and Public Relations, Computer Science, Environmental and Natural Resource Economics, English, History, and Film/Media; among these non-writing majors, the following minors were represented: Geographic Information Systems (GIS) and Remote Sensing, Psychology, Classics, Writing and Rhetoric.

At the time of my study, portfolios were required in the (two) 100-level courses, in the 200-level digital writing course, and in the 400-level professional portfolio course for the major; portfolios were not required in the 200-level argumentative writing course and the 300-level travel writing course; and Wordpress - the free version (i.e. Wordpress.com) —-was the required platform for the 200-level digital writing course and 400 -level course. There is no requirement for having previous experience with writing code for the web (i.e. using HTML or CSS) or with Content Management Systems (CMS)/web-building programs (like Wordpress, Wix, or Squarespace) for students who enroll in any writing course. Sakai is the university learning management system that all students, faculty, and administrators are given access to, and all university email is hosted through Google Gmail. There is no requirement for writing instructors to use Sakai (though many of them do, to varying degrees) and nearly everyone — students and instructors alike — uses the university email to communicate with each other. At the time of my study, writing portfolios were not built or stored on Sakai nor was there a departmental or institutional portfolio-building system on which students created or stored their writing portfolios. Other than for the two courses mentioned 
above, requiring an electronic portfolio and choosing which e-portfolio platform to require students to use is left to the discretion of each course instructor.

The two first-year writing courses at our university, do, however, have a required portfolio textbook, which at the time of my study was the third edition of Portfolio Keeping (Nedra Reynolds and Elizabeth Davis 2013). Adjunct and graduate instructors who teach these 100-level courses are trained in the use of this text (and sometimes its companion teacher resource, Portfolio Teaching), are given access to portfolio resources on a Sakai web portal maintained by the First Year Writing Coordinator, and are encouraged to discuss portfolio instruction and share resources among themselves via the Sakai portal, and/or at one of the allstaff meetings that occur at the beginning of each semester and/or at their own discretion. Most of the resources and trainings that instructors teaching our 100level courses were exposed to at the time of my study, however, were focused on print portfolios. As a result, the technologies that students in my study used to create their e-portfolios—as well as the modalities they employed within those eportfolios-varied greatly.

Though most of the students in my study (88\%) had experience with portfolios of some kind, about one-third (33\%) were compiling an electronic portfolio for the first time. Students had a variety of past experiences with portfolios. A majority of them had completed portfolios in a previous college writing course and several reported having had completed creative portfolios (art, poetry, etc.) and portfolios as a high school graduation requirement. A couple participants had completed a portfolio for a high school English class and one had 
done a portfolio for a study abroad program. They were a mix of electronic and print portfolios and all were graded or otherwise assessed as some kind of final or culminating project. The following chart (Table 4) indicates participants' previous experience with college writing courses, portfolios and electronic portfolios, as well as their perceived levels of preparedness and excitement for this new electronic portfolio.

Table 4: Participants Levels of Experience, Preparedness, and Excitement for the e-Portfolio

\begin{tabular}{|c|c|c|}
\hline Amounts of Previous College Writing Course Experience & $\begin{array}{l}\text { \# of } \\
\text { students }\end{array}$ & $\begin{array}{l}\% \\
\text { of } \\
\text { total }\end{array}$ \\
\hline None: first WRT course of any kind & 9 & $50 \%$ \\
\hline One: took one (1) other WRT course before this one & 3 & $17 \%$ \\
\hline Some: took two (2) other WRT courses before this one & 1 & $1 \%$ \\
\hline Substantial: Took three or more $(3+)$ WRT courses before this one. & 5 & $28 \%$ \\
\hline \multicolumn{3}{|l|}{ Amounts of Previous Portfolio Experience (of any kind) } \\
\hline None: First portfolio experience (of any kind). & 4 & $22 \%$ \\
\hline One: Completed one (1) other portfolio (of any kind) before this one. & 2 & $9 \%$ \\
\hline Some: Completed two to three (2-3) portfolios (of any kind) before this one & 5 & $28 \%$ \\
\hline $\begin{array}{l}\text { Substantial: Completed more than three }(4+) \text { portfolios (of any kind) } \\
\text { before this one }\end{array}$ & 7 & $39 \%$ \\
\hline \multicolumn{3}{|l|}{ Amounts of Previous e-Portfolio Experience } \\
\hline None: This was the students' first electronic portfolio experience. & 6 & $33 \%$ \\
\hline $\begin{array}{l}\text { Some: Student had at least one previous experience compiling an electronic } \\
\text { portfolio. }\end{array}$ & 12 & $67 \%$ \\
\hline \multicolumn{3}{|l|}{ Perceived Levels of Preparedness for this e-Portfolio } \\
\hline Not prepared & 1 & $6 \%$ \\
\hline
\end{tabular}




\begin{tabular}{|c|c|c|}
\hline Somewhat prepared & 10 & $55 \%$ \\
\hline Well prepared & 4 & $22 \%$ \\
\hline Very well prepared & 3 & $17 \%$ \\
\hline \multicolumn{3}{|c|}{ Perceived Levels of Excitement about this e-Portfolio } \\
\hline Not excited & 5 & $28 \%$ \\
\hline Somewhat excited & 10 & $55 \%$ \\
\hline Very excited & 3 & $17 \%$ \\
\hline \multicolumn{3}{|c|}{ Perceived Levels of Nervousness about Their Final e-Portfolio Grade } \\
\hline Very nervous & 3 & $17 \%$ \\
\hline Somewhat nervous & 9 & $50 \%$ \\
\hline Not nervous & 6 & $33 \%$ \\
\hline \multicolumn{3}{|c|}{ Percentages of Final Grade Students' e-Portfolios Were Worth } \\
\hline $20 \%$ of final grade & 4 & $23 \%$ \\
\hline $25 \%$ of final grade & 4 & $23 \%$ \\
\hline $30 \%$ of final grade & 2 & $10 \%$ \\
\hline $40 \%$ of final grade & 8 & $44 \%$ \\
\hline \multicolumn{3}{|c|}{ Final Grades Students' Received on Their e-Portfolios ${ }^{28}$} \\
\hline A or A- & 13 & $72 \%$ \\
\hline $\mathrm{B}+$ or $\mathrm{B}$ & 5 & $28 \%$ \\
\hline C or below & 0 & $0 \%$ \\
\hline
\end{tabular}

The first year students' e-portfolios were all worth forty percent of their final grade, whereas the capstone portfolios were worth just twenty-five percent of seniors' final grades. Of the two 200-level courses required for the writing major,

${ }^{28}$ A few students reported that they were unsure of their final score on the e-portfolio because that grade had not been returned or given by the instructor, but that they guessed they must have received a particular score on it because of the final grade they received in the course. I used their educated guesses in this chart tally. 
e-portfolios were worth either twenty, thirty, or forty percent of students' final course grades, depending on the instructor. The one elective (and only 300-level course) in my study required an e-portfolio worth thirty percent of students' final grade. In other words, the e-portfolio stakes (as far as grade percentages) were the highest in the first year writing courses and either as high as-or progressively lower in-the courses required for the major, the senior capstone e-portfolio being in one of the lowest weighted groups.

As further illustrated by the three charts (Table 5, Table 6, Table 7) below, half $(50 \%)$ of the students in my study had taken at least one college level writing course before the course in which they were currently enrolled, two-thirds (78\%) had at least some experience with print-based portfolios, and/or over half (67\%) had at least one previous experience with electronic portfolios.

Table 5: Participants' College Writing Course Experience

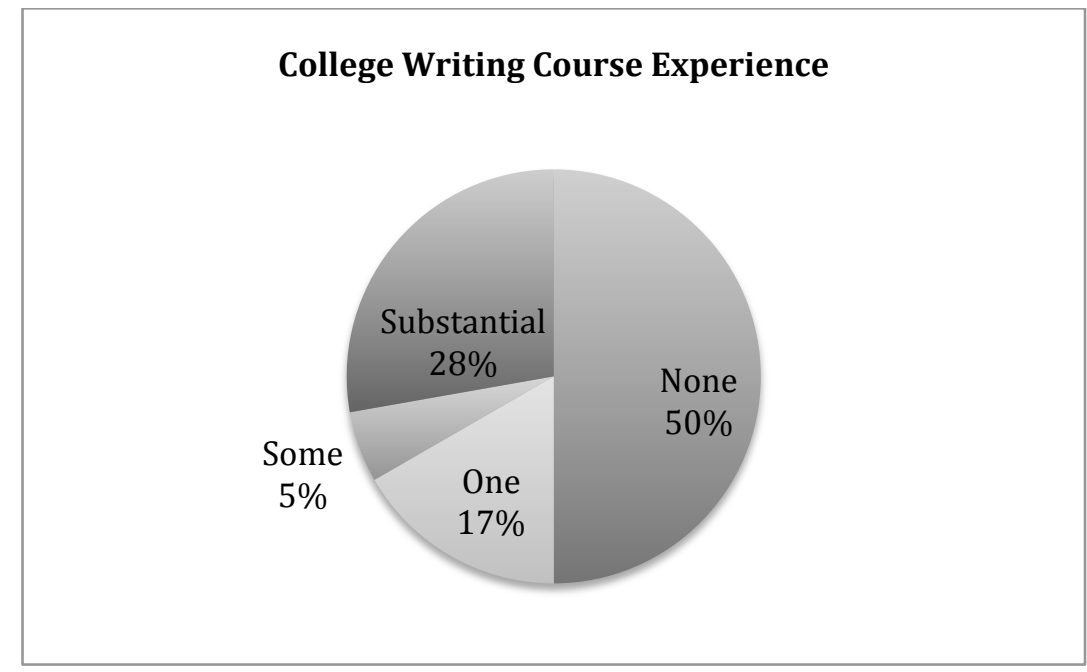


Table 6: Partitipants' Previous Portfolio Experience

\section{Previous Portfolio Experience (of any kind)}

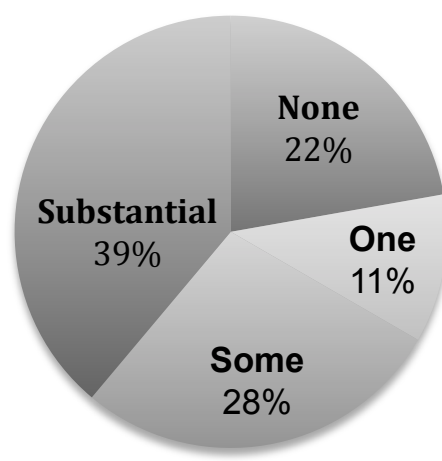

Table 7: Participants' Previous Experience with e-Portfolios

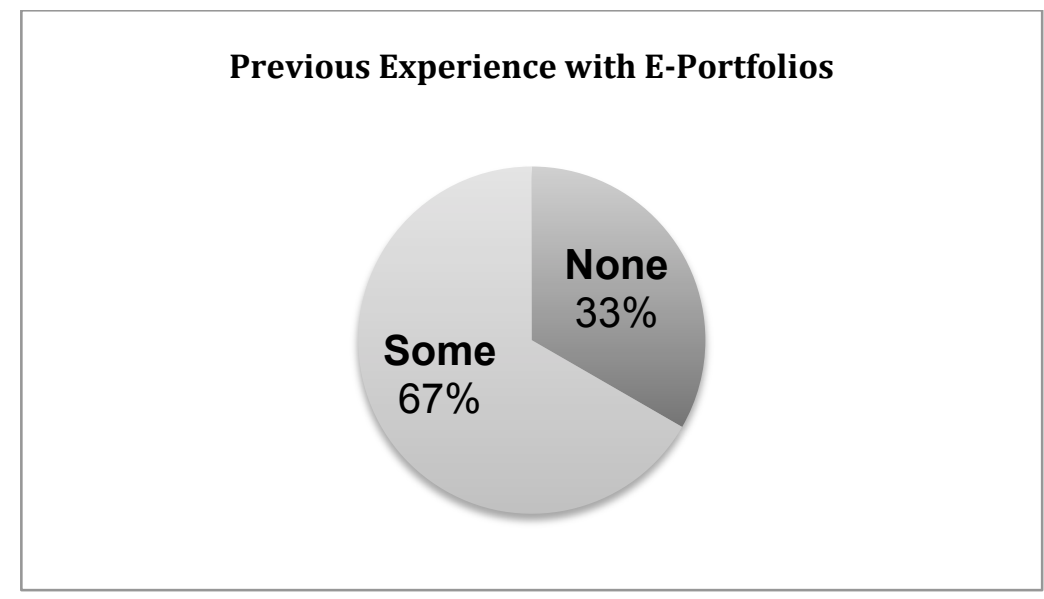

I was also interested in the reasons students gave for their feelings of preparedness, or lack thereof. The following charts shows how perceived levels of preparedness broke down across students who had past experience with a writing course, a portfolio, and/or an e-portfolio (Table 8) and how perceived levels of preparedness broke down across students who were lacking experience (Table 9) in one or more area (writing course, portfolio and/or e-portfolio), yet who still felt "somewhat" or 
"well prepared" for the portfolio in their course. Out of the students in my study who lacked past experience in a writing course, a portfolio, and/or an e-portfolio, none reported feeling "not prepared" nor, on the other hand, "very well prepared."

Table 8: Experienced Participants' Perceived Preparedness

\begin{tabular}{|c|c|c|}
\hline \multicolumn{3}{|c|}{ Experienced Participants' Perceived Preparedness } \\
\hline \multirow{2}{*}{\multicolumn{2}{|c|}{$\begin{array}{l}\text { Not Prepared }(n=1) \\
\text { Well Prepared }(n=4)\end{array}$}} & Somewhat Prepared $(\mathrm{n}=10)$ \\
\hline & & Very Well Prepared (n=3) \\
\hline & 3 & \\
\hline & 4 & 3 \\
\hline 3 & \multirow{3}{*}{6} & 3 \\
\hline 2 & & \\
\hline 2 & & 4 \\
\hline $\begin{array}{c}\text { Had Taken a WRT } \\
\text { Course }\end{array}$ & $\begin{array}{l}\text { Had Portfolio } \\
\text { Experience }\end{array}$ & $\begin{array}{l}\text { Had e-Portfolio } \\
\text { Experience }\end{array}$ \\
\hline
\end{tabular}

Table 9: Less Experienced Participants' Perceived Preparedness

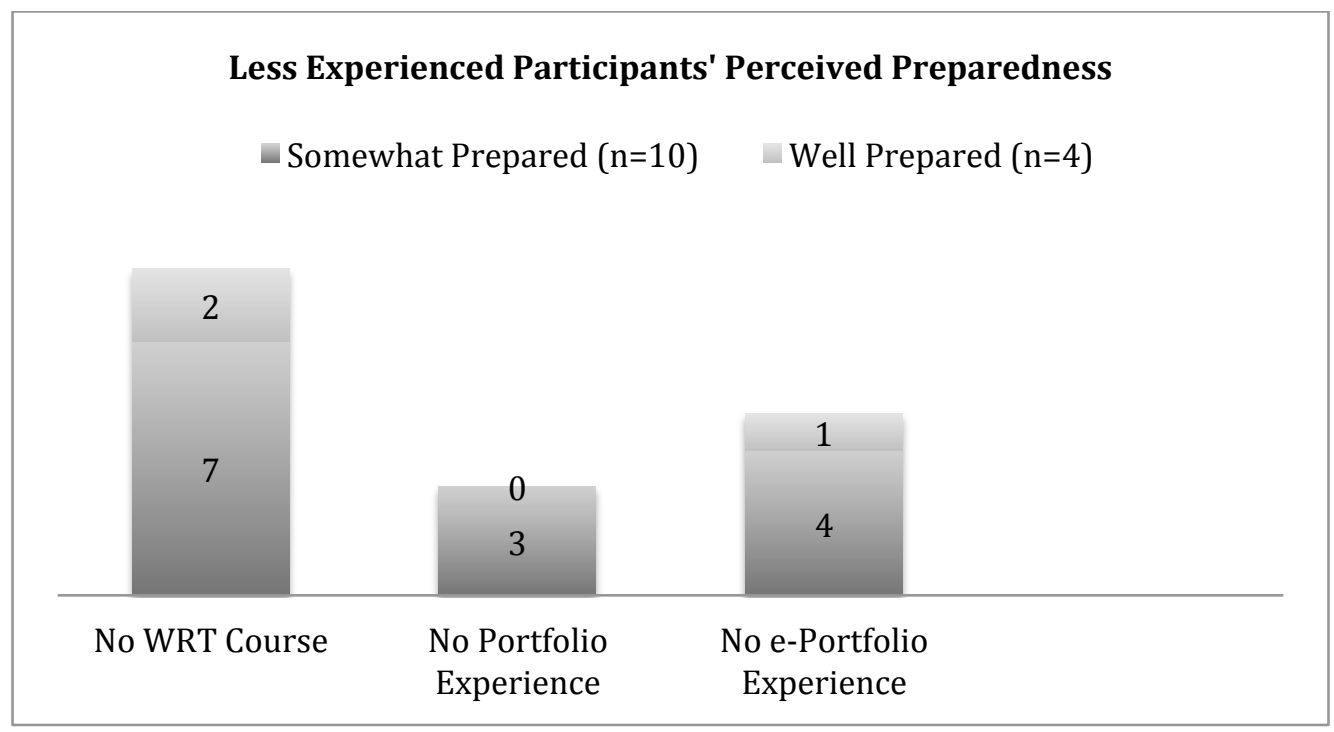

Generally, participants' past experience did not seem to directly correlate with their perceived levels of preparedness. For example, the only students who reported 
feeling "very well prepared" (3) were senior writing majors who each had substantial experience in all three areas; yet, one other senior writing major, with the same high levels of experience, reported feeling only "somewhat prepared." Of the four students who reported feeling "well prepared," two were junior nonwriting majors in a 200-level course who had previously completed e-portfolios for a 100-level writing course, one was a freshman non-writing major who was currently enrolled in his first college writing course and who had completed an eportfolio (in order to graduate high school), and the last was a senior non-writing major currently in her first college writing course with only print portfolio experience. Further, a writing minor who had ample experience in all three areas reported feeling "not prepared" for the e-portfolio in her current class while two students with no experience in any area reported feeling "somewhat prepared." So what did matter to students when it came to preparedness? If it wasn't always past experience with a college writing course or with portfolios, what was it that made them feel prepared or unprepared for the e-portfolio in their current writing course?

When asked about their levels of excitement (not excited, somewhat excited, very excited) about the prospect of completing the e-portfolio for the course, $28 \%(n=5)$ reported feeling not excited, $55 \%(n=10)$ were somewhat excited, and $17 \%(\mathrm{n}=3)$ were very excited (as visually represented in Table 10 below). 
Table 10: Participants' Levels of Excitement

\section{Participants' Levels of Excitement}

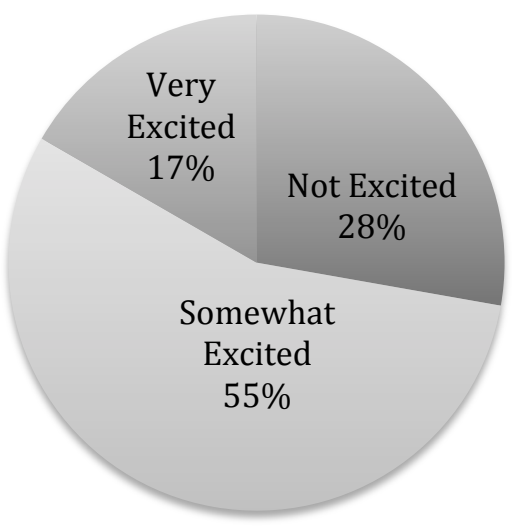

Because what students valued often emerged from students' explanations of/for their levels of preparedness and excitement, as well as the effects they perceived their past experiences had on their current experience, these categories will be alluded to throughout my dissertation.

\section{A General Description of the Eighteen e-Portfolios}

Because this dissertation involves some discussion of the various components and artifacts students included in and throughout their e-portfolios, I offer the following list of terms (Table 11) to which the reader may refer while reading this dissertation.

Table 11: Key Definitions

\begin{tabular}{|l|l|}
\hline \multicolumn{1}{|c|}{ Term } & \multicolumn{1}{c|}{ Definition } \\
\hline e-portfolio & $\begin{array}{l}\text { An assessment tool that asks students to collect, select, and reflect on } \\
\text { various writing artifacts over time; composed and submitted to an } \\
\text { evaluator in an electronic format. }\end{array}$ \\
\hline mode & $\begin{array}{l}\text { Refers to the five ways we communicate meaning: through written- } \\
\text { linguistic (or with alphabetic text), visual, audio, gestural, and spatial } \\
\text { patterns of meaning (New London Group 1996) }\end{array}$ \\
\hline
\end{tabular}




\begin{tabular}{|l|l|}
\hline text & $\begin{array}{l}\text { The term used to describe the final, revised, polished, and complete } \\
\text { writing projects students included in their e-portfolios. }\end{array}$ \\
\hline whole & $\begin{array}{l}\text { A complete text, artifact, or writing project with a discernable } \\
\text { beginning, middle, and end, or that has discernable borders (as in a } \\
\text { piece of art, a poster, or brochure). }\end{array}$ \\
\hline extension & $\begin{array}{l}\text { e-Portfolio artifacts or components that appear within whole texts or } \\
\text { projects and that either support or offer examples of claims students } \\
\text { are making in those projects. }\end{array}$ \\
\hline ornamental & $\begin{array}{l}\text { e-Portfolio artifacts or components included by students primarily } \\
\text { for personal, decorative, or aesthetic purposes. }\end{array}$ \\
\hline borrowed & $\begin{array}{l}\text { e-Portfolio artifacts or components made or created solely by the } \\
\text { student. }\end{array}$ \\
\hline
\end{tabular}

This dissertation uses particular terminology in reference to the types of eportfolio technologies that participants used to create and submit their final eportfolios and the modalities students employed within their e-portfolio texts. As show in Table 12 below, one-third (6) of my participants composed their eportfolio texts first as Google, Word, or Pages documents, then compiled, converted, and submitted them in a final portable document format (PDF) file eportfolio. I will refer to these as Word-to-PDF e-portfolios. The other two-thirds (12) of my participants used various writing and composing technologies (like PowerPoint, Camtasia, Word, Garage Band, AdobePhotoshop, etc.) to create their various e-portfolio texts then further composed, (re)designed, embedded, and submitted those texts as public websites that were built using free online Content Management Systems (CMSs), like Wordpress or Wix (see Table 13). Where the distinction matters, I will refer to these as web or CMS e-portfolios. Some students were given a choice between the two submission types; others were required by 
the instructor to use one or another type. Similarly, some students had the option to choose a CMS they preferred, while others were required to use a particular CMS.

Table 12: Types of e-Portfolio Submissions

\section{Types of e-Portfolio Submissions}

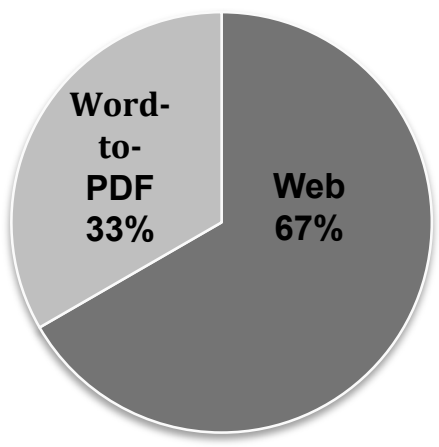

Table 13: Types of CMSs Used to Build Web e-Portfolios

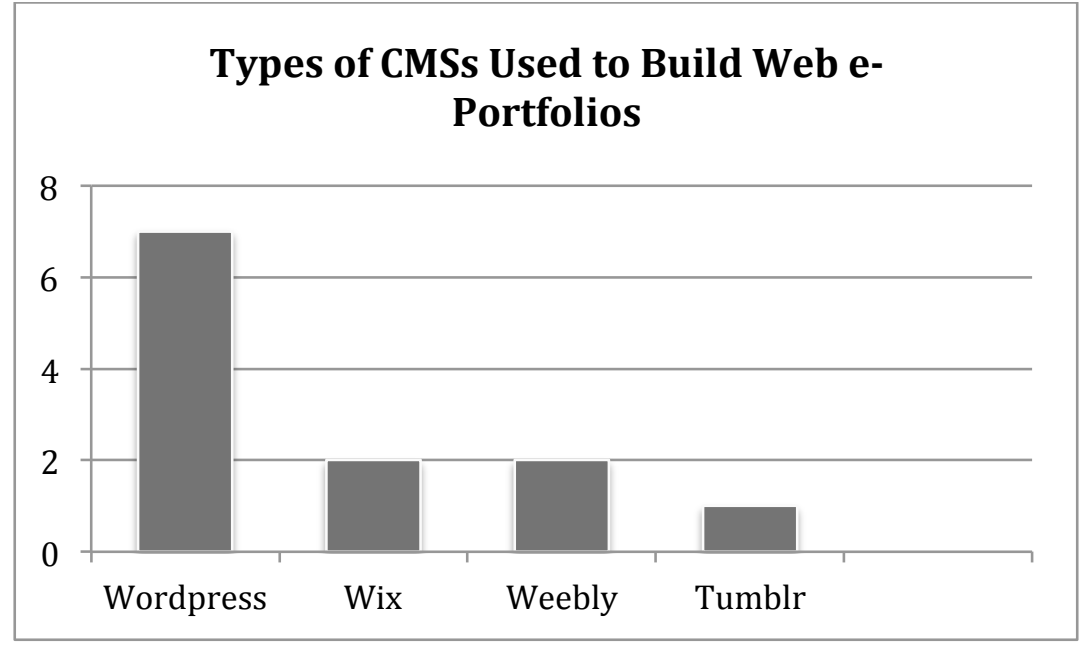

These distinctions and terms come in handy when talking about the difference between, for example, a first-year Word-to-PDF e-portfolio that includes an original extension image and three whole, original projects that were composed solely in alphabetic text (see Figure 2), a senior capstone web e-portfolio that includes whole, original projects in graphic and audiovisual, or multimodal, 
formats (see Figure 3 and Figure 4), and a 200-level CMS e-portfolio that includes a borrowed extension image (chart) embedded into a whole, original (alphabetic text) project (see Figure 5).

RUNNING HEAD: FINAL PORTFOLIO ASSIGNMENT

of training. In the process of researching, I was able to compare High-Intensity Interval Training (HIIT) to MRT. HIIT is recently becoming more known and popular, therefore comparing it to MRT in my persuasive essay was a big advantage for me. Invention was something that I practiced a lot with my persuasive essay. During class, I was instructed to make a web in order to organize my ideas and brainstorm.

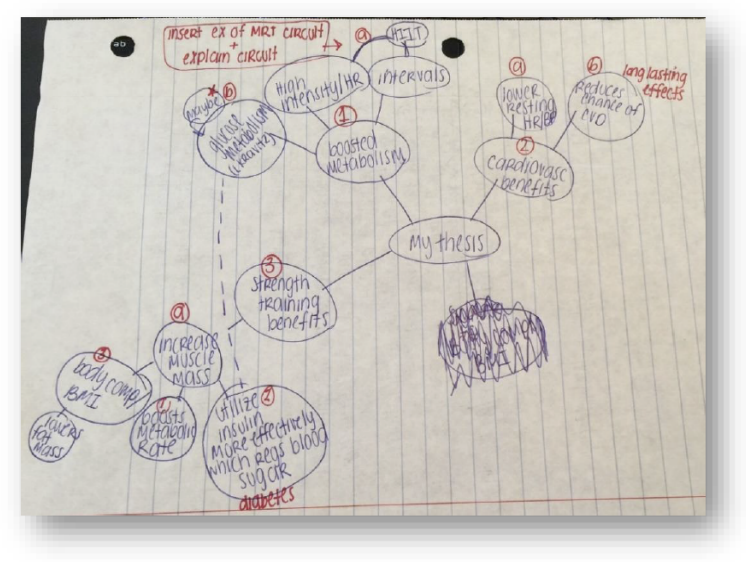

In my web, I wrote my thesis statement in the middle and surrounded it with three branches that represented three reasons that supported my thesis. Branching off of each reason, I wrote various examples that supported each reason. From the web, I created an outline that further organized my ideas and made it easier to turn into an essay. The process of practicing invention aided the success of writing my persuasive essay. Practicing methods of invention in this class has allowed me to apply the invention techniques I have leamed to other classes. For instance, when I wrote my final essay for my English class, I started off by making a web in order to organize my ideas before forming sentences. Another aspect of this learning outcome is

Figure 2: "[This Shows] How Brainstorming, Making a Web, Really Helped Me Organize My Ideas" (Original Extension Image, Valerie). 


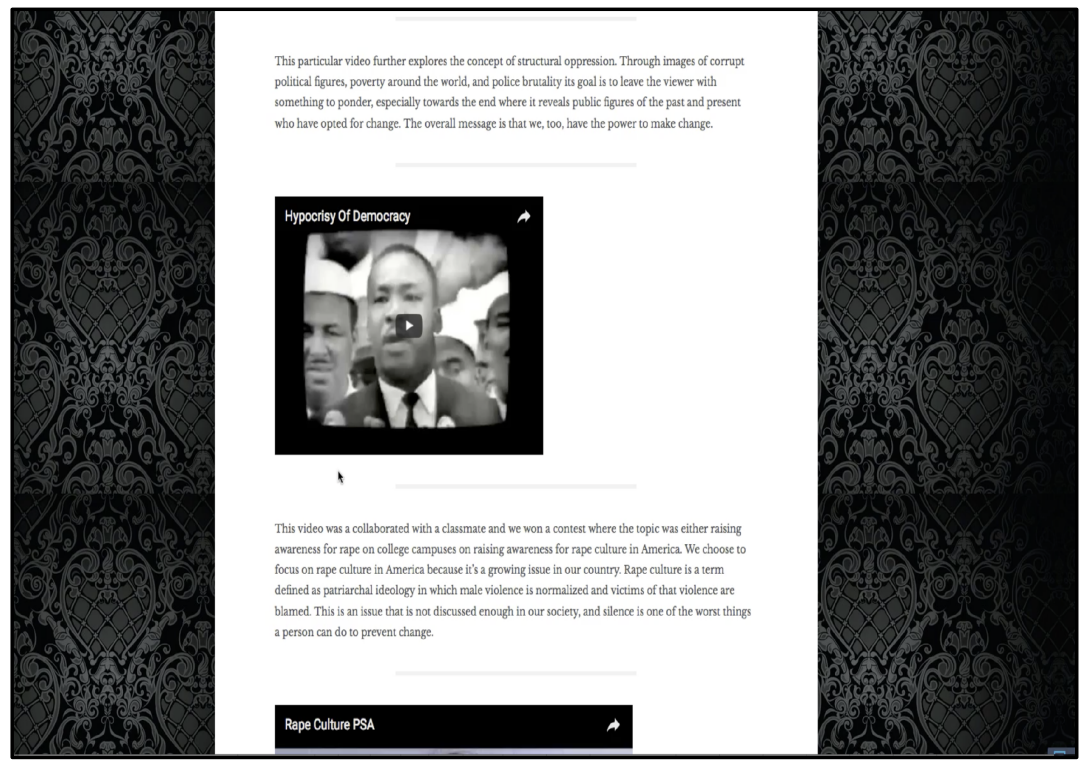

Figure 3: "Something I Did On My Own About ... Our Oppressive System and Poverty and Police Brutality" (Whole Original Video Artifact, though it includes borrowed extension images/videos like the clip of Dr. Martin Luther King, Jr. here, Holly).

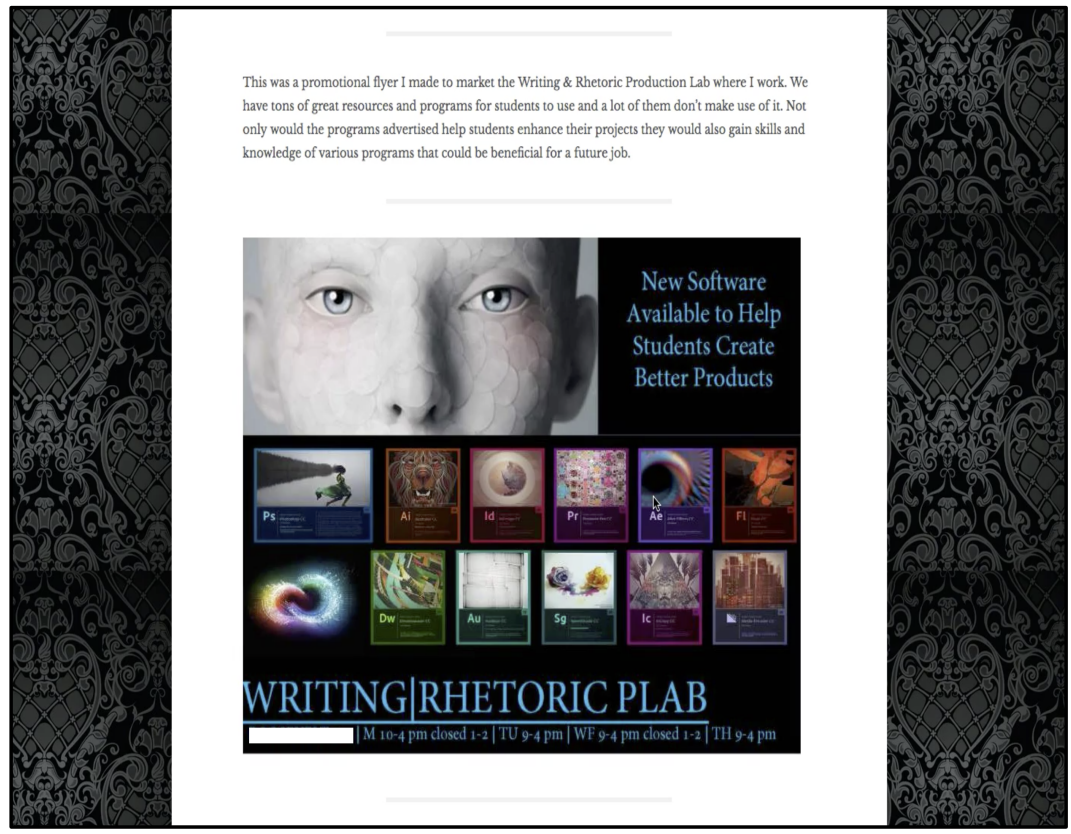

Figure 4: "Something I Did For Our Production Lab ... To Try And Showcase The Programs We Have" (Whole Original Graphic Artifact, Holly) 


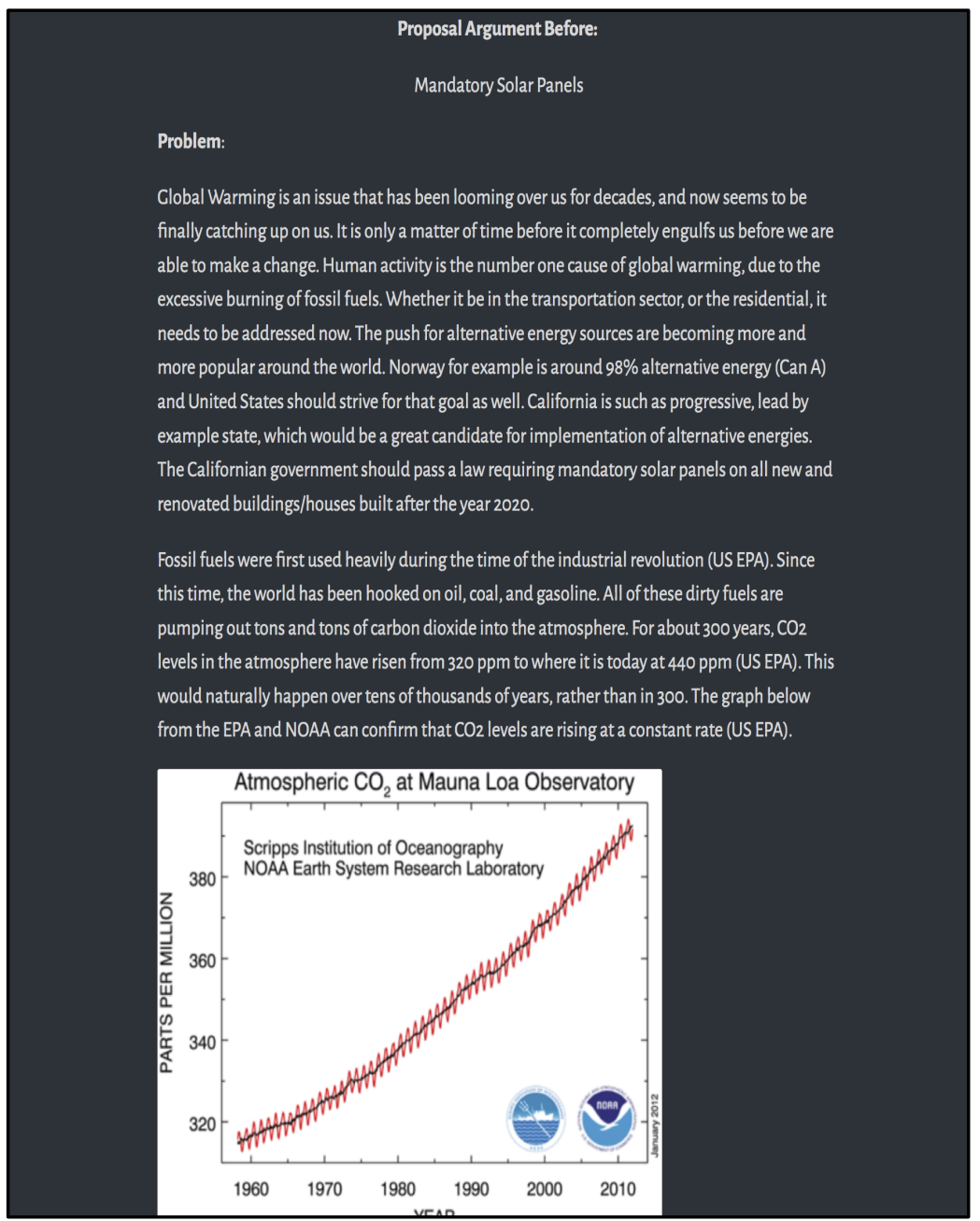

Figure 5: "A Graph From NOAH To Prove, Hey, Since The 1960's, CO2 Levels Have Increased A Lot!" (Borrowed Extension Image, Bethany).

The e-portfolios in my study varied by student preference, instructor, course level, and course focus (or topic). ${ }^{29}$ Most e-portfolios were product or presentation portfolios, though five of the eighteen participants also included some demonstration of the process they underwent to complete their writing projects; these came in the form of downloadable or embedded previous drafts (in their

\footnotetext{
${ }^{29}$ For the purposes of my study, I defined an electronic writing portfolio as a final, culminating course project that (a) required students to collect, select, and reflect upon their writing and writing practices throughout the semester and that (b) was required to be submitted in an electronic format.
} 
entirety), of hyperlinks to GoogleDocs where a viewer could access the revision history of a writing project, and of self-quoted passages from previous drafts and images of brainstorms and research notes embedded into reflections written in alphabetic text. Students included anywhere from no (zero) to twenty-three whole and original final projects. The e-portfolios of the two students who included no whole and original project included a one-(Tumblr/web)page reflection on the course and her writing progress, which included a few self-quoted passages from her projects to support the claims she made in that reflection. The majority of the whole and original projects students included were individual, though two students included a group project (a website redesign) in each of their (Wordpress) eportfolios.

For those that required them, the types of whole, original writing projects included in the e-portfolios in my study were as follows (Table 14): 
Table 14: Types of Whole, Original Writing Projects Included in e-Portfolios

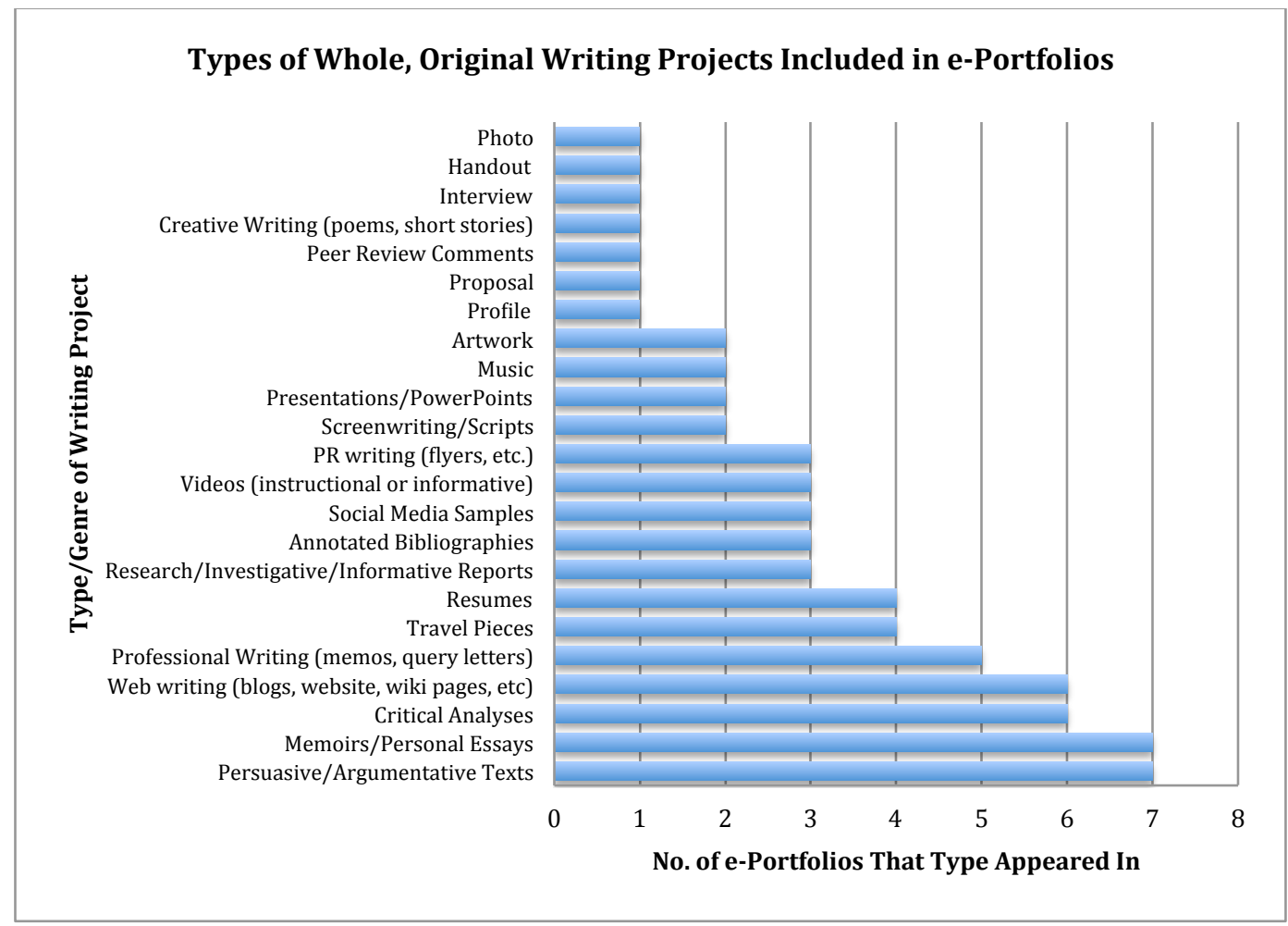

The most prevalent types of projects that appeared in students' e-portfolios were the standard genres: persuasive and argumentative texts, memoirs and personal essays, and critical analysis and most of these-along with research reports and annotated bibliographies-were the dominant genres of writing (in alphabetic text) in the majority of the student e-portfolios in first year writing courses. Writing for the web-in the form of blogs, websites, online news articles, and wiki pagesalso made an appearance, in addition to travel pieces, professional writing (memos, business letters, etc.) and resumes; but these last types of final projects only showed up in the e-portfolios of students enrolled in upper level courses.

Some kind of reflection text (or texts) appeared in all of the e-portfolios in my study. Reflections came in the form of an introductory text or letter, which appeared in the first few pages of a PDF e-portfolio or on website e-portfolio 
homepages, as friendly letters to the instructor, and/or as shorter reflective texts dispersed across e-portfolio pages, some of which students referred to as "wrappers" or "annotations." These wrappers and annotations most often introduced a writing project, described the assignment that led to the creation of the project, and/or explained why a project was included in the portfolio; the process these students went through to complete the project and/or what these students learned from completing the writing project was briefly described in only some of these wrappers and annotations. The screenshot below (Figure 6) shows an example of a student using what she called "wrappers," which she used to introduce the context for her project as well as the challenges she faced in trying to complete the project, yet offers no reflection on her writing process or what she learned from doing the project. 


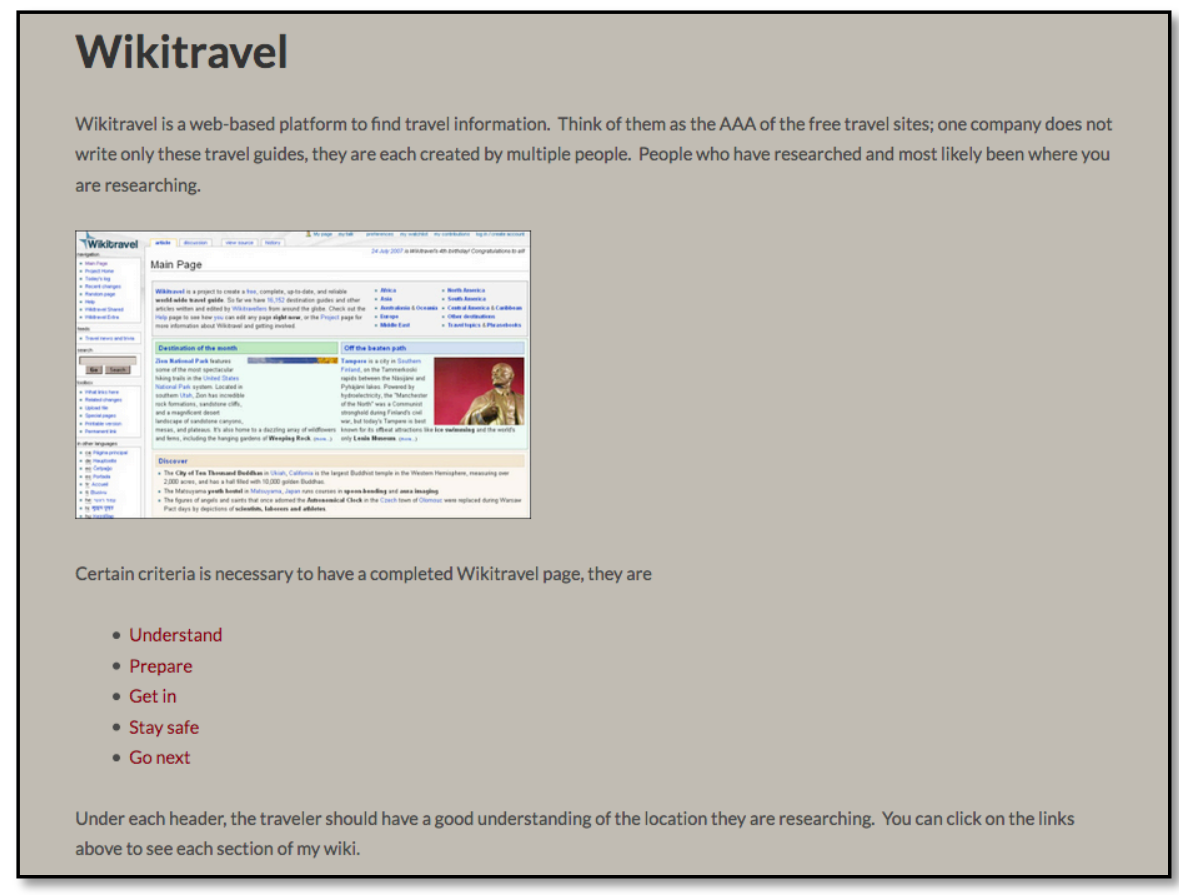

I chose to do my Wikitravel on a place I have spent many years at, the Tri-Pond Park, in South Kingstown. Having walked and photographed many of the trails personally, I felt comfortable describing to others what is available.

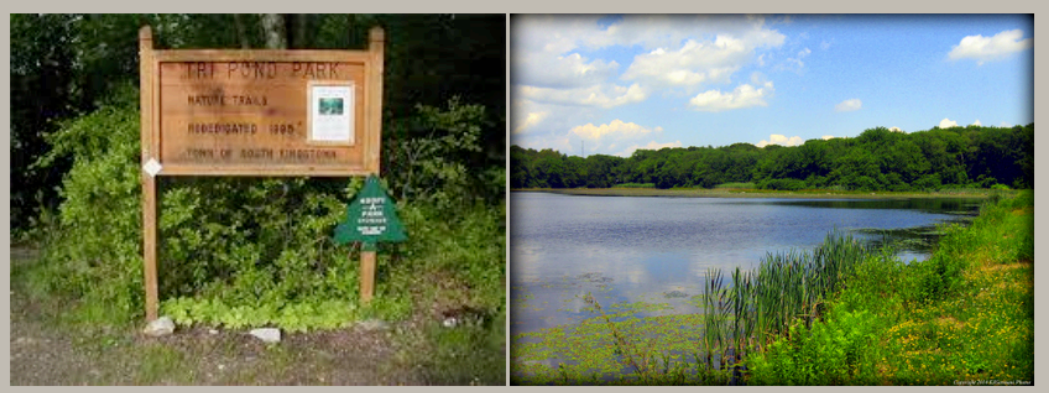

Some tricky items I need to overcome

1. Locating something or somewhere I could write on

2. Overcoming the fact other users could change, dispute or remove my info

3. Navigating the platform

I feel I effectively created a Wikitravel page, and ask that you please visit it today!

http://wikitravel.org/en/Tri_Pond_Park

Figure 6: Example of "Wrapper"

Two student e-portfolios included only a reflection; in other words, the reflection

was the entire e-portfolio. In these reflections, students referred to the writing

projects they completed in the class but submitted no actual whole or original 
writing project, though one student included short sample passages from her writing projects (see Figure 7). 


\section{Memoir}

I picked this piece because I feel that it being the first one of the year it would need the most work. There are two portions of it I feel needed it the most; the end and the beginning. I think that these parts are the most important parts of the piece and I just didn't do a good job with my resolve and how I introduced the time I felt left out. To show the changes I made I am going to start with the original ending and then the new version and explain why I added or got rid of some parts. This piece really did teach me something about myself and I feel I didn't express that enough in the original ending. I'm also going to do the same with the introduction of the paper so that they can match up better together than they did in the original paper.

\section{Original (introduction):}

It was the morning of, October 31st 2015, the day everyone gets to be someone they aren't. Where the make-up is glowing just as bright as the beautifully carved pumpkins. Children are chanting "trick or treat, smell my feet, give me something good to eat" and asking for candy from the gracious neighbors. College students are much different. They get dressed up to throw parties with friends they barely know, fraternities and sororities, with candy filling the halls but the real candy being the girls dressed skanky. It isn't the most enjoyed holiday by me but my friends get really into it which causes me to light up with the joy that fills them to the brim. I am often times the one people come to for cheap costume ideas since if I'm going to be involved in the event I'm not prepared to go all out with my money.

New Version (introduction):

It was the morning of that dreaded day, October 31st 2015. Halloween weekend and my first year as a Resident Advisor. The hallways were all a buzz with the excitement of all the parties they were going to attend that night. Residents wandering the halls and asking for the opinions of my coworker and I on their costumes. The glitter and sparkles that filled the lobby as we sat in office hours nearly choked me. I felt surrounded by the one holiday I disliked more than anything. The night had just begun, but it already felt never ending. I knew that my phone would blow up with all the fun my friends would be having and the building would be filled with joy from all the freshman residence coming back from probably the biggest parties they've been to. Before the night began I already felt left out of this incredible excitement and I could only blame Halloween for this feeling.

Reflection:

The rhetorical situation that was addressed was a time that I felt left out and how I personally handled it. This was intriguing because everyone handles events differently. For my own story, I showed that I can be a bit of a hothead in these situations. Although I don't address my friends and I am a hothead in private, it is still an interesting side to see of a person. I do believe that this is what you, as the professors, were trying to discover about us. The type of writing was also something that you were looking for, with this piece I feel I used a very causal form of writing because it was suppose to be for someone who could relate. This means that we had to take into account our audience and how they would perceive the story. For mine, I wanted them to understand my dislike for Halloween in such a way that, even if they loved Halloween, they could relate. In all writing it is important to understand different types of writing and how to use them in each rhetorical situation. Here, we were trying to connect to people who felt left out at any point in their life. I demonstrated this with my clear dislike for Halloween, but my need to still be apart of my friend's parties.

I also learned what the difference between revision and editing was in this first paper since it was the first time we used I I saw how others responded to my paper, with grammatical errors and nothing of substance really being said. I, too, did the same thing at first, until I looked at the questions provided for the final comments of the paper. I realized then that we weren't editing these papers (fixing grammatical errors), we truly had to reflect upon what was being written and how it made us feel. I wanted to be as in depth as possible to give the people receiving the comments a helpful way to actually fix their papers. I think what I saw here is that revisions are much more important than editing at first just to be sure that all the points are coming across clearly and throughly. My method of revision is definitely different than how we preformed it in class. I personally like to sit down and talk to whoever wrote the paper because I need to be able to throughly explain my thoughts about why something needs to be changed. Over it was suppose to be anonymous which made it hard for me. I had to provide as much detail as I could into those boxes just so the person on the receiving end would understand exactly what I meant by each comment. I like the in person aspect because it makes me feel more connected to this person and be able to give them better feedback that relates to them on a more intimate level.

Figure 7: Example of Single Reflection with Passages from Project 
All reflections in my study were text-centered; there were no audio or video reflections, though a few included borrowed and/or ornamental images (as seen in Figure 8).

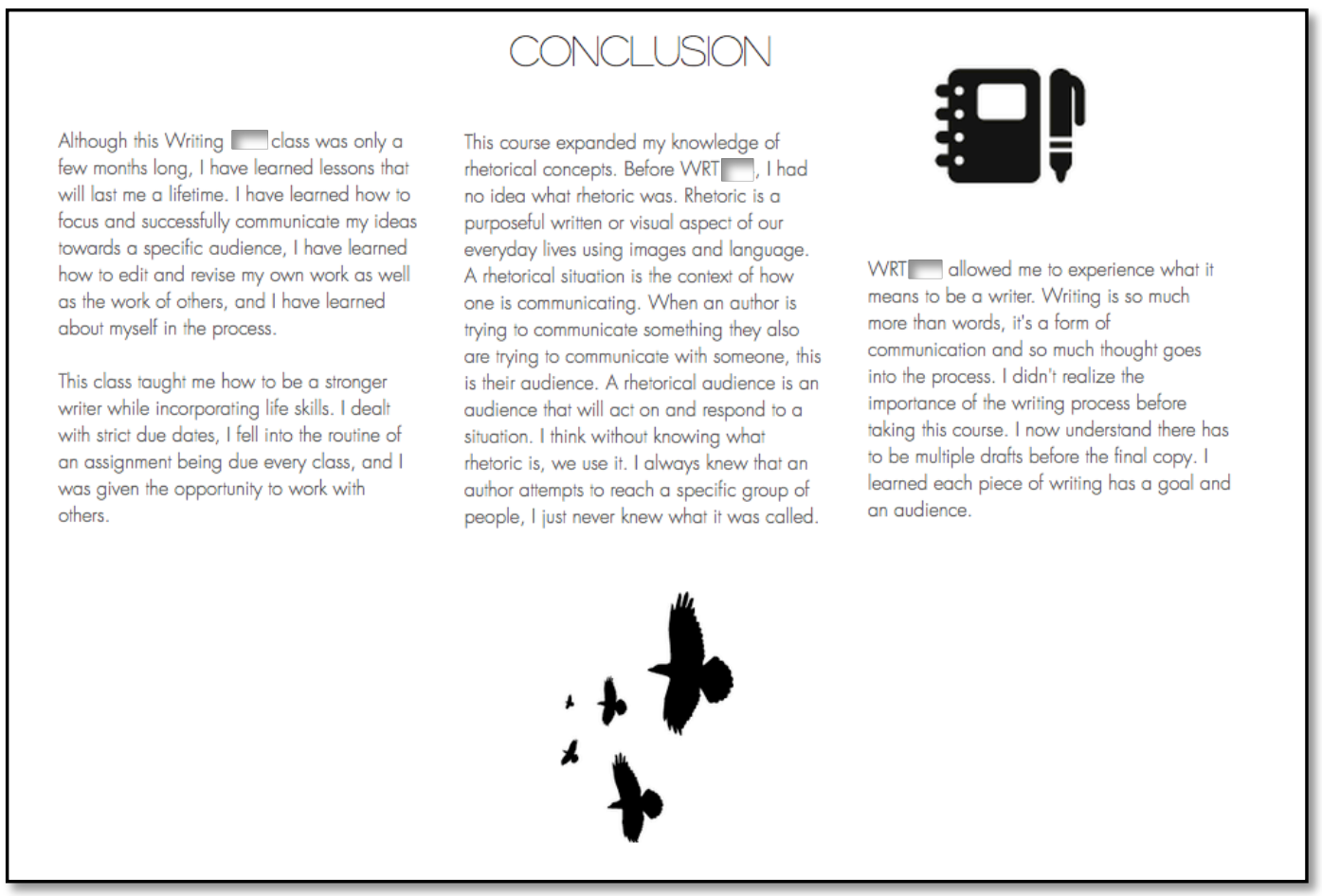

Figure 8: Borrowed Ornamental Images in a Reflection

With these broad overviews of my eighteen participants and their eportfolios in mind, the next three chapters of this dissertation will offer more detailed reports of students' voices and the learning insights and messy truths they offered in regard to their particular and diverse e-portfolio experiences. What follows is also an indication of the various and varied writerly selves they performed in those e-portfolios. 


\section{CHAPTER 2: STUDENTS REFLECT ON EXPERTISE, INSTRUCTION, \& SUPPORT}

\section{Introduction}

Ariel was a freshman business major in a first year writing course. For the course she was asked to create a public web portfolio using a free online webbuilding program, or Content Management System (CMS) called Wix. Though she had created an e-portfolio as part of a high school graduation requirement, this was Ariel's first time using a CMS to compose a web-based e-portfolio from scratch. In my interview with her, I asked Ariel about the CMS she used and how she felt about it. Among other things, she told me that students were instructed to try out the technology and to start designing and creating their e-portfolios on the last day of class. Despite having asked her instructor for models, Ariel reported not seeing any. "We weren't given a whole lot of direction," she said at two different times in the interview. This caused Ariel anxiety: "It was kinda scary because I wanted to make sure that [my e-portfolio] was good enough. It was worth forty percent of my grade! I wanted to make sure [the instructor] liked it, but also wanted to make sure it reflect[ed] my style." On top of being uncertain how to design or create the web e-portfolio, Ariel lacked confidence in her basic technological skills, telling me, "I'm the worst Millennial ever. I just—I'm so bad with technology."

Ariel's comments reflect a general concern with her perceived levels of technological expertise, her grade, and the particular types of instruction and support she felt she received — or did not receive - throughout her e-portfolio experience. Whether students noted it explicitly or implicitly, concerns about 
being "bad" with technology arose often from the students in my study, as did their concerns about past e-portfolio experience(s) and the levels of instruction and support they felt they received during their current experience. This chapter attempts to outline the common themes and trends that arose regarding students' perceptions of their e-portfolio expertise and the instruction and support they felt they either needed or received in an effort to better understand how we might help students feel more prepared and supported throughout any e-portfolio assessment experience.

\section{Findings}

\section{Considering Expertise: Technology (and) Experience}

When talking to me about their experiences with the e-portfolio technologies they used or were required to use, students like Ariel from the opening anecdote often alluded to their perceived technological abilities and/or the amount of past experience they had with writing and/or e-portfolio technologies. Several students reported having some sort of technological anxiety, frustration, or difficulty with their current e-portfolio experience when they felt their skill level or past experience with e-portfolios or e-portfolio technologies was either lacking, unrelated, or insufficient. Other students who had previous website building experience or who had used related writing technologies often reported greater confidence and/or freedom in composing their current e-portfolio. Some students, however, felt their previous experience and/or abilities might be helpful, but only to an extent. 
Generally, student participants who submitted their e-portfolios in a Wordto-PDF format reported few to little frustrations with the technology and expressed no concerns with needing or wanting instruction in how to use it. These students described their experiences as "straightforward," "nothing special," "rudimentary," "convenient," and "comfortable" with "nothing confusing or frustrating." Though Valerie pointed out that it would have helped to know how to upload her final Word-to-PDF e-portfolio to Sakai, other than that, she reported there being "nothing hard" about the technology. In other words, these students each reported having a sense that their previous experience with these technologies (basically, Microsoft Word and Adobe Acrobat Reader) left them with little to no anxiety about composing their e-portfolios. Indeed, many of these students seemed humored (or confused) by my question about the frustrations or challenges they had with the technology. For example, when I asked Eva about the photo she embedded in her Word-to-PDF e-portfolio, she replied,

You know, it says, "Insert Photo." Doesn't take a genius! [laughs] It's kinda like PowerPoint. You just go in and you do it and it tells you [laughs] everything you can do, so you don't need, like, lessons [laughs].

Amber, a senior English and film/media double major, reported "the most nervewracking part" of her e-portfolio, technologically speaking, was submitting it to Sakai (the internal university classroom management system)—because, she laughed, "the internet might explode!" Ultimately, however, Amber felt "fine with" the technology she used to compose her e-portfolio (Apple's word- 
processing application, Pages) and in converting it to a PDF. Indeed, Amber said she performed such conversions for most of her writing assignments already because they "guarantee" submission and "show a little more care towards [a] final product," and even "a [greater] level of professionalism" because Pages-to-PDF documents cannot be "edited and distorted" and "[look] really clean and structured." Amber's experience and confidence with the technology contributed to her feeling "well prepared" for her e-portfolio experience.

Web e-portfolios, on the other hand, seemed to present more challenges for most — but certainly not all—students in my study. A few students, like Ned, a freshman environmental science major, expressed clear confidence in their ability to create their web e-portfolios using the technologies they had at their disposal. In our interview, Ned explained how he had the option to create his e-portfolio using GoogleDocs for his first year writing class, but that he chose to create a web eportfolio using Weebly because he liked the "freedom" a website offered. Ned also had past experience using Weebly for a high school English project and he trusted Weebly's effectiveness as a web-building platform. Ned even reported having to write "one line of code" to complete his e-portfolio, adding, "But I'm comfortable with that."

A comparably clear sense of tech-confidence came across in my interview with Hope, a senior writing major, who had completed over four electronic portfolios before this one - two of which were web-based. She stated in her first reflection log that she felt "very well-prepared" to create her web e-portfolio for 
her capstone course because of past experiences she'd had with the web-building technology they were required to use (Wordpress). Hope reported, When I first began making portfolios [two years ago], I was completely new to Wordpress, which made portfolio making a bit more difficult. Not only did I have to learn how to choose the work to include and how to present it, I had to learn the ins and outs of Wordpress. ... However, [now], I am extremely comfortable with the site and have learned how to make it work for me.... I wouldn't even blink at the thought of creating an electronic portfolio.

Holly, another senior writing major, also felt her past experiences with Wordpress gave her a "leg up" on the other senior majors in the e-portfolio course, which helped her feel confident about composing it:

I remember a lot of [my fellow seniors] were really overwhelmed for a while and didn't know where to begin, so I was kinda grateful that the previous semester I had to do an electronic portfolio because I honestly feel that if I hadn't had that experience, I probably would have been totally frustrated and overwhelmed as well. Especially because Wordpress is such—even though I had experience with it—it is a frustrating site and [even with experience] at times I did [feel overwhelmed] because of all the restrictions and limitations. 
For some students, having a choice of e-portfolio technology was helpful in quelling their e-portfolio anxieties. Like Amy, in the first year cohort, who was given a choice of web-building software to use to compile her final e-portfolio and who, though she worried about being "bad with technology," said she appreciated this choice: "I wouldn't want to be told which technology to use because, for me, technology's hard" and her familiarity with her chosen e-portfolio CMS (Tumblr) helped her feel a bit more at ease.

I looked at the other ones that [our instructor] told us we could use, but I just didn't connect with them, I guess, because I didn't really know how to use them. I have my own Tumblr and for one of my clubs we're also trying to set up a Tumblr.

Overall, however, more students than not who created a web e-portfolio expressed outright anxiety and frustration about the CMS technology they were required to use. In particular, these students referred to their lack—or insufficient level—of past experience. Despite having previously taken six college-level writing courses and composing more than four portfolios (including an eportfolio), senior Julia, for instance, reported in her first reflection log feeling "not prepared" for her upcoming 200-level e-portfolio because of "the different platform [Wordpress]" she was being required to use. Julia, an English and history double major with a double minor in writing and classics, half-jokingly wrote in her second reflection log that the single most valuable thing she learned in the writing course up to that point was "Wordpress is not for me," adding that previous "paper folio's [sic]" she'd completed for other courses were "far easier." Similarly, 
Ethan, a sophomore writing major who had taken previous writing courses and had print portfolio experience, claimed he felt only "somewhat prepared" for his 200level e-portfolio because "[he'd] done [portfolios] before, but never one as a website. Currently," he added, "it feels a bit overwhelming." And Charlotte, a senior major, reported in her reflection logs feeling only "somewhat excited" and "very nervous" about her upcoming senior e-portfolio, in part because she felt she needed to learn more about "work[ing] with Wordpress . . . to improve [her] cohesion." In our interview she talked at length about her anxieties surrounding the technological aspect of the e-portfolio: "I spent a lot of time playing with Wordpress trying to find the things I was looking for."

Several of these students worried how their lack of experience would directly affect their final grade on their e-portfolios. Valerie, for example, expressed feeling nervous about her e-portfolio grade because it was her "first time creating and submitting a portfolio" so she did "not have previous experience" and was "nervous that [she] may not know what [she was] doing." ${ }^{30}$ Ethan said that being "underprepared" for the e-portfolio assessment is what he thought would have the greatest negative effect on his final grade, adding, in hindsight, "if I had to do another e-portfolio for another class [after this one], it would probably go more smoothly."

\footnotetext{
${ }^{30}$ Later, in our interview, however, Valerie reported feeling more confident because of effective instruction. See more on that in the section about Understanding Expectations.
} 


\section{Experiencing Context: The e-Portfolio Genre, and Its Subgenres}

Several students expressed feeling confident about their upcoming eportfolio assessments because of having had ample previous experience with the eportfolio model more generally, especially in having had experience with the selection, revision, and reflection processes common to the portfolio genre. Hope, a senior major, for example, reported,

I have created multiple electronic portfolios throughout the course of my college career, thus ensuring my familiarity with what an online portfolio entails. I have a strong grasp of Wordpress . . . as it is the platform I have used most, and I have had ample practice creating annotations for the work I choose to present on my portfolio.... I think my past experiences will definitely affect my grade in a positive way.

She also reported feeling "not nervous" about her final grade because she had "lots of experience creating portfolios" leading her to have "a good handle on how to make an effective one."

Even students with less experience pointed to their completion of at least one previous electronic portfolio as their reason for feeling "somewhat" or "well prepared" for the current e-portfolio. Ned, a freshman in his first college writing course, referenced an e-portfolio he completed the previous year for a high school graduation requirement and wrote that because of this experience he felt "very capable [of] reviewing [his] own work and reflecting on what [he could] improve." Ned added that such activities were "an important part of the portfolio process" 
and that his past experience with them "might help to improve [his] grade" in the current context.

On the other hand, being confronted with a new genre-or subgenre-of portfolio was high on the list of reasons for concern reported by experienced and inexperienced e-portfolio composers alike. Sometimes these concerns were balanced with a bit of healthy confidence, like, for Ariel, who stated, I think my [high school graduation portfolio and art portfolio] experience will help with completing this portfolio, however, it is not the same, so I have to treat it as such . . . Each portfolio is supposed to be different so you need to comprise each one accordingly.

Likewise, Bethany, who had created a portfolio as a Word document for a previous first-year writing course, expressed some confidence going into her current web eportfolio experience.

I knew kind of what was expected [and] the length it was going to be. And also I knew time management. The first one took a lot of time so I knew this one would take a good amount of time [on revisions particularly]. I knew it wasn't gonna be a one-day thing, but it would take a while with hard revising and working on everything.

However, Bethany also reported that her past experience would likely not help her grade in her 200-level course because "it was a new type" of e-portfolio "that was broken down into parts" (meaning on a web page with different required sections, 
pages, and reflections). Similarly, Julia admitted that she had ample previous experience with paper and electronic portfolios alike, but that she didn't think this "made [her 200-level e-portfolio] any easier" because of "the different platform [CMS]." However, Julia did admit that having experience with "compiling" works and several previous portfolios from which she could find "stuff to pull out of [her] bag and include in [her current] e-portfolio maybe made it a little easier," adding, "but mostly not, because there were still the required new elements that had to be produced." ${ }^{31}$

Other students seemed very concerned about the new subgenre of electronic portfolio they were being asked to create, especially when there was a greater level of autonomy or open-endedness tied to it. Amy, a sophomore in a first year writing course, for example, who had previous print portfolio experience in high school (which she referred to as "like, forever ago") had no electronic portfolio experience and reported feeling concerned about her current portfolio having "such a different set up" and being a "[different] learning experience [that felt] more creative," or more open-ended in a way she had not experienced in high school where the requirements were clearly drawn out for her. Even with extensive past e-portfolio experience, Holly, a senior major, claimed she felt only somewhat prepared for her current e-portfolio because it required her-for the first time-to develop her own content strategy and visual design. She reported feeling anxious about what she called this new sense of "autonomy" because "all the content and

\footnotetext{
${ }^{31}$ For Julia's digital writing course, students were required to include not only projects developed in the course but also several original texts from "outside" the course. This is what she is referring to as the "stuff" she could "pull out of the bag" versus the "required new elements."
} 
strategy behind [the portfolio] is left up to the individual" in a way she had never experienced in her prior work with e-portfolios. Holly reported that she began her senior e-portfolio using the more familiar selection strategy that she had been asked to use in her lower-level writing courses (i.e. include only writing pieces she enjoyed, got good grades on, or was otherwise proud of). Yet upon being told by a writing professor "that the pieces [in her current portfolio] had no connection and didn't give the reader a clear understanding of who [she was] as a [professional] writer," Holly had to scrap her draft and begin anew at midpoint in her final semester of college. This made her anxious about her final performance in the course. Holly went into detail on how this new autonomous approach felt to her: The portfolio for the [senior course] somehow feels bigger. The stakes are higher and it all falls on me. I have to be careful and strategic about what I decided to put in. I went in thinking I knew exactly what I was going to put in for content, but somewhere along the way my decision for content ended radically different.

Charlotte, a senior major with substantial past portfolio experience, also expressed concern in her reflection log about having to create a new subgenre of portfolio-a "professional" portfolio-with which she had no previous experience. Though after the semester ended, Charlotte told me that her past experiences with portfolio composition and curation did end up helping her some.

I think that if I had gone in without any experience and [the instructor] wanted something this specific-something that's this sort of scale of work-I don't know if I even would have gotten a B 
[laughs] just because I find it very easy to get lost in deciding on what work I'm gonna use. ... I think having an idea of what was meant in general by an electronic portfolio and what you do when putting the work on an electronic portfolio helped. Annotation and reflection familiarity was good, too, and being familiar with revision work where you feel comfortable putting it online.

Overall, Charlotte did not worry about failing, really (she was confident in the instruction they would be given), but felt that "fine tuning all the pieces," or having time to revise and compose her artifacts to meet the constraints of her first professional portfolio, would be her greatest challenge. ${ }^{32}$

One student expressed a similar sense of unease with both the new eportfolio subgenre and context within which she was required to compose. Bethany, a junior environmental and natural resources major in a 200-level writing course, drew connections between and placed value upon her past technological experiences while also remaining wary about how those past experiences would translate to this new experience. In her second reflection log, Bethany wrote that she felt "well prepared" to complete her final web e-portfolio because she was "familiar" with Wordpress, having used it in a previous 100-level English course to do "simple postings" and "a small little writing thing." Bethany had also previously composed a 100-level writing portfolio (using Word), which, according to Bethany, was "kind of electronic" and had "kinda the same" components (i.e. an introduction, reflection, and featured writing projects). Though these past

\footnotetext{
${ }^{32}$ And, indeed, this did end up being Charlotte's greatest challenge. For more on this, see the section on Timing.
} 
experiences gave her some confidence in tackling her 200-level e-portfolio, in hindsight, Bethany explained in our interview that the web e-portfolio she ultimately created for the 200-level writing course was different than she'd expected. It was "more portfolio-looking because it was on a website" and there were "just more items to put in," adding that she "understood the posting part" but that "it took [her] a while to learn how exactly to make the [Wordpress] website." In other words, her previous experience was somewhat helpful, but Bethany still struggled with the new demands placed upon her in a new context.

\section{Understanding Expectations: Giving Us "Answers, "Giving Us "A Sense"}

An understanding of the expectations for the final e-portfolio seemed to correlate with several students' reported levels of excitement and preparedness for the e-portfolio assessment as well as their levels of nervousness about grades. Valerie, for example, a first-time portfolio composer, reported in her early logs feeling "not excited" to compose her final e-portfolio because she had never done a portfolio and did not know "what to expect." However, despite Valerie's feeling "hesitant" about the prospect of creating her first portfolio of any kind, she suggested that "[g]iven proper instructions," she felt confident she would "earn an exceptional final grade for [her] portfolio." Later, after submitting her e-portfolio, Valerie reported feeling finally "very confident" about it, especially because it was so well-explained to her:

[The instructor] explained it really well. That's what aided in my success, definitely. She had it very organized where we did one thing [at a time] that helped us. We brainstormed [and outlined] a 
lot and talked about what we would be doing for every assignment. It was very, very good.

On the other hand, with just a month left in the semester, Amy, a freshman non-writing major with past portfolio and e-portfolio experience, reported that she was "not excited" for the final e-portfolio "because we have yet to really touch upon it and [the instructor hasn't] given any real instruction [on how] to start [it] when it is obviously due soon," adding that she felt the e-portfolio was "just going to be thrown at us at the end of the year." In the interview, Amy reported that she and her peers were not able to begin composing their e-portfolios until the last day of class because of a lack of guidance on what was expected. She explained that the requirements for "format, due date and process" were there and helpful, but that the content expectations for the e-portfolio were "ambiguous."

[The instructor] never really gave us a specific date to start [the eportfolio]. [He] mentioned it at the beginning with the syllabus when we went over the syllabus, and then, mid-semester gave us an assignment sheet but said, 'You don't have to worry about it right now' and then a lot of us didn't start it until the last day of class because the last day of class was given to us to work on it and there really wasn't much instruction before that so we didn't-no one really wanted to-start until that day when we could ask questions. ... [which was] definitely [helpful] because I felt a little lost before that class. 
When Amy received her final grade (an 88), she said it made her "so mad" because, she felt,

the instructor was looking for something that I could not touch upon because [his instructions were] so ambiguous. I felt [he] wanted us to be so creative and [didn't] wanna give us too many restrictions, but I also felt like that left too much up to our interpretation and [did] not [allow] us to receive a grade that we would $[$ laughs $]$. . prefer. . . I hit all the points [he] wanted us to hit but [he] wanted something more, but I don't know what [he] wanted more of, so I'm unsure of where the grade came from.

Several other students also pointed to the important nuance between basic formatting requirements and more general content expectations. Carol, a 200-level student with one college writing class under her belt and who had both print and electronic portfolio experience, reported feeling only "somewhat prepared" for this e-portfolio experience because her professor was "not the most clear or concise," adding that "students [in the class] feel like they do not know how to go about even beginning the portfolio." Although basic assignments and due dates were given in a "structured" way on the course management system, Carol reported not being excited for the final e-portfolio because she was "nervous about the expectations," adding that "the assignment sheet [was] not updated [to reflect] what was laid out in the syllabus," so "there [was] definitely confusion in the 
class." ${ }^{33}$ This confusion led Carol to rely "heavily" on the documents and instructions the instructor posted online and because what was said in class didn't line up with what was in those documents (or when instructions were simply "nowhere to be found"), Carol said her e-portfolio experience was greatly "hindered." In the interview Carol told me she was in the process of "fight[ing] for a [higher] grade" due to the instructor's unclear expectations, adding that the instructor most negatively affected her final grade: "She's a wonderful woman and looks great on paper and all that, but, oh my god, I just received so much secondhand anxiety from her. In class there was so much information, it was hard to focus."

Relatedly, Ethan lamented that his instructor spent "about an hour talking about [the weight of each piece]" to be included in their final e-portfolio, which he found "helpful," but that he could have spent "like five minutes" talking about that and more time being "more specific" about what each piece should look like and how to "put them [all] together." And Ariel, a freshman non-writing major with past experience in both print and electronic portfolios, reported that she was "confident of the options of work to put in the portfolio [meaning her writing projects choices], but," felt only somewhat prepared because they had "not yet discussed the portfolio much in class." Ariel reported being "given [only] a single paper with some guidelines" near the end of the semester that gave a basic list of

\footnotetext{
${ }^{33}$ Indeed, the instruction sheet for Carol's 200-level course listed (a) the learning outcomes that she was required to show proof of meeting in her reflective introduction, (b) the number of projects to include in her e-portfolio, and (c) a mandate to allude to those projects "to show how the work proves you have met the Learning Outcomes for the course." Aside from the weighted percentage of the portfolio, formatting, and submission guidelines, that was the entire assignment sheet.
} 
the first year e-portfolio requirements like word count, the learning outcomes upon which she had to reflect, and a rubric. In her second log, Ariel reported

I understand [the instructor] want [s] this portfolio to come from our creativity and [does not] want to create a box for us to try to squeeze in to, but I'm nervous that [she is not] giving a whole lot of answers. [She's] the one grading it, so I want to know what [she's] looking for but [she hasn't] said that in class.

In the interview, Ariel added that the class "asked to see [samples of e-portfolios] but [the instructor] just never got around to it," leading her, in the end, to "mostly . . . figure it out [her]self." Interestingly, Ariel suggested that she felt this "minimal direction pushed [her] to get a $90 "$ and suggested that if more instructors were as vague with their expectations and grading scales that their students, too, might work more diligently on all the parts of the portfolio, not just the minimal components listed on assignment sheets.

As Ariel pointed to, seeing models of other student e-portfolios was an important aspect of several students' understanding of expectations, when it came to both e-portfolio content and form. Julia, for example, reported that the one thing that helped her feel better about the e-portfolio technology was asking to see prior students' e-portfolios. "I wanted to see if what I had in my mind was what [the instructor] was expecting," she told me. "Some were far, far beyond where I was and some were cut and dry and beautiful. I did like having the examples." Julia reported that these examples helped her choose a simple Wordpress template "that didn't look too complicated." Casey, who said that one of her primary concerns at 
first was "knowing where to start" her e-portfolio, reported that she was able to "[use] as an outline" the "example portfolio" given to her by the instructor to "format" her own and to understand which parts of her assignments she could use to "tie into the learning outcomes" as part of her reflection. Similarly, Bethany described that when her instructor showed the class a model e-portfolio done by a student in a previous course, that helped her: "I thought if my professor is showing me this portfolio, [the student] obviously did a good job, so I'm going to try to model mine best I can [after that]." And Carol, the student who had a very difficult time with the "confusion" regarding expectations in her course, told me that she thought an "example [that showed how the e-portfolio was to be written] would have helped [her]" and explained why by recounting her experience reading through one of her peer's writing projects earlier in the course. Carol said that reading a peer's draft helped her write her own project much more than the instructor's instructions for writing because her peer's model gave her "a solid understanding of how it was done." With just the instructions, however, Carol reported, "I felt so in the dark about how to do [the project]," adding "because, with writing, I feel like you need to get a sense of [a project] more than 'This is what you need to do.'" In other words, Carol thought that getting a "sense" of the e-portfolio through similar modeling or exchanging, then, would have helped her feel less confusion about its content.

Some participants pointed to the importance of nuance and variety in the types of models to which they were- and wished to be — exposed. Katja, a senior major, for example, lamented being shown only one type of e-portfolio from a 
student who took the course previously. "It was all her, all the time," she said. "In the end, a lot of my classmates' portfolios looked like hers." In addition to that one, Katja would have liked to have been exposed to some "famous online portfolios," other models of professional portfolios, or to have "heard from" former students' about their "success stories with their portfolios" because, she explained, "looking at other portfolios gets you immediately on board. I mean, you're looking at your competition." She also suggested that doing so would help seniors see "that this portfolio goes beyond getting an A in this class."

Another senior in the same course said the same sample portfolio was not helpful for her particularly because it presented a blend of science and writing whereas she wanted to know how to "present things that are creative and still be professional," adding that "more variety in samples would have been nice." The only guidance she received on this particular aspect of her e-portfolio, or on-as Charlotte put it_-"including things that weren't necessarily writing," was from a peer who, Charlotte said, "went off on the creative aspect." Because the content of some of his projects was not stellar, she tried to use some of his creative ideas but to be "more goal-oriented."

\section{Mindful Timing \& Purposeful Scaffolding}

Not all students, however, were worried about expectations, mostly because of what they reported was ample time to compile, revise, and compose their e-portfolios because of thoughtful assignment scaffolding. About $40 \%$ of participants perceived a lack of ample time or scaffolding and, hence, more stressful or confusing e-portfolio experiences. 
Several first year students reported either having or taking very little time to compose their e-portfolios. Regina, for example, started working on hers on "the Friday before it was due." Ariel reported that though they had the "opportunity to start early, no one really utilized it" and that she only began working on her eportfolio "the very last day of class." Ned reported that it was mentioned on the first day of class and then promptly put on the "backburner" until about two weeks before classes ended, which was when they received the official "directions" on how to "write the reflection essay and do the portfolio." He then began working on his revisions a week before the e-portfolio was due and took a few final hours before it was due to write his reflective essay, stating that he wanted his revisions done first.

These late starts had some anxiety-provoking consequences for students. Amy, for example, complained about only getting clear on the e-portfolio expectations "on the last day of class" which is when she began working on it (mostly tinkering with the website-building platform she'd be using) and reported that she only began working "consistently" on her revisions "just a few days before the portfolio was due," adding "because I had other finals." "This [was] stressful," she continued, "because we all have other classes where things are being thrown at us and this [was] just another on top of it." Though Amy reported that the instructor "made it sound [on the first day of class] like [they] were gonna work on it throughout the semester," she ultimately felt let down, because "we didn't."

A few first year students, however, noted not feeling as concerned about the short amount of time they had to compose their final e-portfolios. Mary stated 
that she worked on it about three days before it was due and that she was "not nervous" at all about the outcome, figuring, "If I had 2,000 words, two papers, and a reflection, I'd be good." In other words, simply hitting the basic requirements was sufficient. Valerie felt she had ample time to work on her e-portfolio-about one and a half weeks-and that this felt like the "proper" time to complete it. She felt particularly confident because she "had the tools [she] needed" and was able to "[take her] time." Casey told me that her class was given instructions "a couple of weeks before the end of the semester," though she chose to work on it only "two or three days" before it was due, adding, "this is how I work-last minute-under stress, I get it done."

Students in the 200-level courses similarly had mixed reviews on timing. Two students (Carol and Jean) reported that they were given an assignment sheet at the start of the semester but both expressed anxiety over not having an "updated [e-portfolio] assignment sheet" available until "very close to the deadline" and that their last projects were "not returned . . . until late," leaving very little time for revisions. Jean lamented about getting "no instructor feedback" on her reflection letter.

Bethany, however, who was in a different 200-level course, reported having a "full week" to complete her e-portfolio with ample feedback from her instructor that she felt would help her "do well on the revising." She took a few minutes to discuss the more anxiety-producing timing of a Word document eportfolio she had to create for a first year writing course she had previously taken: 
It was challenging to create a large portfolio of writing during the same time as finals. ... It took a lot of time, and had a really high . . . cost for me. I remember not being able to study for an engineering class as much as I would have liked because the portfolio was due on the same day as that engineering final.

Alternatively, Bethany felt confident about the e-portfolio in her present 200-level course, saying,

I felt well-prepared throughout the class because I had learned enough to not feel as burdened as I did in all my other classes with cumulative exams, where an entire semester is shoved into one [exam]. I worked on this throughout the entire semester so it was already ready to be put together.

Similarly, the two students in the 200-level digital writing course reported ample time to work on the e-portfolio, suggesting that they began adding artifacts to their web e-portfolios by the "third of fourth week" of the course, and that by "mid-April" the class "really started getting into it." Julia worked on hers for the majority of the semester and Ethan said he spent the last month revising and completing his artifacts and then assembled all that into his e-portfolio about "two weeks before" it was due. However, despite having worked to compile her digital writing on the web e-portfolio over time and having access to a list of requirements, Julia still worried that her lack of preparation would "severely" affect her grade. With about three weeks left in the semester, she reported, "We haven't much time left, and I do not have it done, nor has it properly been drawn 
out for me as to the requirements." Offering an explanation, Julia alluded to personal and familial stressors outside the class. She was in the 33 to 44 years-ofage group and had several children at home. In her first reflection log, Julia wrote, "I require longer prep time. My life is different than others." She expanded upon her response in our interview, telling me,

Testing can produce anxiety for me. I have dyslexia.... And I'm usually up all night. Not the up-all-night-college-kids - partying. I'm up all night with a toddler, doing laundry, [and] making lastminute costumes.

Though she admitted that an e-portfolio assessment was much less stressful for her than a cumulative written exam, Julia told me it still took her "longer [than most students] to finish any writing assignment" and that this e-portfolio felt no different. Further, she wished she'd had more training with e-portfolios prior to this course: "We could use more e-portfolios in other courses. My last writing class should not have been my first electronic portfolio."

Two students in the same course reported not being nervous about their final grades in part because of having been aware of the e-portfolio from the start of class and their instructor having "mentioned it throughout the course to help us keep it in mind." They reported getting the "official assignment about a month before it was due" and worked on it formally from about two weeks out from the due date. Eva, however, did express frustration at multiple times in the interview about the "five days before grades had to be in" that her professor "would have had to grade it" and was skeptical that her e-portfolio was even reviewed at all: 
It just bugged me that there wasn't enough time for it to be evaluated ... I think [the instructor] was putting a lot of effort in. She had a whole week when she opened up her office and had a ton of appointment times and I chatted with her. It's not that she wasn't interested in making our writing better, but where are you gonna get the time to handle forty portfolios [between submission and when grades are due]?

In the end Eva reported that for students like her who were "doing well" throughout the semester, this perceived paucity of time for the instructor to evaluate her e-portfolio contributed to Eva's sense that the e-portfolio was "just like a checkmark. It was like okay, you did it. It wasn't relevant, just another thing I had to do."

The senior majors reported having nearly a full semester to work on their eportfolios. As Katja explained, "We were assigned it from the beginning. 'Create a portfolio and use it to get a job.' That was the welcoming speech." Hope said they had been given a rubric for the senior e-portfolio, but that she "didn't have to refer to it much," primarily because of "the [many] projects and readings" they did "along the way" to the final e-portfolio that "were based on the four [rubric] categories," so that "by the time [they] reached the final," Hope reported, she "knew inherently" what to include in order to receive a good grade. Indeed, what she felt most affected her grade were these "projects" which, "at first" she thought were "random" and "daunting," however, "when they came together," Hope said, 
"they really helped me." ${ }^{34}$ Hope also reported that she thought this scaffolding made the e-portfolio feel unlike a final exam because she had been "working on it the whole semester."

Even though Charlotte reported being "very nervous" about her final eportfolio grade, she claimed it wasn't because of the expectations, which had been clearly laid out for her and enough so that she only "looked back a the rubric once or twice" when composing her e-portfolio. Indeed, Charlotte described the scaffolded projects as very positive exercises for her, as well.

I went into that class [having] no idea what I wanted to do. [The professor] wanted me to be as focused as possible and asked me to hone in on a specific idea [about my future writing career]. Knowing that and then getting projects that were designed to push me in that direction, to keep me focused on that idea, [were] very helpful.

Similarly, Holly reported feeling clear about the e-portfolio "expectations" that by the time she got to the final composing stages, it was all just "common sense," particularly because of the scaffolded projects that led her to the finished product. Most seniors reported beginning to really put their e-portfolios together with about a month or so left before they were due. Holly, for example, used the last two months of the semester to totally revamp the content strategy of her

\footnotetext{
${ }^{34}$ Seniors reported that these projects included looking at "past portfolios" early in the semester, conducting a "disciplinary report" that had them investigate the requirements for the writing-related career path they were on, then moving to curating artifacts and writing "annotations" or justifications for how these artifacts linked to students' career goals. Students also conducted readings on basic web design principles.
} 
professional e-portfolio and she reported being very glad to have had all that time to "scrap" her first draft and compose a new one. Though, Hope, unlike anyone else in the study, had a draft of her e-portfolio "finished for a while." She had been "working on and editing" it "since [the previous] June" as part of a summer internship, adding, "so it [went] through many revisions and updates." When I asked Hope if she thought having that extensive amount of time had contributed to her final grade—an A—on the e-portfolio, she responded, "Probably. ... I barely worked on the e-portfolio itself throughout the semester because I had already had so much knowledge of it and I had already made it." Having ample time to consider her professional aspirations along with carefully scaffolded assignments that helped her further target those aspirations in the final semester of her senior year, helped Hope feel extremely confident that her e-portfolio was not only going to be successful for the class, but also useful for her future career.

Conversely, having only been prompted to consider her professional intentions in the final semester of her senior year left Charlotte feeling like she had too little time for composing and designing her final e-portfolio. Charlotte reported in the last weeks of the semester feeling "very nervous" about her final grade because her e-portfolio did not feel "complete in design" and the "artifacts" she had chosen were not "strong enough;" "better work and better design" were still her major concerns. There were pieces of writing Charlotte was still working on in other courses that she "wished [she']d had the time to polish and put up" because she thought these texts more closely related to the professional writing interests she was just discovering (online/digital writing and music). In this way, though the 
scaffolded projects helped Charlotte finally get clear on a professional focus, they came too late and left her wanting more time to compile an e-portfolio of solid artifacts that reflected her newly discovered professional purpose.

Considering Who's "On My Side" and Who's "In Control": Support, Connections, Feedback, and Agency

Many students in my study placed value on the personal connections and support they felt they received —or did not receive—during their e-portfolio experiences. Most of that support came from people, like peers and professors, but some came from other sources, like through, as Hope put it, "a lot of Googling," or by their own devices.

Despite having little previous e-portfolio experience, there were some students in the lower-level courses who reported being able to "figure out" the technology with a modest amount of self-directedness. Mary, for example, reported that Wix was "really easy to use" because the Wix website "tells you how to use it" when you first set up an account. Mary said she watched the introductory video tutorials offered by Wix, which were mostly all she said she needed to "teach [her]self." Similarly, Regina described having few problems with her choice of CMS - Weebly — despite having been given no instruction on how to use it. Regina said she learned how to use it by "looking around and just clicking on stuff." She considered herself "pretty computer savvy" and explained that she just started a draft the last day of class and began "clicking around to see what there was to offer." Regina said tutorials were available, but that she would rather just "explore [the CMS] on [her] own." Ariel said she considered Tumblr (which was 
given as an option) because she had her own Tumblr page, but because that CMS primarily "dealt with pictures," Ariel wasn't "comfortable" trying to make a textbased writing portfolio with it, so she chose Wix. "In the beginning [Wix] was super foreign —I had no idea how to operate it," Ariel told me, "but towards the end ... it was super easy to use. I liked it. I would use it again for another project."

Other students found support for the e-portfolio technology from people (and in spaces) outside their writing classrooms. Katja, for example, a senior major, expressed feeling particularly constrained by the WordPress interface and to work better within those constraints, Katja told me that she "sat in the lab and worked a lot" and solicited help from a professor (who was different from her course professor and) who ran the writing department's production lab. ${ }^{35}$

I knew he was a good teacher and I knew he was the other portfolio teacher. I never had him, but I felt his opinion would be credible. . . . So I do feel like I got lucky in that respect. ... I definitely approached him about a lot of things.

Katja said that knowing someone "who professed themselves to be fluent in WordPress" was really helpful for her and that, in particular, having this professor reassure her of the soundness of her technological choices along the way helped Katja feel confident that "she was on the right track."

Similarly, Ethan reported being "extremely upset with [Wordpress]" at first: "I just kept working and working and working and it was just so complicated

\footnotetext{
${ }^{35}$ In fact, the single most valuable thing Katja reported learning over the course of the semester in her final reflection log (with some jest) was "Patience for working on a stubborn and sometimes limiting platform (WordPress)."
} 
to use," he told me. "It would always do the opposite of what I wanted it to do." When I asked if the professor offered any instruction, Ethan replied, "Not particularly. [The instructor] just kind of said 'Here's what I want, now go out and do it."' After some time struggling with it, Ethan reported that he eventually "kind of . . . learned the trick of it" and "was able to put [his e-portfolio] together once [he] got the hang of it." An important part of "learning the trick of it" for Ethan was taking the initiative to ask for help from people within the writing discourse community to which he belonged, including another writing major who worked in the writing lab and who had composed a Wordpress e-portfolio, as well as another writing professor who, Ethan said, "helped [him] put it together," adding, "It's a good thing I know people!"

Several other students (who "knew no one"), reported how a perceived lack of support, connection, or feedback had a negative effect on their e-portfolio experiences. Amy, for example, was very familiar with Tumblr and, despite its more graphic-centered conventions, chose to use it to build her first year eportfolio. This presented some additional challenges for her: "As well-versed as I am in Tumblr, I haven't written notes this long yet on it and I didn't really know how to indicate [with bold or highlight] where I made changes [revisions]." Amy also said she found it "weird" to have to create a Tumblr page that was viewed from the top-down, because the widely accepted conventions of the Tumblr genre were to read them bottom-up. Amy reported having to explain these genre conventions to her instructor and his response was to tell her that if she chose to stick with the conventions, that she should "leave a note" about this on her e- 
portfolio for him so when it came to evaluate the e-portfolio he could remember it. "I just figured it was easier to have it so it was top-down," Amy told me (easier for the instructor, I noted; not for Amy). However, Amy reported that she eventually "figured it out" by looking at other Tumblr pages that were "more blog-like as opposed to just pictures" and said she enjoyed being "forced to do something different with the technology." But when I asked her what might have helped her feel more comfortable with the e-portfolio technology, she said, "If [the professor] had known how the technology worked that probably would have made me more comfortable.... [He] shouldn't have made it an option."

Julia spent quite a bit of time talking about the frustrations she encountered using the required CMS for her 200-level e-portfolio, particularly due to a lack of support. She felt Wordpress was non-user friendly, especially as compared to Wix, with which she had extensive experience and which she described as "definitely me." But learning that CMS took time and assistance. "There is no way, unless you educate me to use it better," Julia told me, "[that] I'm gonna like it. I didn't like Wix in the beginning, but that's because I didn't understand how to use it." In her current 200-level course, Julia felt disappointed in having limited access to support and instruction on how to use the CMS technology. Though she had to use Wordpress for writing some travel blog posts in another class, she still had many questions about it that went unanswered.

There's no help at all [from Wordpress]. I must have said every week: "This is an element I'm having difficulty with, can I get some help?" I remember emailing [the professor] saying, "I'm throwing 
my laptop out the window!" [laughs] and [the instructor was], like, "Oh, well, when we brainstorm together we'll figure it out." . . . [But] I do most of my work when my children are asleep so, after midnight, who am I gonna brainstorm with? I can't pick up the phone and say, "Hey, are you having this problem?". . . So that element was very disturbing.

Julia said that she kept hoping they would have a class "on how to use Wordpress, but we didn't" and that didn't bode well for her. She wanted to understand the technology and even asked for help in understanding it, but there was little support, which she found problematic. In fact, Julia told me these technological frustrations "prevented" her from "fully enjoying" her e-portfolio experience, adding, "I went to school for fun at 40! [laughs] It took away some of my fun."

Support mattered, too, when it came to other types of writing technologies that students didn't have experience with but still needed to use to compose their eportfolios. When it was suggested by her professor that students create identity markers, or personal logos, for their e-portfolios using PhotoShop, for example, Charlotte explained that she couldn't "PhotoShop to save my life" and that what she ended up creating was "the most basic form ... you could get." She lamented that "everybody else's [logos] were just a lot more fancy" and wished she had more time to "play with those aspects" of the e-portfolio. Charlotte was particularly disappointed that the Photoshop tutorial given by an expert for the class was offered after class at a time Charlotte could not attend. Conversely, Holly was positively influenced by a writing department professor (other than her course 
instructor) to try Camtasia (a video production and screen-casting software program available in the writing lab) for one of her e-portfolio artifacts. As a film major with ample experience using Final Cut Pro, Holly claimed, "I was glad that [the professor] pushed me to do that" because, she said, it was "fun" and "easier." Aside from technological support, many students placed value on the personal support and connections they felt they had and made — or did not have or make - from and with others during their e-portfolio experiences. For one, in my interactions with students about the prospect of the upcoming e-portfolio assessment, some of their senses of confidence and/or distress about their final performances depended upon how they perceived their instructor's personal feeling about them or their writing. Towards the end of the semester, for example, Bethany reported feeling nervous about her final grade because "what I think is good may not be good in the teacher's eyes." In the interview, she reported feeling even more nervous after two of her drafts were returned to her with "not great grades." Yet, for her final e-portfolio, Bethany said she decided to do an "out there" revision on one of those project for her e-portfolio that she "wasn't sure [the instructor] would like" and so she definitely "did not expect" the perfect score she received on it. (She expected a B.) Bethany's reason for her perfect score?: "I think [the instructor] enjoyed the new perspective, [was] excited about what I was writing about, and liked that I took what she said I should fix and did that." In other words, "in the teacher's eyes," Bethany's revisions were successful and her grade reflected the instructor's approval. 
Such concern over personal connection, in the form of instructor approval and acceptance, was not limited to only female participants. Though Ethan reported feeling "somewhat prepared" for the final assessment because of the feedback he had received from the instructor and therefore knew "what [he] should revise" and "how to identify details that need[ed] to be improved," he still reported feeling "somewhat nervous" about his grade because even though he felt "proud" of the "hip hop" blog and "raps" he created for it, he stated, "I don't know if my teacher will be as open or receptive to them." In the interview, Ethan explained that what continued to trouble him most throughout the semester was "wanting to know [the instructor] as a person and what appeals to him as a person" so that he could do well on his final e-portfolio. After receiving what he described as a final grade "in the high eighties," Ethan expressed feeling "impressed" because he "didn't expect" his final grade "to be as high as it was," partly because he never really felt he grasped what it was that appealed most to his instructor.

Relatedly, there was a common and emergent sense of concern regarding the question of agency and how that agency might positively or negatively affect students' final e-portfolio grades. Regina, for example, stated that she felt "well prepared" for the e-portfolio toward the beginning of the semester, mostly due to her past portfolio experience, however, towards the end of the semester she claimed to be more nervous because, as she put it, "I don't always have control over my grades." Amber, on the other hand, felt "not nervous" about her final eportfolio grade particularly because, as she stated in her final reflection log, "I 
know the professor is on our side for these portfolios, so any questions or concerns I have will be taken seriously and dealt with."

Positive feedback from instructors, generally, seemed to help students feel more confident (i.e., gave them a greater sense of agency) about their final eportfolio performances and validated in their revision choices. Ned, for example, reported a few weeks before the e-portfolio was due that he was very nervous about his final grade because he had not received "as much feedback as [he] would like," adding that he was "hoping to seek out classmates and my professor in the upcoming weeks for more help," especially because he did not know how his writing would be "received" by the instructor (even after having been given a rubric and clear written instructions). Ned reported eventually getting very positive feedback from his instructor in a pre-due date conference and that the instructor even requested using Ned's e-portfolio as a model for high school teachers being trained to teach electronic portfolios. Ned claimed that after this interaction he was much "less anxious" about his final grade because he had "sought out help" from the instructor who, as Ned put it, confirmed "that he liked my writing and that I was a good writer." He was more confident he would do well.

Instructor feedback helped to quell many students' nerves over the course of the semester, and this feedback did not necessarily have to always be positive. Valerie, one of the few who said the percentage seemed "scary at first," reported feeling "not worried" in the end about the weight of the e-portfolio percentage because she "had the [instructor's] suggestions [on how to improve her projects for her final e-portfolio]." Nor did feedback help only lower-level students, senior 
major, Hope, said that "professor and peer feedback" contributed greatly to her own sense of confidence about her final e-portfolio and that she felt "very prepared" to complete it because "there was a lot of time to ask [her] professor: 'Is this what you want it? How can I improve this?"' Despite having some criticisms of her professors and the courses offered in the major, Holly also reported having been well-guided by faculty mentors to build a final portfolio that she was proud of. She relied on her course professor and the help of another writing professor in the department whom she'd had connections to through her work in the writing lab. Holly said she regularly sought out their feedback and referred to their help and guidance often: "Between [Karl] and [Richard $]^{36}$, they guided me to a product I can be happy about using in the future."

Some students in my study alluded specifically to instructor conferencing as a positive experience of support and agency. To Eva, who got good grades throughout the semester and was not as concerned about her final e-portfolio, the conference offered an opportunity for "chatting" with her instructor, which helped her see that she actually "didn't have to do too much revision" and that that she could just "[mess] around with structure a little, nothing major." Whereas Amber stated that being able to "talk through [her] concerns with [the instructor]" in the required one-on-one conference "definitely helped" her feel like the final eportfolio was more of an "exciting challenge" than a "daunting" one (i.e. helped her experience a shift in agency).

\footnotetext{
${ }^{36}$ Pseudonyms used here.
} 
For some students, conferences were not required and/or seeking out feedback was difficult. Amy, for example, reported feeling "so mad" about her final grade (an 88), ${ }^{37}$ and suggested that what would have helped [her] was [getting feedback] not before [she began her e-portfolio], but after [she started it]. . . I know a lot of professors do let you do that, you just have to email them and set up a time, but I had so many other things going on with being an RA and having other finals that I just couldn't set up that time and didn't even bother to ask if [the instructor] would [meet with me]. A particularly difficult experience for one student involved a sense of progressive failure coupled with an unanswered plea for support. Jean, a junior non-major, described how her confidence was eroded because of a deterioration in her project grades leading up to the final e-portfolio. Jean reported in her first reflection log, "I have done [an e-portfolio] before so, I feel like I am just repeating what I have done," adding that she did "well on all [her] paper[s in this class] so, [she couldn't] see the online portfolio affecting [her] grade." However, towards the end of the semester, she wrote in a second log that she was "somewhat nervous" about her eportfolio grade because her final project "didn't get as nice of a grade as [her] previous one(s)," which suggested to her that she had been "doing a good job, but now [she was] worried." Things seemed to get worse from there when Jean reported in our interview being very "bitter" about the eighty-eight (88\%) she received on her final e-portfolio. She reported "begging" the instructor for help

\footnotetext{
${ }^{37}$ See more on Amy's reasons for this anger in the section on Expectations.
} 
(via email) and feedback on her projects and a response to a previous inquiry regarding what she felt were unclear directions that the instructor never responded to. "She just dropped off and stopped caring," Jean reported; "so did I." Yet it was clear in our interview that Jean still did care deeply about her grade, stating that what most upset her was her sense of disconnect with the instructor, particularly that "[we students] actually care about our grades and [the instructor] didn't think we did."

Feedback during the e-portfolio process was not the only type of support that students desired. Two students who performed well on their final e-portfolios wished for post-submission feedback. Like for Julia, who received an A- on her eportfolio (which she reported feeling "okay" with), it turned out that what she really wanted more of was feedback on her e-portfolio after it had been submitted and evaluated.

I hate final anything because you never get them back. A good grade is great, but I want to know where I could have improved in order to go forward with something. I would have liked to have had the elements (texts and projects) dissected.... A grade is great, but feedback is even better. Why did I not obtain a 100 , which is possible? I think finals should be a week before school lets out so you get feedback.

Similarly, despite earning an A, Casey suggested in our interview that "it would be nice to see what the feedback was" on her e-portfolio, "like [the instructor] did on [the other] projects for the course." 
Peer support also emerged as an activity students found not only helpful for improving their e-portfolios or their confidence(s) about their final grades and their writing, but also as an important exercise in support, companionship, and even self-improvement. ${ }^{38}$ Amber, for example, reported that what most positively affected her final grade was the peer reviews for each project.

For each project we always had one peer review with three students looking at your work and we took a class period each time to talk to each other and go through a set list of questions. That was really good because it was your first draft of the piece and it was people who were working with the same assignment so they knew what needed to happen. I got some really, really great feedback, thankfully, so that helped a lot. I think that was a necessary component of the class.

The same held true for the most veteran e-portfolio composers of the bunch. Senior major, Charlotte, for example, told me that peer support was one of the experiences that most positively affected her grade.

I collaborated a lot with the people around me. We joked a lot. Even questions about background were helpful. The quick verbal collaboration was helpful. We were comfortable with each other and reviewing each other's work was helpful. We were close

\footnotetext{
${ }^{38}$ Though I asked no direct questions about peer support or peer reviews in my interview questions, twelve of eighteen participants, or $67 \%$ percent of students, spent time discussing the effects of peers on their e-portfolio experiences. Reports were primarily positive, meaning they had a positive effect on students' e-portfolio experiences, though there were some negative outliers (which I report below).
} 
enough to be honest, like, 'You know I love you, man, but you've gotta tweak that!'

Eva reported that "peer comments were helpful in polishing" her drafts because everyone in her 300-level writing course "seemed to take [each other's writing] seriously" by reading them "seriously and well," "responding in full sentences," and not just making "checkmarks on a sheet." Though Eva reported learning very little in her 300-level writing course (that she didn't already know), she did report "getting better at ... reviewing other people's work [overall]." Similarly, Julia, who reported being a strong writer coming into the 200 -level writing course, said that one of the most helpful experiences in the course was "reviewing others," adding, "I always get more out of doing the see-say-do-showing someone else how to do something. In correcting other peoples' work I see not only where they've faulted, but where I have as well."

Where peer support during the e-portfolio experience was lacking or insufficient, several students expressed a sense of loss or frustration. Ariel, for example, longed for more collaboration and camaraderie in order for her eportfolio anxieties to be lessened.

If we had a few more days in class to work on it, I'm sure we would have had more of that peer help, but since the only day we worked on it was that last day when everyone in the room was kind of like, "I have no idea what to do!" Nobody was really talking to each other. We were just trying to figure out what projects we were picking, so it was more of an individual thing on that last day. If we 
had a couple more days I think we would have talked to each other and it would've been easier.

Conversely, Julia suggested that required peer workshops should be "thrown out" because of the "ineffective" experiences she had in her writing course.

Most people didn't come with their stuff [to peer reviews], so I'm sitting there with mine stapled and collated and [laughs], you know, all my work and they're like, 'Oh, yeah, it's still on my computer,' and, I'm like, well, email it to me! Then ... they'll say, 'Oh yeah, this is really good!' and I'm, like, 'That's nice, honey, but, I need your feedback!'

Julia also reported getting "so frustrated ... watching other students finishing their e-portfolios [or shopping or checking out scores] as others were presenting" drafts for a class workshop.

Other reports of peer exchange pointed to the value of in-person interaction over online interaction. For Bethany, for example, the online peer reviews they were required to conduct in her course were "useless" for her because they required "so much extra work" with little payoff. She reported spending much more time on her responses than her peers did and found it difficult to understand "what was valuable feedback" for her peers because they didn't rate her comments as they were supposed to. Eventually, after "putting in so much and never getting anything out of it," Bethany said she "stopped caring" about the peer reviews.

For veteran e-portfolio composer, Holly, the online reviews were also a "huge problem" and presented the "biggest challenge" of her e-portfolio 
experience in the senior capstone course, mostly because she did not like being unable to "see [her peers'] facial expressions" which she felt was like "taking a step backwards" for students, like her, who expected to "need appropriate social skills in [the] work environment[s]" they would likely soon find themselves. Holly compared this negative experience to the "small, face-to-face" peer reviews she had done for another writing course which she enjoyed because students were able to "talk things out and explain [them]selves better" as well as to "[hear] the tone and [see] the body language" of their peers. Holly said online reviews were "boring" and though some instructors may think students are not okay with "honest feedback," Holly suggested that, in her experience, students were "more honest when face-to-face" and that "everyone enjoyed [that]!" In particular, Holly felt the online reviews did not honor what she felt was the most enjoyable and helpful aspect of her e-portfolio experience - the uniquely "supportive" environment of the writing department at this university, especially as it compared to her other major (film), where, she said, "the students are cut throat" and classes "made her cry."

\section{Conclusion}

This chapter has attempted to hear well and map out the various student voices, messy truths, and learning insights offered by the eighteen participants in my study in regard to expertise, instruction, and support. Students reported that they saw their past experiences with portfolios — electronic or print — as valuable and relevant to their present e-portfolio experience, particularly where that experience was lacking. Participants reported that unfamiliar portfolio genres and 
subgenres posed new demands in new contexts and required levels of autonomy that not all students were comfortable with. Students reported the positive and negative consequences of the various types of instructor expectations they experienced, particularly in regard to assignment guidelines, scaffolding, and feedback. Peer support was also brought up by several participants, who valued the sense of validation and connection they garnered from these exchanges while engaging in an e-portfolio assessment experience. Taken together, these student insights compel writing instructors and program administrators to attend closely to the consequences of our e-portfolio instruction, to the value of students' past portfolio experiences and expertise, and to the (potentially) messy truth that timing, connections, and expectations play an integral part in alleviating student anxiety and assisting in student success.

The next chapter will build on the reports in this one by delving more deeply into the particular digital and technological tensions and preoccupations described by students in the study. 


\section{CHAPTER 3: STUDENTS REFLECT ON MODES, MODAL}

\section{AFFORDANCES, \& DESIGN}

\section{Introduction}

Because composing in modes other than/in addition to alphabetic text is a widely accepted practice in our field, I sought to understand the choices students were making in relation to the modal affordances available to them in an electronic portfolio experience, especially in the web e-portfolio format where audio and video, downloads, links, and images were more likely to show up. To gain such an understanding, one of the questions I posed in the interviews was, "In order to create your e-portfolio, you may have made choices about the modes you used in it, like text, images, or pictures, sounds, videos, or hyperlinks. What modes did you select to use in your e-portfolio? Why did you select these modes? What modes did you not use and why?" I also asked students if there was anything that they felt would have helped them make "better modal selections" and how they would have felt about being required to include other modes (particularly modes other than alphabetic text) in their e-portfolios. Particularly compelling were the reasons students gave for choosing particular modes over others and for composing in the modes they did; those reasons will be reported in this chapter.

In part from students' responses to those same questions, an unexpected and additional trend emerged. Though the design (or form) of the student eportfolios in my study did not play a major role in any grading scale, rubric, or eportfolio requirement list that students shared with me, and despite having asked students no explicit questions about the design or "look" of their e-portfolios, the 
issue of design came up often, either as a feature of the e-portfolios that students enjoyed working on and/or as an aspect of their e-portfolios they were particularly concerned about or struggled with in some way. Students' concerns and comments about design also arose when they walked me through the contents of their eportfolios, describing the artifacts they chose to include and why they chose them. The issue seemed to be inextricably linked to - or simply made more apparent by—students' (multi)modal choices of e-portfolio artifacts. The topic of design also arose simply when students mentioned it as part of a response to a different question (i.e. to tell me what they enjoyed, what was helpful, what they were frustrated by or worried about, etc.).

This chapter, then, will report on students' responses to my prompts (as well as some unprompted comments they made) about the particular (and primary) modalities in which they were required to compose - and those in which they more freely chose to compose - in order to understand (a) the affordances those modal selections offered to students and (b) the effects those affordances then had on students, particularly in regard to how they shaped students' concepts of "writing" and prompted students to consider the design or form of their e-portfolios.

\section{Findings}

What "Count[s] as a Word"?: Writing As/Beyond Alphabetic Text (on Paper)

In this section, I will discuss students' perspectives on the modes and modalities they employed to compose online and how they perceived the affordances of these modes, particularly what they perceived writing to be-as alphabetic text "on paper" or as beyond text. Table 15 shows the types of 
modalities (i.e. text, graphic, video, audio) employed in participants' e-portfolios and e-portfolio texts. ${ }^{39}$

Table 15: Modalities Employed in Students' e-Portfolios

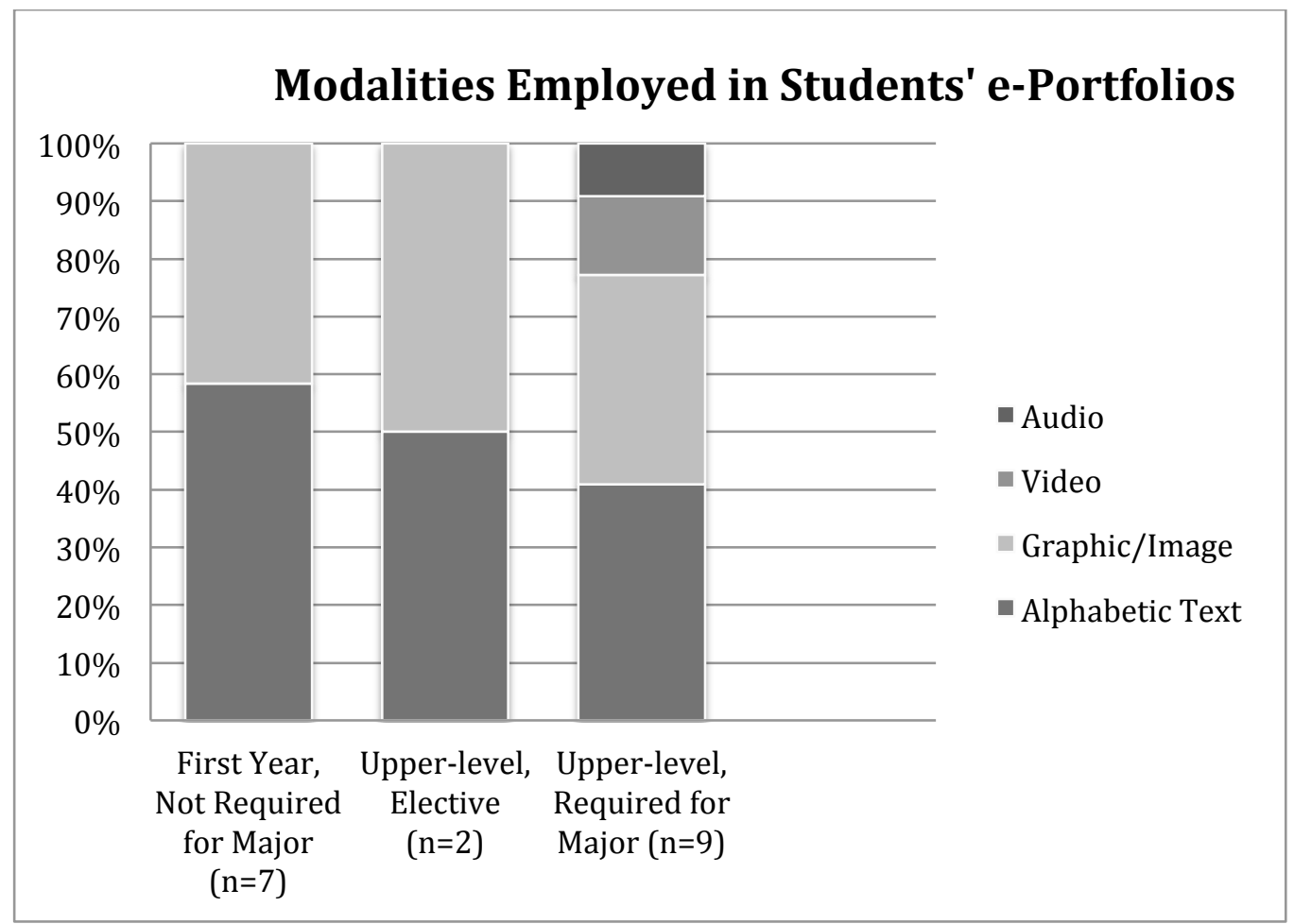

Alphabetic text was the primary mode used by students, especially in the 100-level courses; graphics and images were the second most common. There were three students who created alphabetic text only e-portfolios: two were in the final form of Word-to-PDF e-portfolios and the other was an e-portfolio created using the CMS Wix (see Figure 9 and Figure 10 below). ${ }^{40}$

39 Though hyperlinks and downloads can be considered modes and were also integrated into a few students' e-portfolios, I will not be discussing these at length and so did not include them in the chart.

40 Though not statistically significant, all three text-only e-portfolios were submitted by nonmajors taking lower-level writing courses as a general education requirement. 


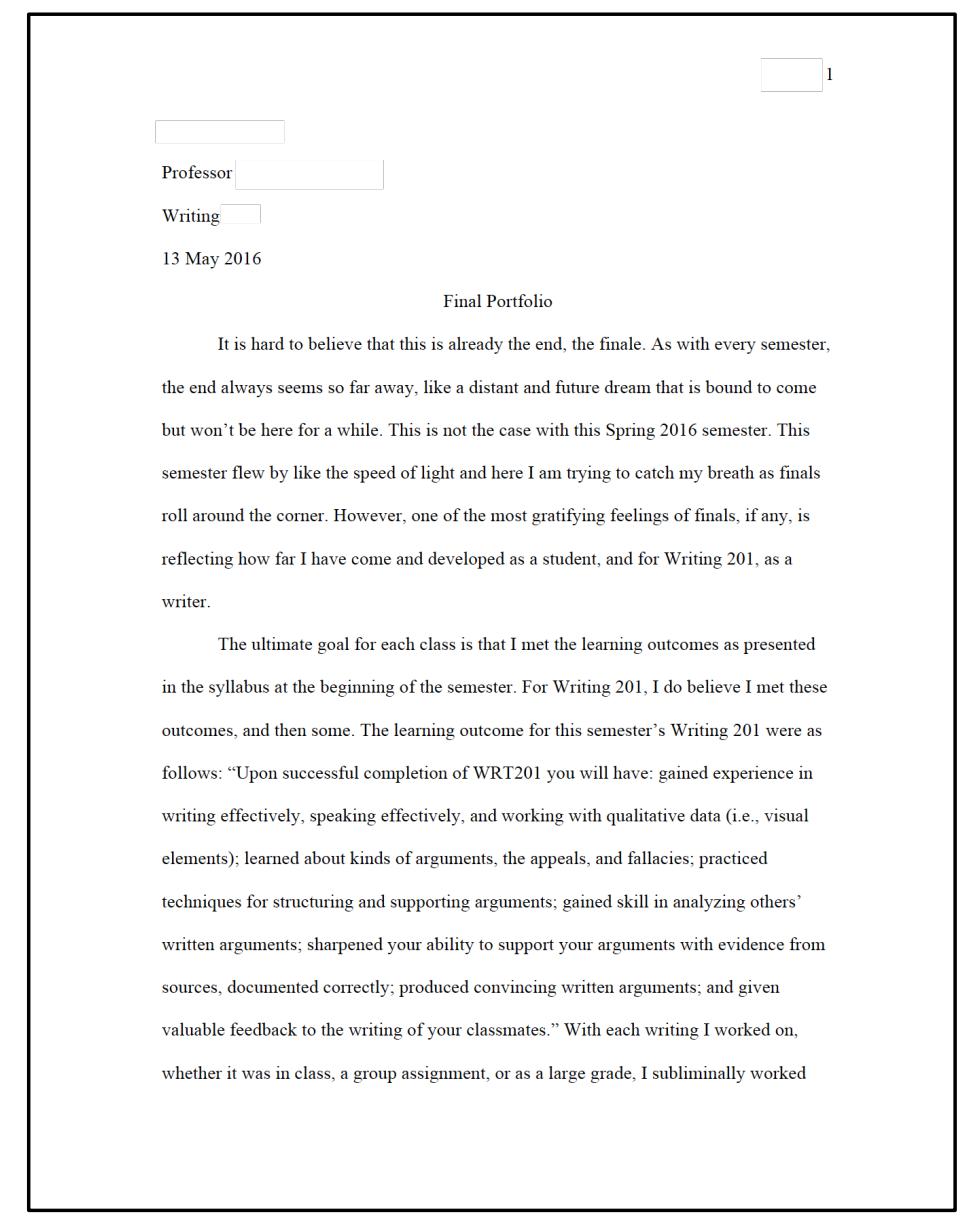

Figure 9: Alphabetic Text-Only Word-to-PDF e-Portfolio 


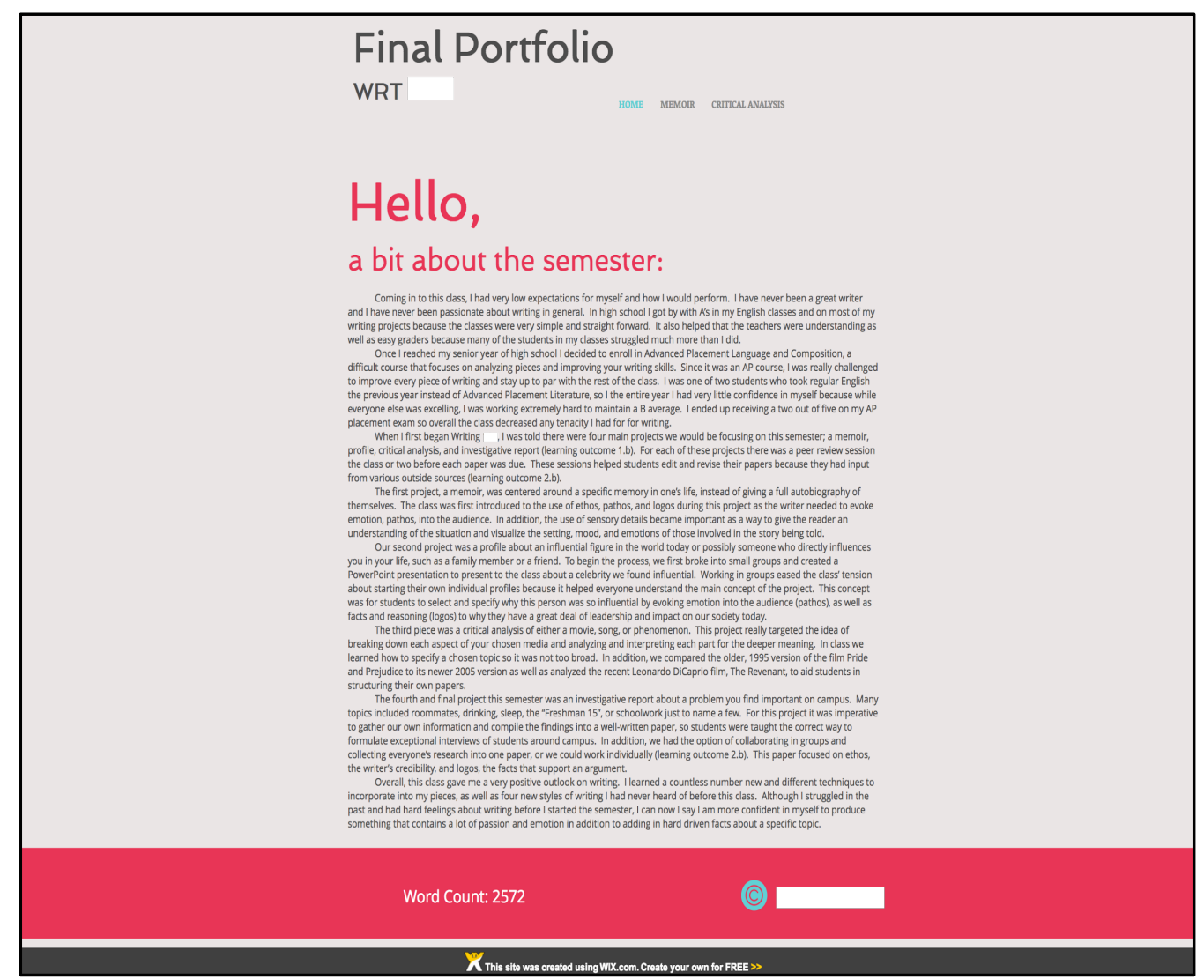

Figure 10: Alphabetic Text Only CMS e-Portfolio

Whether or not a student chose to compose and include artifacts in their eportfolios that were only in alphabetic text did not necessarily depend upon the type of e-portfolios that a student submitted. Most other student e-portfolios (submitted in either format) included final texts and projects that were alphabetic text-centered with only one or two instances of another mode included, and most of these were ornamental and borrowed and not whole, original texts composed by the writer. Students in upper-division writing courses, however, especially in those courses required for the major, were generally more comfortable composing in electronic environments and employed more modal diversity in their texts and eportfolios. Also, the percentage of multimodal texts increased in the upper-level 
courses while the percentage of texts composed solely in alphabetic text decreased (as previously shown in Table 15).

The primary mode used by every student in my study was text (all eportfolios included text), with images being a close second (fifteen of the eighteen e-portfolios included images). Three e-portfolios included video and two included audio clips. ${ }^{41}$ Nine e-portfolios included downloads and five included hyperlinks. One emergent trend in my data suggested a marked difference between what students in the 100-, 200-, and 300-level courses thought about writing as/beyond alphabetic text, compared to the level of complexity with which most senior majors (and a few other participants) used when speaking about writing as/beyond alphabetic text. Generally, students in the lower level writing courses thought mostly of writing as writing-in-alphabetic text, whereas students in upper-level courses understood how writing could be presented in more complex multimodal forms.

When describing their reasons for composing primarily in alphabetic text, $60 \%$ of participants reported that modes other than text were not required, were not discussed or assigned, and/or were not an expectation of the instructor. ${ }^{42}$ Some were fine with that. Casey, for example, said that "since it was [a] writing [course], I thought I'd just stick with that." And Amber said it was "never an option to do audio or video" in her writing course, but even if it were, she was "already

\footnotetext{
${ }^{41}$ Interestingly, though also not statistically significant, the five students who included video and/or audio in their e-portfolios were also the five writing majors in my study.

${ }^{42}$ It is important to note here that in the two courses required for the writing major, expectations for the inclusion of multimodal compositions in the final e-portfolio were laid out in syllabi or eportfolio assignment sheets (and students in these courses reported likewise). Syllabi and assignment sheets from all other courses in this study did not include such expectations.
} 
working on two film projects, so [she] wanted this course to be [only] about writing." Bethany claimed that text and a few images was "enough" for her Wordpress e-portfolio: "We just needed to show how we progressed as writers, and I did that without needing to include audio or video." ${ }^{43}$ Regina reported that she simply felt "better about writing" and that she'd "rather it be on paper," adding that she was also "self conscious about video." ${ }^{44}$ And Eva, a sophomore nursing major, was satisfied with the Word-to-PDF e-portfolio she submitted in her 300level writing course.

Basically what we used in this class was text. There was a big focus on creating a sense of place, using good visual imagery through language, vivid description, showing not telling, you know, as if it were travel writing that would only be writing, not like it was National Geographic where you also get the fabulous pictures [laughs] and everything to illustrate what your talking about. I just threw in the picture [see Figure 11] because, well, who's gonna stop me $[$ laughs $]$ ?

\footnotetext{
${ }^{43}$ Bethany also reported that she found the Word document portfolio she submitted for a previous 100-level writing course "long," "tiring," and "overwhelming" for her "eyes to look at" while the Wordpress e-portfolio she created for this 200 -level course was "easier" and more "visually appealing" because, she said, of the chance the web-based portfolio offered to break up her writing into manageable sections and separate pages.

${ }^{44}$ Though Regina's e-portfolio was presented on Wix, she still referred here to the projects she included in it as "on paper" and considered herself a "visual learner" which she claimed made her "prefer text."
} 


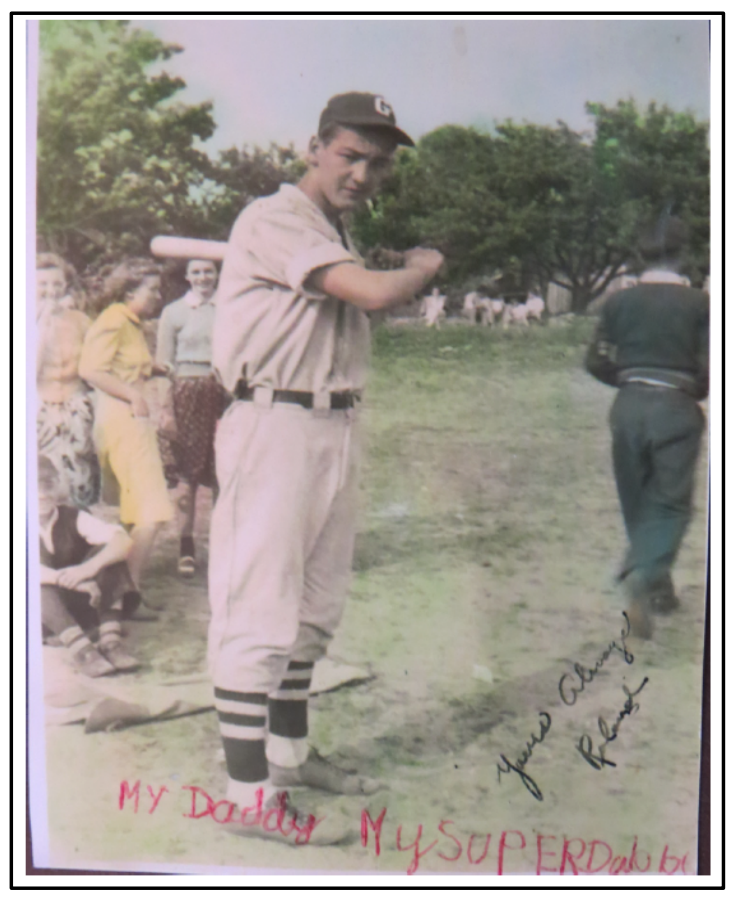

Figure 11: "An Old Picture of My Grandpa That Hangs On The Wall In My Room" (Embedded Original Image, Eva)

Even though Bethany reported that "writing [in text] can get boring for [her]," she still claimed that it was just "easier for [her] to write it all out." Valerie said something similar in that writing in a mode other than text would "take away" from her point and be "distracting" and that video was "too high tech" for her. Jean, who chose to create a Word-to-PDF e-portfolio for her 200-level writing course, preferred the fluency of a primarily textual e-portfolio (with one borrowed extension image):

I like how it's more fluent this way. You're not jumping through; you're just reading. I feel like if you had a hyperlink then you'd have to go check out this whole article, or you have to go watch this video, and when you're reading a paper, you just kinda wanna be in 
the paper. That's my opinion, so that's how I set it up for [the instructor].

Mary felt that, other than the alphabetic text and stock images from Wix, the modes of audio and video were "not needed" because "papers don't have sounds" and "video is a lot of work." Amy was concerned that writing in another mode would have detracted from her ability to hit the required word count for her eportfolio: "Even if I had the choice to do audio or video, I don't think the video or images would count as a word."

Evan, a sophomore writing major, working on his first e-portfolio in a digital writing course, was a bit of an anomaly. He was comfortable including text, images, and hyperlinks on his e-portfolio, as well as audio clips (via embedded SoundCloud links) of rap songs he had written, performed, and composed as part of a blog assignment for the course. Yet even with that level of comfort composing with and including these modes other than text in his e-portfolio, Ethan reported feeling like "a bad guy with technology" and that being asked to include a video would have been "intimidating" because he didn't know how to post it, he didn't know the program he would need to do so, and his past experience composing in an audiovisual mode (i.e. attempting to compose a rap video), he reported, "was a disaster." Still, Ethan reported that the most valuable thing he'd learned in his writing course was moving from what he called "2D" to "3D" writing. He thought it was "exciting" that e-portfolios had "an extra dimension" that forced him to think of writing in "a different style." 
Despite their multimodal anxieties, when I asked participants who had composed primarily in alphabetic text how they would feel about composing a project in a mode other than text or revising a project they originally composed in alphabetic text into another mode, very few students were closed to the possibility. Most students in the non-capstone writing courses reported being at least open to such opportunities, though some were a bit apprehensive. Ariel, for example, who told me emphatically that "writing is strictly words," still reported that the "option to do [writing in other modes] may have made [her] consider it." Amy was similarly open, but uncertain:

I probably wouldn't use [other modes] because I'm so bad with technology. ... I definitely like [words] a lot better, though it would be cool to see other people's portfolios and what they've done. It'd be cool to learn how to use it. If there was more guidance on how to do a video portfolio, I'd do it.

Most others, however, claimed that composing in modes other than text could have been "interesting" or "cool" and that they would have "enjoyed trying" to "get a break from a paper" or to "try something different." Ned, for example, said he would "definitely" have been open to composing an online video and thought it would have improved his first year writing e-portfolio greatly, especially because he had written a text-based research paper about online videos that he would have liked to have been able to revise into an online video. He encouraged me to teach multimodal composition because otherwise, students "probably wouldn't encounter [it] unless it was assigned." 
When I asked, Casey, a Biotechnology major who was less than enthusiastic about her Word-to-PDF e-portfolio experience, to describe what might have made the experience more exciting for her, she suggested that being able to compose in another mode, like audio or video —-"or PowerPoint"—might have helped. She said she "wouldn't mind" being asked to "break away from a big wall of text." And Jean, a junior who also created a Word-to-PDF e-portfolio of primarily text for her 200-level writing course, explained how multimodal assignments would be more useful for her: "If [they were] required—I'm a computer science major-I'd probably just do an entire website at that point. ... [I] could use that! This [her Word-to-PDF portfolio] is just gonna sit there and be done." And though Amber said that she preferred her 300-level writing class focus solely on writing-as-text, she still expressed an interested in the possibility of revising a text-focused project into another mode (or multimodal composition), drawing some sophisticated inferences between the invention and revision processes involved in both writing and film (her major):

It would have been more challenging, but I think that's something I would have liked in the long run. I do like watching ... how writing evolves when you translate it to different modes especially in film. When you start with a script, that script is going to look totally different once it goes through production ... The end result is the script evolves and it grows and I think that happens with any writing once you start reading [text] aloud and adding [modalities 
like video].... The choices you make on what to include are just as important as what you wrote [in text].

None of the senior majors expressed suspicion about multimodal composition and, instead, openly valued it. They also, by in large, employed more modes in their final e-portfolios and reported a much more sophisticated understanding of and a greater openness to the affordances of these modalities (in addition to alphabetic text) in my interviews with them. In the following examples, I will attempt to point to the stark difference between these senior majors' concepts of writing as/beyond text on paper as compared to those outlined above.

Though Charlotte struggled with the Wordpress e-portfolio technology and design aspects of her senior e-portfolio, she was still very clear on the value of online writing and reported her most valuable learning experience was directly related to that struggle. "So much writing is being done digitally," she told me. "It's good we were forced into presenting documents online." Indeed, she came to understand "documents online" and digital writing as something more than just alphabetic text on a screen or website in that, as she explained, e-portfolios "can successfully include projects you might not have considered because they are not primarily [text] based." Charlotte had an eclectic interest in various types of music that was reflected in the radio show she hosted each week and she was happy to have found ways to incorporate this audio interest into her e-portfolio (i.e. in the 
form of the audio introduction to her show; though it would be more effective to hear it, please see Figure 12 below). ${ }^{45}$

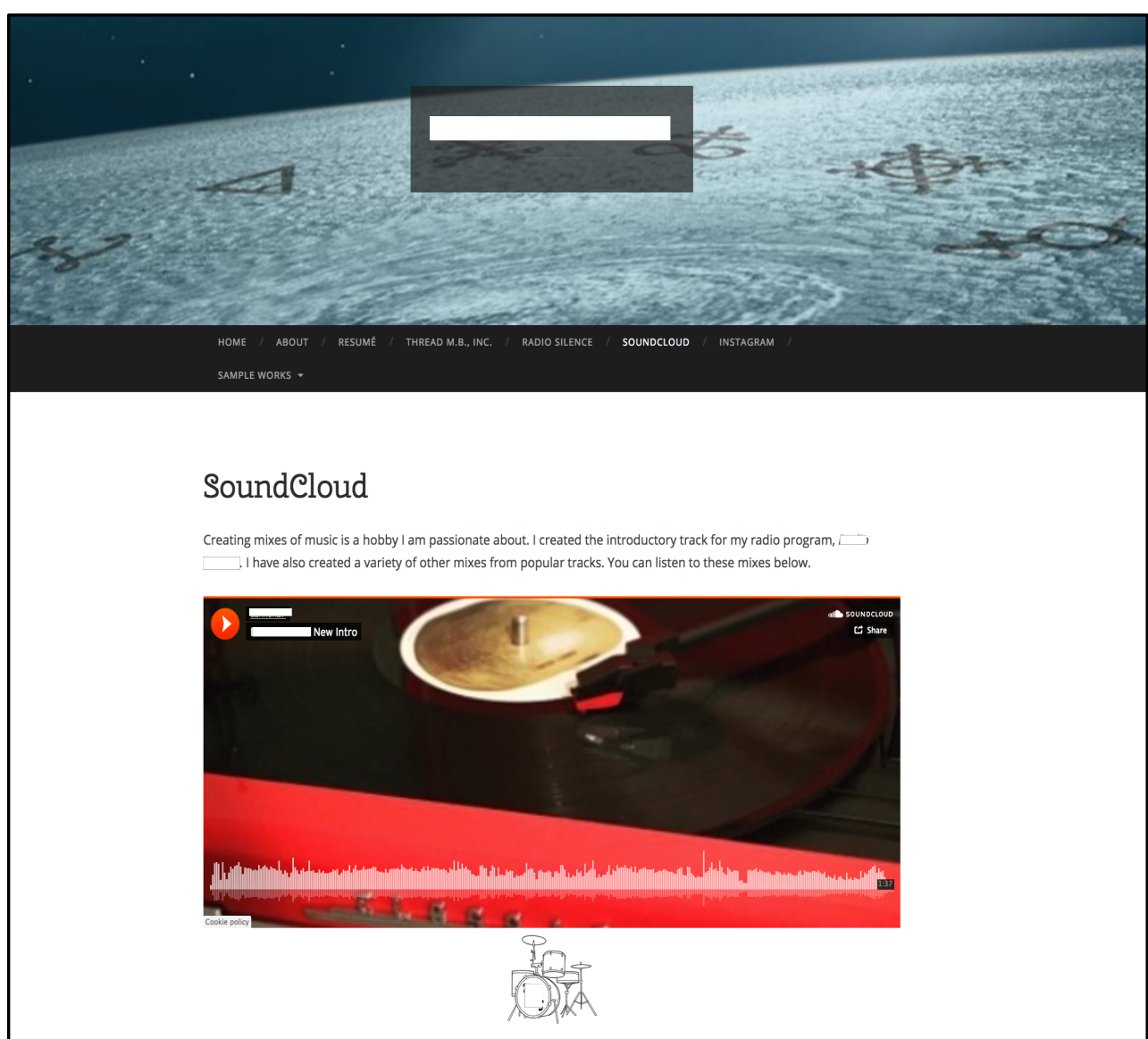

Figure 12: "I Created An Intro For [Our Show]. It's Kinda Crazy, Kinda Goes Along With How We Were" (Whole Original Audio Text, Charlotte)

In addition to audio, Charlotte was aware of and tried to balance visual and textual modalities in her final e-portfolio because she valued — and understood the value of - both. "Visual things resonate with people," she told me, and these "people" (her rhetorical audience of potential employers) played an important role in Charlotte's modal valuations.

\footnotetext{
${ }^{45}$ Charlotte also reported that she was awaiting an audio recording of her final show from a friend that she planned to add to her e-portfolio.
} 
I did try to keep things very visual. I'm not a person that likes ... to read long descriptions of things. I'd rather just see it. . . I'd rather see a flowchart. I understand it better. So I tried to marry explaining it [in text] so that somebody who likes to read things would understand and having visual[s] so that somebody who likes to see things can go, "Ah! That's what you like to do."

She also included slideshows of Instagram, Twitter, and Facebook posts she had composed "so [her audience] got an idea of what [she] like[s] to do on social media" as well as a self-published, online, multimodal, Buzzfeed article she wrote for an upper-level digital and feminist rhetoric course about her journey to feminism. The article included an infographic she composed (along with other borrowed extension images) "to show [she] can write in popular online platforms" (see Figure 13 and Figure 14). Charlotte considered it her "best writing," adding "it was the first writing I'd done in the major where I knew I was a writer." 


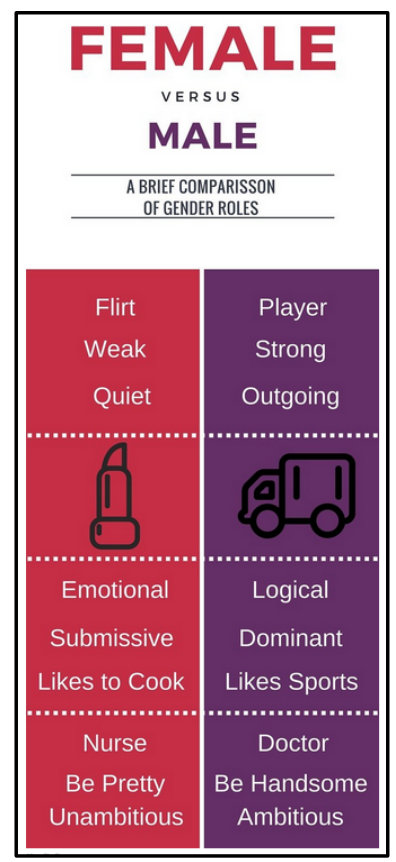

Figure 13: A Digital Artifact Charlotte Created As Part of Her Whole Original Text, i.e. Buzzfeed Article (Original Extension Image, Charlotte)

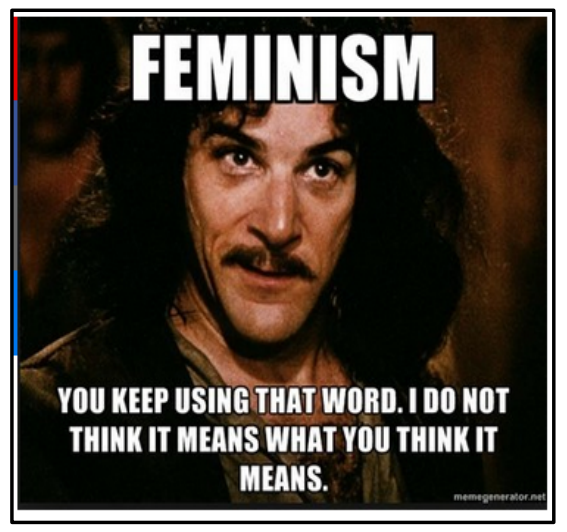

Figure 14: "I didn't want to hear that I was a 'man hater' or that I was only a feminist because I was a woman." (Quote from Whole Original Text, i.e. Buzzfeed Article; Borrowed Extension Image, Charlotte)

The other three senior majors were also very comfortable composing in various modalities and spoke often of the value of creating an e-portfolio that included and showcased such multimodal compositions. Katja, whose e-portfolio included all modes, explained to me that one of the most important things she "picked up from the [writing] program" is that "writing is just not writing anymore." She continued saying that "everything is so visual that if you haven't caught [your audience's] eye in the first two seconds, you've lost them forever." Holly loved working with the writing lab production software (available to students enrolled in upper-level writing courses) and used Camtasia and Adobe PhotoShop to create audiovisual and graphic texts for her e-portfolio to "make 
items look clearer and more professional. ... It's not quite writing and not quite film, but it does tie in visual elements and uses words to enhance the image." The importance of the visual-textual connection was a valuable take-away for Holly. She said she learned it in an upper-level technical writing course in the major: It surprised me to learn how writing is beyond words and that this major is beyond written communication — that it's also visual and oral communication. It was the best class I've ever taken and I fell in love with visual design because I realized it's such a powerful thing. ... Digital rhetoric is becoming a bigger thing. We are really in a digital age and more people need to learn these kinds of skills.

In fact, towards the end of the interview, Holly reported that one of the most important learning insights she had in her entire e-portfolio experience was coming to appreciate the value of that technical writing course and what she'd learned in it about digital and visual rhetoric, or the value of writing as/beyond text on paper.

\section{Concerning Design: Happy Places, Sneak Attack[s], and Retro-90s Designs}

The form, or design of their e-portfolios, also seemed to be an anxietyprovoking element or at least a preoccupation for several students in the study, even when instructors did not privilege the design features of an e-portfolio in their syllabi or rubrics. ${ }^{46}$ It was very clear, for example, that Ethan worried about how his lack of design skills would affect his final grade on the e-portfolio he was

\footnotetext{
${ }^{46}$ I did not ask any questions related to design in my interviews or in the reflective logs, yet half $(50 \%)$ of the participants reported some form of anxiety or worry over the design aspects of their eportfolios; one-third reported working on the design and enjoying it (even in a few cases where design was not a heavily-weighted expectation); and the remaining three participants did not mention any concerns or preoccupations with design at all.
} 
required to compose in his 200-level digital writing course. He spoke at length about how it seemed to him that the course focused primarily on design and less on writing (i.e. more on form than on content) and this caused him concern. "My writing in this [e-portfolio] is pretty interesting," he told me. "I think, verbally, it's pretty neat. But when I looked at the rubric, this 'skill with words' didn't factor into it as much as the design of it." ${ }^{47}$ To add to his worries, when Ethan presented a draft of his e-portfolio to the class and instructor at the end of the course for a workshop, Ethan was worried when the instructor called his design "retro, like something from the 90s," and felt that the class reception to it was otherwise "luke warm."

Similarly, Amy, whose entire e-portfolio was one, long page of text that included only a header and small image of herself at the top (see Figure 15), told me, "I am not that great with technology so it was hard to make it look nice or be easy to click through. I feel like that should be considered when grading these types of projects." The instruction sheet that Amy provided me with did not mention anything about the design or form of the final e-portfolio being a consideration in grading for this 100-level course.

\footnotetext{
${ }^{47}$ The e-portfolio rubric breakdown for this digital writing course was as follows: Completeness (15\%): Are all the required elements included?; Design (10\%): Does the portfolio demonstrate mastery of visual rhetoric (CRAP, Krug) studied during the term?; Home page (15\%): Does the home page clearly identify and target an audience, orient that audience, and introduce the portfolio's contents?; Polish, preservation, and presentation (30\%): How effectively do each portfolio item's wrappers guide readers, offer context, and demonstrate your capacity to reflect on yourself writer; Cohesiveness (30\%): Have you made the portfolio's various elements fit by weaving the portfolio elements and wrappers together into a coherent whole?
} 


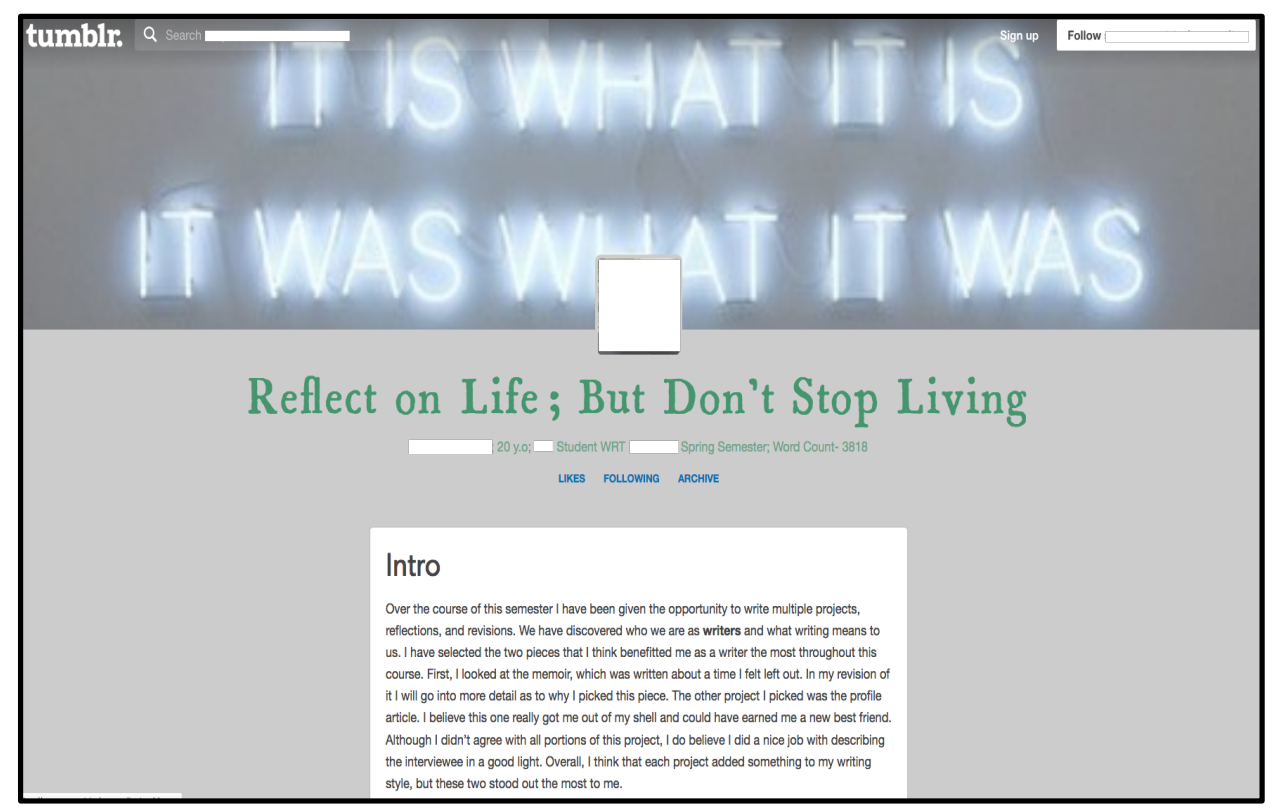

Figure 15: The Top of Amy's Tumblr e-Portfolio with 3,800 words of alphabetic text below "Intro."

Senior major, Charlotte, also reported feeling very anxious towards the end of the semester about what she called the "aesthetic portion" of her e-portfolio, even though such a portion was only briefly alluded to in the rubric for the final eportfolio. ${ }^{48}$ Despite having expressed confidence in her first log that her past experience with portfolios would "help [her] get a better grade" as she was "familiar, for the most part, with the portfolio-making website [Wordpress] and can manipulate the design and content layout fairly well," Charlotte claimed later, in her second log, that she was "having trouble getting [her] portfolio design locked in place ... [and] getting certain pages to do what [she] need[s]." In the interview, Charlotte spoke at greater length about feeling frustrated about the design of her e-portfolio and worrying about how that would affect her final performance.

\footnotetext{
${ }^{48}$ Design was actually mentioned in one place on the rubric for the senior e-portfolio. "Specific visual design choices support the portfolio writer's arguments about her work and herself" was listed as one sentence in the "Content Strategy" section, which represented 25\% of the rubric.
} 
For one, though Charlotte liked gaining the experience with the free version of WordPress and thought it looked much more "professional" than the Wix and Weebly e-portfolios she'd done previously, she liked better the themes offered in the paid WordPress version and found it difficult to "make [the] adjustments" she'd wanted to the free version themes. ${ }^{49}$ Charlotte reported having to neglect the aesthetic portion of her e-portfolio because it took her too long to grasp how to use the design functions of the CMS: "I feel like if [Wordpress] had been the standard for the other writing portfolios that I created, then I would have known where all that stuff was ... and could have been more creative and have gotten the things up there that I wanted [and] that I didn't get a chance to put up." ${ }^{50}$ In the end, Charlotte felt her grade suffered and expressed she had no intention of using her e-portfolio in a professional capacity (i.e. to get a job), in part because of these design struggles.

Several (5) novice e-portfolio composers, however, reported enjoying having an opportunity to lightly engage with the design aspects of their eportfolios and did not seem concerned at all about how their lack of experience might affect their grade. Often these students' references had a quality of lightness

\footnotetext{
${ }^{49}$ The issue of paying for the e-portfolio technology was a common refrain among senior majors (though I asked no questions about this). Charlotte told me that during the course she simply didn't want to pay for WordPress, but that in hindsight she wouldn't have minded it as a course fee upfront because, she said, that "gives you more long-term buy-in." Hope said she wished she'd "invested earlier in a paid subscription," and Katja wished she had access to the paid version, though she said she wouldn't have had the money to pay for it. "Can [the college] pay for something we have to use?" she asked. Holly found the free version "restrictive" and "limiting," adding, "If you want something that looks really cool, you have to pay a lot of money."

${ }^{50}$ It's important to note that this was coming from a senior who had worked with the CMS Wordpress before and who had over half a semester to design her e-portfolio. Most students in my study reported spending a week or less on their e-portfolios at the tail end of the semester (and often during final exams). See more on the issue of time for composing in Chapter 2.
} 
and ease, without too much critical thought. Mary, for example, who used Wix for the first time in her first year writing e-portfolio, explained that she most enjoyed "designing and making" her online e-portfolio, especially choosing the colors and fonts, and setting up tabs and pages. She said Wix was "cool" and that the design features of the CMS helped her make her e-portfolio "look nice and colorful." Similarly, Regina said she chose the "nature-y images" offered by Weebly to make her first e-portfolio "look pretty" and "nice" (see Figure 16). When I asked her about the particular images she chose, she responded, "they reflect some of my happy places, I guess. I didn't want to think too hard about it, though." Regina stressed several times that not having to "think too hard" about design was an element of the Weebly CMS that she particularly enjoyed.

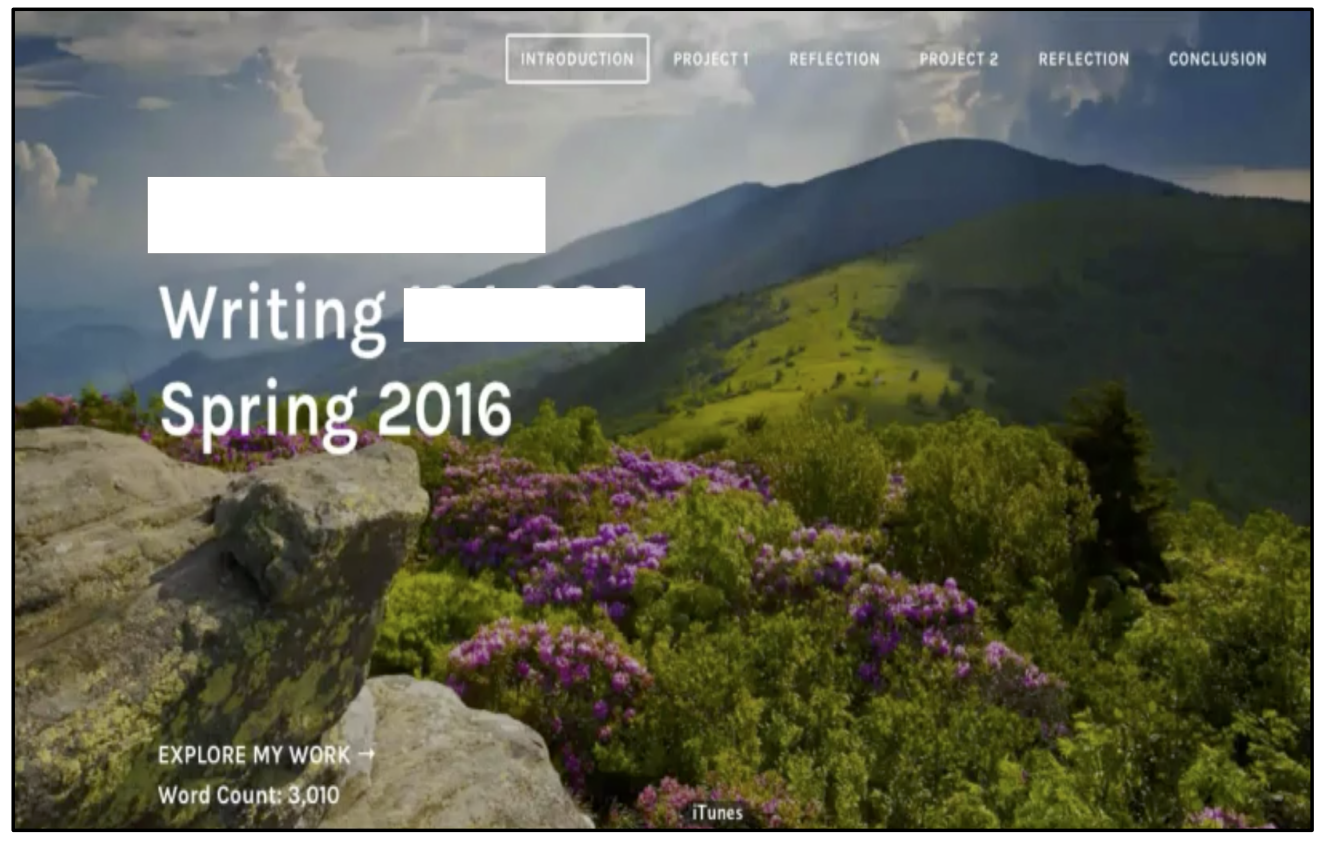

Figure 16: "I just wanted it to look pretty.... Weebly just offers them.... I guess it reflects some of my happy places" (Borrowed Ornamental Image, Regina).

Similarly, Bethany, who used Wordpress for the first time to compose her e-portfolio for a 200-level argumentative writing course, found the final product 
more "artistic" and "visually appealing" than the Word document portfolio she had previously composed for a first year writing course. She reported being "somewhat excited" for her final e-portfolio because creating "a webpage on Wordpress ... looks very cool." Though Bethany's text-centered web e-portfolio could have been easily converted into a Word-to-PDF document because of its modal simplicity, Bethany talked about the importance of having the option to choose a color scheme (white text on black background; see Figure 17) that was "the opposite of a Word doc" because it "was so much more fun." Bethany embraced Wordpress as if it were her own personal graphic designer, telling me, "It automatically said 'Hey, let's not make it white! Let's do this!' I picked this theme and it picked the color blue for me. . . It let me choose a theme, then did the rest for me." Not only did Bethany enjoy this design assistance, it also helped her compose an e-portfolio that she felt was "not crazy ... with pictures everywhere and things popping up" but that instead was "just simple, sweet, and to the point." 


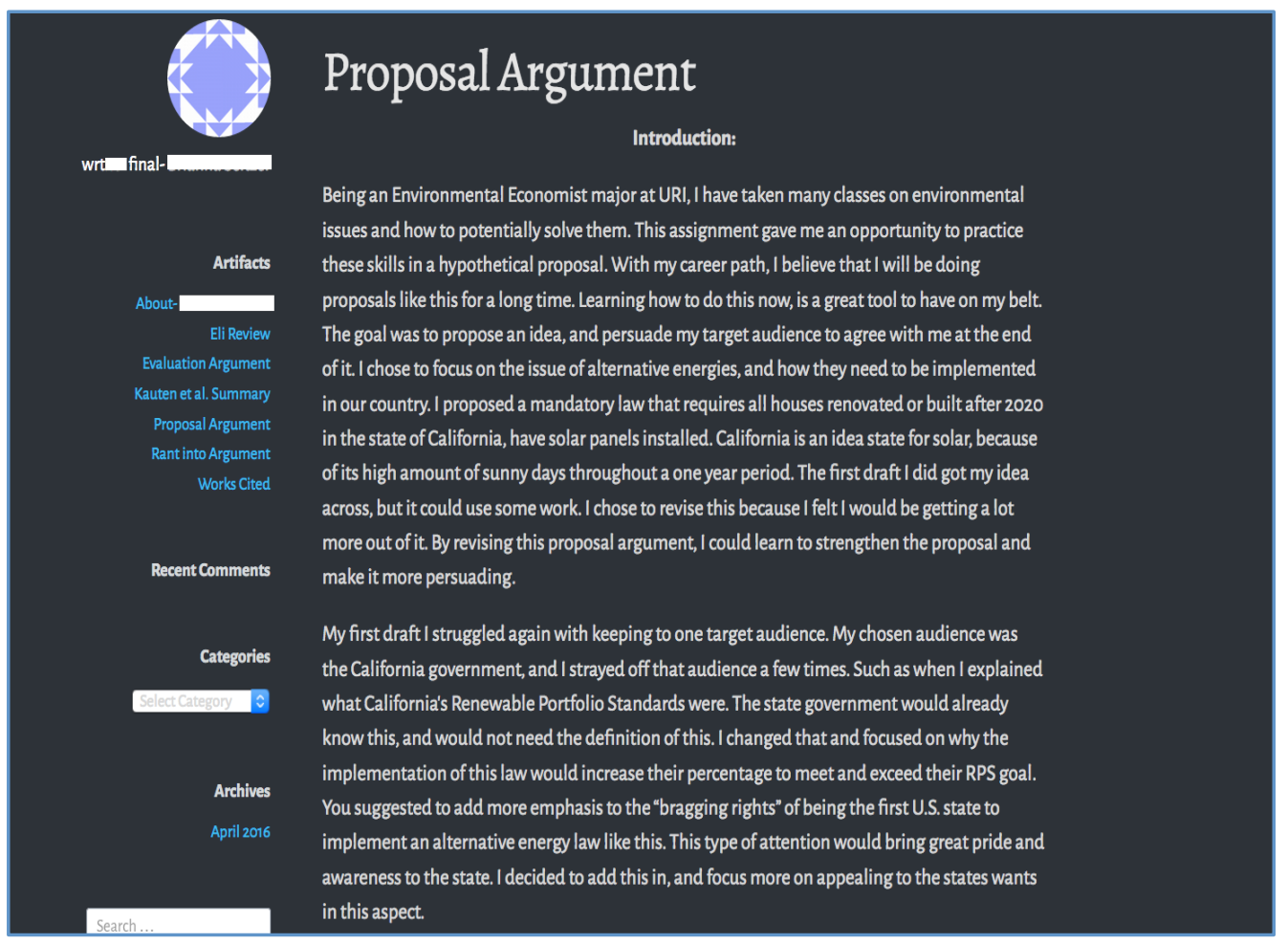

Figure 17: Bethany's Web e-Portfolio

Additionally, instead of having to read through a "long, tiring" Word document

that "overwhelmed" her to review before submitting it, Bethany reported that

being able to separate her e-portfolio into six separate pages (an introduction and five texts) made for an "easier" composing process: "I could read one page then take a break and go on to the next one ... a new page, a new set for my eyes to look at." She concluded that composing such an e-portfolio was something she would like to try again.

As a "very visual person" who "love[s] art," first-time web e-portfolio composer, Ariel, seemed also to have spent a great deal of time considering the design of her first year writing e-portfolio (more than any other participants in the first year writing cohort). She said she enjoyed that, with Wix, you could "literally customize every part of it" including where you wanted each "piece of text" to go 
and what clip art images to choose. Amber had a similarly positive experience in her 300-level writing course. One of the projects Amber completed and included in her Word-to-PDF e-portfolio (as an embedded URL/link) was a blog post about riding a bike in the rain (see Figure 18 and Error! Reference source not found.Figure 19).

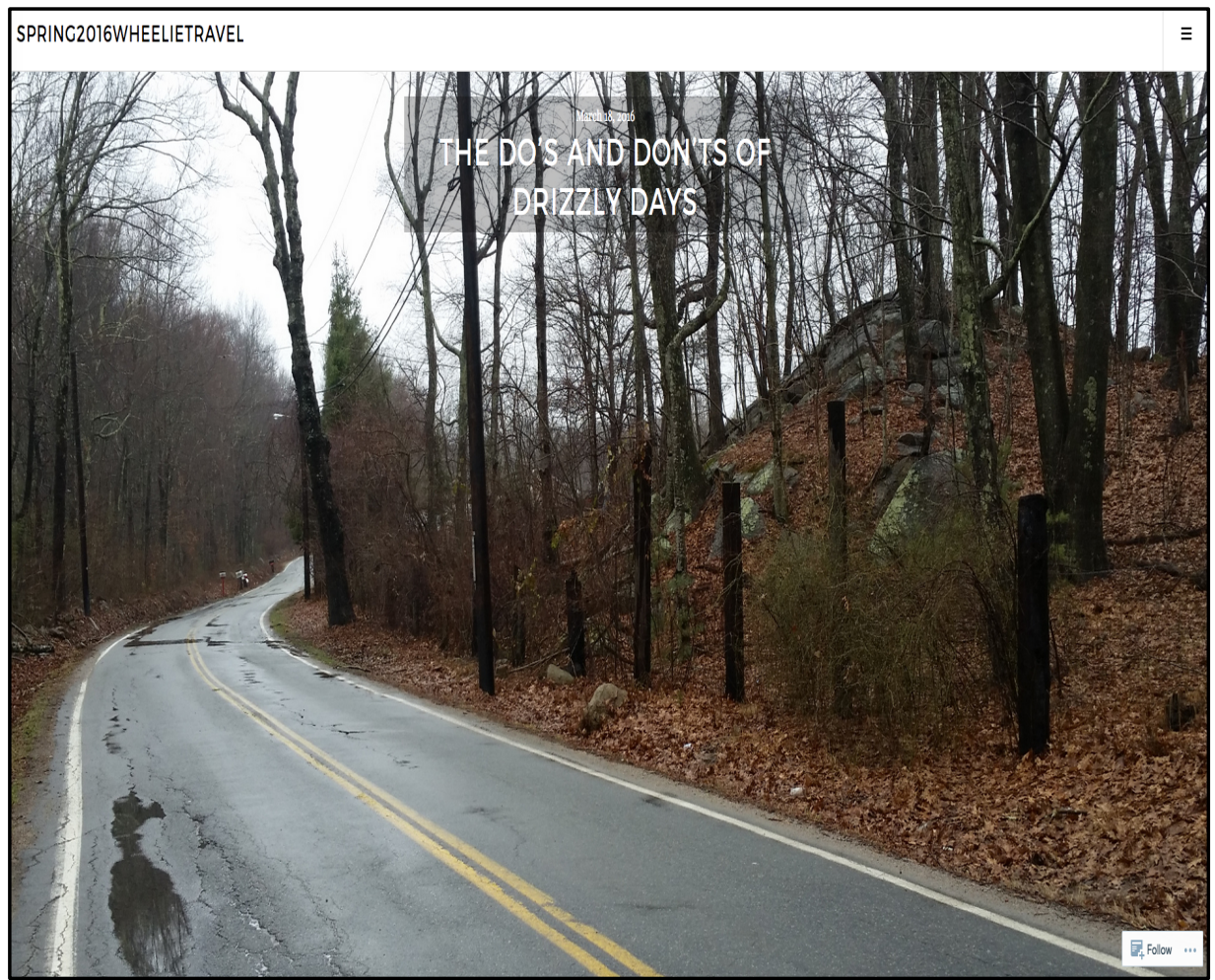

Figure 18: Amber's Blog 1 (w/ original, ornamental image) 


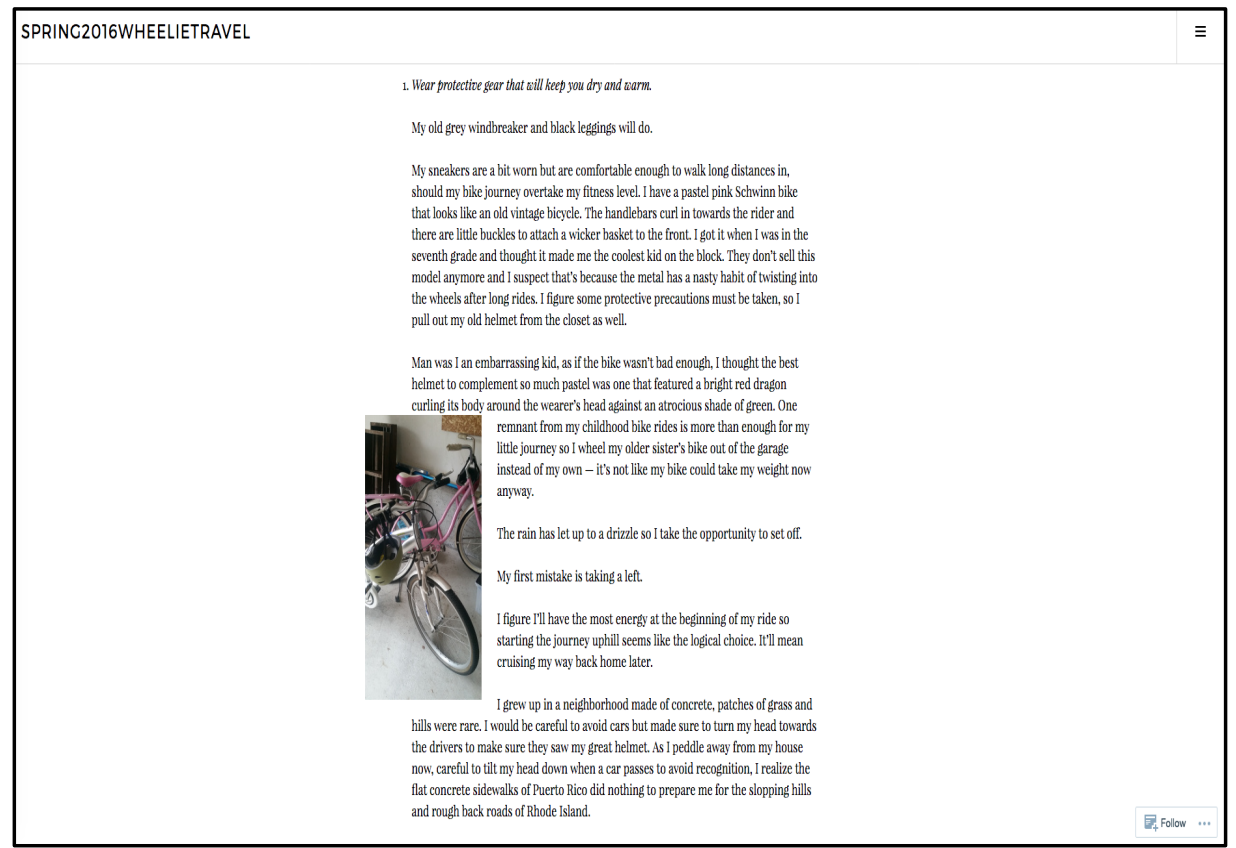

Figure 19: Amber's Blog 2 (w/ original, extension image)

Though she said she was challenged by blogging for the first time, Amber claimed that writing in this electronic environment "opened up some freedom" for her and allowed her to "play around a lot" with the structure of the writing. In going back to this assignment to prepare it for her final e-portfolio, Amber said she didn't have much to revise though she became very "conscious of how it would be viewed on screen." She reported enjoying "playing with formatting" of her blog, "letting lines [single sentences] sit by themselves," and "breaking up [writing into small] paragraphs." She also carefully considered —at the instructor's insistence-how to include and "keep images in mind" when writing the blog, but also, "not [to] be redundant." Already interested in design (Amber was a film/media major), this visual focus felt natural for Amber; "I enjoyed it," she reported. 
Other students, often those who had more experience with or confidence about web design, alluded to the tenuous balance between control and freedom when it came to the design aspects of the CMSs they used. Ned, for example, a freshman non-major who "knew a little code" and who had composed a web-based e-portfolio in high school, liked having control over how his site looked. However, he described with some dismay the images he chose to use for his e-portfolio as "just the best I could find," adding, though, that they at least "expressed the ideas he wanted" (see Figure 20).

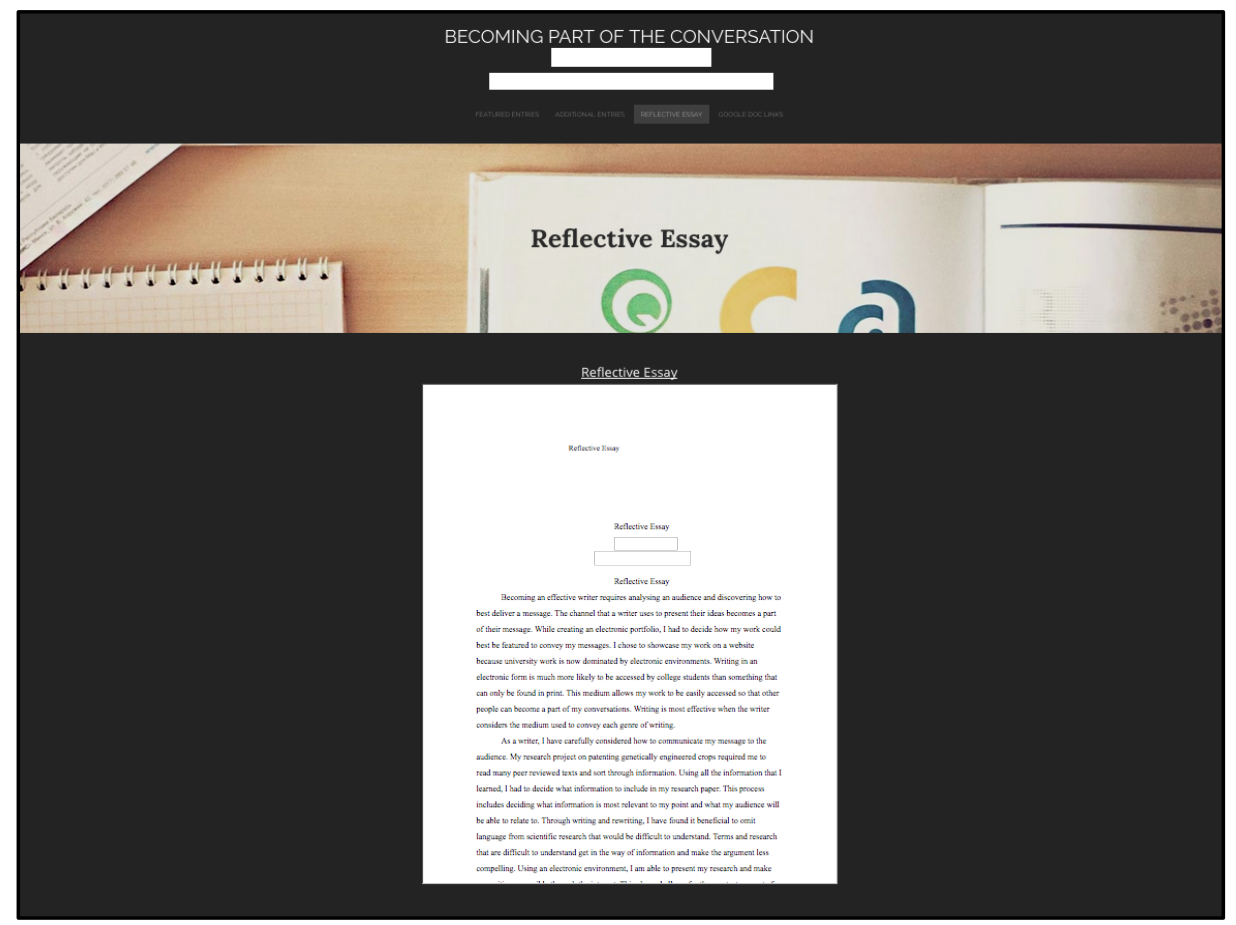

Figure 20: Ned's e-Portfolio

Ned referred a few times in our interview, however, to his concerns about wanting more design freedom, having it in some ways, yet still feeling constrained by other aspects of the CMS he used. When I asked how he felt about the technology, he said, 
It was fun to work with [Weebly], even though [it] did most of it for me. ... I felt more freedom than with the other option- $-\mathrm{a}$ GoogleDoc. There wasn't much you could do with that besides put the entries in there, whereas with [the CMS] you could choose what images to feature, where to put things, and how anyone viewing the portfolio could experience the portfolio. [Weebly] gave a lot more control over that.

Others students also spoke about the frustrations they felt in regard to the design constraints and limitations put upon them by the technologies they used to compose their web e-portfolios, especially where they felt not enough design control was in their hands. Julia, for example, who previously used Wordpress to compose an e-portfolio for her 200-level digital writing course, was frustrated by the way Wordpress "restricted her set up," especially when she attempted to design how her words appeared on the page: "visual prosity is very important to me," she said. She also felt the color choices offered by the CMS templates were "hideous" (see Figure 21). 


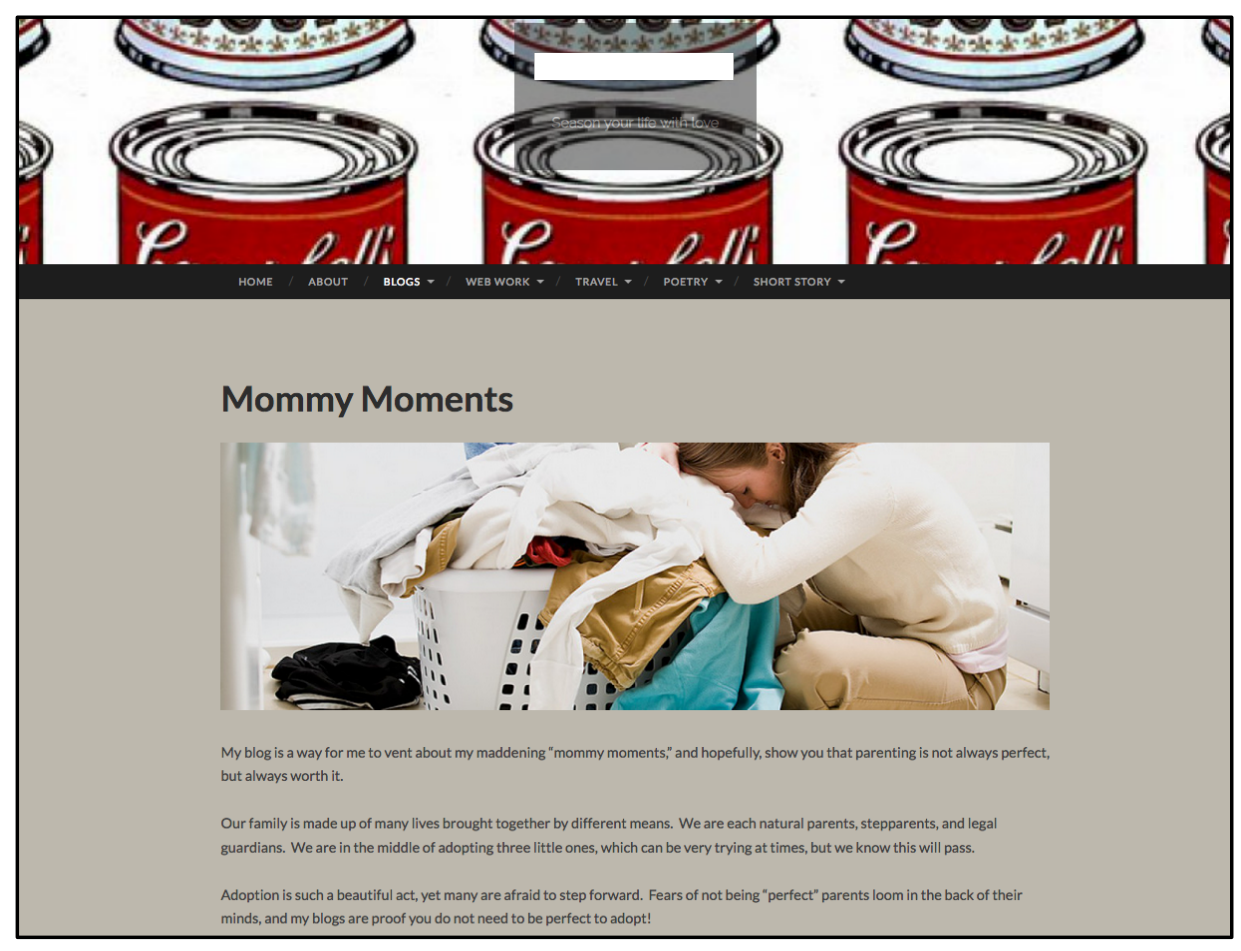

Figure 21: Julia's e-Portfolio

Senior major, Hope, said she generally liked the CMS Wordpress and its (free) themes because they "looked nice" and "even if you don't have a strong knowledge of HTML or any kind of web formatting, it just does it for you and it can still look good even if you don't know what you're doing." However, though she was by far the one participant in my study who felt the most confident about composing a web e-portfolio because of her extensive past experience with the required CMS, she still expressed that her biggest concern was "that it wouldn't look like [she] wanted it to." She called herself a "perfectionist" and said she had a clear vision "in her head" of what she wanted her e-portfolio to look like, and the way it finally turned out did not live up to that vision (see Figure 22). "Even now there's stuff I wish I could change but I can't," she told me, and she blamed the "limitations of the platform" for that. At the end of the interview, I asked Hope about the biggest 
challenge she faced in composing the e-portfolio and she said, "learning to do the things you couldn't do with the themes. Like with that picture [referring to a photo of herself on her homepage]. I moved it like seventy-two times [laughs] and it would not line up the way I wanted it to, so I just had to deal with it and let it go."

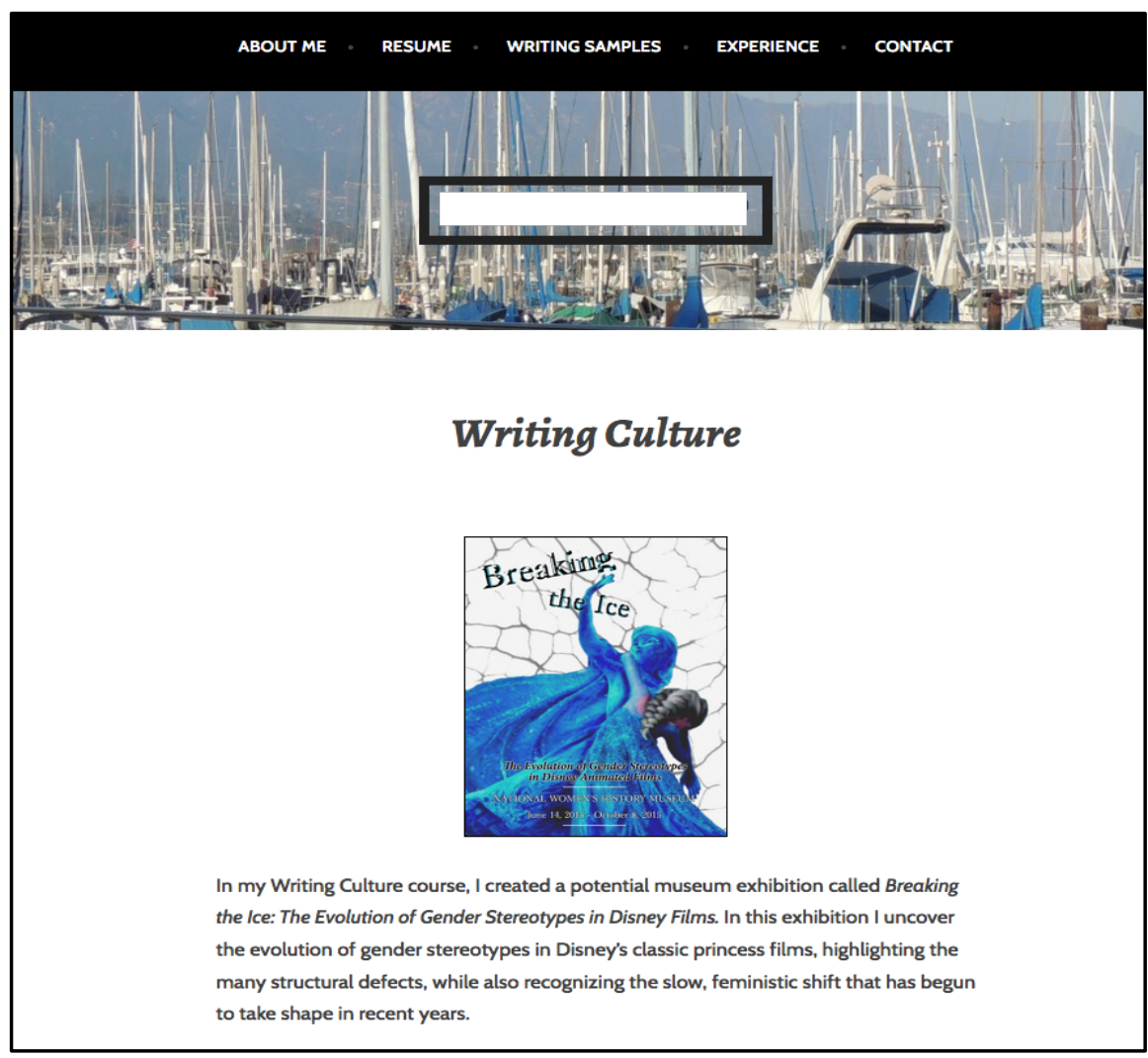

Figure 22: Hope's e-Portfolio

Similarly, Katja, a senior major who had a great deal of confidence about the design of her final e-portfolio, still reported feeling limited by the CMS she was required to use. Katja had ample technological experience and reported feeling "very excited" about her e-portfolio in her final reflection log, primarily because "the layout and design" was "coming together." Katja's e-portfolio was by far the most sophisticated in my study as far as design, and she often alluded to the 
time and effort she put into this aspect of her senior e-portfolio, explaining why she thought it was so important.

My site ended up looking different than everybody else's [see

Figure 23] because I went looking for something that would give me a lot more creative freedom to create something that looked like maybe I did it myself, that didn't just—you know—-[look like a] standard format Wordpress template.

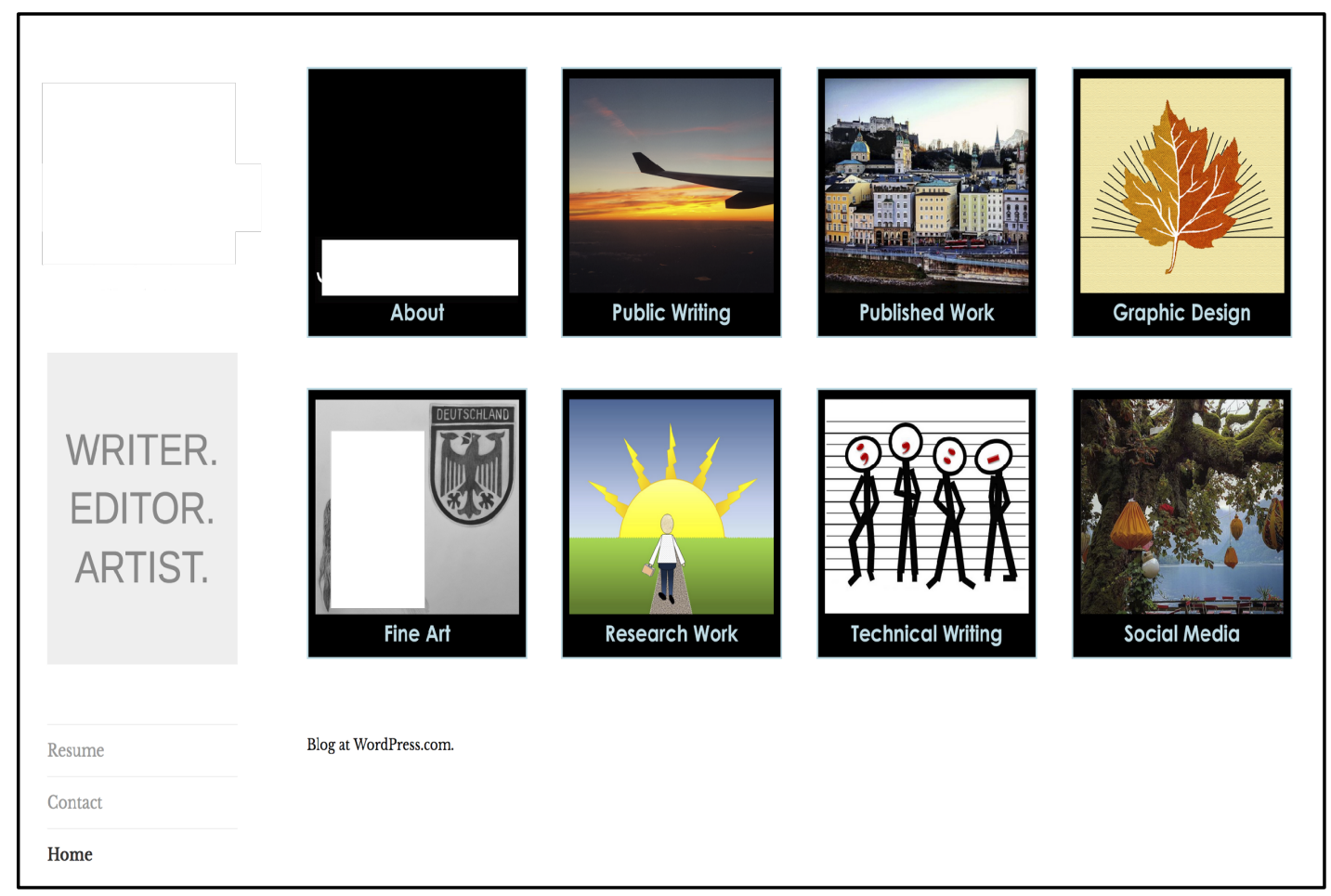

Figure 23: Katja's Homepage (all original art, photos, and graphics; self-portrait on "Fine Art" graphic omitted, though I wish you could see it—beautiful!)

Later in the interview when I pointed out to Katja that she was one of the few in my study to employ such a variety of modalities in her e-portfolio, she referred back to the design of her e-portfolio and her clear intention to blend form and content so she stood apart from her classmates. 
It was so important for me to do that. No job out there right now is just about one thing. ... You gotta be able to do it all. You have to think visually at the same time you're thinking about the message and how you're going to combine them at once into one thing that someone will read in two seconds and not get bored with. That's what I really wanted to go for. I feel like if you had ten Macs lined up [with all our senior e-portfolios on them], you're probably going to look at mine. Mine has got this weird grid where[as] everyone else's has a big header with their name on it. I think it draws attention. I think the images I chose also draw your attention, like, 'Oh, what a cute tree that is!' [laughs]. I just feel like you gotta dare to be different. You gotta stand out.

Katja described her design strategy as a "sneak attack." She said "words aren't usually the first thing to get your attention" and that by designing a portfolio that "played" her audience's emotion ("it's all about pathos"), Katja aimed to "draw you in with your heart then [she'd] give you the logical."

In spite of her design fervor and impressive background in art and digital design, however, and even after being one of three seniors selected to present her e-portfolio at the end-of-year showcase, Katja was still left unsatisfied with the design elements of the CMS she was required to use. Like other students in the study, Katja felt the free Wordpress templates were "limiting" and reported having to search far and wide to find one that suited her needs. And not only did she feel the burden of design under pressure, but she felt that requiring senior majors to use 
a particular CMS put unfair limitations on an important piece of their college career.

I felt confident with [the end product] . . but would have liked the option to be more creative. I'm happy with the results, but I had to learn so much [about Wordpress] and it was pushed off to the last few weeks. ${ }^{51}$ You couldn't negotiate [in regard to the required CMS] and I think the option for people who think they can push out should be there. I mean, I understand that in the workplace they're gonna tell you you have to do something a certain way, but as far as a portfolio to express our four years and more? I mean, the option [to branch out to other CMSs or build upon e-portfolios we've created in the past] should be there.

\section{Conclusion}

The voices in this chapter add yet another layer to the topography of technological experiences of the (primarily) Millennial students in this study $-\mathrm{a}$ topography of joys, tensions, and preoccupations. Student reports here suggest that new and intermediate-level college writers may still see writing primarily as a textual literacy and highlight their uncertainty about what other modes, beyond the textual, count as words. It seems also that while some students are reticent to move beyond a $2 \mathrm{D}$ concept of writing, most are either interested in attempting the move

\footnotetext{
${ }^{51}$ The issue of time for composing an e-portfolio arises here again. Most participants reported working on their final e-portfolios in the last week or two of the semester, except senior majors, like Katja, who had an entire semester to compose their e-portfolio and even they felt pressured to finish. See Chapter 2 for more on time for composing.
} 
to $3 \mathrm{D}$ —or multimodal—composition and are invigorated when they are pushed by instructors to do so, as indicated mostly by the voices of the seniors and writing majors in this study.

Further, the e-portfolio model seems to present students with varying levels of worry and enjoyment when it comes to the issue of design, particularly when students develop their e-portfolios using a CMS, or open source software, like Wordpress or Wix. Their insights offer a glimpse into the senses of freedom and autonomy and general enjoyment students feel in regard to the design features of their e-portfolio technologies as well as the constraints and limitations they sometimes come up against when "playing with" design. Evoking such personalized terms as freedom and restriction, these students compel us to consider the writerly selves they are able and unable to perform in their eportfolios as tenuously tied to the technologies, modalities, and design features they have access to.

These messy truths reflect those that composition scholars have contended with for quite some time in regard to the challenges of multimodal instruction and the e-portfolio assessment model. In 1998, for example, composition scholar, Jeffrey Grabill, presciently warned:

Writing is always already technological, and institutional systems (like writing programs) are dynamic and continually shape how we conduct our lives as writing teachers; institutional systems continually shape what is possible for our students. Simply put, we can't choose to ignore writing technologies, and furthermore, 
writing technologies matter so much to the identity of writing programs (and therefore what is possible in the classroom) that we must participate in the design of the technological systems available to basic writing. Technological design, in other words, is an avenue for agency, for changing basic writing. (94)

More recently (2009), Cynthia Selfe implored the field to recognize the importance of aural—and other modal—literacies by integrating them into our writing instruction as a way to get us to move beyond the dangerous limitations of text-focused literacy. One of her biggest concerns, which helps put in perspective the messy truths reported by the students in this study, is the implications that the privileging of writing-as-text has for us and our students:

When teachers of composition limit the bandwidth of composing modalities in our classrooms and assignments, when we privilege print as the only acceptable way to make or exchange meaning, we not only ignore the history of rhetoric and its intellectual inheritance, but we also limit, unnecessarily, our scholarly understanding of semiotic systems ... and the effectiveness of our instruction for many students.

The stakes for students are no less significant - they involve fundamental issues of rhetorical sovereignty: the rights and responsibilities that students have to identify their own communicative needs and to represent their own identities, to select the right tools for the communicative contexts in which they 
operate, and to think critically and carefully about the meaning that they and others compose. When we insist on print as the primary, and most formally acceptable, modality for composing knowledge, we usurp these rights and responsibilities on several important intellectual and social dimensions and, unwittingly, limit students sense of rhetorical agency to the bandwidth of our own interests and imaginations (618).

The student voices in this chapter indicate that privilege, identity, and agency —or, what I would argue are some of the most important features of students' writerly selves - are indeed tied up with the technological, design, and modal affordances and limitations students encounter in an e-portfolio experience. That students in this study seem to inherently sense this (or outright know it) is a messy truth with which writing instructors and program administrators must contend.

The next chapter will continue to explore agency and voice in students' eportfolio experiences, but with a focus on assessment, outcomes, and expertise. 


\section{CHAPTER 4: STUDENTS REFLECT ON CLASSROOM ASSESSMENT}

\section{Introduction}

Before entering a $\mathrm{PhD}$ program in writing, I served for fifteen years (19942009) as an English educator and teacher-trainer in secondary public school systems in several states. During my tenure, No Child Left Behind started up and moved into full swing and states were falling over themselves to write state outcomes and craft learning standards that would help teachers prepare their students to meet AYP (Annual Yearly Progress) on the standardized assessments and high stakes tests beginning to take over secondary education at a national level. Having spent many hours of my teaching career developing lesson plans and learning units based on such outcomes and geared towards such summative assessments, I became very interested in (and a bit anxious about) the learning outcomes initiatives and assessment practices also becoming a more common expectation at the post-secondary level. As I had so often wondered about the effects — both positive and negative — these assessments were having on me, my colleagues, and our middle and high school students, I began to wonder the same at the post-secondary level, particularly how those standardized practices and institutionally-developed initiatives were relevant, purposeful, and/or motivational to and for students.

In our field the portfolio is often lauded as a more ethical and thoughtful model of assessment that better represents and honors the discursive processes and practices that writing requires, or, as Kathleen Blake Yancey has claimed, it is a model that creates a "shift from a desire for the uniform replication of scoring 
practice to an assumed negotiation and acceptance of different readings" (1999, 491). In my first years as a graduate teaching assistant, I was hopeful about this communally negotiated and practice-based assessment model and particularly excited by its formative aspects, like frequent instructor feedback and peer review, and time for collection, selection, self-reflection, and revision. Yet after using the model in several of my own writing courses, I began to sense, as my participants Holly and Ethan, respectively, put it, that the e-portfolio method of assessment still caused students a sense of "high stakes" pressure and "overwhelm," particularly because, to return to Yancey, it is difficult to "bifurcate [a portfolio assessment] from [every other end-of-course, curriculum-based] high-stakes assessment" depending upon how and where it is located in a course curriculum, program, and institution (492). In other words, when there is so much riding on a classroom eportfolio assessment, it can tend to look and feel more like a summative assessment to students, like the final grades, exams, outcomes, and weighted percentages used in so many education settings and designed primarily to judge or score learning after it has happened (summative) and not to contribute to learning while it is underway (formative).

Therefore, in this study, I sought to understand how students' sentiments regarding e-portfolios as assessments compared to our own, paying particular attention to how students received its formative and summative components and to the writerly selves they enacted in regard to each. Because I was particularly interested in the stressors and/or motivating factors that students felt contributed to their feelings of confidence and/or concern about their e-portfolios as an 
assessment experience, I asked them several assessment-related questions, particularly in regard to what I'm calling in this chapter "The Four Pillars of College Assessment," or, weighted percentages, final grades, final exams, and learning outcomes. What follows is a report of the trends that emerged from this line of inquiry with the intention of gaining a more realistic and nuanced understanding of the ways students' e-portfolio experiences - and writerly selves —are shaped and influenced by these pillars of college assessment and the summative purpose they often, though not always, serve.

\section{Findings}

\section{Concerning Weighted Percentages, Final Exams, \& Final Grades}

In our interviews, I asked students how their final e-portfolios were weighted towards their course grades (see Table 16), when they found out about those percentages, and how they felt about them. ${ }^{52}$

Table 16: Weighted Percentages of e-Portfolio Final Grades

\begin{tabular}{|c|c|c|c|}
\hline $\begin{array}{l}\text { Percentages of Final Grade Students' } \\
\text { e-Portfolios Were Worth }\end{array}$ & Course Level & \# of Students & \% of Participants \\
\hline $20 \%$ & 200 - and 300-level & 4 & $23 \%$ \\
\hline $25 \%$ & 400 -level/capstone & 4 & $23 \%$ \\
\hline $30 \%$ & $200-$ level & 2 & $10 \%$ \\
\hline $40 \%$ & 100 - and 200-level & 8 & $44 \%$ \\
\hline
\end{tabular}

\footnotetext{
${ }^{52}$ I also collected students' course syllabi and instruction sheets or rubrics for their e-portfolio to confirm the accuracy of their reports.
} 
Additionally, I asked students if and how (or why) their e-portfolios felt like a final (i.e. summative) exam and to offer comparisons between their current e-portfolio assessment and some of the other ways their writing had been evaluated in the past (i.e. were those assessments more, less, or similarly difficult, confusing, frustrating, or anxiety-provoking and how?). I asked students, too, if, when and/or how they were made aware of their instructors' final expectations for the eportfolio (i.e. via rubrics, and/or other instructions) and if, how, and/or why they thought that awareness would likely affect their final e-portfolio performances (positively and/or negatively). Relatedly, I inquired about the time between when students were introduced to the specifics of the e-portfolio (i.e. when it was assigned) and when they chose to begin working on it after that.

In their first logs, I asked students to reflect on if and/or how they thought their previous portfolio experiences might affect their final e-portfolio grades in the current course. In the second reflection logs, as students got closer to the submission due dates for their e-portfolios, I asked them how nervous they were about their final e-portfolio grades (on a scale of very nervous, somewhat nervous, or not nervous) and to expand on their selected responses, adding, "Why do you feel this way?" And finally, in the interviews, I asked students what grade they received on their e-portfolios and how they felt about that grade, ${ }^{53}$ read back to students the levels of nervousness they reported in their second logs, and asked them if, how, and/or why their feelings had changed since their grades had been

\footnotetext{
${ }^{53}$ I was clear to students that they were not required to tell me, but all of them did.
} 
returned to them. I also asked students to reflect on any experiences from the course that they thought had the greatest impact on their final grades. ${ }^{54}$

The majority of students in my study expressed very little concern about the percentage of their final grades that their e-portfolios were worth. Though two first year students both said forty percent felt "scary" at first, they and the other students in that cohort (and at all other levels) reported that they generally felt "fine" with or "[were]n't worried about" weighted percentages in the end and/or claimed the percentages listed in the syllabi "made sense." Some participants even reported that they "didn't pay attention to [the percentage] until the end of class," or that they "[weren't] aware of," "didn't care about" or "didn't think much about" them at all. For example, Ethan explained that even though it was "a huge chunk" of his grade $(30 \%)$, most students, like him, still "tend[ed] to forget what percentage it [was] from the first day." ${ }^{55}$ Only a few students were taken aback by a percentage, like Bethany, one of the only ones who could tell me the accurate percentage upon request and who reported that when she first got the syllabus and saw her 200-level e-portfolio would be worth forty percent of her grade, she thought, "Oh my god! What does this exactly include?" However, she said that when she received the final instructions for the e-portfolio "two to three weeks before it was due," that percentage "made sense" to her because "it was the final."

\footnotetext{
${ }^{54}$ At times, when discussing a non-related issue or theme, students would bring up one of these three pillars of assessment. Those comments and insights are also included here.

${ }^{55}$ Indeed, several students needed time to review the syllabus during our interview when asked about percentages. For example, Eva's e-portfolio was worth twenty percent of her grade, which she guessed correctly but not before adding, "I mean, I think so? I really don't know. It's probably in the syllabus." And Casey, a first year student, was totally surprised upon finding out in our interview that what she thought was "twenty-five or thirty" percent, was, "Oh! . . actually forty percent!", adding "that seems a little overwhelming, almost half the grade! But in the end," she concluded, "it wasn't that bad."
} 
What caused such a preponderance of indifference to percentages is unclear (though perhaps fodder for another study), however, it is worthy of noting that despite students mostly not feeling bothered by those percentages, they still reported several concerns about the approaching end-of-semester e-portfolio as a summative assessment of their writing ability and learning in the course. ${ }^{56}$

About two-thirds of the students in my study reported that their final eportfolios did not feel like a final exam; the other third either said it felt like an exam or that it felt like an exam in some ways, but not in others. Some students in my study confirmed that the portfolio's focus on the more formative assessment aspects of revision and reflection had more calming effects on them. Valerie, for example, stated that it was "so much less stressful" to focus on showing her growth as a writer, which felt like a "break from an exam," especially because she was able to take the time she needed to finish it. Jean said her 200-level e-portfolio felt "a lot easier," like "writing another paper" which she "prefer[red] over exams." Julia said it didn't feel like an exam because she wasn't "answering from memory" or "compiling thoughts from different selections in a sit-down setting, or, orally." Instead, she claimed, aside from the "anxiety" she felt about the "platform" she was required to use (Wordpress), that composing her e-portfolio was a more "relaxed" experience than an exam primarily because of the focus on "revision," or having "the ability to go back and correct something that was a mistake or needed an enhancement," which Julia said, "eliminates that feel of a final exam."

\footnotetext{
${ }^{56}$ All e-portfolios in this study were required to be submitted for grading from students at the end of the semester and/or during final exams and were assessed by only the classroom instructor.
} 
A couple students, however, pointed to some of the more final exam-like, or summative, aspects of their e-portfolios, particularly in regard to some of their e-portfolios' more psychometric characteristics. For Amy, the e-portfolio "definitely" felt like a final exam because it was similarly "cumulative" (i.e. was meant to show "what [students] learned throughout the year") and would be "graded how the instructor wanted." Mary, another first year student, said the learning outcomes and the rubric they were given made it feel "the same as other assessments." And in her previous writing courses, senior major Katja claimed that her portfolio artifacts were always graded, making those e-portfolios "feel more like evaluations or exams" to her. In comparison, Katja explained how her capstone instructor didn't even comment on (and certainly did not grade) the artifacts she included in her professional portfolio, making it feel less so.

A few other participants pointed to some similarities with final exams but mostly to some welcomed, less anxiety-inducing differences. At first, for example, Ariel reported in her second reflection log that she was "glad [their] final [wa]sn't a written exam" and was "excited" to create her final e-portfolio because she "love[d]" having an "opportunity to ... put all of [her] work together ... in a creative way." In the interview, however, Ariel added that the e-portfolio did feel like an exam in that her instructor didn't "come up with" the learning outcomes upon which students had to reflect (the department did). In other words, the institutional(ized) learning outcomes made the e-portfolio feel more exam-like, or summative, to Ariel, though, otherwise, she claimed, it was more "expressive" than a typical final exam. 
Though the majority of participants in my study reported not knowing or even really caring about the often substantial percentages that their e-portfolios were worth, and only one-third felt an exam-like sense of worry about their final eportfolios, several students expressed concerns regarding their final e-portfolio grades. Indeed, with a month to two weeks remaining before their e-portfolios were due, two-thirds of the students in my study reported feeling very or somewhat nervous about the final grades they were anticipating [see Table 17 below].

Table 17: Participants' Levels of Nervousness About Final e-Portfolio Grade

\begin{tabular}{|l|c|c|}
\hline Perceived Levels of Nervousness about Their Final e-Portfolio Grade & \# of & \% \\
& Students & Participants \\
\hline Very nervous & 3 & $17 \%$ \\
\hline Somewhat nervous & 9 & $50 \%$ \\
\hline Not nervous & 6 & $33 \%$ \\
\hline
\end{tabular}

Students' levels of nervousness, however, did not directly correlate with their course levels, majors, or amounts of experience: students in upper level and first year courses reported all levels of nervousness, as did majors and non-majors, first time e-portfolio composers and veteran composers. Neither did their reported anxieties or confidence levels correlate to what grades they finally received, as most of the students in my study did very well on their final e-portfolios (i.e. received only As and Bs; see Table 18). 
Table 18: Final Grades Students Received on e-Portfolios

\begin{tabular}{|c|c|c|}
\hline Final Grades Students' Received on Their e-Portfolios & \# & of \\
& Students & Participants \\
\hline A or A- & 13 & $72 \%$ \\
\hline B + or B & 5 & $28 \%$ \\
\hline C or below & 0 & $0 \%$ \\
\hline
\end{tabular}

What did emerge with some consistency and/or persuasiveness, however, were some of the reasons for the particular anxieties and/or senses of confidence that students felt regarding this pillar of summative assessment. ${ }^{58}$

For some, concern for their grades detracted from the pride they took in working hard on their final e-portfolios. Ned claimed to be "proud of the work" he put into the writing projects and also "enjoyed the topics" he wrote about, but reported only being somewhat excited about his final e-portfolio because he was "nervous to have it evaluated for a grade." Eva, a sophomore in a 300-level course, similarly reported feeling "proud of the work [she was] putting into it" but "nervous" in hoping her "grade reflects [this work]."

Senior Holly believed the grading of writing to be a fraught practice that too often depended upon an individual instructor's preferences; it was something she disdained: "I don't like being graded on writing quality. Someone's opinion of writing is subjective. Some professors insert their own bias, quality of writing, or

\footnotetext{
${ }^{57} \mathrm{~A}$ few students reported that they were unsure of their final score on the e-portfolio because that grade had not been returned or given by the instructor, but that they guessed they must have received a particular score on it because of the final grade they received in the course. I used their educated guesses in this chart tally.

${ }^{58}$ I also report on some of the causes for students' concerns and confidence about their grades in Chapter 2, in particular those that had to do with support, instruction, and interpersonal connections.
} 
their opinion," adding an anecdote about a writing professor who she thinks gave her a B on a paper because that instructor "didn't agree with the content" of her project. Such personal judgment, for Holly, seemed to have neither a positive effect nor be an accurate measure of individual ability or talent. When I asked her about the ways her writing had been assessed in other (non-e-portfolio) contexts, she responded,

A bad grade on a paper or text makes you feel like you're dumb or a failure, but that's not always the case. Sometimes you're just not a good test taker. I'm not a passive learner. Sometimes in those other classes a teacher just stands up in front of the class and talks at you. I'm an active learner, so I need to be doing things and creating things, and I think it's more fair to assess students on their abilities rather than their memorization skills. A portfolio you can put creativity and diversity into it. You're being graded for so many other things. For me, it's better.

Though the formative aspects and opportunities for self-expression that portfolios offered Holly were appealing, the instructor's final assessment of her senior capstone e-portfolio wasn't what Holly really cared about:

Honestly, I was more concerned about what it would do for my future than for my grade. I don't know if any biases come in to the way you grade a portfolio the same way you do when you grade a paper, but showing my skills and capabilities for a potential employer was, in the end, more important because that's a long term 
thing. A grade is a grade. I once had an [11th grade English] teacher-I used to get really upset when I didn't get an A on a paper, because it made me feel like I wasn't a good enough writerand one time he said to me, "A grade doesn't measure talent. Anyone who just follows the rubric to a $\mathrm{T}$ can get an A, but that doesn't mean they're actually great writers."

For another senior major, Hope, who had extensive experience with graded e-portfolios, writing to evoke a summative judgment of success from a course instructor, or working for one single "grade on a paper," also felt "more daunting" than her present e-portfolio assessment. She was glad to have been working on a draft of her senior e-portfolio for nearly a year now, especially because the work she included in it "had already been graded" in previous courses and this meant her e-portfolio was more about "presenting [all the most successful projects together] as a whole." In other words, Hope felt less daunted by the prospect of presenting only writing that had already been deemed, or judged, successful.

The students who expressed little to no anxiety about their final grades nearly unanimously reported that they felt confident about how they would fare in their final e-portfolio performances because of how well they did on the writing projects and other assignments in the course leading up to the e-portfolio. Regina, for example, told me, she had gotten "a lot of positive feedback" on her writing throughout the course. Mary said that she got "A's all the way through" and so she didn't "see how the portfolio would be any worse." She also felt her teacher was "nice" and didn't "like to give bad grades," so the personality or character of an 
instructor was also part of her valuations of grade anxiety. Valerie, one of the few students who said the weighted percentage seemed "scary at first," reported feeling "not worried" in the end about her grade because she "got 100s on [her] essays." Amber said she "wasn't really worried about" her e-portfolio because she "had pretty good grades already," and Casey reported not being nervous about her final e-portfolio grade because she knew she was "doing well" in the course. When I asked her what grade she received on her final e-portfolio in the interview, Casey said, she didn't know and didn't really care: "I got As on most of my papers. I was confident that I was going to be fine."

For some respondents, strong performances on previous portfolios were a positive indicator of their upcoming performances. Katja, a senior major, reported in her second reflection log that she felt "very well prepared" to complete her portfolio and "earn an excellent grade" (which, as it turns out, she did) because she had "earned As ... on all [her] previous portfolios." Similarly, Bethany, a junior non-writing major, reported feeling "well prepared" because she had "done a portfolio in a previous writing class, and did well on that one." Likewise, Bethany reported that she "didn't feel as worried or burdened by" the upcoming assessment of her work in the present course because the grades on her projects were good, which helped her feel she had a "handle on everything."

This trend was conversely applicable in a few student's cases. Julia's perception of her inadequate course grades, for example, led to her feeling "very nervous" about her final e-portfolio grade because she had "yet to [receive an A] in this class" on a project. Jean described how her initially high level of confidence 
was eroded because of a perceived deterioration in her project grades leading up to the final e-portfolio. Jean reported feeling "well prepared" for her final e-portfolio in her first reflection log, writing, "I have done [an e-portfolio] before so, I feel like I am just repeating what I have done," and adding that she did "well on all [her] paper[s in this class] so, [she couldn't] see the online portfolio affecting [her] grade." Towards the end of the semester, however, she wrote in a second log that she was "somewhat nervous" about her e-portfolio grade because her final project "didn't get as nice of a grade as [her] previous one(s)," which suggested to her that she had been "doing a good job, but now [she was] worried."

For one particular student in my study, receiving high grades on her class assignments and projects leading up to the final e-portfolio actually reduced her motivation for completing it. Eva said her 300-level e-portfolio did "not particularly" feel like a final exam because she did well on all her projects leading up to the e-portfolio, so, for her, she said, it would not be "a grade boost" like she thought it may have needed to be for other students in the course. Eva reported being "not nervous" about her final grade, stating, "I'm doing well in the class and I don't have any idea how the good work I've done could be graded down in a resubmission, unless this portfolio system has something really wrong with it." In the interview, Eva explained to me that in having received high grades on her papers she was, therefore, not compelled to work on or revise them for her final eportfolio. Though she noted that she probably could have revised one of her projects for her final e-portfolio, when she got it back from the instructor with a

\footnotetext{
${ }^{59}$ See more on Jean's deteriorating experience in Chapter 2, the section on Instructor Expectations.
} 
grade, she said to herself, "It's a B+. Why should I revise?" ${ }^{60}$ Eva couldn't say what she eventually received on the portfolio, except she assumed it was an A because that is what she received in the course and reported thinking her portfolio made no difference to her final grade. "It didn't do anything to my grade, didn't improve my writing to do it. I had put in enough work to begin with, so I didn't have to do too much revision. I messed around with structure a little, but nothing major." In fact, Eva wondered several times in our exchanges about the overall purpose of the portfolio. When asked in the second reflective log what she hoped to learn by the end of her writing course, Eva wrote, "Why? Literally, why does this thing [the portfolio] have to exist? It's like being double graded, which would be fine if I wasn't doing well in the class and needed the boost, but I am doing well and it just seems like extra work" (my emphasis). In our interview, she expanded on this sentiment:

I would have preferred not to have done it . . It didn't feel relevant to me . . . because of my grade. If I had been getting a B, I would have put a lot more work into the portfolio, to try and kick it up. Eva suggested that for students like her, who received good grades throughout the course, the portfolio was unnecessary, "but [that] for others not doing so well, it would probably help."

\footnotetext{
${ }^{60}$ Brian Huot (2002) has warned about the effects of offering grades alongside revision suggestions on student writing, saying that, for students, summative judgments will often trump formative feedback: "Giving students an A or B, even when we suggest revision, probably doesn't encourage them to revise, because the grade itself carries more weight as an evaluation than what we can say about the need to revise" (167)
} 


\section{Concerning Institutional Learning Outcomes and e-Portfolio Reflections}

Students in my study who took either of the two first year writing courses or the 200-level argumentative writing course offered by the university were required to compose a reflective text as part of their final e-portfolio assessment. A major portion of those texts required students to reflect on their progress towards the established learning outcomes for the courses. Though linked to a final summative assessment in that the students' reflections would be part of instructors' considerations about the overall e-portfolio grade they assigned students, writing reflections as part of the portfolio process is a commonly accepted formative aspect of the model. The consequences, insights, and messy truths students reported in regard to this particular approach to the e-portfolio reflection, reveal some tensions between its formative and summative purposes.

At the time of my study, the first year writing outcomes were as follows:

Table 19: Learning Outcomes for First Year Writing Courses

\section{Learning Outcomes for First Year Writing Courses}

Upon completion of this course, students will have gained experience in the following areas:

1. Understanding of Rhetorical Situation

a) Students recognize that different rhetorical situations (audiences, purposes, contexts) call for different types of writing.

b) Students practice different types of writing appropriate to different rhetorical situations (audience, purposes, contexts). 
c) Students reflect upon and explain the appropriateness of their choices for the rhetorical situation.

2. Composition Processes and Practices

a) Students recognize differences between revision and editing.

b) Students practice various methods of invention, collaboration, research, ethical incorporation of sources, peer review, and revision.

c) Students describe and analyze their different methods of invention, collaboration, research, ethical incorporation of sources, peer review, and revision.

3. Conventions and Craft

a) Students recognize standards of correctness, usage, and style.

b) Students practice a range of styles, registers, and conventions.

c) Students revise and edit their work to produce polished texts that meet the demands of the rhetorical situation.

The 200-level argumentative writing courses in my study had the following outcomes:

Table 20: Learning Outcomes for the 200-level Argumentative Writing Courses Learning Outcomes for 200-level Argumentative Writing Courses 
Upon completion of this course, you will have:

1. Gained experience in writing effectively, speaking effectively, and working with qualitative data (i.e., visual elements).

2. Learned about kinds of arguments, the appeals, and fallacies.

3. Practiced techniques for structuring and supporting arguments.

4. Gained skill in analyzing others' written arguments.

5. Sharpened your ability to support your arguments with evidence from sources, documented correctly.

6. Produced convincing written arguments.

7. Given valuable feedback to the writing of your classmates.

8. Demonstrated your learning in a portfolio.

The first year writing outcomes had been collaboratively developed by the writing faculty to reflect best practices in composition pedagogy. ${ }^{61}$ All instructors were familiar with and supported in teaching "to" these outcomes through the required or suggested textbooks, trainings, and support materials. The 200-level outcomes were at least shared in common by the instructors in this study and included in their syllabi, which were approved by the writing department. In other words, these outcomes were created by, approved, and implemented via institutional mechanisms and actors, so when I mean to allude to this fact, I will refer to them as institutional learning outcomes (as I did in the title of this section).

\footnotetext{
${ }^{61}$ The first-year outcomes were developed in 2009 and based largely upon the CCCC Position Statement "Principles for the Postsecondary Teaching of Writing" which can be accessed at the following URL: http://www.ncte.org/cccc/resources/positions/postsecondarywriting.
} 
At the time of my study, all first year writing portfolios were worth forty percent of each student's final course grade and, in addition to the reflective text, needed to include two to three revised versions of the four major writing projects students worked on over the course of the semester (i.e. a memoir, proposal, annotated bibliography, persuasive argument, and/or etc.). Though exactly what portion of that forty percent the reflection was worth varied from instructor to instructor, the institution clearly valued a first year student's ability to understand and reflect upon the outcomes. I, however, wondered if and how it was a valuable part of the e-portfolio assessment to the students, particularly the requirement for students to reflect on institutional learning outcomes. So, in my interviews, I asked students to first read aloud the first year writing learning outcomes and then followed up with the following questions: How did you feel about these outcomes? Which do you feel you improved upon the most? Which were difficult for you (and why or how)? Was there anything you felt you learned that was not part of the outcomes for the course? In other words, what else did you take away or think was valuable for you in this e-portfolio experience? Several students also commented on the learning outcomes when I asked questions about the reflective elements of their e-portfolios. For example, when I asked them the following questions: What was your main intention in writing this reflection? Who or what influenced you to write it the way you did? Was their anything particularly difficult, frustrating, or confusing about writing it? What did you enjoy? Though I asked these questions of all participants, only those in the 100- and 200-level writing courses were required to reflect on institutional learning objectives as part 
of their e-portfolio. Therefore, the following report of students' responses to the questions will focus solely on that group of students.

Three of the ten students in this cohort had positive reactions to the institutional learning outcomes, seeing them as confirmation of their comprehension and learning in the writing course. Though still a primarily summative reflection, engaging in a reflective act of writerly self-evaluation had valuable formative properties, too: it helped students understand something about their growth as writers and learners. As Ned explained, he read them at the beginning of the course, but had forgotten about them until having to write the reflective essay. Upon returning to them to write his final reflection, Ned noted that they were an aid to his confidence and helped him be "targeted" in his reflection. "It was nice to see that I really had done some of these things in the course and I could think of examples immediately," he said. Similarly, Valerie said that she'd forgotten about the outcomes until required to reflect upon them at the end of the course. When she began to write her reflection, she realized, "Wow! I already know most of these outcomes and I didn't even realize that that's what I was doing," and that she'd "really grown." She referred to her reflection experience, then, as "kinda like learning in disguise" which, she reported, "was pretty cool." Bethany said that reflecting on the 200-level learning outcomes was an important part of her e-portfolio experience. They helped her feel confident that "at the end of the class [she] definitely got all the goals" and wrote as much in her reflection, which concluded 
I have improved as a writer tremendously. I have learned so many valuable tools to use in my future college and career path. All of the artifacts I have chosen show my strengthened writing abilities. From creating a brand new argument paper, to revising and strengthening another. This portfolio definitely meets the goal set, "demonstrating your learning in a portfolio." I am certain that all artifacts will showcase how much I have learned in this class. I am excited for you to read all artifacts before and after portions and see what I am talking about. Enjoy!

Bethany didn't complain about any outcomes in the interview and only expressed that they were a helpful barometer for how well she did in the class (she received an A). More importantly (as I will refer to later in this section), Bethany's eportfolio reflection on her learning in no way seemed painful or stifling of her writerly self.

Though these three students generally felt the outcomes gave them direction and confidence, the two first year students, Valerie and Ned, still reported facing some challenges with them, and the other seven first year student writers in my study were generally less positive about the learning outcomes. Valerie, for example, wished that there had been more discussion about and explanation of the learning outcomes in class and that the instructor had given examples of integrating them into a reflection. She also thought that they could have been broken down into smaller parts. Relatedly, Ned felt that nine outcomes were "too much," that they could be simplified or combined. 
Mary was the most disconnected from the outcomes and as she read them in uncomfortable fits and starts to me, she made several comments about not knowing "how to apply them," which she said led her not to choose to reflect on several of them (first year students were only required to reflect on a minimum of five of the nine outcomes). While trying to describe to me why they were difficult to include in her reflection, Mary gave the example of students being able to "recognize differences between revision and editing" (2a) and said, "I mean, I don't know what the difference [is] —aren't they the same thing?" As evidenced in her eportfolio, however, Mary had both revised and edited her final drafts before submitting them, yet she was neither able to point to evidence that she revised and edited nor able to make the distinction between the two in her reflection or in our interview. Similarly, Casey told me that she wrote in her portfolio reflection that she understood the difference between revising and editing and that she engaged in these practices often. However, in our interview she reported that she didn't really understand the difference, saying only that she thought "one of them is global, one is smaller scale," but she couldn't say which. She also told me she did not revise or edit her final portfolio projects much at all.

Some students described reflecting on the outcomes as feeling forced and uncomfortable. For Regina, for example, "it was a little weird." She reported that because the outcomes were not covered explicitly in the class until the end when the reflection was due that "they came outta nowhere and all of a sudden we just had to start applying them." She described the experience of incorporating the learning outcomes into her reflection as "awkward" because they "really disrupted 
[her] reflection process" and didn't allow her to write "what came to [her]." Regina explained that when she finally included the outcomes, they "stuck out like a sore thumb."

Ariel mentioned engaging in a similar exercise of reflecting on learning outcomes (which she referred to "SLEs") as part of an e-portfolio requirement she had to fulfill to graduate high school, so writing about outcomes was not a new experience. Ariel described the process of reflecting on learning outcomes as "robotic" and said that having to include them made the e-portfolio feel "more like an exam or assessment" because she had to include them in such a scripted and overt manner. "I literally labeled it, like, '2b' and 'c4,'" she said, using an exaggerated tone to state the numbers and letters of the outcomes, and described how she created a page completely separate from her other reflective elements so that she could be sure to cover the outcomes as required. "I wanted to really drill in the fact that I met those learning requirements . . . I wanted it to be structured so that I got the credit for doing them." When I asked if she got anything out of the exercise of reflecting on the learning outcomes, Ariel replied tentatively, "Probably?", adding, "So many of them [seem] the same." She did suggest that she felt she was learning the field's terms, like rhetorical audience, which, she said, she understood as a concept but didn't know the official name for. When she learned that it meant people, who, "like, see a flyer that's for a yard sale and not everyone's going go to the yard sale, but the people that want to go are going to act on it," she said it "ma[de] sense." Ariel felt that the required outcomes were ones she likely would have pointed to anyway. 
Assuring that the outcomes stood out in order to receive proper credit for reflecting on them was a common theme. Casey, who called the outcomes "pretty straightforward" and said she could "see how to connect them [with her writing progress reflection] after thinking about it," chose to boldface the learning outcomes within her reflection in order to, as she stated, "make them stand out so the reader would be able to focus on them more." When I pressed her to define this "reader," Casey quickly responded, "the teacher—-that's the only reader there's gonna be." She went on to describe the challenge of making sure her reflection "tied ... to each learning objective." When I asked her why this was a challenge, she said, "because you have to make it work for [you]-like-you have to fit your exact situation into each of the objectives where it might not-you have to kind of stretch it a little bit to make it work." Whether Casey actually made progress towards the learning objectives was less important to her than being sure to include them in her reflection and make it seem as though she made progress in them, and all for her target audience: the instructor.

Not all students, however, were so explicit. Amy, for example, tried to avoid stating the outcomes directly, because she said "that was too cookie-cutter and not fun to read." Amy said she generally avoided stating the outcomes directly by first reflecting on each of the projects she included in her portfolio, then, later, as sort of an after-thought, she attempted to restate and covertly integrate them into her own reflective writing. For example, in her reflection she wrote,

I allowed someone to look over my paper and described to them what I was looking for. I wanted someone who would revise it, not 
edit it. I didn't need help with the grammatical errors in my paper, those are easy enough to catch. But I did want help with what to get rid of or add to the paper.

In this example, Amy shows evidence that she understands the difference between revising and editing (2a), but she neither recites the outcome word-for-word nor states overtly that she knows - or learned — the difference between revising and editing. This type of agency in relation to the institutional learning outcomes, at least in students in the first and second year writing courses focused on here, was rare in my study.

Towards the end of our interview, Amy suggested that the outcomes "be worded completely different," adding that they felt too "out of the book" and that they were "talked about differently in the class." Instead, Amy suggested that the integration strategy she took should be part of the first year writing course:

"I think [the institutional learning outcomes] should be rewritten, that we should spend a day in class where we go over all nine and we have [them] rewritten in a more coherent way for all the students in the class." Though Amy was able to do this re-wording of the outcomes on her own, most first year students in my study did not take such risks.

Perhaps a similar lack of agency led the other two students in the 200-level argumentation course to reflect on their learning and the outcomes in a tentative and forced manner. ${ }^{62}$ Carol, a sophomore Communications and Public Relations

\footnotetext{
${ }^{62}$ These students had both previously taken a first year writing course at the university in which they had composed e-portfolios with similar requirements for the reflections, so this was not their first time with such self-assessment.
} 
major, said she generally found the course learning outcomes "hard to prove" and "hard to relate to" because they "just didn't do it"—-meaning, she felt they weren't covered - in her class. Carol said the instructor provided her with a list of items to include in the reflection and emphasized including the learning outcomes, but still told me, "I felt so in the dark about how to do it." She said she was unclear on how her reflection would be graded and wished she'd seen an example. Despite these concerns, Carol still took great pains in her reflection to cover all seven outcomes. As she told me in our interview, she wrote her reflection entirely "based on the learning outcomes," which she dutifully supported with examples from her included writing projects.

What struck me was the easy, assured tone Carol used in her e-portfolio reflection as compared to the tentative tone she used when talking to me about her reflection in our interview. In the e-portfolio reflection, Carol sounded confident of meeting the outcomes, but her comments to me suggested an uncertainty about whether she really made such progress in the outcomes. For example, in the second paragraph of her reflection, Carol wrote, "The ultimate goal for each class is that I met the learning outcomes as presented in the syllabus at the beginning of the semester. For [Argumentative Writing], I do believe I met these outcomes, and then some." In our interview, however, she told me, "I state the goals that, ultimately, I hopefully learned" (my emphasis). Similarly, in her conclusion Carol wrote,

After all is said and done, the learning outcome I believe I have achieved the most fully is the sixth, which is having 'produced 
convincing written arguments.' Looking at all of my work, flaws and improvements, I truly believe that I accomplished what I set out to do, which is to better myself and my writing ability. In attempting to do this, I think that it can be seen that I also produced convincing written arguments.

After reading this section aloud to me, Carol said, "I wrote this in the conclusion because I feel like, if I really learned that, it can be seen throughout all of my work" (my emphasis). Though the declarative statements throughout her reflection suggest Carol's writerly self-confidence about her progress on the learning outcomes, her comments in our interview betrayed that assertiveness and revealed something less certain. Instead, Carol revealed that she only felt obligated to center her reflection entirely around the learning outcomes because this was what she thought the instructor wanted to see. The final sentences of her reflection are:

Granted, I am still learning tricks of the trade for writing, I firmly trust that if I keep the learning outcomes in mind from this course, other past courses, as well as future courses, my writing can do nothing else but continue to grow and become more eloquent, thought out, and professional.

Though her reflection was a march through the outcomes, Carol assured me that she tried not to make it sound this way. "I was trying to make connections," she said, "not just state 'This is one ... This is two'," though this is how her reflection ended up reading, despite her best efforts to the contrary. Though Carol did 
express enjoying "thinking about, like, how did I do this [meet an outcome]," in the end, the outcomes were mostly a cause of uncertainty and struggle for her.

I came across a similar march through the outcomes (this time in the form of a seven-paragraph essay) in my interactions with Jean. Jean was a junior Computer Science major who had a very challenging experience in her argumentative writing course (which was not the first she'd taken at the university). The course was a requirement for Jean's major. I was surprised by her comments in our interview because her e-portfolio reflection did not reveal any of the tensions she expressed to me face-to-face. Though it is always difficult to hear criticisms of our hard-taught writing courses from students, I think Jean's story is important to hear out. What I hope to point out here is an extreme case of what could happen when a student does not feel supported by an instructor or that their writing really matters and how such disconnections might manifest in a final reflection.

Jean's reflective introduction and conclusion were very positive and hopeful. Right from the start, she dutifully turned to the course learning outcomes, writing,

This semester I think I have accomplished a lot in terms of my writing skills. They have been really matured as a writer a lot over all with the different types of arguments we had to write about. Over all, the writing really helped me develop my skills to match with the writing outcomes. I think my skills have shown my progress the most in gaining experience in writing effectively, 
speaking effectively, and using qualitative data along with, sharpening my ability to use evidence to enhance my papers and document them correctly and, giving valuable feedback to my classmates.

After five body paragraphs summarizing her progress towards each of these learning outcomes and offering evidence to support her summaries, Jean closed with the following:

Collectively, I think I have developed a lot as a writer. I had honed [sic] a bunch of different skills this semester and learned a lot. I really started to enjoy what we got to write about and was really happy that we had a chance to write about whatever we wanted and felt passionate about. Over all, I really enjoyed this class which made me learn a lot more.

In our interview, I asked Jean to read through each outcome with me. She stopped at various times to point to a few that "maybe" she learned, like how to better integrate visual support, how to interview, and how to structure her arguments a little better, "which," she joked, "makes it easier to argue with my mom now, I guess." When she finished reading through them, however, Jean expressed an overall disappointment with them. "Basically, I knew them all before I got here, so, I mean, I just sharpened it, like, a little bit. . . . I didn't learn anything in there." Obviously, this was not the story told in Jean's reflection, and I pointed this out to her. She responded, "Yeah, I wrote [that] I did [learn the outcomes] because I didn't know what else to write about." 
I asked her to talk to me a bit more about this. For example, in her reflection, Jean supported her claim that she grew towards the "speaking effectively" outcome by doing group presentations in the class, writing, "I think I am more confident as a public speaker and have an easier time figuring what to say to make the time I have to speak be more effective." But in our interview, Jean told me, "I taught last summer, so speaking in front of a public-like, that's nothing to me anymore." Then Jean called the final learning outcome (giving valuable feedback to the writing of classmates) "ironic." When I asked why, she told me, because the instructor did not give them consistent feedback on their papers during the semester and virtually no feedback at the end of the semester as the final eportfolio loomed. Most of the students, she said, relied on each other for final revision and editing choices, as well as how to write their reflections.

Despite earning a $\mathrm{B}+$ on the e-portfolio, Jean stated about her reflection that it was "the most forced paper I had to write this year," adding, "I kinda just wrote a five-paragraph essay. There was nothing special to it [and] nothing good about it. It was a terrible paper." When I asked her, then, what her intention was in writing it, she very candidly said,

I was just trying to appease [the instructor]. Honestly, I didn't care. It had nothing to do with me. The papers proved more about me. It [the reflection] proved that I can write like a fifth grader. I mean, it doesn't tell you anything. I mean, the papers are the ones that actually tell you if I learned something. So that [the reflection] was just to kill time and make [the instructor] happy. 
Jean said that she "wanted to care and to choose papers [she] care[d] about," but that would have required her to "throw away" the reflection. "I took the rest seriously," she said, "because I actually cared about the work," but the reflection "felt horrible" to write and she "hated it" because she felt it was unnecessary. Generally, she felt the reflection wasn't "teaching [the instructor] anything that [the instructor didn't] already know [about us]." In other words, the act of writerly selfassessment that Jean underwent had no formative value for her or, in her eyes, for the instructor.

Jean's claims about the quality of her assessment experience stood out from the others in my study, so I asked her to tell me how this all happened and how it affected her. Eventually, she explained,

I feel like towards the end we were all on our own, like . . there could not have been a teacher and we would've been fine. . . I used to love writing . . . and this has tainted [that feeling]. Teachers don't realize how much they have an effect on students and I think [our instructor] stopped caring. Even though we're in college it still makes a difference.

Jean felt the professor's poor rapport with and lack of support for her students seemed to pique as the due date for their final e-portfolios drew near. Jean reports this sequence of events as leading to a distressing e-portfolio experience and a ineffective act of self-assessment. 


\section{Conclusion}

The messy truths revealed in these student reports include the anxieties and tensions students may feel particularly when it comes to the more summative aspects of their e-portfolio experiences. In particular, final grades were cause for concern for many of these students, all of whom had accumulated mostly As and Bs going into the final e-portfolio. A few students, however, were totally unconcerned about their final grades because of those same As and Bs. If students are unmotivated to revise their writing for an e-portfolio based on grades and/or are also unnecessarily preoccupied with final scores on their e-portfolios, perhaps writing instructors and program administrators might reconsider the use of eportfolios as a summative classroom assessment practice, or at least consider more carefully the adverse effects on students of the summative aspects of an e-portfolio assessment.

Further, student insights in this chapter offer some messy truths about what happens when students are required to reflect on institutional learning outcomes in their e-portfolio assessments. On the one hand, some students felt validated by the formative qualities of such writerly self-reflections, which they saw as verifying their progress and learning in the course. The experience seemed to be particularly gratifying for those students who were able to adapt and assimilate the learning outcomes in a way that offered them agency, choice, and self-expression. On the other hand, there were other students who felt they had to stretch and wrestle their writerly selves to awkwardly fit them into a more summative reflective act and who, as a result, felt uncertain and tentative about their own learning and progress. 
In the following and final chapter, I will reflect on several of the overarching trends that were revealed after listening well to and dynamically mapping the voices of the eighteen students in my study. 


\section{CHAPTER 5: SUMMARY, ANALYSIS, \& IMPLICATIONS}

\section{Summary}

In an attempt to meet Jaqueline Jones Royster's call to hear well the voices of those often not heard, I have attempted in Chapters 2, 3, and 4, to "map out"—à la Broad - some of the dynamic criteria valued by students. In doing so, as they did for Broad, messy truths emerged about instruction and support, about writing as/beyond text, about design in digital spaces, and about assessment. These student values, or what I came to understand as their emergent learning insights, were not always inconsistent with our own. Indeed both the spaces where they converge and diverge (i.e. become messy truths) are compelling and serve as possible points for further consideration and study. ${ }^{63}$

Further, listening to the messy truths and emergent learning insights of students' e-portfolio experiences helps us discover (and map) the unique and varied writerly selves that emerge within — and are constructed by—an e-portfolio assessment. As Kathleen Blake Yancey has argued,

In a digital portfolio, remediated on a gallery, the arrangements are plural. And the students invented in each are quite different, ... [are] multiple, ... [as] defined by links. Because you can link externally as well as internally and because those links are material, you have more contexts you can link to, more strata you can layer,

\footnotetext{
${ }^{63}$ Emergent learning insights is an adaptation of Chris W. Gallagher's term "operative aims," which he defines as "the ones that matter most for student learning." For Gallagher, a focus on operative aims represents a pragmatic shift in attention away from "what we do (teach)" and towards the "consequences of what we do (student learning, or lack thereof)" (43, my emphasis).
} 
more 'you' to invent, more invention to represent. In sum, the potential of arrangement is a function of delivery and what and how you arrange — which becomes a function of the medium you choose-is who you invent" ("Made Not Only" 317-8).

These abundant and varied writerly selves, as Yancey suggests, are worth considering and, though certainly multiple and course and context dependent, several will be offered here to provide a glimpse into the various "who's" invented and performed through and in various e-portfolio experiences across a vertical writing curriculum. Attending to students' varying writerly selves offers one way to consider how those selves are shaped by our e-portfolio assessments and pedagogies and how they might help us "chart the course of our universities" and writing classrooms as Darren Cambridge suggests they can and should.

Privileging the writerly selves, emergent insights, and messy truths suggested by the students in this study (or, by extension, in any other study or internal assessment that chooses to privilege student voices), represents a Gallagherian shift in attention away from what we do when we teach and use eportfolios assessments and toward the consequences of our e-portfolio assessments for students, especially those consequences that may not be represented in our professional development for instructors, our discussions about e-portfolio assessment, our syllabus and curriculum plans, or the institutional learning outcomes students are so often required to reflect upon. This shift will likely force 
writing program instructors and administrators to grapple with some curious contradictions and messy truths as those truths become evident. ${ }^{64}$

We may also feel affirmed, however, when we find established e-portfolio practices are effective and relevant to college students and/or when the values and passions of those students are in harmony with those of the instructors and programs who serve them. In other words, my attempt to map student perspectives is not a form of normalization or standardization, or in a broader sense, an act of colonization. On the contrary, it is intended as a rhetorical, pedagogical, and political act of disrupting the notion that only the values of writing instructors and writing programs matter in writing assessment, and this disruption will enrich, enliven, and complement our assessment discourse(s). ${ }^{65}$

Although the student reports advantageously mapped out in this dissertation, as I said above, are course and context dependent and not necessarily generalizable, they arose as consequences of common e-portfolio classroom instruction tactics and methods; hence, they still have implications for e-portfolio instruction writ larger than only at this particular university. The remainder of this chapter will focus on the messy truths, emergent learning insights, and writerly selves that students reported and performed in respect to the critical connections, tech-anxieties and digital preoccupations, and assessment expectations they experienced. Finally, it will offer some ways these reports might help writing

\footnotetext{
${ }^{64} \mathrm{Or}$, as Broad put it, "available for discussion, negotiation, and informed policy decision . . . rather than driv[en] . . underground" (94).

${ }^{65}$ Similarly, Broad argued that taking the time to discuss and map the similarities and differences that existed among instructors at City University about what they valued in their students' writing productively disrupted the notion of consensus evoked by writing rubrics, the particular model of assessment in which he was interested.
} 
instructors, writing departments, and writing program administrators adjust their writing assessment practices to better meet the needs of students.

\section{An Overview of Student Insights}

\section{Critical Connections}

One common learning insight that emerged from the students in this study was the high value they placed on connections: connections between past and present e-portfolio experiences, between e-portfolio artifacts and assignments, between themselves, peers, instructors, and outside audiences, and between writing courses and across programs and majors. When such connections were lacking or seemingly purposeless, generally, students expressed anxiety and frustration. When these connections were strong, they expressed enjoyment and confidence. By extension, diversity and disconnects were not always a bad thing, as long as there was a purpose for them, or guidance as to how to wrangle with them. This is not a particularly novel insight, but an important one because it suggests what eportfolios do well and also offers a window into the consequences of e-portfolio instruction and assessment on students particularly when that instruction and assessment appears stratified and disconnected.

For one, students in this study offered insights into what kinds of connections they value as an integral part of their e-portfolio experiences within a classroom context. Connections between peers mattered, as well as connections between students' past e-portfolio experiences and their current ones, connections with their instructors, and connections between course assignments, outcomes, and expectations for the final e-portfolio. For example, those students who had past 
experiences were generally able to benefit from their past experiences in the form of eased nerves, boosted confidence, and at least some sense of preparation for the present e-portfolio context; on the other hand, students who were keenly aware of the differences between their past and present portfolio experiences often wondered and worried about what would carry over and what would change.

Several students reported valuing peer exchange and face-to-face (vs. online) interaction as they composed their e-portfolios, particularly when those peer exchanges involved students coming prepared with correct and complete materials, sharing understandings of e-portfolio assignments and e-portfolio or writing technologies, and/or simply offering support and motivation for getting through a writing project or e-portfolio assessment.

The affective relationships that students formed with their instructors also mattered to them and, when positive, seemed to buoy students' perceptions of their e-portfolio experiences. When negative, students reported disengagement and feelings of demotivation. ${ }^{66}$ This study suggests that students may be more motivated and positive about their e-portfolio experiences when instructors seek to connect with them and simply let them know we care. The level of connection a student felt with an instructor also seemed to relate to the quality of instruction and clarity of expectations that instructor offered in preparing students for their eportfolio assessments.

\footnotetext{
${ }^{66}$ Like Jean, who reported, "I stopped caring when our relationship with the instructor went downhill. This has tainted my feelings about writing. Teachers don't realize how much they have an effect on students. Even though we're in college, [how teachers treat their students] still makes a difference."
} 
Connections across courses also arose as a significant part of students' eportfolio experiences. Non-writing majors generally reported feeling more excited about or more engaged with an e-portfolio assessment when they felt it connected to the writerly selves they performed in courses for their other majors. When a connection was not readily apparent, students either worked independently to build one or simply reported less excitement and/or buy-in to the e-portfolio assessment. The value of connection for writings majors who had extensive experience in writing courses across this vertical curriculum was similarly reported. For example, students reported struggling when they had to travel back through time, space, and into the depths of various electronic files (if they still worked) to locate the best artifacts for their professional e-portfolios. When the importance of longterm curation strategies had not been made overtly clear to these students, they were particularly frustrated by the avoidable additional work this required. Further, majors felt overly-burdened when they were pressed to connect these artifacts and consider them together in light of a particular professional goal only in the final semester of their senior year. Several expressed wishing to have been encouraged to make these connections earlier and continuously, even if only to be able to look back and have a track record of their progressions and digressions towards the particular writing career they were now pursuing.

Another instance of connections and messier disconnections arose in students' descriptions of the panoply of e-portfolio subgenres and content strategies they encountered across courses. In this single study alone, students had encountered e-portfolios bound by a writing course/topic focus, a career focus, a 
major focus, a local culture focus, and/or some medley of these. They described eportfolios with a product-focus, a process-focus, and a combination product/process focus. They composed mock or preparatory e-portfolios written for a simulated audience or an audience of one (i.e. the instructor), ${ }^{67}$ and professional or graduation requirement e-portfolios meant for a real audience (of potential employees or committees of high school teachers). Students described their e-portfolio as creative and/or scientific and/or research-based, and showed me a variety of mono-modal and multimodal e-portfolios at varying levels of complexity. The writerly identities that each of these e-portfolios subgenres required students to perform were sometimes uncomfortably unfamiliar for students on several levels. For example, when a student was required to combine several different genres of writing (i.e. a memoir, a proposal, and an investigational report) in one course-based e-portfolio, those students reported struggling a great deal to tie them all together in a way that represented a successful writerly performance. Such a performance became particularly difficult when students saw the topics they wrote about within each of their e-portfolios texts as unduly divergent. When students were offered a sufficient amount of guidance on thinking through such connections, it was less of a struggle, though a challenge nonetheless.

The subgenre of e-portfolio was often driven by the particular content strategy and/or type of reflective element(s) student-writers were required to enact, each with its own limitations and possibilities. Whether a student was required to

\footnotetext{
${ }^{67}$ Like the reader Casey suggested, "for the teacher—-that's the only reader there's gonna be."
} 
write an informal letter to the instructor-evaluator, to more formally explain his or her writing process and revisions to a larger evaluative audience, to write short wrappers that briefly explained and connected all the required artifacts under one theme or purpose, or to write longer annotations clarifying the rhetorical purpose and professional pertinence of each selected artifact, each letter, wrapper, and annotation enacted a particular content strategy and constructed a student's performed writerly self. Students often rose to the occasion, but not without difficulty and sometimes, as mapped out in Chapter 4, often with some amount of tentativeness, confusion, and even apathy. Further, though it was not easy, students reported learning more from developing their own content strategy from the ground up and enjoyed taking greater artistic and creative license to write more (writerly) self-directed reflections.

The types of e-portfolio artifacts and types and numbers of modalities that students included and employed in the various required subgenres of e-portfolio also represented a wide range (see, for example, Table 14 on page 65 and Table 15 on page 115). The layers of technological adeptness demanded of students in each of these subgenres caused several a good deal of frustration and/or anxiety, especially when those technologies differed from course to course (more on this in the next section). There were, however, certainly some consistencies. For example, memoirs and persuasive texts were the genres that students most often included in their e-portfolios. In other words, the most dominant (writerly) voices enacted across courses in this sample of students were the narrative and argumentative. Further, alphabetic text was the primary mode employed by students, with the 
significant exception of senior majors who employed a much greater level of multimodality in their e-portfolios.

Just as portfolios require students to make clear the connective tissues that join their artifacts and to reflect on the writing strategies they employ, these student insights and messy truths compel us to clarify and reflect on the connective (and dis-connective) tissues between our e-portfolio assessment strategies within our courses and across our programs.

Curious Contradictions, Tech-(Un)Assertiveness, \& Digital Preoccupations

For a generation that seems to labor extensively and effortlessly at communicating via text, audio, video, and image in and through digital spaces in ways no other generation has done before, it seemed curious that so many students in this study claimed to be "bad" at and anxious about the demands of such labor in an e-portfolio performance. For example, let us return for a moment to Ariel, the self-proclaimed "Worst Millennial Ever" of Chapter 3. Though she did not have any formal web design training and this was her first web e-portfolio experience, it was clear that Ariel, a business major, had some inherent artistic sensibilities, which she clearly drew upon to design her course e-portfolio. Much thought went into her e-portfolio and she adeptly used the technologies, modes, and design features at her disposal. In fact, despite her claims to being "so bad with technology" (and even in comparison to several of the upper-level web-based portfolios), Ariel's final e-portfolio was one of the most aesthetically pleasing and well-designed e-portfolios in the study (and, see Figure 24 and Figure 25). 

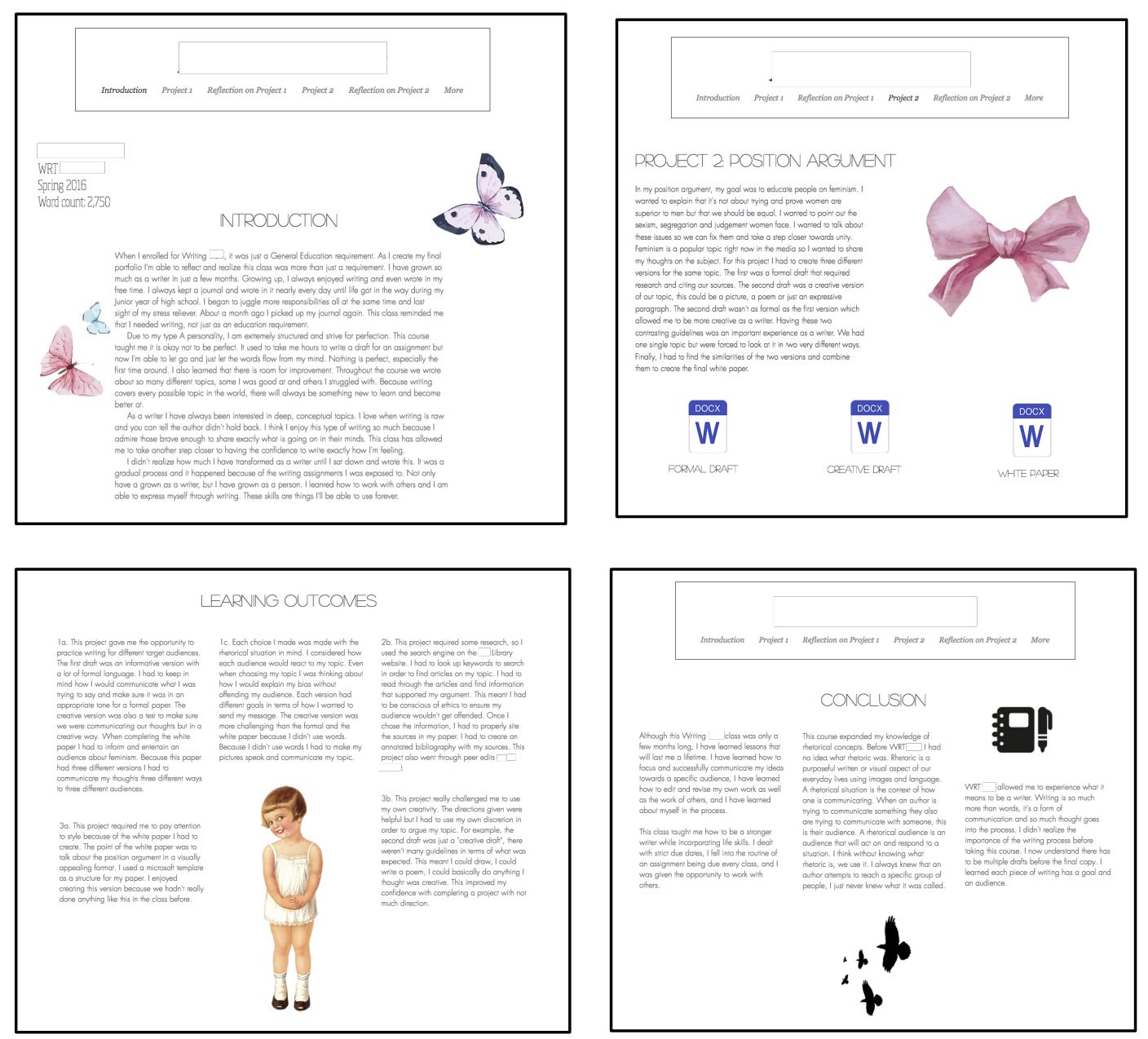

Figure 24: Screenshots of Ariel's e-Portfolio, "The Worst Millennial Ever"

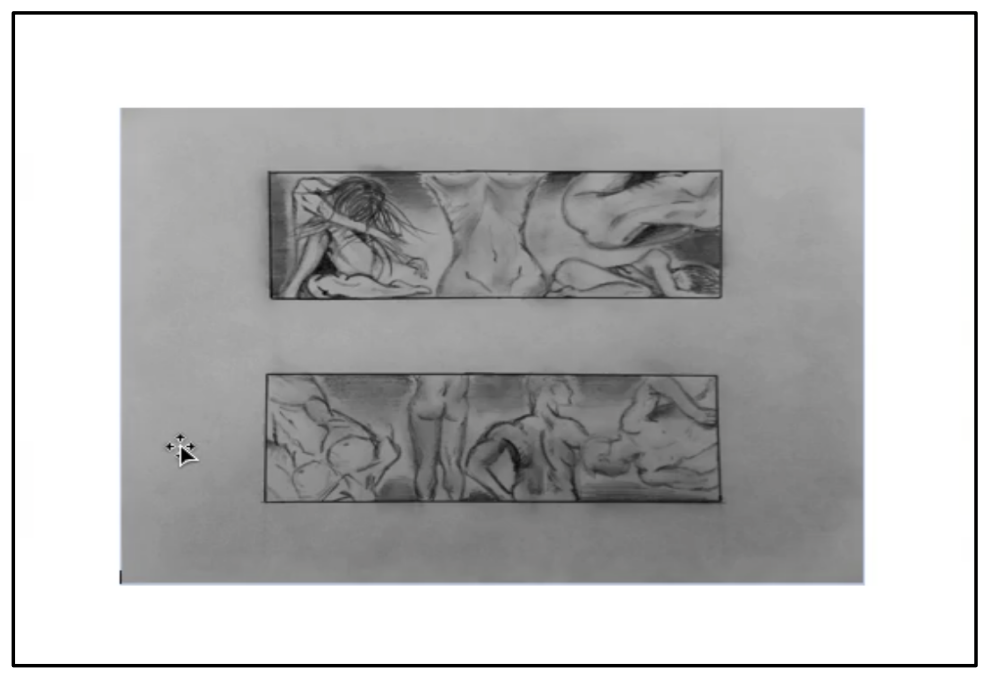

Figure 25: "I Did An Equal Bar, Because Feminism Is About Being Equal. I Put Women [In The Top] and Men In The Bottom. It's Literally As Simple As That" (Graphic of a Whole Original Art Piece, Drawn by Ariel) 
Ariel's work followed the basic design conventions of strong contrast, unity and consistency, clean alignment, and thoughtful consideration of proximity. ${ }^{68} \mathrm{In}$ layman's terms, her e-portfolio was easy on the eye and easy to navigate.

Additionally, Ariel's self-directedness and positive attitude in regard to the digital aspects of her e-portfolio experience were refreshing (and rare in my study). ${ }^{69}$

Despite her claims to the contrary, Ariel's technological skills were not "bad," her modal selections were not willy-nilly, and her design choices and artistic sensibilities were not "simple." Yet even with all this on her side, Ariel still considered herself technologically inept.

The curious contradiction of a Millennial generation of "digital natives" (Prensky 2001) who fear technology in the writing classroom, or who, at least, seem skeptical of what in many ways is their birthright, suggests a messy truth worth considering. Privileging students' emergent learning insights about the eportfolios technologies they were required to use, the modal affordances they were aware of and used (or were not aware of and did not use), and the design aspects of their e-portfolio performances may offer us some ways to confront this contradiction and help build students' tech-assertiveness (or to simply remind them of the gifts they already have).

\footnotetext{
${ }^{68}$ In two of the upper-level writing courses in my study, these "CRAP design principles" (contrast, repetition, alignment, and proximity) were briefly referred to in either the e-portfolio rubric or course syllabus. This was the first I had heard of them. They are not to be confused with the CRAPP Test we often refer students to in order to help them assess the credibility of their sources. The CRAP principles of design offer a similarly simple way for us to talk about design, for example, to our first year students as they begin to think about the design elements of their eportfolios.

${ }^{69}$ Ariel was one of the few participants who responded positively to my questions about the web eportfolio technologies: "It was fun seeing what the website could offer to me," she reported. "It was fun exploring it."
} 
Generally, all students in this study placed a high value on technological expertise and its implications for their e-portfolio experiences. Students with previous web-building or CMS experience generally felt more confident going into a new e-portfolio experience than those who had little or none. A few students, however, were still anxious even when they had past experience. Importantly, nearly all of these students expressed feeling a lack of classroom support and instruction in how to grapple with the web e-portfolio technologies they were required to use.

Further, the writing majors, who all had a decent amount of web-based eportfolio experience, unanimously spoke about the expert technological skills and greater lengths of tech-training they would have liked to have had earlier in their program to finish their senior year with more highly sophisticated web-based professional e-portfolios. The only students who expressed few to no concerns or anxieties about the required e-portfolio technologies were those who composed their e-portfolios primarily in Word and simply had to convert them into PDFs for submission. Notably, however, these students generally expressed not seeing any future use for these files. In other words, the idea of having to build a website in addition to a writing e-portfolio loomed large and ominously for most students, yet learning to build one well was an aspect of students' tech-writerly selves that many wished to improve upon.

Another messy truth of students' tech-writerly selves that became apparent in this study was the varying levels of modal complexity, comfort, and awareness they enacted in their e-portfolios, particularly what they —and, presumably, their 
instructors-considered worthy of calling "writing." For example, the emergent insights from this study suggest that this particular writing program's efforts to get its students to consider writing as composing in and beyond alphabetic text are working, at least in the upper-level courses. As I pointed out in Chapter 3, the levels of modal complexity in senior majors' e-portfolios were generally far beyond those of non-major students' in lower levels. Later on in my study, when I mentioned to a few of the writing majors that I was seeing many modally simplistic e-portfolios in my research, they replied with disbelief. Katja, for example, said,

Teachers only assigning text-heavy things? I don't know what they're looking at, but everything now is visual. Graphic design and writing are on a huge collision course. Old school teachers have old school ways, I guess. That's probably heartbreaking for [students]. I feel like those students are like, "Oh, this is exciting. I'm going to change majors now."

Indeed, no first-year students (and a few in upper level courses) exhibited an understanding that their writing projects could be composed in modes other than text and several of these students even reported feeling that only alphabetic text could or should be considered writing. Generally, too, these students seemed mostly indifferent about their e-portfolio experiences (which suggests Katja may be right: composing only text-centered writing can be heartbreaking). However, when I asked students who composed text-only or text-centered projects and eportfolios whether they would be interested in composing projects in modes other 
than alphabetic text, nearly all of them responded enthusiastically and affirmatively and suggested that to attempt such multimodal compositions, even if they were nervous, they would only need to be asked to trym provided they were offered support in their attempts. As Ned suggested, "Anyone my age would be able to do it. Help them see it's not that challenging, because it's not!" (emphasis mine). Indeed, of those students who composed in modes other than text (or as Ethan put it, moved from "2D to 3D") for the first time, several reported valuing being "pushed" to try multimodal composition, even when they dreaded the prospect of it. Being given opportunities to build their modal confidences became significant moments in the development of these students' writerly selves.

Finally, students in this study reported the design of their e-portfolios to be of concern — and of value - to them, suggesting that these digital natives may also feel uncertain about their design competencies in addition to their technological skills and multimodal choices. Designing e-portfolios, particularly for the web eportfolio composers in this study, was mostly an enjoyable part of the process. Several students reported being preoccupied with design, even when it was not a particularly important evaluative component of the e-portfolio assessment (i.e. was not a significant part of any instruction sheet, grading percentage, or rubric). One negative consequence, or messy truth, of such a preoccupation reported by several students was their becoming overly invested in the design of their e-portfolios, which meant having less time for the more important (and more heavily weighted) writerly processes of revision and reflection. 
The curious contradiction and messy truth that this e-generation may have deep anxieties about writing technologies, a lack of critical awareness about the affordances of the modalities so many of them regularly use, and a preoccupation with design — perhaps at the expense of a more-needed occupation with contentare important insights for us to consider.

\section{Concerning Assessments \& Expectations}

A great deal of anxiety was expressed by the students in my study over the types and kinds of expectations — spoken and unspoken — directly offered and/or ambiguously alluded to by instructors about the forthcoming e-portfolio assessment in their courses. The most stress seemed to arise for students around not having a clear "sense" of what the final e-portfolio should look like. Suffice it to say that clear expectations, generally, were appreciated by students and unclear, ambiguous, or confusing expectations resulted in anxiety-provoking challenges for them. This is not to say that clarity of expectations correlated directly with students' decreased anxiety levels, but only that, based on students' emergent insights, when instructors offered at least some clarity about their e-portfolio expectations, students appreciated it and worked diligently to meet those expectations.

Specifically, students reported that receiving the basic requirements (i.e. word counts, required projects and reflective elements, due dates, etc.) for the form of an e-portfolio assessment was not nearly so helpful for their confidence and understanding as receiving "answers" to their questions about what the contents of the e-portfolio should or could look like and how to connect those contents 
together in the way the instructor "wants" or is "looking" for (i.e. in a way that would be pleasing to the "teacher's eye"). Being exposed to models of working, professional, and/or previous student e-portfolios was suggested by several students in this study, especially the senior majors, as an important component of their e-portfolio assessment preparation. They requested models mainly to get a "sense of" what the instructor was looking for, to see what an e-portfolio, more generally, looked like, to understand how other students connected their artifacts or designed their e-portfolios, and even to see what the "competition" looked like. In other words, students were particularly interested in the writerly selves performed by peer predecessors (and their future competitors) in order to get a sense of how they compare and might perform their own writerly selves. In short, these students were asking permission to enter the discursive parlor of e-portfolio assessment and to watch the conversation for a while before engaging in it themselves - an astute rhetorical move, indeed (and one that all of us who publish and present in academia are encouraged to make).

The types of models students were exposed to also made a difference. For some, the model(s) they were exposed to were not connected to the particular rhetorical situations with which they were contending in their own e-portfolio assessments. That's not to say that these students still did not glean ideas or insights from these models, but that they wished to see others as well—especially models that were more in line with their own rhetorical purposes and writerly styles. One messy truth, however, that emerged around the issue of models is that some students reported an excessive reliance, or dependency upon models, even 
when instructor expectations were clear, suggesting that models may hold greater sway over how students compose their e-portfolios than other types of instructor directions, particularly when those models are presented as excellent (or pleasing to the eye of the teacher).

Generally, the students in this study reported that they did not systematically rely upon, refer to, or deeply consider the more institutionalized and/or psychometric aspects of their e-portfolio assessment experiences (i.e. instructor's lists of basic requirements, rubrics, and course learning outcomes). Instead students' emergent insights suggested that they relied more on affective and intuitive resources, such as instructor conferencing, peer exchanges, and models of e-portfolios in order to get a "sense" of - or grasp the general "concept" of - an e-portfolio assessment. Senior majors reported seldom referring to their eportfolio rubric because of the carefully scaffolded course assignments that had them work towards the rubric components while also working with the language and vocabulary used in the rubric. Further, students expressed either little concern for weighted grading percentages and/or an unwarranted amount of anxiety about their final grades (or no worry at all). In other words, the institutionalized and summative components of the e-portfolio assessments in this study seemed to work more for the instructors than the students.

Learning outcomes, in particular, presented a significant challenge for the first and second year writing students who were required to reflect upon them as part of their e-portfolio assessments. There was a sense of awkwardness, discomfort, and/or tentativeness that came across in several of those students' 
reflective performances. Many of the students in my study reported that no matter how "awkward" it felt or how "from the book" their reflections sounded, they still diligently sought to receive credit for referencing learning outcomes and understood such a reflection to be a writerly self that required performing - $\mathrm{a}$ savvy rhetorical move, to be sure. The results of this study also suggest, however, that such moves may come at the expense of a student understanding that he or she actually did make progress on a learning outcome, of getting a formative sense of validation and verification from those outcomes, and/or of feeling able or empowered to reflect on insightful moments of learning that they otherwise engaged in.

Though not exclusively, students in the lower level writing courses also reported feeling a lack of control over the e-portfolio grades they would eventually receive. Whether or not that lack of control was real, the perception persisted. Further, for several of the students who received high scores on their coursework, the prospect of having to complete a final e-portfolio for a course grade seemed a fruitless one. Students who did not do as well on coursework leading up to the eportfolio (and even those who did do well), reported a heightened sense of anxiety about their final e-portfolio grades, which, in the end, seemed unnecessary and unwarranted; these students all received As and Bs on their final e-portfolios. In other words, these messy truths suggest we might do well to consider the negative and/or counterproductive effects of attaching summative grades to our classroom e-portfolio assessments. 
Finally, the students in this study also (and almost unanimously) reported that the e-portfolio assessment felt more open-ended and creative and in most cases less stressful to them than a typical final exam or paper. Getting the chance to work on writing over time and to revisit that writing several times before submitting it were common reasons students gave for their lowered senses of anxiety about this final course assessment. Students also particularly enjoyed composing the reflective elements of their e-portfolios. Certainly these are strengths of the e-portfolio model to retain and highlight — where students' values are in harmony with our own. However, the more messy truths and challenging insights regarding some of the other evaluative components of our classroom eportfolio assessments also deserve our respectful attention.

\section{Recommendations for Writing Instructors and Programs}

Obviously, we can never ensure through our pedagogy alone that our students will be more confident or feel less overwhelmed or anxious about an eportfolio assessment. This study suggests, however, that there are ways to help students make more of the connections they desire, build more of the digital and design confidences they need, deal more effectively and confidently with, and sense a greater relevance for these ubiquitous assessment models. At the very least, hearing well the emergent learning insights our students offer has the potential to provide writing instructors and writing program administrators with valuable information they may use to improve their e-portfolio pedagogies, first 
year courses, and/or vertical curriculums to better guide (and serve) our students in composing e-portfolios that, like Katja's, take off like rockets. ${ }^{70}$

\section{Making and Drawing Connections}

The results of this study offer writing instructors some ideas as to how they might improve their classroom e-portfolio instruction so that it includes more productive divergences and more cohesive connections for students. For example, instructors who do not yet do so may consider honoring the e-portfolio experiences and writing technologies skills their students already bring to the classroom and guiding them through supportive and realistic discussions and assignments that ask students to investigate these aspects of their past and compare them to the current assessment context. Such bridge-building activities should offer opportunities for instructors (and students) to recognize how and when e-portfolio skill-transfer occurs and to improve students' self-confidence and investment.

Instructors may also seek to build more opportunities for interpersonal interactions in the form of e-portfolio support workshops and to better regulate such exchanges to provide students with the kind of peer support they want and need (and that is most generative). Though likely most of us already seek to build positive relationships with our students, it is also good to know that in doing so we are also having effects on our students' levels of confidence and motivation and, by extension, their e-portfolio experiences in our classroom. Additionally, it is helpful

\footnotetext{
${ }^{70}$ For Katja, the perfect recipe for her assessment assertiveness and eventual professional success (she actually landed a job right after graduation in large part due to her senior e-portfolio), was a mix of peer and instructor support, a strong sense of personal aptitude built over time in a writing program that helped her eventually see the connective tissues of her writerly self and experience, and a clear grasp on how and why the e-portfolio could and should serve her.
} 
to know that students seem to feel a greater sense of connection with us when we offer clear and consistent instructions for an e-portfolio assessment, which may have us more carefully consider the affective components and consequences of our e-portfolio assignments. Assignments that are scaffolded, purposeful, and welltimed seem to have a positive effect (and affective consequences) on (for) students, particularly when those assignments help students gain a clearer sense of writerly self-awareness; let's aim for that.

That students value connections between the writerly selves they perform in e-portfolio and writing experiences across courses is also an important insight for writing instructors and program administrators to be aware of. Such an awareness can help us revise and reconsider the genres, modalities, and topics we are requiring or privileging — and those we are leaving out - as part of our eportfolio pedagogies so that students are getting practice employing a wide variety of rhetorical tools that more readily complement, extend, and are otherwise more useful for students in their lives and majors and outside our classrooms. Such revisions, re-mediations, and re-toolings create openings for interested faculty across disciplines to engage in discussions about the writerly selves students are enacting in their classrooms and how best to support and connect those selves.

Finally, writing administrators, instructors, and departmental faculty would likely do well to consider how best to connect with each other, particularly regarding the content strategies, subgenres, and long-term purposes of the eportfolios they teach and require in their first year writing courses and vertical writing curriculums. Conducting roundtable discussions that allow for dissensus 
and "pulling hair out" together, or otherwise dynamically mapping what they value in these areas, could help present a more realistic and honest overview of the convergences and divergences of rhetorical contexts and purposes required of students across courses.

\section{Building Tech-Confidence}

Bearing witness to students' emergent learning insights also pointed to a fair amount of technological anxiety in this curious Millennial generation. These findings should lead writing instructors and program administrators to consider the unexamined technological, modal, and design demands we make—or do not make - on our students. In other words, these insights compel us to inquire about, hear, and consider the multimodal and technologically complex writerly selves students are being required to perform in an e-portfolio assessment.

Firstly, this study suggests that writing instructors and program administrators may wish to consider ways to offer their students better technological training, particularly when asking them to compose an e-portfolio with a program they have never used before (like a web-building tool) and not just assume they will pick it up easily. Further, building students' confidence with the writing technologies and programs they will likely use in the workplace after college can be an important preparatory activity and valuable part of what we offer in an e-portfolio experience (particularly for writing majors). Certainly if writing departments plan to require their writing majors produce a professional online presence, it seems imperative to help those students strengthen and practice the 
technological skills they must have to confidently compose those presences. $^{71}$ Listening well to and honoring insights like these can provide fertile ground for a writing instructor or program (or university) to improve the adequacy, relevance, and consistency of its tech-training and e-portfolio technologies within and across classes. Further, such trainings and technological confidence building initiatives should include a concerted effort by faculty and administration to work with students in determining the ways in which students must also be self-directed and accountable for their own technological skill growth, or, in other words, for owning up to their status as digital natives and for fully embracing their membership in the Millennial generation.

One way that writing programs and writing instructors might increase their visibility on campus may be to spearhead efforts to assess (by asking students and instructors across the curriculum) the most ubiquitous writing technologies students are compelled to use for courses across the institution and to lead efforts to train students to write using all the affordances of those technologies by integrating them more readily into their e-portfolio assessments. Writing programs may even go one step further to determine in what writing technologies their writing majors are most often being required to compose in their places of work after college in order to prepare them for those future contexts. This study suggests that writing courses provide a valuable space for students to gain more practice

\footnotetext{
${ }^{71}$ Katja described such an endeavor to be as valuable to her as the typewriting course she had to take in high school.
} 
with e-portfolio and writing technologies, and that they are also interested in and motivated to get more practice in them. ${ }^{72}$

It is also recommended that writing instructors and program administrators spend more time building their students' multimodal awareness. The messy truth that students, particularly those outside the major, reported a lack of awareness about — and even outright suspicion of —writing as anything other than alphabetic text prompts us to wonder how far we've come in prioritizing multimodal fluency and the digital and screen literacies that compositions scholars have resolutely suggested we should (see Yancey, Shipka, or nearly anything co-written by Cynthia Selfe and Gail Hawisher). A related messy truth to contend with is that students are producing text-heavy e-portfolios, which means they and/or their instructors are not critically aware of the modal possibilities and affordances at their fingertips in an electronic or digital environment.

Instructors can certainly offer students the option of composing writing projects in alphabetic text (and e-portfolios in Word/Word-to-PDF formats), but in doing so they must be wary that these students, like several students in my study, may choose to stick with the option with which they are familiar out of fear and/or lack of confidence. If instructors desire students to build tech-confidence, this

\footnotetext{
${ }^{72}$ Such "depth of practice" may require adding a course to a writing program that focuses solely on the technologies students will be required to use in the majority of their writing experiences in college (or just for e-portfolio composition); it may require writing departments to adopt an additional course textbook or online tutorial training system, or simply collaborating on how to create more consistency between courses through careful technological scaffolding. These support methods can be optional for those students who already feel confident in their technological abilities, but if the students in my study are any indication of the greater whole of college students, likely many will sign up or sign on to build their digital confidence(s) in just as great numbers as those who self-select to take our first year writing courses to build their confidences in writing.
} 
study suggests that most students only need a slight push to move out of their writing-as-text-only comfort zones and into something slightly more modally complex and robust. For example, to build more multimodal awareness and opportunities for practice, instructors might offer incentives, like extra points for incorporating one additional mode into a text-centered project or e-portfolio or for revising (or remediating) text-based projects into totally new (multi)modal formats. Instructors can offer time count limits in addition to word count limits on project assignment sheets so that students know "what counts as words" in an eportfolio composition that does not only speak through text alone. If seeing themselves on video seems intimidating, as it was for one student in this study, offer an alternative that requires only their voice with images to support it (i.e. an audio-guided PowerPoint or PechaKucha project). ${ }^{73}$ We don't want to push multimodal composition on students just because "it's fun" or "cool" or new. Instead we want to be clear with students that if a multimodal e-portfolio is composed with thoughtful rhetorical purpose and intent, it can be fun, new, and also an opportunity to deepen their multimodal and e-writerly self-awareness.

Finally, if writing course syllabi and e-portfolio assignments (like those analyzed in this study) do not overtly stress or value the design and visual rhetoric components of an e-portfolio assessment, instructors may be missing the design preoccupations that still play a part of our students' experiences, levels of

\footnotetext{
${ }^{73}$ Pecha Kucha is a Japanese word for "chit chat" and is a multimodal presentation format that I have used with much success in my classrooms, particularly when requiring students to remediate an argument into a short presentation or to conduct brief, but pointed, group proposals. There are many sample PechaKuchas and more information about them at this website: http://www.pechakucha.org/.
} 
motivation, and engagement. Choosing to honor the emergent insight that design matters to students may compel instructors to include an explicit design criteria in their e-portfolio rubrics, grading scales, assignments and/or instructions. Doing so would require an extra commitment to design instruction, but it is a commitment the students (in this study at least) seemed ready to get on board with. ${ }^{74}$ The one caveat is to assure students are not spending an exorbitant amount of time on the design of their e-portfolios at the expense of the content of that portfolio. Perhaps in giving them better design guidance, students will not be so preoccupied (or weighed down) by it.

Heeding these emergent insights from students regarding their desire to build technological, modal, and design confidences to perform their most effective digital-writerly selves in an e-portfolio assessment will also help us confront the messy truths that "old school teachers" and "old school ways" (i.e. analogue and mono-modal writing practices) still linger in our writing courses and programs. This is not necessarily a bad thing; but if we wish students to see our e-portfolios (and writing courses and programs) as more relevant, competitive, and technologically engaging than did several of the students in this study, administrators may wish to add technological, modal, and design skill building to their professional development initiatives or to at least discuss these important

\footnotetext{
${ }^{74}$ We need not be highly trained graphic designers to speak knowledgeably about or to reiterate often the basic design features of any text students produce; we need only the intention to try. Whether that intention takes the form of a conversation about the use of headers, font, and white space in a Word document, or a more in-depth discussion about the more specific, yet simple CRAP design principles of contrast, repetition, alignment, and proximity (see Footnote \#68 on page 179) of any graphic or audiovisual text they are asked to compose, students' design-confidence will likely be buoyed for that project and they will feel more prepared for the final design demands of their e-portfolios.
} 
aspects of the e-portfolio model more openly with their writing instructors. Just because a program requires an e-portfolio does not mean students are being asked to understand and utilize all of the digital, modal, and design affordances therein. In understanding students' messy truths and emergent insights about the e-portfolio technologies with which they much contend, we also learn how to more effectively encourage and train ourselves to compose with and employ such technologies effectively (and, hopefully, we also encourage students to stay in our majors and take more of our courses!).

In sum, writing instructors and program administrators may not want to assume that students will be confident about composing an e-portfolio in a particular platform simply because it is a digital one, employing multimodalities simply because they post pictures regularly on Instagram, nor designing their eportfolios simply because they have access to clip art images and templates on the CMS they are using. Nor do instructors want to avoid pushing students to try a web-based e-portfolio over a Word-to-PDF portfolio simply because students may feel some discomfort in making the transition from the 2D "on paper" likeness of an e-portfolio to a portfolio platform with greater 3D possibilities; as this study suggests, pushing students to try such tech-transitions is often a worthwhile endeavor. Most certainly, however, instructors will want to clearly articulate to, explore with, and support their students in understanding the various affordances, constraints, and possibilities of the writing and e-portfolio technologies they have the option to — or are required to — compose. Not doing so will likely lead to some of the same anxieties and frustrations reported by students in this study. By not 
grappling with these messy truths, writing instructors might also continue to overlook the curious contradiction that these digital natives, in fact, require a boost in tech-confidence, support from the $2 \mathrm{D}$ to $3 \mathrm{D}$ transition, and a more critical awareness of the modal, technological, and design affordances that are an integral part of every e-portfolio experience.

\section{Re-Assessing the e-Portfolio as a Classroom Assessment Model}

The insights privileged in this dissertation also compel writing instructors and program administrators to compare how the summative and formative assessment components of an e-portfolio serve us and how they serve our students. This is not to say that e-portfolios should not serve our summative needs nor that the ways we use e-portfolios to evaluate student writing are inherently harmful; in fact, the summative components of the e-portfolios in this study (i.e. standardized learning outcomes, rubrics, grades, and percentages) can be very useful for offering students a fair and transparent evaluation system and for justifying the reliability and validity of our writing assessments (and writing programs!) to outside stakeholders. If we are also, however, going to value student voices in our assessment initiatives, the findings in this study suggest that we might also do well to accentuate the more formative components of an e-portfolio assessment that our students find relevant, purposeful, and/or useful and to re-assess those components that produce anxiety, tentativeness, or apathy in students. Indeed, if a more multiimpactful assessment is possible, why shouldn't it be a goal?

In this regard, this study suggests that there are components of the eportfolio assessment that students enjoy and that are in harmony with our own 
values (i.e. that some truths are not that messy). Understanding what students enjoy about the e-portfolio as a classroom assessment—-such as they are not as stressful as final exams and they allow students to work on their writing over time, to get feedback, to revisit and revise their writing, and to reflect on their writing processes and writerly selves - are strengths of the e-portfolio method to retain and reiterate. Indeed, it may serve us well to market our programs and courses with such formative components as selling points.

But where this assessment model serves to result in only anxiety, apathy or confusion for students, we might do well to reconsider those components of it. For example, students seem to care a great deal about our adjudicating gazes and often (still) think of us as the ultimate appraisers of their e-portfolio performances and writerly selves. Though we may feel uncomfortable (or entitled) by this insight, it is important for us to be aware of our positions of power in the writing classroom and of the effects such a position has on students' abilities to develop confidence, to take risks, and to have agency in their writerly self-performances during an eportfolio assessment. For example, such a consideration might have us more democratically present, discuss, and revise with students the institutional terms and outcomes that we require them to adapt and assimilate into their e-portfolios. Perhaps doing so will empower them to present a less tentative, less awkward, and more assertive, discerning writerly self.

Student insights also suggest that spending time in class with our students to critique and respond to models of e-portfolios can provide a very generative and 
validating exercise for them (and perhaps for us, as well). ${ }^{75}$ When, however, instructors offer models, they should also pay close mind to the kinds of models and writerly self performances they are privileging in those models, knowing the messy truth that students may work diligently to simply mimic those models at the expense of their own more inventive and self-directed performances. Indeed instructors might consider offering access to a wide(r) variety of e-portfolio models for their students and for different and explicit rhetorical purposes (and not only because of the "high quality" of those e-portfolios). This variety could reflect the various subgenres of e-portfolio within a program or across course sections and e-portfolios with very different design schemes, modal compositions, or technological platforms.

Student insights also suggest that when using rubrics and/or institutional learning outcomes as part of an e-portfolio assessment, instructors would do well to assure students (a) understand the language and vocabulary used in the rubrics and outcomes used to evaluate their e-portfolios, (b) have ample time and practice using that language and vocabulary, or otherwise assimilating it, and (c) are exposed to preparatory e-portfolio activities and exercises that lead them thoughtfully towards a higher level of competence in each component of the rubric or outcome. Doing so would likely strengthen their assessment confidences and

\footnotetext{
${ }^{75}$ Compiling and making internally available such a "model showcase" of e-portfolio subgenres would likely have benefits not only for the students in a writing program but for the instructors who teach within a program to "get [their own] sense" of the kinds of e-portfolios students are working on and working towards across courses and across (and beyond) a writing program. Facilitating conversations among those instructors, too, about what they notice and value in these varied and various e-portfolios could also provide generative fodder for WPA-led part-time instructor/adjunct faculty workshops and trainings, especially if e-portfolios are a key component of their assessment practices. This would be particularly helpful for instructors who are new to e-portfolio assessment, as many adjunct faculty are.
} 
lessen their anxieties. In other words, the results of this study suggest that the most effective e-portfolio instruction will provide clear and obvious links between the assignments students engage in to build their e-portfolios and the instruments used to evaluate those e-portfolios (clear and obvious not just to $u s$, but also to our students). The same has been said about the careful connections we make for-and with - our students between what we teach them to write and the tools we then use to evaluate that writing.

Further, students' emergent insights also suggest that should e-portfolio assessments use weighted percentages, points, or grades, that these summative grading practices should be carefully considered, both by the department and by the instructors who assign the e-portfolio so that students understand their purposes. For example, as I stated in Chapter 1, the e-portfolio stakes (as far as grade percentages) were the highest in the first year writing courses and either as high as — or progressively lower in — the courses required for the major, the senior capstone e-portfolio being in one of the lowest weighted groups. This presented a quandary: Why were the final e-portfolio assessments of the most veteran eportfolio composers, who, arguably, have the most to gain from composing a professional e-portfolio (i.e. one that is meant to help them get jobs out of college) weighted fifteen percent lower than the mostly novice e-portfolio composers in the first year courses, who, arguably, have the highest learning curve to tackle to get their first college-level e-portfolio assessment off the ground ${ }^{76}$ Such a messy truth

\footnotetext{
${ }^{76}$ If e-portfolios are going to be tied to percentages and grades, perhaps they could be weighted progressively greater as the courses progress in a vertical curriculum. This may also help novice college writers feel they have a greater chance of succeeding in a first year course, especially as
} 
should at least lead writing instructors and programs to some deeper considerations about the differences in percentages and grading scales tied to the various eportfolio assessment models being used in and across courses at their institution, the results of which should aim to help those students sense a clear purpose for and progression — or at least an interrelatedness or complementarity—between those methods.

In particular, the messy truths students reported about the lack of control they felt over final grades, their progressive and/or unwarranted anxiety about those grades, and their lack of understanding as to why they needed to complete an e-portfolio (for a final grade) at all should lead writing instructors and administrators to reconsider attaching a final grade to an e-portfolio if it only serves to lower our students' motivation and senses of sovereignty. In hearing well students' emergent insights, writing instructors and programs are called upon to offer a sufficient response to the messy truths they raise regarding final grades on classroom-based e-portfolios. Eva's question, in particular, should continue to ring loudly in our ear: "Why? Literally, why does this thing have to exist? It's like being double graded." And when we consider those messy truths alongside the insights offered by senior majors like Katja, Hope, and Holly, who were not at all concerned about their grades but only with how well their e-portfolios served their own professional and personal purposes, we might be led to consider omitting the grading and weighted aspects of the classroom e-portfolio assessment altogether to allow an alternative type of e-portfolio assessment model to emerge (see, for 
example, Jane Danielewicz and Peter Elbow or Asao Inoue's work on contract grading). If that seems too radical, perhaps we can simply consider how eportfolios might better serve students as a writerly self-assessment model by asking about and seeking to meet the particular and unique writerly goals they have; in other words, we can at least consider how e-portfolios might not only "work" for us, but also for our students. ${ }^{77}$ This may require we take a Freireian approach to our e-portfolio re-assessments to assure they are less representative of the "banking model" of education and instead more of the "libertarian" one, but the student insights outlined here suggest that re-assessing (and possibly downgrading) the importance placed on grading and institutional evaluation in a single e-portfolio performance might open up the possibility of e-portfolios becoming more generative spaces within and through which we work with and for students as they curate, reflect, and own the growth of their writerly selves over time - and teach us something in the process. $^{78}$

\section{Areas of Further Study}

It is a messy truth to contend with that disconnections and stratifications exist across courses in our vertical writing curriculums and/or between the writing we ask students to produce in our courses and the writing they do in their majors.

\footnotetext{
${ }^{77}$ For example, senior Holly described to me why her initial anxieties about her final grade subsided after her e-portfolio assessment had ended, saying "I'm proud of what I've created, regardless of the grade. It's working for me. [It has already landed me three job interviews in one of my chosen fields]. That's most important." In other words, for Holly, the long-term purpose of the portfolio eventually trumped the short-term grade assigned to it.

${ }^{78}$ In Pedagogy of the Oppressed, Freire wrote, "Education must begin with the solution of teacherstudent contradiction, by reconciling the pole of the contradiction so that both are simultaneously teachers and students" (72). Where are our e-portfolio assessments performing such reconciliations, and where are they not?
} 
As Broad tells us, however, regularly working to reveal, reassess, and remap the variable and fluctuating truths behind the seemingly neat and tidy institutionalized practices we preserve and sustain, can be much more productive than ignoring them, particularly if such knowing leads to increased student motivation, interest, and transfer (as $I$ contend it would). Scholars in our field have already begun studying these areas and the student insights offered here underscore the importance of this research, particularly as it relates to the limitations and possibilities of the e-portfolio model to play a significant role in such pedagogical aims. ${ }^{79}$ Further, this study compels us to consider the kinds of peer and instructor connections students value and benefit from in an e-portfolio experience, and particularly the effects these - and other - affective components of our classroom pedagogies have on students' writerly (and assessment) performances.

In general, the student reports in this study suggest that writing programs and instructors should seek ways to disabuse students of the "I'm bad with technology" script, which sounds too painfully similar to the "I'm bad at writing" script that so many of them come to our courses believing. Just as writing is an endeavor - a labor - that students (and all of us) can improve upon, so are the writing technologies, multimodal compositions, and design principles that are part of every students' electronic portfolio experience; perhaps we would do well to suggest as much to our students. This may seem simple, but as the results of my study suggest, that these digital natives are often "bad" with technology is not a messy truth we can too quickly and easily dispose of. In fact, we might do well to

\footnotetext{
${ }^{79}$ See, for example, Kathleen Blake Yancey, Liane Robertson, and Kara Taczak's award-wining text Writing across Contexts: Transfer, Composition, and Sites of Writing (2014).
} 
linger on it for a bit, to delve more deeply into this phenomenon: What do students mean by "I'm bad with technology?" What do they think they require in order to be "not bad" at it? In what ways are students already successfully engaging with writing technologies, judiciously composing multimodal texts, and intuitively utilizing design principles in their writerly performances outside the writing classroom? How can we help them see these skills as transferable to an e-portfolio performance and to feel confident enough to tackle an e-portfolio assessment or project that requires them to extend those skills and compose outside of their ecomfort zones? If we continue to ask them, conduct further research in these areas, and reflect on our practices, we may find out the answers (and more messy, but generative, truths).

Finally, portfolios were originally designed to be collaboratively scored among several writing instructors and mostly in a pass/fail context which assumed "the ideal end product [to be] a population of students who have all finally passed because they have all been given enough time and help to do what we ask of them" (Elbow and Belanoff 99). Though the students in this study did pass, many of them did not feel confident they would and worried often about their grades. Further, many students perceived their classrooms instructors often as "raters" and less as the "readers" that the first portfolio models intended them to be. As Yancey has argued, the third wave portfolio model followed from a first wave of timed writing tests designed by testing specialists and a second wave of more holistic and pedagogically-informed writing assessments; the portfolio presented a novel trimodal, or expertise-sharing approach that included reader expertise, theoretical 
expertise, and student expertise (in the form of reflections; "Historicizing" 141-2). The messy truth that students feel less "expert" than perhaps they could or should - and certainly less expert than the instructor — then, compels us to further study the ways our field may be straying from the original participatory, collaborative design of portfolio assessment and in some contemporary contexts yielding (back) to the very psychometric and indirect testing measures over which they first sought to prevail. Of particular importance is further research on the effect such regressions (if/when present) have on students' ability to critically reflect on and feel empowered by the ways an e-portfolio might serve, or work for, them.

\section{A Final Heuristic (Adapted and) Offered}

As a way to put these findings and recommendations to work at the local level, I offer an adaptation of a four-question heuristic that Bob Broad (2003) poses to the field about determining "what [instructors] really value in a ... writing program" with the focus shifted away from ourselves and towards our students:

How do we discover what [students] really value?

How do we negotiate difference and shifts in what [students] value?

How do we represent [our understandings of what students] value? and What difference do our answers to these questions make? (4, my adaptations bracketed and italicized)

This dissertation offers one attempt to respond to these questions: It asks what students value in an e-portfolio assessment; it negotiates and wrangles with the 
differences and shifts in (or the messy truths of) students' reported values (or their emergent learning insights); and, as respectfully as possible, it offers one representation (in the form of a multimodal dissertation) of my understanding of what these students value (using scholarship to suggest how others in the field might agree). Finally, this dissertation follows Broad's lead in offering some of the "ethical, pedagogical, and political" implications that my/our answers to those questions might and/or could have on writing instructors and programs interested or engaged in e-portfolio assessment and challenges those instructors and programs to consider their own localized answers to the adapted heuristic (4-5).

My ultimate hope is that the student voices in this dissertation — and in our own writing classrooms and programs - prompt us to (continue to) consider, in both broad and distinct ways, how we might more effectively adapt and/or present our e-portfolio assessments so that they promote responsive relationships (a la Darren Cambridge) between our students and our institutions. Whether an institution is considering more carefully scaffolding and connecting its e-portfolio assessments across a first year writing program or vertical writing curriculum, or writing teachers are considering ramping up their efforts at technological, modal, and design instruction, or departments are considering more relevant and multiimpactful e-portfolio models (or any assessment model for that matter), this dissertation calls for the pragmatic details of such programmatic and pedagogical revisions to be negotiated thoughtfully not only between faculty, instructors, and administrators but to also and absolutely include the perspectives of those stakeholders who will always have the most at stake in them—our students. 


\section{CONCLUSION}

Linda Adler-Kassner and Peggy O'Neill have suggested that writing and assessment lie at the center of what matters most on most college campuses today, particularly because of the material and political implications these rhetorical practices have on our jobs, our programs, and our students. Having navigated some difficult assessment experiences in my years teaching secondary public school, particularly in regard to the detrimental effects of one version of this truth played out (via decreased student motivation, strains on teacher retention, and stunted curricular progress and evolution), I wish for another version of it to be played out in my spheres of influence at the post-secondary level, mostly in the classroom, but also at the program and university levels (should my influence reach that far).

One part of this new version of how writing and assessment plays out in my spheres of influence includes conducting this study and writing this dissertation in which I attempted to meet Adler-Kassner and O'Neill's challenge that "post secondary writing instructors and program directors get involved in assessment conversations, especially those that are explicitly about writing assessments" (4). This dissertation represents my attempt to join the conversation now so that I may have more agency in the discussions about writing and assessment that will inevitably happen in — and have real and palpable effects onmy future position(s) in the academy, my responsibilities in the classroom, and my rapport and connection with — and, to be overtly pragmatic, my use-value to - the students I teach. 
Further, this new version of how writing and assessment plays out in my spheres of influence (obviously) includes students in the conversation. Again, to quote Adler-Kassner and O'Neill,

Successful reframing effort involves creating a conceivable model . . for assessment grounded in a track record of content and practice. ... [S]tory-changing is much more than just a window dressing through language (what those outside of our field pejoratively refer to as "just rhetoric") — it requires simultaneously conceptualizing, acting upon, and representing work thoughtfully grounded in research, method, and practices. ... [T] hese models must be designed and built collaboratively, with careful attention to the values and passions of all involved, through a process that provides access to all. ... This work requires careful listening, a level of understanding that probably approaches empathy, and a commitment to shared action that must be supported within academic disciplines, by academic institutions, and by those outside the academy, often referred to as "stakeholders," who are invested in what students learn in college. (183-4)

Because our students are not often privy to and virtually never asked to be involved in these conversations, I do (and will continue) this work in an attempt to ethically enrich our writing assessments, while keeping them context-sensitive, local and site-based, and located in and responsive to (best) practice, as Brian Huot (1996) has suggested we must. 
One of the voices that has continued to hauntingly echo in my mind since I concluded my interviews, has been that of Eva's, who asked, "Why does this thing have to exist?" When that voice is placed beside some of the others like hers, particularly those in the first and second year courses who also struggled to find relevance for and a personal connection to their e-portfolio experiences, my teacherly and feminist sensibilities are put on high alert. If you'll permit me (in script form) to "replay" some of the voices I did not (yet) have the space or time to honor before now:

Eva: Why does this thing have to exist?

Casey: I will definitely need writing in science, but not necessarily this kind of writing.

Jean: In my career, it won't be important. I'm a computer science major. I don't know how a writing portfolio with a cover letter on the changes I made to my papers is gonna be important. ... It's just gonna sit there and be done.

Mary: As a nursing major I do not feel the need to gather all my papers into a portfolio. ... I I figured if I had 2,000 words, two papers, and a reflection, I'd be good.

Charlotte: Science kids know their work is going to build up. That gets forgotten in the writing major. 
Julia: I'm torn about portfolios: for the creative element, [it's] fantastic . . but only if all the [technological] elements [and requirements] are understood.

As compared to:

Ariel: This portfolio is a snip-it of my life. It's about my experiences and passions. ... Growing up, I always enjoyed writing and even wrote in my free time. I always kept a journal and wrote in it nearly every day until life got in the way during my junior year of high school. I began to juggle more responsibilities all at the same time and lost sight of my stress reliever. About a month ago I picked up my journal again. This class reminded me that I needed writing, not just as an education requirement.

Ned: I like [my portfolio writing and research] to be available to everybody because of the information I was trying to communicate and get people aware of. I like that it's public. ... It's best when it's . . not behind any walls.

Bethany: All the pieces in my portfolio relate to my major. That was fun because it's what I know; it's what I enjoy learning [and writing] about. Katja: It shows a creative side of myself. It demonstrates my rhetorical strengths. It's filled with imagery and work reflecting my passions, goals, and 
talents. It's like a mini-me in digital form ... a memoir of [my] life ... a testimony of what $[\mathrm{I}]$ did, what $[\mathrm{I}]$ can do.

Hope: It's more like a dream portfolio. It ... reflects everything I've done and everything I hope to do.

Holly: It's working for me.

I find myself wondering how to bridge the affective gap in experience represented in these two "dialogues" (with an appreciation that the conversation is much more nuanced than the script I present). Not that we can make every writing students' e-portfolio experience a stress-relieving, mini-me, dreamy occurrence; but the students in my study were, for the most part, hard-working, conscientious, and engaged (and kind enough to take time out of their summers to talk to me for an hour), yet still some of them reported feeling overwhelmed with, apathetic about, or disconnected from their e-portfolio experiences. I mean, they cared enough to want to tell me all this, so I continue to wonder how we might try to do better by them and their voices; simple as that.

Conducting this study has changed the way I think about students in my writing classrooms and about the assignments (even the term "assignment") and portfolio projects I ask them to complete. For one, I have experimented these past two semesters with grading contracts in place of a typical grading scale that are based on students' writing labors and less on the quality of their writing (indeed, I have begun to focus more on consequences and not aims). I did this in part because of student voices like the ones I heard above and also because Asao Inoue 
has argued (and continues to argue) that "using grades based on judgments of quality (or in comparison to expected, dominant academic discourse) usually devalued the students' labor, and therefore devalues students' writing as experience" (80). Further, he argues,

[When] grading systems based on judging and ranking the quality of writing are used in the classroom, teachers and students unwittingly become victims of larger societal structures like racism, sexism, and classism that use (often invisible) whiteness as the default yardstick by which to make judgments on student writing.

While I am still trying to wrap my head around some of Inoue's bold claims (including those made in his recent keynote speech, entitled, "Racism in Writing Programs and the CWPA," at the 2016 Council for Writing Program Administrators conference last summer, which had me in tears), I have been continually interested in his work as it informs my thinking about grading and assessment in the writing classroom, particularly because Inoue posits writing as labor and experience: "it is time and increased intensity" and it "involve[s] assessment and reflective practices that allow the writing to continue to evolve" (79).

The truth of such labor in action, however, is a little messier. In piloting contracts this past year (after attending a CWPA workshop led by Inoue), I noticed in my own classroom that the "labor journals" I asked students to write focused so much on labor that students seemed overly burdened by them, as if the focus on 
writing as only labor took away from the joyful and creative experience of it. In the spring, I began calling them "slowing down" journals in which I asked students to discuss a few supplemental readings that I made optional (and that many of them actually chose to read) and that I wished to have the effect of privileging the affective and embodied experiences of my student's writerly-selves in and outside the classroom. I anonymously surveyed students on these experiences and, though I have not had the chance to read their reports yet, generally felt such a re-focusing back on students' embodied experiences as writers was much more fruitful and less stressful for them.

Two popular texts in particular-The Space Within: Finding Your Way Back Home by Michael Neill (2016) and Slowing Down to the Speed of Life: How to Create a More Peaceful, Simpler Life from the Inside Out by Richard Carlson and Joseph Bailey (1997) —-helped students (and me) reflect on their/our experiences with stress, rush, and worry and the effects of such thinking on our ability to slow down, center ourselves, and write well. Contemplative writing is a growing subfield of composition and rhetoric with I am just starting to engage with, but I feel they have important positive implications for writing and assessment (and hopefully positive consequences for students). In this study—and in my own teacher/action research, class observations, and informal student surveys - I have been alarmed by the pervasive stresses and anxieties expressed by students about the academic course loads, personal issues, and work-school balances they contend with. In particular, I am concerned about the opportunities for growth, pause, and personal introspection we and our students miss when our 
writing courses offer yet one more (writing) labor to attend to, especially when that labor is stratified and technologically demanding (or even intrusive) and primarily geared towards earning a single course grade. I also love the opportunity for a disruption of our human tendency to jump on board with such busymindedness_ - or, what I have come to see as, "habits of mind" and "outside-in" thinking ${ }^{80}$ - through portfolios that focus on self-reflective writing, writerly-self awareness, and writing as a deeply embodied and affective experience.

These are privileged problems, to be sure, but that doesn't make them any less real for our students and our work. Indeed, if our students — and our "selves"—are too often buying into and taking and designing courses and entering and building programs that contribute to stressful thinking and stratified thought digressions that (a) focus more on the labor and challenge and difficulty of performing writing, that (b) overtly or indirectly suggest writing should be not for ones' self but pleasing to (an ever-illusive) teacher or administrator's eye, and that (c) center primarily on a final portfolio assessment (and not on personal growth, exploration, or greater self-writerly-awareness), I believe not only are we and our students less likely to take risks and think outside the box but that we and they are much less likely to write and teach well and with enjoyment, presence, and deep impact. In response to this being, perhaps, a problem for only a privileged few, I offer the possibility of a portfolio model that works to center and point our attentions, to gently but actively consider a "bigger picture" and our role (and the

\footnotetext{
${ }^{80}$ These are terms I've borrowed from Syndey Banks and others in the international Three Principles Community. Please see more at http://www.sydneybanks.org/, http://threeprinciplesfoundation.org/, and http://www.3pgc.org/.
} 
role writing can play) in it, and to seek creative, non-linear, and collaborative solutions to the social and economic questions and political and educational activities in which we - students and instructors together — are always already engaged. If such a portfolio model aids in students' self(writerly)-growth, and in our own growth as educators, perhaps we will all be better equipped to- to put it simply_ do good work in our classrooms and in the world.

Instead of e-portfolio assessments performing a final judgment (via a grade or percentage) of the greatness — or defectiveness — of our students' writing abilities, I am led by this study to attempt to implement and research in my classrooms less anxiety-producing and, hopefully, more useful e-portfolio models in which students are guided to actively work on their writerly-self evolution; such a model would seek to offer e-portfolios as a multimodal skill-building, mantrasetting, transformative, and transferrable exercise. Such an approach would obviously still honor its original reflective and curatorial purposes while downgrading its psychometric aspects and highlighting its embodied and affective possibilities. I will continue to consider the ways to lessen the negative consequences of this assessment model and highlight the best of them and to be interested in students' perspectives of "best" e-portfolio practices and what effects those practices have on students. My hope is that such an approach would move us more towards e-portfolios as tools for "lifelong learning," as Darren Cambridge has suggested they can and should be (2010)_ or as both an effective assessment model for instructors and a means of writerly-self research and reflection with a and long-term purpose for students. 
I consider the reports of student experiences here the beginning of my "real" work in the academy, the stepping-off point into a career that will be concerned with writing, with assessment and its consequences, and with building collaborative and local models of writing assessment that inform our classroom practices and scholarship while also informing, furthering, and affirming the professional goals and personal aspirations of our students. I believe the best writing assessments can and must do all of these. 


\section{APPENDICES}

\section{Appendix A: Recruitment Email}

Dear URI Student,

\section{Are you creating and submitting an electronic portfolio for your} writing course this semester? If so, would you be interested in participating in my research study?

My name is Bridget Heaney, and I am a Ph.D. student in the Writing and Rhetoric Department here at URI. I am presently preparing a research study for my dissertation and am writing to invite you to participate in the study. For this study, I am interested in hearing students' perspectives about their electronic portfolioor e-portfolio- experiences in their writing courses at URI.

The study would require you to complete $\mathbf{1}$ brief survey (online) and $\mathbf{2}$ reflection logs (online) about your progress on your e-portfolio during the semester. If you complete them, you would be entered into a raffle to win $\mathbf{\$ 2 5}$. I may also select you to complete $\mathbf{1}$ interview (in-person, with me) about your final e-portfolio after the writing course has ended and your final grade is posted on eCampus. At this interview you would need to be willing to share your e-portfolio with me. If selected, we would schedule this interview at your convenience sometime between May 3 and June 15, 2016. If interviewed, you would receive a \$25 thank you gift. 
Your participation in this study would be confidential; your writing professor would not know if you choose to participate and in no way would your participation affect your grade in the writing course. Additionally, none of the information I collect from you would identify you by name. If you do participate, you can choose your own pseudonym, or I can choose one for you.

If you are interested in participating, have questions, and/or would like to hear more about this study, please call, text, or email me to set up a one-on-one meeting with me on campus. My contact information is below. I intend to begin the study in February 2016, so please contact me soon.

Sincerely,

Bridget Fullerton

bridget72@uri.edu

401-533-4371 
Appendix B: Recruitment Flyer

I will hang these in strategic locations around campus.

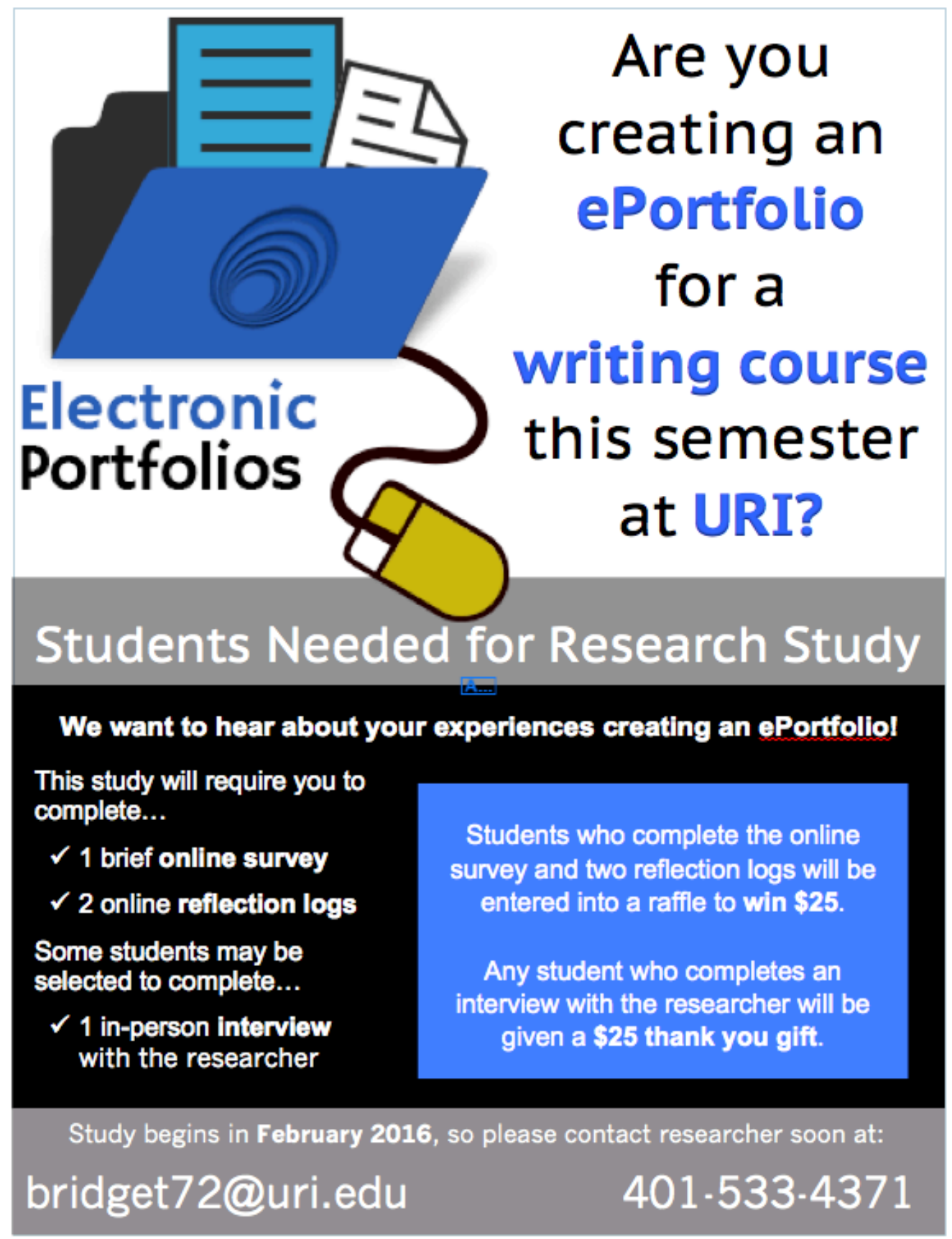




\section{Appendix C: Recruitment Script}

NOTE: I will read this script to every writing class I get permission from the instructor to visit. When presenting in Principal Investigator Dr. Nedra Reynolds's classrooms, she will leave the room; otherwise, instructors may choose to stay or leave the room. I will also use this script in one-on-one meetings with students who receive my email or see my flyer and reach out to me because they are interested in participating in the study.

Hello, [student name or "everyone"], and thank you for letting me take a few minutes of your time to talk to you about a research study I am conducting and that I hope you will consider being involved in. My name is Bridget Fullerton and I am a writing instructor here at URI and also a graduate student in the Writing and Rhetoric program. Out of curiosity, [are you a major or double major or how many of you are majors or double majors] in our program? [Are you minoring in the program? or Are there any writing and rhetoric minors here today?] Great! Well, for my study, it doesn't matter whether or not you are a writing major, a writing minor, or if you love, fear, or hate writing. In fact, I absolutely welcome all kinds of writers and all kinds of feelings about writing. In fact, the more diverse the participants, the more interesting the study will be!

So here's the deal: I'm looking to recruit any student taking a writing course at URI who is also required to complete an electronic portfolio for that course. For my study, I am going to ask students to tell me about their electronic portfolio experiences. In other words, I am interested in how students in writing 
courses experience the electronic portfolio process, especially as it relates to this portfolio being an assessment of your writing, a final evaluation of your writing ability and growth in this course, and a major percentage of your final grade. If this will be your first time creating a portfolio—electronic or otherwise—-for a writing class — or any class, for that matter — then, great! I would love to hear your perspective. If you have had several experiences—or even just one other experience creating a portfolio, even in another course, for another subject or purpose, or maybe even in high school — then, great! I would love to hear your perspective, too. Your previous experience does not matter for my study as much as your experience in the writing class you are in this semester with the particular electronic portfolio you are going to create and submit for grading. The information you provide me can be used to help writing instructors and college administrators develop more effective electronic portfolio assignments and assessments that are more relevant to and useful for college students like yourself in the future. In particular, if you choose to participate, I'll ask you about your previous experiences with portfolios, your current experiences with the key portfolio processes of collection, selection, and reflection, about your level of interest and engagement in the portfolio assignment, and about what you eventually learn from the portfolio experience, especially what you didn't expect to learn but did.

You're probably wondering what kind of time commitment this will entail. Well, I'm hoping to make it as easy on you as possible and will even offer a thankyou gift for your participation. Take a look at the consent form I handed out. What 
I'm about to say is detailed there under the section "What Will Be Done." If you choose to be involved in the study by signing the consent form, I will ask you to complete a few tasks for me in two stages. During the first stage of the study, I will ask student participants to complete a short online demographic survey between February 1 and March 1,2016. The survey will ask you a few basic questions about yourself, like your major, your age, and how many portfolios you've done and writing classes you've taken at URI. It should only take about 10 minutes. Then, I will email you two reflection logs at two different times later in the semester, between March 1 and May 2, 2016. For each log, you have to answer a few questions about your past portfolio experiences and how your portfolio preparation is going in this course. Each log should not take you more than 30 minutes. So your total time commitment for the semester would be up to 70 minutes and by completing the demographic survey and two reflection logs, you will be entered into a raffle to win a thank-you gift of $\$ 25$. This is your first chance to win $\$ 25$.

For the second stage of the study, I will be selecting 15 to 20 students who completed the online survey and two reflection logs to be interviewed by me, oneon-one between May 3 and June 15, 2016. If you are selected for that interview, I will ask you questions about your electronic portfolio experience in this class. During the interview, you will also show me and talk to me about the learning outcomes for the course, your e-portfolio assignment instructions or directions, and your final e-portfolio. So, if you choose to participate, you'll need to be okay with sharing your e-portfolio with me in that interview. Interviews will last from 
60 to 90 minutes. It's important for you to know that I will not conduct the interview until after your final electronic portfolios are submitted to your professor and after your final grades are poste on e-Campus. This interview will not affect your grade in any way, nor will what you say be shared with anyone else. If you are selected for the interview, your total time commitment will be up to 90 minutes and this will be your second chance to earn a $\$ 25$ thank-you gift for your time.

It also states in the consent form that your choice to participate in this study will NOT affect your grade in this course or on your final portfolio in ANY way. The research I am doing is completely separate from your performance and assessment in this class. Your professor will not know who participated in this study and who did not. In fact, no one except me will know that you are participating in this study and your name will never be included in any publications or presentations that relate to this research and the information you share with me will not be used to personally identify you, nor will it be passed on to anyone else. All participants will remain anonymous; in fact, I will encourage participants to select their own pseudonyms, or fake names. If you don't choose one, I will assign one for you. Also, if at any time you wish to drop out of the study, you may do so with absolutely no consequences at all. I have secured permission from the Institutional Review Board at URI, so you should also know that the Division of Research at URI has approved my study. Please take some time to review the rest of the consent form in front of you. In order to be involved in the study or selected for the interview, you must sign this consent form but remember you can drop out at any time. [If in a class presentation, say: I will not 
know who signed the form and who did not until after I have left this room, so don't feel any pressure to sign it right now.]

Do you have any questions for me? [answer questions]

If you think you would like to participate in the study, please take a few moments to review and sign the consent form in front of you. There are two copies of this form. One says "for the student participant" and is three pages. Please sign and keep that one for your own records. The other one says "for the researcher" and is four pages. That one has an extra page for your email and phone number so I can be in touch with you to begin the study. If you are not sure you want to be in the study, I suggest you either (a) sign the forms and return them to me now; you can decide later to drop out with no consequences, or (b) keep all the forms and get in touch with me if you decide you would like to be in the study. My name and email are on the form. Just be sure to do this soon because the study will begin soon. If you are certain you do NOT wish to be in my study, then please simply do not sign the consent form and return it blank.

[If in a class presentation, say: Please put the consent form with your Contact Information in this envelope after I have left. Remember to sign the forms if you wish to be in the study, or leave them blank if you don't. If you choose to participate in the study by signing the form today, please don't forget to print your email and phone number on the fourth page so I can email you a link to the first survey. I will return at the end of class to collect the envelope. Then move to the final paragraph.] 
[If in a one-on-one meeting with prospective participant, say: Do you need some time to think about it or have you made a decision now? If the student wants to be in the study, ask them to sign both forms and keep one for my records, give the other copy to the student, and move to the final paragraph. If they are unsure or do not wish to join right now, move to the final paragraph.]

Do you have any other questions? [answer any questions] Okay, thank you, again, for your time. Please contact me via email if you have any questions or change your mind one way or the other. [If in a class, say: I look forward to working with those of you who select to be in the study!]. 


\section{Appendix D: Demographic Info Survey}

NOTE: After a student has signed the consent form, I will email a link to an online version of this survey (using SurveyMonkey) between February 1 and March 1, 2016.

\section{Email Introduction}

Dear [student name],

Thank you for volunteering to participate in my study about students' perceptions of electronic writing portfolio assessment. Please click on the following link to complete the first demographic survey: [include URL/link to survey here]. There are 12 questions and it should take you no more than 10 minutes. If you complete this survey and the two online reflection logs (which I will email you links to later this semester), you will be entered to win a $\$ 25$ thankyou gift. I will email the winners of the raffle by May 3, 2016. Please complete this survey by March 1, 2016.

If you have any questions or concerns, please email, call, or text me. My contact information is below.

Sincerely, Bridget Fullerton 
$401-533-4371$

bridget72@uri.edu

\section{Online Survey Introduction}

Thank you for volunteering to participate in my study about students' perceptions of electronic portfolio assessment. This is a brief demographic survey that I will only ask you to complete once; it asks questions about you. This information is necessary to help me be in touch with you, as well as to better understand you and your experiences with writing and portfolios. The data you share with me will not be used to personally identify you, and will not be passed on to anyone else. Please be sure to complete this survey on a computer you know is safe and in a location you feel is private. You may stop or cancel this survey at any time by clicking $[X X]$. There are 12 questions in this survey and it should take you no more than 10 minutes. Please complete this survey by March 1, 2016.

1. What is your name?

2. In order to protect your privacy, I will use a pseudonym, or fake name, when referring to you in my data and research reports. Would you like to select your own pseudonym?

a. YES [Please list your name choice here] 
b. NO, you may choose my pseudonym.

3. Please indicate the best email and phone number at which I can reach you (so I can get in touch with you about the study over the course of the semester; I will not share this information with anyone):
a. Email:
b. Phone:

4. What year did you graduate high school?

5. What year are you currently in at URI?
a. Freshman
b. Sophomore
c. Junior
d. Senior

6. What is your age?

7. Please choose one:
a. Male
b. Female

8. What is your major at URI (list more than one if needed)? 
9. What is your minor (if you have one)?

10. Please enter the writing course code you are enrolled in right now (example: “WRT 104" or "WRT 495").

11. Please indicate how many writing courses you have taken at URI:

a. None, this is my first

b. 1 before this one [please indicate which one (example: "WRT 106" or "235")]

c. 2-3 courses [please indicate which ones]

d. More than 3 courses [please indicate which ones]

12. Please indicate how many portfolios (of any kind) you have created in a writing course or in any other course, either in college or high school:
a. None, this is my first
b. 1 before this one
c. $\quad 2-3$ portfolios
d. $\quad$ More than 3 portfolios 


\section{Appendix E: Reflective Log I}

NOTE: Students will be asked to complete the reflective log below near the start of the semester. I will email students a link to an electronic version of the log (using SurveyMonkey) between March 1 and April 1, 2016.

\section{Email Introduction}

Dear [student name],

Thank you for your continued participation in my study about students' perceptions of electronic writing portfolio assessment. Please click on the following link to complete the first reflection log: [include URL/link to survey here]. There are 5 main questions and 3 related sub-questions. The log should take you no more than 30 minutes. By completing the demographic survey and two online reflection logs for this study, you will be entered to win a $\$ 25$ thank-you gift. I will email the winners of the raffle by May 3, 2016. Please complete this log by April 1, 2016.

If you have any questions or concerns, please email, call, or text me. My contact information is below.

Sincerely, Bridget Fullerton 
$401-533-4371$

bridget72@uri.edu

\section{Online Log Introduction}

Thank you for volunteering to participate in my study about students' perceptions of electronic portfolio assessment. This is your first reflection log that I will only ask you to complete once; it asks questions about your experience creating portfolios. This information is necessary to help me better understand you and your experiences with writing and portfolios. The data you share with me will not be used to personally identify you, and will not be passed on to anyone else. Please be sure to complete this log on a computer you know is safe and in a location you feel is private. You may stop or cancel this log at any time by clicking [XX]. There are 5 main questions in this survey, and 3 related sub-questions. This log should take you no more than 30 minutes. Please complete this log by April 1, 2016.

1. In general, how prepared do you feel to create an electronic portfolio in this class?
a. Not prepared
b. Somewhat prepared
c. Well prepared
d. Very well prepared 
i. EXTENSION: Please expand a little on your response. Why do you feel this way?

2. Is this class your first experience creating a portfolio of any kind (for example, a print/paper portfolio, an artistic/creative portfolio, a portfolio for high school graduate, etc.)?
a. YES
b. NO

3. Is this class your first experience, specifically, with creating an electronic portfolio assessment?
a. YES
b. NO

4. If you answered NO for either questions 2 or 3 above, please briefly respond to the following questions (otherwise skip to the next question).

a. Tell me a little about your past experience with portfolios.

For example, talk about when you did it/them, what kind of portfolio(s), for what subject, and if for a grade, score, graduation requirement, or for something other purpose.

b. Overall, how did you feel about that portfolio experience? What did you enjoy about it or learn from it? What was frustrating or challenging about the experience? Why? 
5. How do you think your past experiences—or lack of experiencemight affect your final grade for this electronic portfolio in this class? Please briefly explain your answer. 


\section{Appendix F: Reflective Log II}

NOTE: Students will be asked to complete the reflective log below as they are working on or preparing their final e-portfolios. I will email students a link to an electronic version of the log (using SurveyMonkey) between April 1 and May 2, 2016.

\section{Email Introduction}

Dear [student name],

Thank you for your continued participation in my study about students' perceptions of electronic writing portfolio assessment. Please click on the following link to complete the second, and final, reflection log: [include URL/link to survey here]. There are 6 main questions and 7 related sub-questions. The log should take you no more than 30 minutes. By completing the demographic survey and two online reflection logs for this study, you will be entered to win a $\$ 25$ thank-you gift. I will email the winners of the raffle by May 3, 2016. This is the final online form you will be asked to complete for this study. Please complete this $\log$ by May 2, 2016.

After completing this reflection log, you may be selected for a final interview. If selected, I will contact you near the end of the semester to schedule 
the interview at your convenience. You will be offered a $\$ 25$ thank-you gift for your participation in that interview.

If you have any questions or concerns, please email, call, or text me. My contact information is below.

\author{
Sincerely, \\ Bridget Fullerton \\ 401-533-4371 \\ bridget72@uri.edu
}

Introduction: Thank you for volunteering to participate in my study about students' perceptions of electronic portfolio assessment. This is the second and final reflection log. I will ask you to complete it only once. This log asks questions about your progress on your electronic writing portfolio so far in your class. You may complete this log whether you have made no progress, a little progress, or a lot of progress - there is no progress requirement for completing this log. This information is necessary to help me better understand you and your experiences with this writing portfolio so far. The data you share with me will not be used to personally identify you, and will not be passed on to anyone else. Please be sure to complete this log on a computer you know is safe and in a location you feel is private. You may stop or cancel this log at any time by clicking [XX]. There are 6 
main questions in this survey, and 7 related sub-questions. This log should take you no more than 30 minutes. Please complete this $\log$ by May 2, 2016.

1. How excited are you about this final electronic portfolio?
a. Not excited
b. Somewhat excited
c. Very excited

i. EXTENSION: Please expand a little on your response. Why do you feel this way?

2. In what ways do you feel this portfolio relates to your life, your interests, or your educational or career goals? In what ways does it not relate?

3. What do you hope to learn from this electronic portfolio experience? What have you learned so far?

4. Have you begun collecting and selecting artifacts to include in your final portfolio?

a. YES

i. EXTENSION: What are some of those artifacts?

ii. EXTENSION: How are you collecting and selecting them? 
iii. EXTENSION: Why are you collecting and selecting them?

b. NO

i. EXTENSION: Why not?

5. Have you done any reflecting on your writing?

a. YES

i. EXTENSION: How are you doing these reflections?

ii. EXTENSION: Why are you doing these reflections?

b. NO

i. EXTENSION: Why not?

6. How nervous are you about your final electronic portfolio grade?

a. Not nervous

b. Somewhat nervous

c. Very nervous

i. EXTENSION: Please expand a little on your response. Why do you feel this way? 


\section{Appendix G: Student Interview Questions}

PREAMBLE: [Student name], thank you for coming today and thank you for continuing to be a part of this study. It looks like you completed the online survey and both of the online reflection logs. Nice work! They will be very helpful in my research. And, now, welcome to the final interview. As I have mentioned to you before, this study is to understand college student experiences with electronic portfolios in writing classrooms. The information you provide can be used to help writing instructors and college administrators — both here at URI and beyonddevelop more effective electronic portfolio assignments and assessments that are more relevant to and useful for college students. In this interview, I am going to be asking you several questions about electronic portfolios, especially your experience with portfolios as a method of assessment. When I say "as a method of assessment," I mean as a form of testing or evaluation. Throughout this interview, I will use words like grading, testing, evaluation or evaluating, and assessment or assessing and they all relate to a similar concept that I'm interested in hearing your perspective on: that the portfolio in this course was used as a test or evaluation of your writing. That's just something to keep in mind as you answer my questions. Do you have any questions about this? [answer questions]

I'll remind you of the consent form I asked you to sign at the beginning of the study. You can choose not to answer particular questions or may stop the interview at any time. While I have a list of questions I'd like to ask, I hope this interview feels more like a conversation than a series of scripted questions. I'll leave time at the end for any questions you might have. Do you have any questions 
now, before we begin? Okay. I am now going to turn on the recording device and ask you the first question.

\section{QUESTIONS}

1. I asked you to bring three things with you today: your e-portfolio, the learning outcomes for the course (if you had them), and your e-portfolio assignment instructions or directions. Can I see those instructions while you

explain to me, generally, what you were asked to do for your final portfolio in this course?

a. PROBE: In general, how did you feel about the prospect of creating such a portfolio?

2. Did this portfolio feel like an evaluation or final exam to you? Please explain your responses.

a. PROBE: What factors-like people, technologies, past experiences - do you think affected how you felt about this portfolio evaluation?

3. The portfolio was worth a certain percentage of your grade, correct? What percentage of your grade was this e-portfolio worth? When did you find out about this percentage and how did you feel about it? Please explain your answer a bit.

4. Can you tell me about some of the ways your writing has been evaluated in the past? For example, what kinds of writing tests, exams, or evaluations have you been exposed to? 
a. PROBE: How did you feel about these evaluations as compared to the portfolio evaluation in this class for you? For example, were they more difficult or easier, more or less confusing, more or less frustrating, more or less anxiety-provoking? Or did you not feel a difference at all? Please explain your response.

5. In preparing for your portfolio, were you told to collect items to include in it throughout the course? [if yes, then...] Did you do this? If so, how? If not, why not?

a. PROBE: Was there anything else you did to collect items for your portfolio?

6. What technology or software programs(s) did you use to create your e-portfolio? How did you feel about the technology you used? Was there anything particularly difficult, frustrating, or confusing about the technology?

a. PROBE: What did you enjoy about the technology?

b. PROBE: What might have helped you feel better about the technology you used?

Let's take a look at your e-portfolio for the next set of questions, okay? Just so you know, I will now be recording a video of the clicks and moves you make on the computer screen as well as your voice. [Here I will give students time to pull up their e-portfolio on a computer screen. At this time, I will also turn on the screencasting software to record both the computer screen and the student's voice.] 
7. WHILE LOOKING AT THE e-portfolio: As I ask you the following questions, please click through your e-portfolio to respond to them. What particular pieces of writing did you select to include in your e-portfolio?

a. PROBE: When did you begin selecting these pieces?

b. PROBE: Why did you select these items? How did you select them?

c. PROBE: Who or what influenced you to select them?

d. PROBE: What did it feel like to select these pieces?

e. PROBE: Was there anything particularly difficult, frustrating, or confusing about the selection process for you?

8. WHILE LOOKING AT THE e-portfolio: In order to create your eportfolio, you may have made choices about the modes you used in it, like text, images or pictures, sounds, videos, or hyperlinks. What modes did you select to use in your e-portfolio? Please point out some of them. Why did you select these modes?

a. PROBE: What modes did you not use and why?

b. PROBE: Is there anything that could have helped you make better modal selections?

9. WHILE LOOKING AT THE e-portfolio: I've read your reflection, but would like to hear a little more about it. Where is your reflection in this eportfolio? Why did you choose to include it here? 
a. PROBE: What was your main intention in writing this reflection? In other words, what were you trying to do with it?

b. PROBE: Who or what influenced you to write it the way you did?

c. PROBE: What did it feel like to write this reflection?

d. PROBE: Were you aware of how much the reflection piece would affect your final grade on the portfolio? How did you feel about this?

e. PROBE: Was there anything particularly difficult, frustrating, or confusing about writing the reflection for you?

f. PROBE: What did you enjoy about it?

g. PROBE: Is there anything else you would have liked to have known about the reflection before you had to write it? Anything that might have helped you?

10. WHILE LOOKING AT THE e-portfolio: Do you feel your eportfolio and the writing you chose to include in it represents your true self, or shows who you really are?

a. PROBE: If so, please explain your response a bit more and show me sections of the e-portfolio that you think represent you the most. If not, why does this e-portfolio not represent you-what does it lack? 
b. PROBE: Which selections represent your best writing?

What makes these your best? Please show me those selections while you explain your response a bit more.

The next set of questions has to do with the final evaluation of your eportfolio and your grade on it. I will keep the screencasting software on, however, you only need to refer to your e-portfolio on the computer screen if you wish to.

11. Do you mind sharing with me the grade you received on this eportfolio?

a. [If no, then...] Thank you. I appreciate your candidness. What was your grade?

b. [If yes, then ...] Okay. I understand your desire for confidentiality about your grade. I am still interested in your response to the following questions.

12. In your second reflection log, you stated that you felt [not nervous, somewhat nervous, very nervous] about your final electronic portfolio grade. Did your feelings change about this grade now that you have it? If so, how did they change and why? If not, why not?

13. Who put the final grade on your e-portfolio? Did the evaluator make clear to you how s/he/they would be judging your e-portfolio? In other words, did you have access to a list of learning outcomes, a rubric, or a checklist of some sort? 
a. PROBE: How do you think did your understanding of how your e-portfolio would be graded or evaluated affect your performance on it?

b. PROBE: Was there anything else you would have liked to know about the expectations of the instructor or evaluator before you submitted your e-portfolio?

14. In your first reflection log, you talked about your past experiences with portfolios. You said [remind them of their past experience or lack thereof they wrote about]. Do you think that experience affected your final grade on your e-portfolio in this course? If so, how? If not, why not?

a. PROBE: Are there any experiences that happened in this class that you think affected your final grade on this e-portfolio? Tell me a bit about those and how you think they affected your grade.

The next set of questions relate to your level of engagement, excitement, and interest in this portfolio. They also relate to what you learned from your portfolio experience.

15. In the second reflection log, you wrote that you were [not excited, somewhat excited, very excited] to complete the portfolio. Now that you have finished it and your portfolio has been graded, would you say that level of excitement has changed or stayed the same? Please explain your answer. 
16. You also wrote about how you felt the portfolio related—or did not relate - to your life, your interests, or your educational or career goals [remind them what they wrote]. Do you still feel this way now that you have completed the portfolio and have a final grade on it? Please explain your answer.

a. PROBE: Is there anything that could have made the portfolio more relevant for you? Please explain your answer.

17. May I see the learning outcomes for the course that I asked you to bring (if you were given any)? [Whether they brought them or not, the following questions can still be asked.] How did you feel about these learning outcomes? Which outcomes do you feel you improved upon the most? Which were difficult for you?

a. PROBE: What would you say were some things you learned from this portfolio assessment that were not part of the learning outcomes for the course? In other words, what did you take away or think was valuable for you in this portfolio experience that perhaps you didn't expect or that wasn't covered in these course goals and outcomes?

I have just two more questions about your final suggestions and thoughts. I will turn off the screencasting recording software now. The audio recording will remain on. [turn off screencasting] 
18. If you could sit on a committee that helped instructors redesign their assignments, syllabi, or courses to improve students' experiences with eportfolios, what would you suggest they do?

19. Do you have any final questions for me or anything else you would like to say about your e-portfolio experience?

20. My last question is regarding your pseudonym, or the fake name I will use when referring to you in my data and research. In the initial demographic survey, you stated that you [would/would not $]$ like to choose your own pseudonym. [You/I] chose [pseudonym]. Is this okay with you? [Make changes as needed]

CLOSING: Thank you for your time. The insight you shared is incredibly valuable. [Give info on next steps/follow up/member check and turn off the audio recording device after student has left the room. I will also present interviewees with a $\$ 25$ thank-you gift at this point.] 


\section{Appendix H: List of Course Learning Outcomes}

\section{0-level Expository and Research Writing}

Upon completion of this course, students will have gained experience in the following areas:

1. Understanding of Rhetorical Situation

a. Students recognize that different rhetorical situations (audiences, purposes, contexts) call for different types of writing.

b. Students practice different types of writing appropriate to different rhetorical situations (audience, purposes, contexts).

c. Students reflect upon and explain the appropriateness of their choices for the rhetorical situation.

2. Composition Processes and Practices

a. Students recognize differences between revision and editing.

b. Students practice various methods of invention, collaboration, research, ethical incorporation of sources, peer review, and revision.

c. Students describe and analyze their different methods of invention, collaboration, research, ethical incorporation of sources, peer review, and revision.

3. Conventions and Craft

a. Students recognize standards of correctness, usage, and style.

b. Students practice a range of styles, registers, and conventions.

c. Students revise and edit their work to produce polished texts that 
meet the demands of the rhetorical situation.

200-level Digital Writing

Students will:

- Identify and analyze the affordances of different digital writing environments

- Evaluate messages in different electronic environments.

- Create and deliver effective messages in different digital writing environments

200-level Writing Arguments

Upon completion of this course, students will have:

- Gained experience in writing effectively, speaking effectively, and working with qualitative data (i.e., visual elements);

- Learned about kinds of arguments, the appeals, and fallacies;

- Practiced techniques for structuring and supporting arguments;

- Gained skill in analyzing others' written arguments;

- Sharpened your ability to support your arguments with evidence from sources, documented correctly;

- Produced convincing written arguments;

- Given valuable feedback to the writing of your classmates;

- Demonstrated your learning in a portfolio. 
300-level Travel Writing

Upon completion of this course, students will have

- Developed creative capacity in writing

- Developed skill in expressing oneself in writing

- Acquired skills in working with others as a member of a team

- Gained experience in writing effectively, reading complex texts, and understanding human difference

- Identified rhetorical situations calling for a wide range of responses

- Evaluated the appropriateness of your rhetorical choices

- Evaluated and responded to other writers, both professionals and your peers

- Practiced organizing your texts according to the conventions of the genres and forums you choose

- Produced sophisticated texts with correctness, recognizing and self-editing your errors

- Demonstrated coherence and cohesion in your written texts

- Considered, applied, and controlled different stylistic options in crafting your texts

- Synthesized and integrated insights across your projects in this course. 
400-level Senior Portfolio in the Major

Upon completion of this course, students will have

- Practiced conceptualizing electronic portfolios for writing.

- Reflected on the role of electronic writing portfolios in learning and society.

- Studied "how-to" accounts of electronic portfolio design.

- Designed your own collection of representative writings for the Web.

- Implemented your portfolio design in a stand-alone Web site.

- Reflected on your electronic portfolio in a public way. 


\section{BIBLIOGRAPHY}

Addams, Jane. 20 Years at Hull-House. San Bernadino, CA: Empire Books, 2012. Print.

Adler-Kassner, Linda and Peggy O'Neill. Reframing Writing Assessment to Improve Teaching and Learning. Logan: Utah State UP, 2010. Print.

Alexander, Kara Poe. "Material Affordances: The Potential of Scrapbooks in the Composition Classroom." Composition Forum 27 (2013). Web.

Auerback, Carl F. and Louise B. Silverstein. Qualitative Data: An Introduction to Coding and Analysis. New York: NYU Press, 2013. Print.

Baker, Nancy Westrich. "The Effect of Portfolio-Based Instruction on Composition Students' Final Examination Scores, Course Grades, and Attitudes toward Writing." Research in the Teaching of English 27.2 (1993): 155-174. Print.

Barbour, Rosaline. Doing Focus Groups. Los Angeles: Sage Publications, 2007. Print.

Bizzell, Patricia. "'Contact Zones' and English Studies." College English 56.2 (1994): 163-169. Print.

Black, Laurel, Donald A. Daiker, Jeffrey Sommers, and Gail Stygall. "Writing Like a Woman and Being Rewarded for It: Gender, Assessment, and Reflective Letters from Miami University's Student Portfolios.” New Directions in Portfolio Assessment. Eds. Laurel Black, Donald A. Daiker, Jeffrey Sommers, and Gail Stygall. Porstmouth, NH: Boynton/Cook. 1994. 235-247. Print. 
Bower, Matt. "Affordance Analysis: Matching Learning Tasks with Learning Technologies." Educational Media International 45.1 (2008): 3-15. Print.

Broad, Bob. What We Really Value: Beyond Rubrics in Teaching and Assessing Writing. Utah State UP: Logan, Utah. 2003. Print.

---. 'Pulling Your Hair Out: 'Crisis of Standardization in Communal Writing Assessment'." Research in the Teaching of English 35.2 (2000): 213-260. Print.

Brodkey, Linda. "Writing on the Bias." College English 56.5 (1994): 527-547. Print.

Burch, C. Beth. "Inside the Portfolio Experience: The Student's Perspective." English Education 32.1 (1999): 34-49. Print.

Burnham, Christopher. "Portfolio Evaluation: Room to Breathe and Grow." Training the New Teacher of College Composition. Ed. Charles W. Bridges. Urbana, IL: National Council of Teachers of English, 1986. 125138. Print.

Cambridge, Darren. e-portfolios for Lifelong Learning and Assessment. San Francisco: Jossey-Bass, 2010. Print.

---. "Universities as Responsive Learning Organizations Through CompetencyBased Assessment with Electronic Portfolios.” The Journal of General Education 57.1 (2008): 51-64. Print.

Chang, Heewon. Autoethnography as Method. London: Left Coast Press (now part of Routledge), 2008. Print. 
Danielewicz, Jane and Peter Elbow. "A Unilateral Grading Contract to Improve

Learning and Teaching." College Composition and Communication 61.2 (2009): 244-268. Print.

DeWalt, Kathleen M. and Billie R. DeWalt. Participant Observation: A Guide for Fieldworkers. Lanham: Altamira Press, 2011. Print.

Durst, Russel K., Marjorie Roemer, and Lucille M. Schultz. "Portfolio

Negotiations: Acts in Speech.” New Directions in Portfolio Assessment.

Eds. Laurel Black, Donald A. Daiker, Jeffrey Sommers, and Gail Stygall.

Porstmouth, NH: Boynton/Cook. 1994. 286-300. Print.

Elbow, Peter. "Will the Virtues of Portfolios Blind Us to Their Potential Dangers?" New Directions in Portfolio Assessment: Reflective Practice. Eds. Laurel Black, Donald A. Daiker, Jeffrey Sommers, and Gail Stygall. Portsmouth, NH: Boynton, 1994. Print.

--- and Pat Belanoff. "Portfolios as a Substitute for Proficiency Examinations." College Composition and Communication 37 (1986): 336-339. Print.

Gallagher, Chris W. "The Trouble With Outcomes: Pragmatic Inquiry and Educational Aims." College English 75.1 (2012): 42-60. Print.

Galletta, Anne. Mastering the Semi-Structured Interview and Beyond: From Research Design to Analysis and Publication. New York: NYU Press, 2013. Print.

Gibson, James J. "The Theory of Affordances." Perceiving, Acting, and Knowing: Toward an Ecological Psychology. Eds. Robert Shaw and John Bransford. Hillsdale, NJ: Lawrence Erlbaum Associates, Inc., 1977. 67-82. Print. 
Grabill, Jeffrey T. "Technology, Basic Writing, and Change." Journal of Basic Writing 17.2 (1998): 91-105. Print.

Guest, Greg, Emily E. Namey, and Marilyn Mitchell. Collecting Qualitative Data: A Field Manual for Applied Research. Los Angeles: Sage Publications, 2013. Print.

Guest, Greg, Kathleen M. MacQueen, and Emily E. Namey. Applied Thematic Analysis. Sage Publications: Los Angeles, 2012. Print.

Hamp-Lyons, Liz and William Condon. "Questioning Assumptions about Portfolio-Based Assessment." College Composition and Communication 44.2 (1993): 176-190. Print.

Herrington, Anne and Charles Moran. "Challenges for Writing Teachers: Evolving Technologies and Standardized Assessment." Teaching the New Writing: Technology, Change, and Assessment in the $21^{\text {st }}$-Century Classroom. Eds. Anne Herrington, Kevin Hodgeson, and Charles Moran. Teacher College Press: New York and National Writing Project: Berkeley, CA. 2009. Print. Huot, Brian. "Toward a New Theory of Writing Assessment." College Composition and Communication 47 (1996): 549-567. Print.

---. "Toward a New Discourse of Assessment for the College Writing Classroom." College English 65.2 (2002): 163-180. Print.

--- and Michael M. Williamson. "Rethinking Portfolios for Evaluating Writing: Issues of Assessment and Power." Situating Portfolios: Four Perspectives. Eds. Kathleen B. Yancey and Irwin Weiser. Logan: Utah State UP, 1997. 43-56. Print. 
Inoue, Asao B. "A Grade-Less Writing Course That Focuses on Labor and Assessing." First-Year Composition: From Theory to Practice. Eds.

Deborah Coxwell-Teague and Ronald F. Lunsford. South Carolina: Parlor Press, 2104. Print.

Jewitt, Carey, Ed. The Routledge Handbook of Multimodal Analysis. London: Routledge, 2016. Print.

Jones, Susan R., Vasti Torres, and Jan Arminio. Negotiating the Complexities of Qualitative Research in Higher Education: Fundamental Elements and Issues. New York: Routledge, 2014. Print.

Kimball, Miles A. The Web Portfolio Guide: Creating Electronic Portfolios for the Web. New York: Longman, 2003. Print.

Kress, Gunther. Multimodality. A Social Semiotic Approach to Contemporary Communication. London: Routledge, 2010. Print.

---, Gunther and Steffan Selander. "Multimodal Design, Learning and Cultures of Recognition." Internet and Higher Education 15 (2012): 265-268. Print.

Lenhart, Amanda. "Teens, Social Media, and Technology Overview 2015." PewResearch.org. Washington, DC: Pew Research Center, April 2017. Web.

National Council of Teachers of English. "Writing Assessment." College Composition and Communication 63.3 (2012): 528. Print.

---. "Writing Assessment: A Position Statement." CCCC Position Statement. Illinois: Urbana, 2015. Web. 
The New London Group. "A Pedagogy of Multiliteracies: Designing Social Futures." Harvard Educational Review 16.1 (1996): 60-92. Print.

Peters, Brad and Julie Fisher Robertson. "Portfolio Partnerships between Faculty and WAC: Lessons from Disciplinary Practice, Reflection, and Transformation." College Composition and Communication 59. 2 (2007): 206-236. Print.

Pratt, Mary Louise. "Arts of the Contact Zone." Ways of Reading. Eds. David Bartholomae and Anthony Petroksky. New York: Bedford/St. Martin's, 1999. Print.

Prenksy, Marc. "Digital Natives, Digital Immigrant." On the Horizon 9.5 (2001): 1-6. Web.

Reed-Danahay, Deborah. Auto/Ethnography: Rewriting the Self and the Social New York: Bloomsbury Publishing, 1997. Print.

Reynolds, Nedra and Elizabeth Davis. Portfolio Teaching: A Guide for Instructors, $3^{\text {rd }}$ ed. Boston: Bedford/St. Martin's, 2014. Print.

Selfe, Cynthia. "The Movement of Air, the Breath of Meaning: Aurality and Multimodal Composing." College Composition and Communication 60.4 (2009): 616-663. Print.

---. "Technology and Literacy: A Story about the Perils of Not Paying Attention." College Composition and Communication 50.3 (1999): 411-436. Print.

Shipka, Jody. "Negotiating Rhetorical, Material, Methodological, and Technological Difference: Evaluating Multimodal Designs." College Composition and Communication 61.1 (2009): 343-366. Print. 
Stein, Joel. "Millennials: The Me Me Me Generation." Time, 20 May 2013, http://time.com/247/millennials-the-me-me-me-generation/. Accessed 15 February 2017. Web.

Turley, Eric D. and Chris W. Gallagher. “On the 'Uses' of Rubrics: Reframing the Great Rubric Debate." The English Journal 97.4 (2008): 87-92. Print.

Wang, Caroline C. "Photovoice: A Participatory Action Research Strategy Applied to Women's Health.” Journal of Women's Health 8.2 (1999): 185-192. Print.

White, Edward M. "The Misuse of Writing Assessment for Political Purposes." Journal of Writing Assessment 2.1 (2003): 21-36. Print.

---. "The Scoring of Writing Portfolios: Phase 2." College Composition and Communication 56.4 (2005): 581-600. Print.

Yancey, Kathleen Blake. "Digitized Student Portfolios.” Electronic Portfolios: Emerging Practices in Student, Faculty, and Institutional Learning. Eds. Barbara L. Cambridge, Susan Kahn, Daniel P. Tompkins, and Kathleen Blake Yancey. American Association for Higher Education Press, 2001. 15-30. Print.

---. "Electronic Portfolios a Decade into the Twenty-first Century." Peer Review (2009): 28-32. Print.

---. "Looking Back as We Look Forward: Historicizing Writing Assessment." College Composition and Communication 50 (1999): 483-503. Print. 
---. "Looking for Sources of Coherence in a Fragmented World: Notes Toward a New Assessment Design." Computers and Composition 21 (2004): 89-102. Print.

---. "Made Not Only in Words: Composition in a New Key. College Composition and Communication 56.2 (2004): 297-328. Print.

Yin, Robert K. Case Study Research: Design and Methods. Los Angeles: Sage Publications, Inc., 2014. Print. 